\title{
Assessment and Evaluation of Ceramic Filter Cleaning Techniques Task Order 19
}

\section{Topical Report}

\author{
Herbert Chen \\ Roman Zaharchuk \\ Lora Beth Harbaugh \\ Michael Klett
}

October 1994

Work Performed Under Contract No.: DE-AC21-89MC25177

For

U.S. Department of Energy

Office of Fossil Energy

Morgantown Energy Technology Center

Morgantown, West Virginia

By

Gilbert/Commonwealth, Inc.

Reading, Pennsylvania 


\section{DISCLAIMER}

This report was prepared as an account of work sponsored by an agency of the United States Government. Neither the United States Government nor any agency thereof, nor any of their employees, makes any warranty, express or implied, or assumes any legal liability or responsibility for the accuracy, completeness, or usefulness of any information, apparatus, product, or process disclosed, or represents that its use would not infringe privately owned rights. Reference herein to any specific commercial product, process, or service by trade name, trademark, manufacturer, or otherwise does not necessarily constitute or imply its endorsement, recommendation, or favoring by the United States Government or any agency thereof. The views and opinions of authors expressed herein do not necessarily state or reflect those of the United States Government or any agency thereof.

This report has been reproduced directly from the best available copy.

Available to DOE and DOE contractors from the Office of Scientific and Technical Information, 175 Oak Ridge Tumpike, Oak Ridge, TN 37831; prices available at (615) 576-8401.

Available to the public from the National Technical Information Service, U.S. Department of Commerce, 5285 Port Royal Road, Springfield, VA 22161; phone orders accepted at (703) $487-4650$. 


\section{DISCLAIMER}

Portions of this document may be illegible in electronic image products. Images are produced from the best available original document. 


\title{
Assessment and Evaluation of Ceramic Filter Cleaning Techniques Task Order 19
}

\section{Topical Report}

\author{
Herbert Chen \\ Roman Zaharchuk \\ Lora Beth Harbaugh \\ Michael Klett
}

Work Performed Under Contract No.: DE-AC21-89MC25177

\author{
For \\ U.S. Department of Energy \\ Office of Fossil Energy \\ Morgantown Energy Technology Center \\ P.O. Box 880 \\ Morgantown, West Virginia 26507-0880 \\ By \\ Gilbert/Commonwealth, Inc. \\ P.O. Box 1498 \\ Reading, Pennsylvania 19603
}

October 1994 
TABLE OF CONTENTS

1.0 INTRODUCTION AND SUMMARY 1-1

1.1 CONCLUSIONS AND R\&D RECOMMENDATIONS

1.1.1 Conclusions $1-1$

1.1.2 R\&D Recommendations $1-2$

1.2 SUMMARY 1-3

1.2.1 Review of Literature $1-3$

1.2.2 Discussion of Concepts $1-4$

1.2.3 Analysis and Modeling of Filter Blowback Systems 1-4

1.2.4 Conceptual Design $1-5$

1.2.5 Economic Analysis $1-8$

2.0 REVIEW OF LITERATURE $2-1$

2.1 HOT GAS PARTICULATE REMOVAL UNDER OXIDIZING
AND REDUCING ATMOSPHERES - AN OVERVIEW

2.2 HTHP CERAMIC PARTICULATE REMOVAL DEVICES

2.3 MATERIALS FOR FILTERING APPLICATIONS

2.4 FILTER TESTINGS/APPLICATIONS IN IGCCS

2.5 FILTER CLEANING TECHNIQUES - ANALYSIS AND MODELING $2-8$

2.6 CONCLUDING REMARKS 2-11

2.7 REFERENCES $2-12$

3.0 DISCUSSION OF CONCEPTS $3-1$

3.1 ON-LINE $400^{\circ} \mathrm{F}$ PULSE 3-1

3.2 OFF-LINE $400^{\circ} \mathrm{F}$ PULSE $3-3$

3.3 RAPID COMBUSTION PULSE 3-3

3.4 APPROACH FOR CONCEPTUAL DESIGN $3-4$

4.0 ANALYSIS AND MODELING OF FILTER BLOWBACK SYSTEM 4-1

4.1 ANALYSIS OBJECTIVE AND SCOPE 4-1

4.2 ANALYSIS BASIS AND FORMAT 4-1

4.3 ANALYSIS AND MODELING OF BLOWBACK SYSTEM 4-5

4.4 EXAMPLE OF SPREADSHEET MODELING - CASE 1

4.5 SUMMARY FOR OTHER CASES $\quad 4-29$

4.6 CONCLUDING REMARKS $\quad 4-30$

5.0 CONCEPTUAL DESIGN $5-1$

5.1 PLANT DESCRIPTIONS 5-1

5.1.1 . Foster Wheeler Second Generation PFBC 5-1

5.1.2 KRW Air Blown Fluidized Bed Gasifier 5-2

5.2 SELECTION OF CONCEPTUAL DESIGN CASES 5-2

5.2.1 Pros and Cons of Potential Cleaning Techniques 5-3

5.2.1.1 On-line $400^{\circ} \mathrm{F}$ Pulse 5-3

5.2.1.2 Off-line $400^{\circ} \mathrm{F}$ Pulse 5-3

5.2.1.3 Rapid Combustion Pulse $\quad 5-4$

5.3 SPREADSHEET MODELING RESULTS $5-4$ 
5.4 CONCEPTUAL DESIGN DETAILS

5.4.1 Case 1 - FW CPFBC with On-line Conventional Blowback

5.4.2 Case 2 - FW CPFBC with Off-line Conventional Blowback

$5-13$

5.4.3 Case 3 - FW CPFBC with On-line Rapid Combustion Pulse Blowback

5.4.4 Case 4 - FW CPFBC with Off-line Rapid Combustion Pulse Blowback

5.4.5 Case 5 - FW Carbonizer with On-line Conventional Blowback

$5-15$

5.4.6 Case 6 - FW Carbonizer with Off-line Conventional Blowback

$5-15$

5.4.7 Case 7 - KRW IGCC with On-line Conventional Blowback

$5-16$

5.4.8 Case 8 - KRW IGCC with Off-line Conventional Blowback

5.5 CONCLUSIONS

6.0 ECONOMIC ANALYSIS

$5-16$

5-16

6.1 METHODOLOGY

6-1

6-3

6.2 CAPITAL COSTS

6.2.1 Bare Erected Cost

6.2.2 Total Plant Cost (TPC)

6.2.3 Capital Cost Estimate Exclusions

6-4

6-4

6-4

6-6

6.3 OPERATING COSTS AND EXPENSES

6-6

6.3.1 Operating Labor

6.3.2 Maintenance

6-7

6.3.3 Consumables

6-7

6-8

6.4 COST OF ELECTRICITY (COE)

6-8

6.5 CONCLUSIONS

6-9

$7-1$

7.1 FINDINGS

7-1

7.1.1 Analyses And Modeling Of The Filter Blowback Systems

7.1.2 Conceptual Design

7.1.3 Economic Analysis

7.2 CONCLUSIONS

$7-3$

7.3 R\&D RECOMMENDATIONS

$7-4$

APPENDIX A APPENDIX B APPENDIX C
Correspondence with Dr. Leith Spreadsheet Tables for Case 2 through 8 Cost Summary Sheets 
1.2-1

1.2-2

1.2-3

2.3-1

2.3-2

2.3-3

2.4-1

4.2-1

4.2-2

4.2-3

4.4-1

4.4-1A

4.4-1B

4.4-2

4.4-3

4.4-4

4.4-5

4.4-6

4.4-6A

4.4 .7

4.4 .8

4.4.9

5.1-1

5.4-1

5.4-2

6.1

6.2
Summary of Pulsed Gas Reverse Flow Conditions

Candle Filter Vessel Parameters

HGCU Systems Cost Summary

Material Formulation

Material Tolerance to Process Variables

Material Tolerance to Operating Variables

R\&D Projects Involving HTHP Filtration

Summary of Modeling Parameters Unique to Each Case

Summary of Modeling Parameters Common to All Cases

Summary of Pulsed Gas Reverse Flow Conditions

Properties of Fuel Gas and Flue Gas

Viscosity Correlations

Specific Heat Correlations

Flow Through Porous Media - Pressure Drops (1)

Flow Through Porous Media - Pressure Drops (2)

Flow From Candle to Ejector Mixing Zone Pressure Drops

Ejector Mixing Zone Balances

Flow From Nozzle/Lance-To-Reservoir Tank

Other Design Calculations

Reverse Flow P/T Profile

Sensitivity of Tank Volume Vs. Initial Tank P/t

Blowback System Time Factors

Candle Filter Vessel Parameters

Candle Filter Vessel Design

Blowback System Design

HGCU Systems Cost Summary

Total Plant Cost Comparison M\$
Page

1-6

$1-7$

$1-9$

$2-5$

$2-5$

$2-6$

2-6

4-2

4-3

4-4

4-16

4-17

4-18

4-19

4-20

4-21

4-22

4-23

4-24

4-27

4-27

4-28

5-2

5-5

5-6

6-1

6-2 


\section{LIST OF FIGURES}

Page

$3.1-1$

On-Line Pulse Driven

3-2

Rapid Pulse Driven

3-5

Commercial Candle Filter Design

$5-7$

Case 1 Blowback System CPFBC Simplified Schematic

$5-8$

Case 7 Blowback System IGCC Simplied Schematic

$5-9$

Case 3 Blowback System CPFBC Rapid Combustion Pulse

$5-10$

$5.4-4$

5.4-5

Venturi Details

$5-11$ 


\subsection{INTRODUCTION AND SUMMARY}

The objective of this study was to assess and evaluate the effectiveness, appropriateness and economics of ceramic barrier filter cleaning techniques used for high-temperature and high-pressure particulate filtration.

Three potential filter cleaning techniques were evaluated. These techniques include, conventional on-line pulse driven reverse gas filter cleaning, off-line reverse gas filter cleaning and a novel rapid pulse driven filter cleaning. These three ceramic filter cleaning techniques are either presently employed, or being considered for use, in the filtration of coal derived gas streams (combustion or gasification) under high-temperature high-pressure conditions.

These cleaning techniques were evaluated initially from a first principles approach followed by conceptual designs and cost estimates. This approach resulted in the development and analysis of the fundamental mechanisms involved in the cleaning of ceramic barrier filters. A primary objective in the first principal analyses of the proposed cleaning techniques was to identify the governing mechanisms, and the values of parameters which would support these mechanisms, so that satisfactory filter cleaning can be obtained.

This study was divided into six subtasks, as outlined below:

Subtask 1: First Principle Analysis of Ceramic Barrier Filter Cleaning Mechanisms

Subtask 2: Operational Values for Parameters Identified With the Filter Cleaning Mechanisms

Subtask 3: Evaluation and Identification of Potential Ceramic Filter Cleaning Techniques

Subtask 4: Development of Conceptual Designs for Ceramic Barrier Filter Systems and Ceramic Barrier Filter Cleaning Systems for Two DOE Specified Power Plants

Subtask 5: Evaluation of Ceramic Barrier Filter System Cleaning Techniques

Subtask 6: Final Report and Presentation

The report is organized in a slightly different order than the subtasks. Initially, a review of existing literature on ceramic filter technology and a survey of DOE and EPRI funded hot gas cleanup programs was conducted. This is reported in Section 2.0. In order to complete Subtasks 1 and 2, the concepts, cases and design bases had to be identified. This was completed in Subtask 3 and is presented in Section 3.0, Discussion of Concepts. The results of Subtasks 1 and 2 are presented in Section 4.0, Analyses and Modeling of Filter Blowback Systems. Subtasks 4 and 5 are presented in Section 5.0, Conceptual Design Detail and Section 6.0, Economic Analyses. The final section of the report, Section 7.0, presents conclusions and $R \& D$ recommendations.

\subsection{CONCLUSIONS AND R\&D RECOMMENDATIONS}

Within individual sections of this report critical design and operational issues were evaluated and key findings were identified. This section presents some overall conclusions on the issues and recommendations for $R \& D$ design challenges.

\subsubsection{Conclusions}

- The on-line $400^{\circ} \mathrm{F}$ pulse blowback system is commercially available and has been widely tested under both PFBC and IGCC conditions. Potential limitations include thermal shock and particle redeposition resulting in poor overall filter cleaning efficiency. 
- The off-line $400^{\circ} \mathrm{F}$ pulse blowback system should provide an improved filter cleaning efficiency by allowing the dust particles to fall to the bottom of the filter vessels. However, this has yet to be demonstrated and quantified through large scale tests. The greater efficiency will come with a higher capital costs associated with additional valve and vessels. As with the on-line system, thermal shock could also be a potential limitation.

- The rapid combustion pulse blowback system, while at this time only a concept, has the potential to eliminate thermal shock in a cost effective manner. A significant amount of test work will be needed before this concept can be considered viable. The rapid combustion pulse system was not included for the carbonizer and IGCC cases due to concerns about controlling a reducing gas pulse.

- The criteria for determining at what temperature thermal shock starts occurring for candle filters is based on tests which showed that at temperatures $100^{\circ} \mathrm{F}$ below operating temperature micro cracking of the candle is observed. However, long term test results with candle filters blown back with "cold" air have not shown that micro cracking necessarily leads to candle filter failure.

- The off-line cleaning system has a higher cost due primarily to the extra vessels required too maintain a constant face velocity. However, if testing shows that off-line cleaning can sustain a higher face velocity this cost differential will disappear. These costs, however, were a small portion of the entire plant costs. Technical feasibility and not cost will determine which technique is chosen.

- The cost driver for the ceramic barrier filter cost are the vessel costs. The blowback systems including gas compression represent a small percentage of total system costs.

- The spreadsheet model developed for this task can be used to assist conceptual design of a blowback system or used as an analytical tool to compare performance of different filter cleaning techniques. It became clear during the model development that many of the fundamental process parameters required for the effective design of blowback systems are not commonly available in the literature nor easily estimated by theoretical means.

- Based on calculations for plenum blowback using G/C's spreadsheet model, it appears that a fast acting valve may not be needed. If this is the case, a less expensive, high temperature valve may be used and the reservoir gas temperature could be heated to alleviate thermal shock.

\subsubsection{R\&D Recommendations}

- Several fundamental parameters (such as cake separation stress) required for the effective design of blow back systems are not commonly available in the literature nor easily estimated by theoretical means. It is recommended that R\&D effort be directed in establishing/compiling this class of information.

- The main advantage of off-line cleaning is that dust particles have sufficient time to fall to the bottom of the filter vessel before redepositing. However, there is no quantitative data on the mean particle size of dust blown off candle filters. This needs to be determined and ways of achieving rapid settling by additives, blow back techniques or filter and vessel design should be explored.

- In order to prevent thermal shock it is advantageous to use as hot a gas as possible. The operating temperature of the back pulse valve is the present limit on blow back temperature. The development of higher temperature, fast acting valves could alleviate this situation. 
- The rapid combustion system has the potential to eliminate thermal shock limitations in a cost effective manner. A significant amount of development work is needed including fuel * selection, fuel and oxidant feed control, firing mechanism and sonic orifice design.

- More data is needed on the plenum cleaning technique to verify the uniformity of gas distribution and cleaning. These concerns should be addressed during the testing at Tidd.

- The piping system between the gas reservoir and the filters has a very strong impact on the pressure drop of the blow back system. Much more attention in the future needs to be paid to the design, testing and standardization of this system.

\subsection{SUMMARY}

A summary of the key findings and issues identified in each section is presented below.

\subsubsection{Review of Literature}

A review of existing literature on ceramic filter technologies and survey of DOE or EPRI funded hot gas cleanup programs were conducted. The objectives were: (1) to gain a better general understanding of the state of the art, and (2) to identify the analytical and modeling/simulation methods suited for evaluating the various barrier filter cleaning techniques. In the latter category, the review was focused on those built upon fundamental principles that govern particulate removal mechanisms.

From the review of the literature, it can generally be concluded/remarked that:

(1) An ideal on-line pulse cleaning technique is one that is capable of building a sufficiently high pressure in the candle filter cavity to blow off the cake with the least amount of pulse gas in the shortest possible time.

(2) In general, the minimum pulse pressure needed to blow off the cake layer is a function of the operating parameters (e.g., cleaning cycle duration) and cake separation stress (related to the cake adhesivity/cohesivity). The cake separation stress must be known for effective design of the filter blowback system.

(3) Ideally, the temperature and composition of cleaning fluid should be as close as possible to that of clean gas to mitigate thermal shock and thermal fatigue.

(4) Extended cleaning cycle duration is likely to cause permeability reduction and increase in residual dust layer thickness. If the cycle time is too long, the filtering operation may become unstable unless the pulse pressure is increased.

(5) Increasing pulse duration causes increased pulse gas consumption, lower filter temperature, and increased potential for thermal shock. However, it may improve cake cleaning efficiency because a correspondingly longer free-fall time is available for the detached cake to settle to bottom of the filter vessel.

(6) The specific operational characteristic and response time of the solenoid valve that initiates and terminates the pulse of jet is important in analyzing the performance of pulse blowback system.

(7) When filtering coal gas in integrated gasification combined cycle (IGCC) applications, there may be a need for long-term regeneration of the filter elements (such as "burning-out") in addition to short-term cyclic cleaning of the filter/cake. 


\subsubsection{Discussion of Concepts}

The three candle filter cleaning systems that have been evaluated include:

- On-line $400^{\circ} \mathrm{F}$ pulse

- Off-line $400^{\circ} \mathrm{F}$ pulse

- Rapid combustion pulse

A technical and economic analysis was done for the three described blowback systems operating under three different filtration conditions: gasifier, circulating pressurized fluidized bed combustor (CPFBC) and a carbonizer. Conceptual designs of commercial size systems were developed using process data based on a $G / C$ 's analysis and modeling of the filter blowback system. Physical characteristics such as blowback reservoir size, compressor requirements were determined by the model's calculation procedure.

The analyses were done for eight different cases as requested by METC described as follows:

- Case 1: CPFBC with conventional on-line cleaning, $400^{\circ} \mathrm{F}$ pulse.

- Case 2: CPFBC with conventional off-line cleaning, $400^{\circ} \mathrm{F}$ pulse.

- Case 3: $\mathrm{CPFBC}$ with rapid combustion $1500^{\circ} \mathrm{F}$ pulse, on-line cleaning.

- Case 4: $\mathrm{CPFBC}$ with rapid combustion $1500^{\circ} \mathrm{F}$ pulse, off-line cleaning.

- Case 5: Carbonizer with conventional on-line cleaning, fuel gas $400^{\circ} \mathrm{F}$ pulse.

- Case 6: Carbonizer with conventional off-line cleaning, fuel gas $400^{\circ} \mathrm{F}$ pulse.

- Case 7: IGCC with conventional on-line cleaning, fuel gas $400^{\circ} \mathrm{F}$ pulse.

- Case 8: IGCC with conventional off-line cleaning, fuel gas $400^{\circ} \mathrm{F}$ pulse.

For the CPFBC cases, each of the three candle filter cleaning systems were evaluated. For the rapid combustion pulse system, both on and off-line cleaning techniques were included.

The rapid combustion pulse system was not included for the carbonizer and IGCC cases. For very short pulses the valves, which control the amount of fuel and oxidant entering the combustor, must be very accurately controlled. This is especially crucial for gasifiers where a reducing pulse gas is required. Because of this limitation this system has not been evaluated for use in gasifier or carbonizer filtration systems.

\subsubsection{Analysis and Modeling of Filter Blowback System}

One of the objectives of this project is to identify the basic mechanisms and functional relationships governing cake removal as they relate to the ceramic barrier filter cleaning techniques described in the previous section. This involves, for example, analysis of pressure drops through porous media (filter and cake layers), or the pressure level required in the candle filter cavity for effective cake removal. A companion objective is to determine a range of values for operational parameters, such as the flow rate of the cleaning fluid, its pressure and temperature at the pulse lance. The values of these parameters are to be established by taking into consideration the properties of cleaning fluids such as air, nitrogen, or recycled fuel gas as appropriate, and the properties of filter medium and cake that forms on the surface of filter medium. 
In short, given a suitable geometrical and process description of the components and constituents involved in the filter blowback system, the analysis and modeling objectives are to establish the necessary design data for the Conceptual Design Task, including:

(1) The required gas flow rate and the associated pressure $P$ and temperature $T$ conditions at various points in the blowback system.

(2) The volume, $P$, and $T$ of the cleaning fluid reservoir and the duration of blowback.

Three types of dirty gas in combination with the three filter cleaning techniques give rise to the eight design cases to be studied. While each of these eight cases has its unique process conditions that would lead to a different blowback requirement (see Table 1.2-1 for a summary of common/unique parameters and blowback requirement for each case), it is clear that the analysis procedure itself would be similar, and it can be "copied" from one case and applied to another. For example, the main difference between the "cold pulse" and "hot pulse" cases is the temperature of the cleaning fluid, and the main difference between the "on-line" and "off-line" cases is the settling time available for the separated cake to fall to the bottom of the filter cake. But the first principle that governs cake separation per se is the same for all cases.

The relatively large number of physical/process parameters involved in characterizing the systems can often be treated as "inputs" or interchangeably as calculated "outputs" or assigned as common "constants". The analyses, therefore, were implemented by a series of spreadsheets using commercially available software.

During implementation of the spreadsheet model, Dr. David Leith, Director, Air, Radiation and Industrial Hygiene Program, University of North Carolina, Chapel Hill, N.C., was used as a consultant to review the approach and to answer specific questions. A summary of his comments and his report on specific questions are included in the Appendix A.

\subsubsection{Conceptual Design}

DOE/METC has selected the KRW air blown gasifier and Foster Wheeler's second generation PFBC for the candle filter cleanup system conceptual designs. Table 1.2-2 provides candle filter vessel parameters for the PFBC and carbonizer, and also the KRW gasifier. The general design criteria followed included:

- The candle filter vessel is based on a Westinghouse commercial design. Candles are attached to plenums which are blown back by a single pulse using compressed air or fuel gas stored in a reservoir.

- To reduce the harmful effects of thermal shock it is desirable to blowback with the highest temperature gas as possible. With a $400^{\circ} \mathrm{F}$ temperature limitation on the currently available fast-acting valve it is not possible to entrain enough hot, clean gas to produce a blowback gas which is $100^{\circ} \mathrm{F}$ lower than operating temperature. As a result no effort was made to maximize the blowback gas temperature.

- The candle filter vessels for the eight cases are the same size, $16 \mathrm{ft}$. diameter $x 67 \mathrm{ft}$. height, and have the same number of tiers and clusters per tier. The different power plant flows are accommodated by the number of vessels and somewhat by the number of candles per vessel. This was done to simplify the process design for blowback requirements and also to lessen the amount of effort to cost the vessels.

- Reasonable face velocities were chosen to size the filter vessels based on published reports: $10 \mathrm{fpm}$ for the PFBC and $5 \mathrm{fpm}$ for the gasifier and carbonizer. 
SUMMARY OF PULSED GAS REVERSE FLOW CONDITIONS

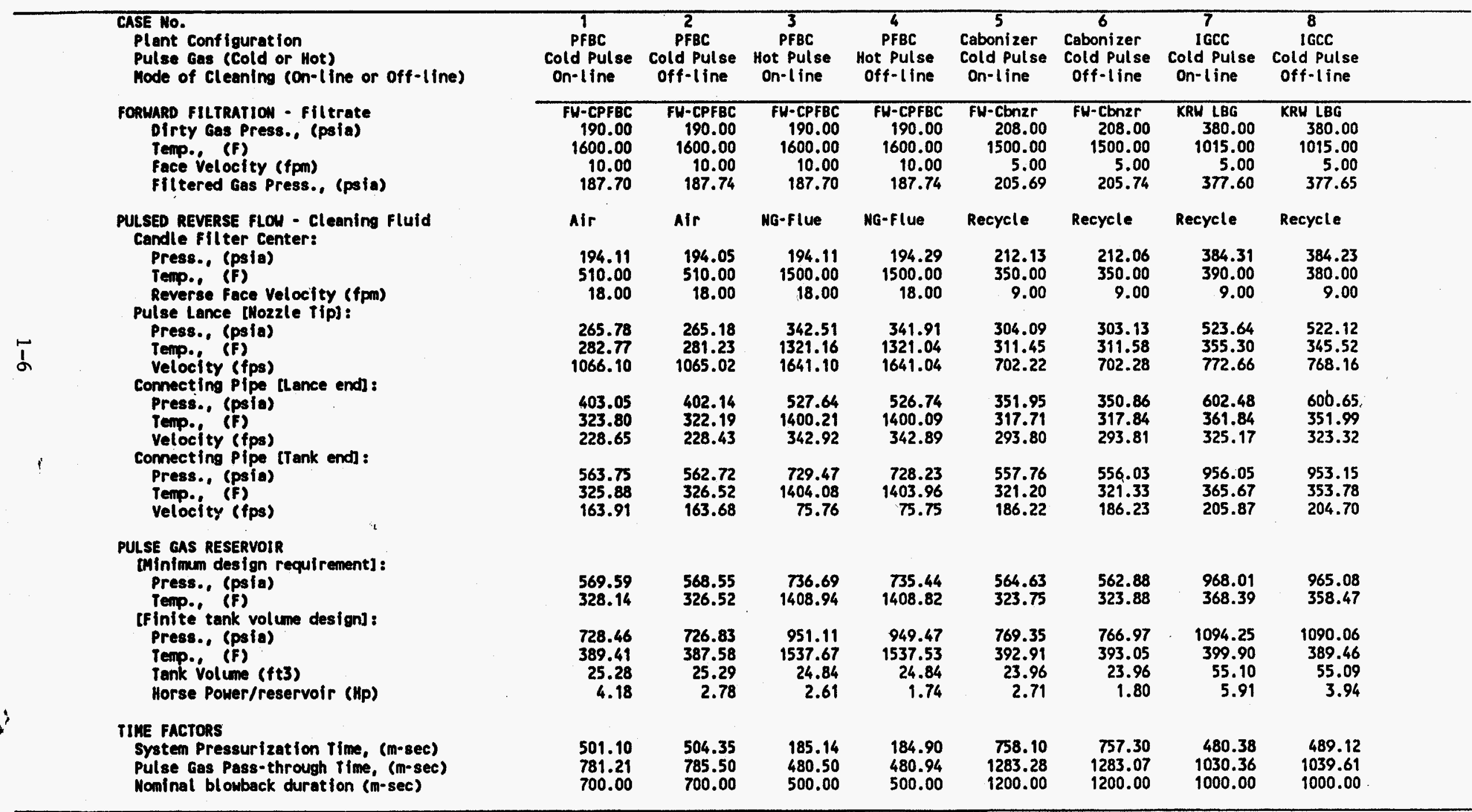


Table 1.2-2

Candle Filter Vessel Parameters

No. Parameter

1. MWe net

2. Pressure, inlet, PSIA

3. Temp., inlet, ${ }^{\circ} \mathrm{F}$

4. Flow, inlet, $\mathrm{lb} / \mathrm{hr}$ gas

5. Flow, inlet, ACFM

6. Inlet particulate loading, ppmw

7. Particle size, microns, D50

8. Particle loading, lbs $/ \mathrm{hr}$

9. Candle filter data Size O.D., mm Size I.D., mm Length, $m$ Material

10. Candle filter vessel design Diameter, ft. O.D.

Height, ft.

Total candles needed

No. of candles per vessel

No. of vessels

No. of tiers

No. of candles per blowback cluster

Design face velocity, fpm

Flow, ACFM per vessel
Foster Wheeler

Second

KRW

$\underline{\text { IGCC }}$

458

380

1,015

$1,904,867$

57,507

1,500

1.2

2,857

60

30

1.5

$\mathrm{SiC}$

16

67

3,978

995

4

4

62

5

14,377
Generation PFBC

$$
453
$$

192

1,600

$5,288,600$

343,721

1,000

2.1

5,289

60

30

1.5

$\mathrm{SiC}$

16

67

11,888

1,188

10

4

74

10

34,372
Carbonizer

453

208

1,500

492,562

31,811

3,000

1.6

1,478

60

30

1.5

$\mathrm{SiC}$

16

67

2,272

1,136

2

4

71

5

15,906 
- A difference from the Westinghouse design is that the blowback reservoirs are larger in capacity. At Tidd a $4 \mathrm{ft}^{3}$ vessel is used to blowback 38 candles. For Case 1 a $25 \mathrm{ft}^{3}$ vessel is used for blowing back 74 candles. The larger vessels were designed to lower the required blowback pressure.

- Compressor horsepower requirements, as calculated in the model, were not rounded off to reasonable numbers because this study is concerned more with system comparisons rather than detailed design of equipment.

\subsubsection{Economic Analysis}

The economics of the ceramic barrier filter hot gas cleanup (HGCU) systems were developed on the basis of consistently evaluating the capital and operating costs and then performing an economic analysis based on the incremental cost of electricity (COE) as the figure of merit. The conceptual cost estimate was determined on the basis of system scope as described in Section 5.0, equipment quotes, the PFBC reference plant, and inhouse cost data.

Table 1.2-3 Itemizes the Total Plant Cost (TPC) and the component COE costs for each of the eight estimated cases. Cases 1 - 4 represent HGCU systems as applied to Circulating Pressurized Fluidized Bed Combustors, Cases 5 - 8 represent HGCU systems applied to carbonizers and gasifiers. The face velocities for these applications as well as particle loading determine the number of vessels required for each system. As shown in Table 1.2-3, the COE of the systems with similar applications are equivalent. As expected, the cases with off-line cleaning are slightly higher than the same system with on line cleaning, since additional vessels are required. All but Cases 7 and 8 have the same working pressure so the TPC is equivalent on a cost per vessel level. Cases 7 and 8 have a higher working pressure, more costly vessels, thus a higher TPC's on a per vessel basis. The cost difference between the $1500^{\circ} \mathrm{F}$ and $400^{\circ} \mathrm{F}$ pulse on-line cleaning technique is negligible. Technical feasibility and not cost will determine which is used. 
Table 1.2-3

HGCU SYSTEMS COST SUMMARY

\begin{tabular}{|l|c|c|c|c|c|c|c|c|}
\hline & $\begin{array}{c}\text { Case 1 } \\
\text { PFBC } \\
400^{\circ} \mathrm{F} \\
\text { Pulse } \\
\text { On-Line }\end{array}$ & $\begin{array}{c}\text { Case 2 } \\
\text { PFBC } \\
400^{\circ} \mathrm{F} \\
\text { Pulse } \\
\text { Off-Line }\end{array}$ & $\begin{array}{c}\text { Case 3 } \\
\text { PFBC } \\
1500^{\circ} \mathrm{F} \\
\text { Pulse } \\
\text { On-Line }\end{array}$ & $\begin{array}{c}\text { Case 4 } \\
\text { PFBC } \\
1500^{\circ} \mathrm{F} \\
\text { Pulse } \\
\text { Off-Line }\end{array}$ & $\begin{array}{c}\text { Case 5 } \\
\text { Carbonizer } \\
400^{\circ} \mathrm{F} \\
\text { Pulse } \\
\text { On-Line }\end{array}$ & $\begin{array}{c}\text { Case 6 } \\
\text { Carbonizer } \\
400^{\circ} \mathrm{F} \\
\text { Pulse } \\
\text { Off-Line }\end{array}$ & $\begin{array}{c}\text { Case 7 } \\
\text { IGCC } \\
400^{\circ} \mathrm{F} \\
\text { Pulse } \\
\text { On-Line }\end{array}$ & $\begin{array}{c}\text { Case 8 } \\
\text { IGCC } \\
400^{\circ} \mathrm{F} \\
\text { Pulse } \\
\text { Off-Line }\end{array}$ \\
\hline MW & 453 & 453 & 453 & 453 & 453 & 453 & 458 & 458 \\
\hline TPC - \$/kW & 132.7 & 158.3 & 130.8 & 157.5 & 26.5 & 39.1 & 62.1 & 75.6 \\
\hline \# of Vessels & 10 & 12 & 10 & 12 & 2 & 3 & 4 & 5 \\
\hline TPC/Vessel & 13.3 & 13.2 & 13.1 & 13.1 & 13.3 & 13.0 & 15.5 & 15.1 \\
\hline
\end{tabular}

\begin{tabular}{|l|c|c|c|c|c|c|c|c|}
\hline $\begin{array}{l}\text { Fixed O\&M - } \\
\text { mills/kWh }\end{array}$ & 1.6 & 1.9 & 1.6 & 1.9 & 0.5 & 0.6 & 0.7 & 1.0 \\
\hline $\begin{array}{l}\text { Variable O\&M } \\
\text { mills/kWh }\end{array}$ & 0.9 & 1.0 & 0.9 & 1.0 & 0.2 & 0.3 & 0.4 & .5 \\
\hline $\begin{array}{l}\text { Carrying } \\
\begin{array}{l}\text { Charge } \\
\text { mills/kWh }\end{array}\end{array}$ & 4.1 & 4.8 & 4.0 & 4.8 & 0.8 & 1.2 & 1.9 & 2.3 \\
\hline $\begin{array}{l}\mathrm{COE}(1) \\
\text { mills/kWh }\end{array}$ & 6.5 & 7.7 & 6.5 & 7.7 & 1.5 & 2.1 & 3.2 & 3.8 \\
\hline
\end{tabular}

(1) No consumables were large enough to be recognized on a unit cost basis, although the costs are included in the annual costs. No fuel cost difference was recognized. 


\subsection{REVIEW OF LITERATURE}

As part of Tasks 1 and 2 activities, a review of existing literature on ceramic filter technologies and survey of DOE or EPRI funded hot gas cleanup programs were conducted. The objectives were: (1) to gain a better general understanding of the state of the art, and (2) to identify the analytical and modeling/simulation methods suited for evaluating the various barrier filter cleaning techniques. In the latter category, the review was focused on those built upon fundamental principles that govern particulate removal mechanisms.

The domain of literature reviewed consists of reports, proceedings and papers that are available from recent conferences and workshops, including:

- Twelfth EPRI Conference on Gasification Power Plants, San Francisco, CA, Oct. 27-29, 1993

- Tenth Pittsburgh Coal Conference, Pittsburgh, PA, Sept. 20, 1993

- Coal-Fired Power Systems 93 - Advances in IGCC and PFBC Review Meeting, Morgantown, WV, June 28, 1993

- Twelfth International Conference on Fluidized Bed Combustion, San Diego, CA, May 9, 1993

- Twelfth Annual Gasification and Gas Cleanup Systems Contractors Review Meeting, Morgantown, WV, Sept. 15, 1992

- Second EPRI Workshop on Filtration of Dust from Coal-Derived Reducing and Combustion Gases at High Temperature, San Francisco, CA, March 11, 1992

- Eleventh Annual Gasification and Gas Cleanup Systems Contractors Review Meeting, Morgantown, WV, August 13, 1991

- Eleventh International Conference on Fluidized Bed Combustion, Montreal, Canada, April 21, 1991

- Transactions - ASME Journal of Engineering Materials and Technology; ASME Journal of Engineering for Gas Turbines and Power; Chemical Engineering Progress

- In-house DOE, EPRI and other agency reports/papers on FBC and coal gasification published in the recent years

- Technical articles on conventional low temperature filters

- Reports specifically supplied by the METC participants for this project

Papers/articles that are more relevant to or of interest to this project are listed individually in the references at the end of this section.

The following is a summary of the status of high temperature high pressure (HTHP) filtration technologies development. It is presented and discussed from the vantage point of this project (pulse cleaning of barrier filters), and is not intended to be an all encompassing review. 


\subsection{HOT GAS PARTICULATE REMOVAL UNDER OXIDIZING AND REDUCING ATMOSPHERES - AN OVERVIEW}

Pressurized fluidized bed combustion (PFBC) and integrated gasification combined cycle (IGCC) are two advanced energy conversion technologies currently under development for electric power generation. In both PFBC or fluid-bed type gasifiers, the sulfurous species in the coal are captured by adding sorbent such as limestone or dolomite to the combustor or gasifier. In PFBCs, particulates in the raw gas must be removed in an external device under a high temperature, high pressure (HTHP) condition so that the particulate loading in the hot gas is reduced to an acceptable level to the downstream gas turbines (GT). In IGCC systems, HTHP particulate cleanup is an option, since the raw fuel gas could be conventionally water-scrubbed (to remove particulates as well as water-soluble components) and then desulfurized in a commercially available low temperature desulfurization (LTD) process.

Initially, the HTHP particulate removal devices were developed solely for removal of flyash from the PFBC flue gases. These were the rigid barrier type filters, made of ceramic materials to withstand erosive particulates as well as the corrosive actions of alkali vapors in the flue gas. More recently, use of these devices has been extended to high-efficiency IGCC systems, in which sulfur in the hot raw gas is removed by passing it through high temperature desulfurization (HTD) absorbers operating at $1,000-1,200^{\circ} \mathrm{F}$ or higher. Typical of these are the zinc titanate external type moving or fixed beds; consequently, the hot fuel gas must be removed of particulates under an HTHP condition to protect the HTD absorbers from plugging. (Another filter may also be needed after the absorber for GT protection.) The ultimate benefits from such implementations of ceramic filters and HTD include not only increased IGCC conversion efficiency (because the fuel gas is kept hot), but potentially also a simpler wastewater treatment scheme (no solid/liquid separation and hence lower costs), and increased plant reliability/availability. Other incentives include reduced heat exchanger erosion and deposition.

In recent tests, however, the barrier-type HTHP particulate removal devices (as developed for PFBC oxidizing atmospheres) have encountered somewhat unexpected difficulties under the IGCC reducing atmospheres. Unlike the relatively inert flue gas from a PFBC, which consists largely of $\mathrm{N}_{2}$ and $\mathrm{CO}_{2}$, the hot fuel gas produced in gasifiers contains not only a large fraction of reducing components such as $\mathrm{CO}$ and $\mathrm{H}_{2}$ but also reactive hydrogen sulfide $\left(\mathrm{H}_{2} \mathrm{~S}\right)$ and carbonyl sulfide (COS), in addition to alkalis and halogens such as $\mathrm{HCl}$. These reducing/reactive components (and alkalis) in the coal gas are suspected of interacting more aggressively with the ceramic materials to cause more rapid chemical degradations over time, especially under high temperatures.

Under the reducing atmosphere, the coal gases were also found to contain stickier, smaller yet more irregular-shaped high carbon particles (unreacted chars) than those found in the flue gas from a combustor. They are suspected to cause more severe filter bridging and drainage blocking, and/or to penetrate deeper into the interior of barrier filters, although carbon deposition from the gas within the filter is also a suspect. Because of the increased pressure drops across the filter, the filter face velocity has generally been found to decrease by one-half or more, dropping from greater than 10-5 fpm under PFBC conditions to 5-3 fpm or less under IGCC conditions. This lowering of face velocity potentially has a large impact on filter costs, although the actual volume of gas that needs to be filtered is much less for IGCC compared with PFBC at the same power output level.

Furthermore, in either PFBC or IGCC, the on-stream cleaning of filter elements using countercurrent pulse of relatively cool gas is thought to subject the rigid ceramic elements to a thermal stress that is believed to reduce the lifetime of the material (as micro-cracks can form when the temperature difference is in the order of $100^{\circ} \mathrm{F}$ or greater). In short, the current concerns regarding rigid type gas filtering materials/methods are: (a) chemical attacks of the filter 
elements (by alkalis and other reactive components), (b) cleanability of the filter itself (when filtering coal gas), and (c) thermal shock (caused by pulse cleaning at lower temperature). All these are significant concerns and must be resolved or minimized with additional R\&Ds. Two of the potential solutions being investigated to at least partially mitigate the above problems are: (1) off-line reverse gas filter cleaning and (2) rapid combustion gas driven filter cleaning. Both methods will be studied in this project to compare their performance/costs against the conventional technique.

\subsection{HTHP CERAMIC PARTICULATE REMOVAL DEVICES}

Ceramic barrier filter devices currently under development include the general class of candles, cross-flow, tubes, bags, and granular bed. For this project, we are focused only on the rigid type filters (i.e., candles, cross-flow, and tubes) for which the pulse cleaning techniques are most applicable. Among the rigid type, we are mainly interested in the candle and, only to a limited extent, the cross-flow and tubular types. A brief description of these rigid type filters (and the associated pulse cleaning technique) is given below:

The candle filter has been tested for the longest periods under various conditions, including both PFBC oxidizing and IGCC reducing atmospheres. Although the filter dimensions can be varied, the most common size is 1.5 meters in length with a $60-\mathrm{mm}$ outside diameter and a $30-\mathrm{mm}$ inside diameter, each weighing about 6 kilograms. The typical composition of candles is clay-bonded silicon carbide or aluminum oxide, although more costly sintered $\mathrm{SiC}$ candle is also available. The bonded ceramics are fired such that the finished candles are monolithic. Major suppliers of candle filters include Schumacher, Refractron, Coors, IF\&P, and Forseco.

Characteristically, one end of the candle is plugged and the other is flanged for mounting on a tube sheet, which is housed in a pressure vessel. The tube sheet can be solid or water cooled. To ensure proper sealing of the candles in case of high pressure differences across the tube sheet, the candles are sometime held down in their places by counterweights at the top. To prevent dirty gas from inadvertently entering the clean gas side of the tube sheet in case of candle failure, a special safety valve (which would close automatically by the lift force due to increased gas velocity, e.g., the Schumacher patented fluid dynamic valve) may be used (above the filter).

In filtering operation, dirty gas enters the pressure vessel, impinges on the outside of the suspended candles, passes through the nominal 15-mm gas path in the filter, and exits up through the center of the filter. The face velocity can vary from 2 to $20 \mathrm{fpm}$ depending on the dirty gas and filter cake characteristics. As the cake builds up and as the pressure drop through the filter/cake reaches a pre-selected value ("trigger" pressure), a high pressure pulse of cleaning fluid (air, nitrogen, or gas process gas) is activated to blow off the cake. Typically, the pulse jet is generated by a quick acting electromagnetic solenoid valve that is connected to a high pressure gas reservoir, and the valve would open for a fraction of a second on command. The pulsed gas accelerates itself through interconnecting pipes and enters via a pulse lance to an ejector. At the ejector opening, the high velocity motive gas (cleaning fluid) entrains and mixes with a portion of the clean filtered gas, converting its kinetic energy (momentum) into the pressure energy of the mixed gas. The ejector essentially functions as a fluid pump to reverse the flow of the mixed gas to pressurize the candle cavity, and the reverse pressure drop through the cake layer in turn exerts a "separation stress" to blow off the cake. The minimum separation stress that must be developed to separate the cake is a function of cake cohesivity or adhesivity.

Depending on the blowback system configuration, the gas reservoir pressure can be varied to achieve the impulse intensity required to blow off the cake. Depending on the pressure ratio at the nozzle, the high velocity gas passing through the lance tip can become sonic or subsonic. The actual pulse duration may last as short as 0.1-0.2 second or as long as 1 to 2 seconds or more, and a complete filtering cycle may be as short as 1 minute or as long as 60 minutes or more. The wide 
operating conditions reported attest to the fact that filtering of HTHP cake is extremely complex, depend strongly on specific cake properties, design, operation, and optimization requirements at individual facility.

The largest candle filter test unit ever built until recently is the American Electric Power's Tidd PFBC facility in Brilliant OH, where as many as 384 1.5-meter candle elements are contained in a single 10-ft diameter by 40 -ft tall pressure vessel. In mid-1993, a ceramic filter unit comprising of 600 candles (reduced height version) became operational at the KoBra HTW gasification demonstration plant in Germany, which is presumably the largest. The unit is $11.8 \mathrm{ft}$ in diameter and is $36 \mathrm{ft}$ tall, and the candles are arranged in two levels. The unit can reportedly accommodate as many as 900 candles.

The cross-flow (XF) type filter has been championed by the Westinghouse (WH) since the early 1980s primarily for PFBC applications. The XF filter element is typically a $12 \times 12 \times 4$ inch ceramic membrane layered and oriented at 90-degree angles so that dirty gas enters, passes through the membrane, and exits perpendicularly to a sealed end of the filter. Multiple elements are attached to a plenum through which clean gas exits. The plenums are hung from a tube sheet which can be water cooled. Cleaning of the filters is done periodically by a pulse jet technique (as described above). Field tests of the WH XF filters have been done at several sites, including the one conducted under IGCC conditions at the Texaco pilot plant in Montebello, CA. Typical materials for XF filters include mullite, cordierite, and sintered silicon nitride. Suppliers include Coors, GTE, and Allied-Signal.

The CeraMem Ceramic Monolith Filter (parallel channel flow filter made of cordierite) has some similarity to the WH cross-flow filter. The inlet/outlet openings of the honeycomb monolith are much smaller than the Westinghouse cross-flow filter, resulting in a very high filtration area per unit volume, $155 \mathrm{ft}^{2} / \mathrm{ft}^{3}$, as compared to 40 for the latter. Another difference is the membrane coating which, at 50 microns, is said to allow higher filtration rates at lower resistances. All these are said to lead to reduced filter vessel cost, structural steel, and plant space.

The tube filter manufactured by Asahi Glass Co. (Japan) is 2 to 3 meter long, $170 \mathrm{~mm}$ in O.D. and $140 \mathrm{~mm}$ in I.D, and is typically made of porous cordierite ceramic. The elements can be butted together to form a 20-ft vertical unit, and 9 to 66 of these may be housed in a pressure vessel. While dimensionally somewhat similar, the tube differs from the candle in that it requires mounting fixtures on both ends. Furthermore, in operation, the dirty gas enters from the tube top, flow downward at high velocity through the inside of the filter tube. Clean gas then exits horizontally and outside of the vessel through side outlets. The filters are cleaned by a reverse pulse blowback which enters the clean gas exit pipe.

An example of operation using Asahi tubes for PFBC applications is the $10 \mathrm{MW}_{\text {th }}$ Ahlstrom PFBC Pilot plant facility in Karhula, Finland. One of the novel feature of the pulse cleaning system (designed by Asahi Glass Co.) is the use of a regenerative wire mesh heat exchanger to heat up the pulse cleaning air (and entrained clean gas) prior to it entering the clean gas compartment, the intention being to minimize thermal shock to the tube during pulse cleaning. In spite of this, failure rates were high and the durability of the tubes has yet to be demonstrated. Its performance in treating coal gas is also uncertain since only a relatively short period of testing has been conducted under IGCC conditions. (Note: A new effort to minimize thermal shock is the "rapidcombustion" technique being developed by METC in which a hot gas is generated in a combustion chamber by an ignition device. This is discussed in detail in Section 3.)

\subsection{MATERIALS FOR FILTERING APPLICATIONS}

The major ceramic filter materials that are currently used in the manufacturing of porous HTHP filters include: (1) oxides (such as alumina/mullite or cordierite), (2) aluminosilicate foam, 
(3) non-oxides (such as clay bonded silicon carbide), (4) bonded/sintered silicon nitride, and (4). oxide-nonoxide hybrids. In both oxide and non-oxide, there are basically two classes of ceramic materials: high density and low density. The high-density materials are bonded ceramic granules having porosity of about $40 \%$, and low-density materials are bonded ceramic fibres having porosity of 80 to $90 \%$. Currently, the high-density type is prevalent; however, the low density vacuum formed ceramic fibers are beginning to being tested more widely, especially in Europe.

The long-term stability of ceramic materials is not only affected by ceramic materials but also by factors such as ceramic granule size, binder type, and manufacturing techniques. Glass of any type can be detrimental since it can absorb alkali rapidly, leading to increased fluidity and thermal expansion. Silicon carbide and silicon nitride can be seriously corroded by steam, especially above $1,400^{\circ} \mathrm{F}$. The overall durability of major ceramic materials under PFBC and gasification conditions are still under laboratory and/or field tests. Some better known names and materials include:

TABLE 2.3-1 MATERIAL FORMULATION

\begin{tabular}{|l|r|r|}
\hline Material Name & Formulation & Suppliers \\
\hline Mullite/Alumina & $3 \mathrm{Al}_{2} \mathrm{O}_{3} \cdot 2 \mathrm{SiO}_{2} / \mathrm{Al}_{2} \mathrm{O}_{3}$ & Coors, Forseco \\
\hline Cordierite & $2 \mathrm{Al}_{2} \mathrm{O}_{3} \cdot 5 \mathrm{SiO}_{2} \cdot 2 \mathrm{MgO}$ & CeraMem, Asahi \\
\hline Aluminosillicate & $3 \mathrm{Al}_{2} \mathrm{O}_{3} \cdot 2 \mathrm{SiO}_{2}$ & Forseco, Fibrosics \\
\hline Silicon Carbides & $\mathrm{SiC}$ & Schumacher, Refractron, \\
& IF\&P \\
\hline Silicon Nitrides & $\mathrm{Si}_{3} \mathrm{~N}_{4}$ & GTE, Allied-Signal \\
\hline
\end{tabular}

The relative reactivity of ceramic materials with respect to alkali, steam, or other reducing gaseous components in the hot raw gas at or above $1,200^{\circ} \mathrm{F}$ is a major concern. A general ranking of the material tolerances to the process variables are:

TABLE 2.3-2 MATERIAL TOLERANCE TO PROCESS VARIABLES

\begin{tabular}{|l|r|r|r|}
\hline Material Name & \multicolumn{3}{|c|}{ Tolerance to Process Gas Characteristics/Variable } \\
\hline & Alkali & Steam & Coal Gas \\
\hline Mullite/Alumina & High & High & High \\
\hline Cordierite & Med & High & High \\
\hline Aluminosillicate & Low & High & High \\
\hline Silicon Carbides & Low & Med/Low & Med \\
\hline
\end{tabular}


The material tolerances at or above $1,200^{\circ} \mathrm{F}$ to thermal fatigue, thermal shocks, and mechanical, strength degradation (that can occur due to cyclic variation in temperature and gas flow direction) are generally thought to be:

TABLE 2.3-3 MATERIAL TOLERANCE TO OPERATING VARIABLES

\begin{tabular}{|l|r|r|r|}
\hline Material Name & \multicolumn{3}{|c|}{ Tolerance to Operating/Design Variables } \\
\hline & Thermal Fatigue & Thermal Shock & Mech. Strength \\
\hline Mullite/Alumina & Med & Med/Low & Med \\
\hline Cordierite & Med & Med/Low & Med \\
\hline Aluminosillicate & High/Med & High & Low \\
\hline Silicon Carbides & Med & Med/Low & Med \\
\hline
\end{tabular}

The above general assessments naturally can change as additional R\&Ds produce newer and more specific data/information in the future.

\subsection{FILTER TESTINGS/APPLICATIONS IN IGCCS}

For IGCC applications, candle filters (especially the Schumacher silicon carbide type) and cross-flow filters have been tested most widely, as summarized in the following table. The table lists more notable R\&D efforts here and abroad as well as several near-term DOE/Clean-Coal Technology and other energy agency demonstration projects:

TABLE 2.4-1 R\&D PROJECTS INVOLVING HTHP FILTRATION

\begin{tabular}{|l|l|}
\hline Project & \multicolumn{1}{|c|}{ Notes } \\
\hline KRW/Waltz Mill & $\begin{array}{l}\text { Tested 16 sintered metal and 33 Schumacher (SCH) candle } \\
\text { filters }\end{array}$ \\
\hline DEA/HTW & Tested 90 SCH ceramic candles at Wesseling \\
\hline Rheinbraun/HTW & Tested 9 SCH ceramic candles at Berrenrath \\
\hline Shell/Deer Park & $\begin{array}{l}250 \text { TPD; 44 SCH and 44 IF\&P candles tested at 500 }{ }^{\circ} \mathrm{F} \text {; good } \\
\text { results with face velocity to 5.8 cm/sec }\end{array}$ \\
\hline Texaco/Montebello & $\begin{array}{l}4 \text { WH XF and } 19 \text { SCH candles tested; } \\
\text { high pulse gas consumption at } 1 \mathrm{~cm} / \text { sec face velocity }\end{array}$ \\
\hline CRIEPI/Yokosuka & NGK tubes and SCH candles; recycle gas for pulse cleaning \\
\hline VTT/Otaniemi & $\begin{array}{l}5 \text { SCH and 5 Didier ceramic candles tested with coal and } \\
\text { biomass feeds }\end{array}$ \\
\hline Tampella/U-Gas & Tested SCH candle and tube filters \\
\hline
\end{tabular}




\begin{tabular}{|c|c|}
\hline GKT/PRENFLO & $36 \mathrm{SCH}$ candles tested at Furstenhausen \\
\hline $\mathrm{FW} / 2 \mathrm{PFBC}$ & WH XF and candles tested with the carbonizer at Livingston, $\mathrm{NJ}$ \\
\hline Westinghouse & $\begin{array}{l}\mathrm{XF} \text { tested with reentrained Texaco } / \mathrm{KRW} \text { gasifier char; fair } \\
\text { results with face vel }=1 \text { to } 3 \mathrm{~cm} / \mathrm{sec}\end{array}$ \\
\hline British Coal (CRE) & 12 TPD spouted FBG; testing of ceramic candle filter \\
\hline IGC/MHI/Iwaki & $\begin{array}{l}20 \text { TPD; NGK ceramic filters; in-situ regeneration of filter with } \\
\text { hot air }\end{array}$ \\
\hline Demkolec/Shell & $\begin{array}{l}253 \mathrm{MW} \text { IGCC at Buggenum, Netherlands; testing of ceramic } \\
\text { candle filters to start in 11/93; LTD for sulfur removal }\end{array}$ \\
\hline Rheinbraun/HTW & $\begin{array}{l}367 \text { MW IGCC KoBra project at Hurth near Cologne; testing } \\
600 \text { ceramic candles since 6/93; LTD for sulfur removal }\end{array}$ \\
\hline ELCOGAS/PRENFLO & $\begin{array}{l}335 \text { MW IGCC at Puertollano, Spain; to start testing of candle } \\
\text { filters in } 6 / 96 \text {; LTD for sulfur removal }\end{array}$ \\
\hline SCS/Wilsonville & $\begin{array}{l}\text { Development of various barrier filter types at the PSDF; dust } \\
\text { properties data to be collected/analyzed }\end{array}$ \\
\hline PSI/Destec & $\begin{array}{l}\text { 265 MW IGCC at Wabash River, IN; to test barrier filters in } \\
\text { 1995; LTD for sulfur removal }\end{array}$ \\
\hline Sierra Pacific/KRW & $\begin{array}{l}80 \text { MW IGCC Pinion Pine project; to test barrier filters, } \\
\text { including candles in 1997; Fixed bed HTD for sulfur removal }\end{array}$ \\
\hline TECO/Texaco & $\begin{array}{l}250 \mathrm{MW} \text { IGCC at Lakeland, FL; to test } 100 \% \text { LTD and } 50 \% \text { GE } \\
\text { moving bed HTD coupled with barrier filters in } 1996\end{array}$ \\
\hline TAMCO/U-Gas & $\begin{array}{l}58 \text { MW IGCC repowering project at Toms Creek, VA to test } \\
\text { barrier filters with fluid bed HTD; project site uncertain }\end{array}$ \\
\hline CLWP/CE & $\begin{array}{l}60 \text { MW IGCC repowering project at Springfield, IL; to test } \\
\text { bag-type ceramic filters with HTD; project status uncertain }\end{array}$ \\
\hline $\mathrm{APCI} / \mathrm{FW}$ & $\begin{array}{l}95 \mathrm{MW} \text { Four River (formally Calvert City ) 2PFBC CCT5 } \\
\text { project; to test WH filters }\end{array}$ \\
\hline
\end{tabular}

Overall, most of the past filter tests were considered reasonably successful, but some were only fair. Typical problems were that the face velocities for coal gases were generally low, only in the order of 1 to $3 \mathrm{fpm}$. They also experienced similar mechanical problems common to all HTHP devices for PFBC applications. In the area of chemical degradation, vapor phase alkalis appeared to contribute to deterioration of silicon carbide filters above $1,400^{\circ} \mathrm{F}$, but less so for alumina/mullite ceramics. Below $1,200^{\circ} \mathrm{F}$, alkalis are condensed and their attacks are thought to be much weaker and less problematical.

It is important to note that, in many of the newer IGCC projects (the Demokolec/Shell/Buggenum, Rheinbraun/HTW/KoBra, ELCOGAS/PRENFLO/Puertollano, and PSI/Destec/Wabash River projects), the ceramic filters are or will be tested at a relative low 
temperature in the range of $500-700^{\circ} \mathrm{F}$. In these, which involve cleanup sequence that may be termed partial hot gas cleanup, the separated chars are returned to the gasifier after $d r y$-filtration but the particle-free gas is conventionally wet-scrubbed to remove halogens (HCl, HF) and other water-soluble components ( $\mathrm{NH}_{3}, \mathrm{HCN}$ ), followed by a low temperature desulfurization (LTD) process for sulfur removal. The main purpose of using ceramic filters in this fashion is not so much as to maximize thermal efficiency (by conserving sensible heat for HTD and GT) but rather to simplify the downstream wastewater treatment steps to minimize costs. Apparently, in switching to the dry solid/gas filtration from wet solid/liquid separation schemes, there is net capital and/or O\&M savings by eliminating or minimizing use of bulky solid/liquid separators such as settlers and clarifiers. The overall conversion efficiency may not be as high as those coupling the filters to a HTD but there is still improvement in the thermal efficiency. Use of ceramic filters for partial hot gas cleaning at a medium temperature level represents a practical near-term solution for IGCC applications since it minimizes chemical attacks/thermal shock problems. It is a worthy implementation along with other "partial" processing concepts that are being tested, e.g., partial gasification (British Coal Topping Cycle; FW 2nd generation PFBC) and partial air integration (GT/Air Separation Unit; GT/air-blown gasifier).

\subsection{FILTER CLEANING TECHNIQUES - ANALYSIS AND MODELING}

While there is available a large body of $R \& D$ reports on hardware-oriented topics such as materials development, physical/chemical degradation tests, mechanical strength analyses, and pilot or large-scale demonstration operations, there is limited number of reports devoted solely to the analysis and modeling of HTHP filter cleaning technology. The following is a discussion of reports we found useful for the current project:

Westinghouse In 1989 Westinghouse published a set of reports on the performance evaluation of their ceramic cross-flow filter system which they tested with a bench-scale coal gasifier. In one of the appendices, they described a mathematical model for the pulse jet blowback unit which they developed in conjunction with a cold flow model. It appears that the mathematical model was developed in part to help verify test results and scaleup design parameters for large unit applications.

The basis of the dynamic simulation model involved a set of unsteady-state energy, momentum, and material balances that simultaneously described the gas dynamics around the cross-flow filter plenum during pulse blowback. The model was intended to examine whether a particular blowback design would work -- for a given input data set (hardware configuration, operating conditions, cake and gas properties), it calculates key process variables such as the maximum plenum pressure rise, the associated plenum temperature, total quantity of the motive gas expended during the pulse, total quantity of the clean gas entrained during the blow-back process, etc. One of the key parameters that is required as input is the cake breakage constant (related to cake/filter adhesivity) $B$, which together with a definition of mean particle diameter $d_{p}$ ' defines the pressure drop del $\mathrm{P}_{\mathrm{b}}=\mathrm{B} / \mathrm{d}_{\mathrm{p}}$ ' across cake needed to blow off the cake during backflush. The model considers the cake successfully blown off at the instant the transient maximum plenum pressure exceeds del $\mathbf{P}_{\mathbf{b}}$.

In sample calculations, the model showed that:

(1) The filter cake would detach quickly and early in the pulse cleaning cycle (in a fraction of second after valve opening) if the pulse flow was initiated with a sufficiently high initial reservoir pressure. [Otherwise, the printout message would say "The cake is still on. Blow harder", suggesting the reservoir pressure be raised higher.] 
(2) The model indicated that the bulk of the pulse jet (which continued to escape from the tank due to relatively slow closing action of the valve) would not contribute beneficially to cake removal but only serve to cool the filter elements.

(3) For most of the test cases, the predicted pressure rises were reasonably close to the observed values (within 10-20\%) but some were quite off (greater than $50 \%$ or more). The differences were attributed to experimental noises.

The WH filter cleaning computer program was coded in Fortran could be run on a PC. The basic version of the mathematical model was actually established earlier (1982-83); the 1989 version include changes such as: new treatment of nozzle piping flow resistance (actual pressure drops accounted for as head losses), wall resistances (with inertia term added to the viscous term), solenoid valve opening and closing characteristics (finite speed instead of instantaneous), entrainment clean gas contraction/expansion losses, blowback suction area, effective filtration area, and mixing zone energy balances. While the model was specifically derived and set up for the WH cross-flow filters, the general approach described in the report can be applied to other rigid barrier filters such as the candle with appropriate modifications.

RWTH (Germany) In 1986-1989, the Aachen University of Technology (RWTH Aachen) of Germany tested a pilot scale candle filter system co-sponsored by EPRI and Schumacher GmbH, FRG. In the tests for AFBC and PFBC applications, six Schumacher sintered silicon carbide candle filter elements were cleaned using air as cleaning fluid in an on-line cleaning setup. The filtering tests were done with a slip-stream of combustion gas at (up to) $850^{\circ} \mathrm{C}$ and $3.8 \mathrm{bar}$. As part of study on filtration efficiency, pressure drop characteristics, power consumption, temperature and pressure transient, and pulse regeneration behavior, they also developed filter cleaning models using various analysis techniques. The flow in the pulse-jet lance was modeled as quasi-steady state flow in one case since the initial unsteady period was found to be short. In others, the steady and/or the unsteady flow and heat transfer through the tube sheet, filter element and clean gas manifolds were modeled using the commercially available FLUENT code and/or the ABAQUS finite element code.

Overall, the RWTH models and their computer codes were larger and more complex as they could handle more elaborate situations, such as two- and three-dimensional transient temperature, pressure and streamline distributions in polar coordinates and variable grid spacing. The data generated from the models were characterized useful for structural/fatigue analyses of the filter elements or tracking of particle movement. The models could show for example, under a certain operating condition, a strong vortex would develop at the lance tip, and that the bulk (85\%) of the pulse gas would not enter the candle during the first $40 \mathrm{~ms}$ of the pulse and that the top of the candle would be at much different temperature than that of the surrounding gas. The conclusion was that the permeability of the filter element determined the amount of gas entering the filter which impacts the degree of transient cooling of the ceramics material by the pulse jet.

In many cases, the model (and tests) indicated no entrainment of clean filtered gas under their operating conditions. Other RWTH findings that are of interest to filter cleaning analysis include:

(1) Increasing pulse duration has no effect on permeability and only caused an increase in pulse air consumption. Increasing pulse duration tends to introduce a significant amount of low temperature air into the ceramic candle filter cavity which, in turn, leads to lowering of the minimum temperature in the filter elements. Thus, the pulse duration relates closely to the length of thermal shock conditions.

(2) The cake separation efficiency improved considerably with increasing reservoir pressure. For example, while sufficient cleaning was attained at a pulse pressure of 3.0 bar in AFBC tests but, 
when the pulse air pressure was increased to 4.0 bar, the temporary as well as the residual dust layer thickness were nearly cut into half.

(3) An increase of the pulse pressure, however, atso causes an extended transient gas temperature drop in the candle filter cavity (due to an increased mass flow) which increases the thermal shock potentials.

(4) Increasing cleaning cycle duration, i.e., reducing pulse frequency, was found to lead to increasing temporary dust layer thickness as well as increasing residual dust layer thickness. At equilibrium, the given pulse was able to remove the entire temporary layer; however, the intensity was too small to keep the thickness of the residual layer at the same low value compared to shorter cleaning cycle durations.

(5) Residual dust layer could only be removed by mechanical means. The dust may have interacted with the pores in the filter element and caused irrecoverable blinding that could not be removed by pulse jet.

(6) The relation between pulse pressure and cleaning cycle duration appears to be very important. Testing at an extended cleaning cycle duration and low pulse pressure generally ran "out of control" - i.e., the pressure drop continued to increase and no steady state clean-up was achieved. In contrast, when cleaning cycle durations were short, successful steady-state cleaning were achieved at low pulse pressure even if the permeability was reduced.

(7) Precise data on the transient behavior of the solenoid valves is important for a good result of the numerical model. Often, the nominal pulse duration set at the timer and the actual duration of the pulse jet are found to be different.

CRIEPI (Japan) In a recent EPRI workshop on dust filtration, the researchers from the Central Research Institute of the Electric Power Industry of Japan (CRIEPI) described the design of a pulse cleaning system which was used to test tube filters at their 20 TPD pilot gasification plant near Iwaki City, Japan. (The pilot plant is located in the close proximity of a 200 TPD IGCC demonstration plant in Nakoso power station.) In their analysis, the flow in the tube filter was found to approach a steady state very quickly. Consequently, the general relationships among temperature, pressure, and flow were analyzed/modeled under a steady state assumption for both filtration and cleaning periods. The predicted data based on Fanno mass, momentum, and energy balances were shown to compare favorably against measured data obtained from the 2-TPD process development unit at their Yokosuka laboratory.

Based on the model predictions and PDU data, some of the conclusions they arrived at were:

(1) For a given nozzle of fixed diameter, the relationship between the flow rate of entrained clean gas $Q_{2}$ and that of pulse jet $Q_{1}$ was nearly linear. They could be related in the form: $Q_{2}=a+b Q_{1}$, where $a$ and $b$ are constants depending on nozzle diameter. $Q_{2}$ could become negative when $\mathrm{Q}_{1}$ was small and the nozzle diameter was large, i.e., when the momentum of the pulse jet was small.

(2) The slope of $Q_{2} / Q_{1}$ (the constant $b$ in the above equation) would increase as the nozzle diameter was reduced, i.e., more clean filtered gas could be entrained per unit volume of motive gas as the momentum of the jet was increased by reducing the nozzle diameter.

(3) The mixing of the motive gas and the entrained clean gas resulted in a pressure increase which, in turn, resulted in the reversal of flow through the filter element and eventual removal of the cake. In a relatively short filter, the reservoir pressure $P_{0}$ required to remove the cake was 
found to be essentially proportional to the cleaning face velocity $U_{f}$, i.e., $U_{f}=c+d . P_{0}$ approximately, where $c$ and $d$ are constants related to the nozzle diameter.

(4) For the 20 TPD pilot plant which operated at 20 atm, it was determined that a pulse jet pressure of $50 \mathrm{~atm}$ or more would be needed to blow off the cake, if a cleaning face velocity of $10 \mathrm{~cm} / \mathrm{sec}$ or greater were used during the forward filtration period.

(5) The pulse gas used in the tests were the filtered coal gas, compressed and stored in a gas reservoir.

(6) Filter plugging was thought to be caused by intrusion of sub-micron particles into the depth of filter pores. It was deemed that most of these fine particles found in the filter interior were generated through the "gas-to-particle conversion" process, i.e., by implication, the carbon deposition due the Boudouard reaction. In tests, the fines were found to be mostly carbon and could be removed by "burning out" using hot air at atmospheric pressure.

(7) In testing the filter regeneration concept, it was found that the ignition temperature stayed below $500^{\circ} \mathrm{C}$ and the temperature did not increase any higher if the amount of fines was small. The ashy layer remaining on the surface of filter (after burning out) did not have be removed since they would actually protect the filter surface.

CRIEPI applied these findings in scaling up their pulse blowback system, including the hot air filter regeneration scheme for removal of deeply trapped fine carbon particles. In commercial application, the filters would be regenerated in-situ (i.e., the filters stay in the filter vessel) once a year during the period of annual maintenance.

\subsection{CONCLUDING REMARKS}

From the review of the literature, it can generally be concluded/ remarked that:

(1) An ideal on-line pulse cleaning technique is one that is capable of building a sufficiently high pressure in the candle filter cavity to blow off the cake with the least amount of pulse gas in the shortest possible time.

(2) In general, the minimum pulse pressure needed to blow off the cake layer is a function of the operating parameters (e.g., cleaning cycle duration) and cake separation stress (related to the cake adhesivity/cohesivity). The cake separation stress must be known for effective design of the filter blowback system.

(3) Ideally, the temperature and composition of cleaning fluid should be as close as possible to that of clean gas to mitigate thermal shock and thermal fatigue.

(4) Extended cleaning cycle duration is likely to cause permeability reduction and increase in residual dust layer thickness. If the cycle time is too long, the filtering operation may become unstable unless the pulse pressure is increased.

(5) Increasing pulse duration causes increased pulse gas consumption, lower filter temperature, and increased potential for thermal shock. However, it may improve cake cleaning efficiency because a correspondingly longer free-fall time is available for the detached cake to settle to bottom of the filter vessel.

(6) The specific operational characteristic and response time of the solenoid valve that initiates and terminates the pulse of jet is important in analyzing the performance of pulse blowback system. 
(7) When filtering coal gas in IGCC applications, there may be a need for long-term regeneration of the filter elements (such as "burning-out") in addition to short-term cyclic cleaning of the filter/cake.

\subsection{REFERENCES}

Papers/articles that were relevant or of interest to this project are listed below:

1. Foster Wheeler (FW) Topical Report on "Second Generation PFBC Plant Conceptual Design and Optimization", Sept., 1989.

2. Westinghouse (WH) Final Report on "Performance Evaluation of a Ceramic Cross-Flow Filter on a Bench-Scale Coal Gasifier", Sept., 1989.

3. Aachen University of Technology (RWTH) Reports on "High Temperature Gas Filtration", Vol. 2 to 5, EPRI GS-6489, Oct., 1992.

4. Southern Company Services, Inc. (SCS) Final Report on "Assessment of Coal Gasification/Hot Gas Cleanup Based Advanced Gas Turbine Systems", DOE/MC/26019-3004, Dec., 1990.

5. Newby, R. A. and Bannister, R. L. (WH), "Hot Gas Cleaning Makes Promising Progress", p. 51, Modern Power System, Sept., 1993.

6. White, L. R. et al (3M), "Ceramic Filters for Hot Gas Cleanup", p. 665, J. of Eng. for GT\&P, July, 1993.

7. Lippert T. E. et al (WH), "Development of HGC systems for Adv. Coal Based GT cycles", p. 658, J. of Eng. for GT\&P, July, 1993.

8. Zievers, J. F. et al (IF\&P), "What Affects the Cost of HG Filter Stations?", p. 652, J. of Eng. for GT\&P, July, 1993.

9. Gonzalez, S. et al, "High Temperature Ceramic Particulate Filter", U.S. Patent No. 5,087,277, Feb. 11, 1992

10. Rath, L. K. et al (METC), "A Third-Generation IGCC systems", a paper prepared for 10 th Pittsburgh Coal Conf., Sept. 20, 1993.

11. METC, "PFBC and HGC Program Review", an internal paper, Sept., 1992.

12. Brown, R. A. and Leitch, A. J. (EPRI), "Filtration of PFBC Dusts Using A Rigid Ceramic Tube Type Filter", p. 1229, 1993 Int. Conf. on FBC, May 9, 1993.

13. Laux, S. et al (RWTH), "Hot Gas Filtration with Ceramic Filter Elements", p. 1241, 1993 Int. Conf. on FBC, May 9, 1993.

14. Clark, R. et al (Grimethorpe), "Some Recent Experiences with the EPRI HGC Ceramic Filter at Grimethorpe PFBC Establishment", p. 1251, 1993 Int. Conf. on FBC, May 9, 1993.

15. Semler, C. E., and Bakker, W. T. (Semler/EPRI), "Evaluation of Silicon Carbide Candle Filters", p. 1259, 1993 Int. Conf. on FBC, May 9, 1993. 
16. Newby, R. A. et al (WH/FW), "XF Filter Performance with 2PFBC Carbonizer Fuel Gas", p. 703, 1993 Int. Conf. on FBC, May 9, 1993.

17. Jalovaara, J. et al (Helsink U), "Particle Rèmoval in PFBC Using A Fibrous Ceramic Candle Filter", p. 713, 1993 Int. Conf. on FBC, May 9, 1993.

18. Mudd, M. J., and Hoffman, J. D. (AEP), "Operating Data From the Tidd HGCU Program", p. 719, 1993 Int. Conf. on FBC, May 9, 1993.

19. Valentino, K. R. et al (Virginia Tech), "Durability Testing of Ceramic Candle Filters in PFBC Environments", p. 1375, 1993 Int. Conf. on FBC, May 9, 1993.

21. Lippert T. E. et al (WH), "Development and Commercialization of HG Filtration Systems", p. 1073, 1991 Int. Conf. on FBC, April 21, 1991.

22. Durst, M. et al (Schumacher), "Performance of Rigid Ceramic Filter Elements in An 8000 Hour Durability Test At High Temperatures", p. 1081, 1991 Int. Conf. on FBC, April 21, 1991.

23. Laux, S. et al (RWTH), "Performance of Ceramic Filter Elements for CC Power Plant HGCU", p. 959, 1991 Int. Conf. on FBC, April 21, 1991.

24. Singh S. (Flex-Kleen), "Pulse-Jet Dust Collectors", p. 125, Chem. Eng., Feb., 1993.

25. Eggerstedt, P. M. et al (IF\&P), "Choose the Right Ceramic for Filtering Hot Gas", p. 62, CEP, Jan., 1993.

26. Jadaan, D. M. (U of Wisconsin), "Methodology to Predict Delayed Failure Due to Slow Crack Growth in Ceramic Tubular Components", p. 204, Trans. of ASME, April, 1993.

27. Stringer, J. and Leitch, A. J. (EPRI), "Ceramic Candle Filter Performance at the Grimethorpe PFBC", p. 371, J. of Eng for GT\&P, April, 1992.

28. Sorell, G. (Sorell), "Materials Engineering Challenges in Clean Coal Technologies", p. 342, 8th Pittsburgh Coal Conf., Oct. 14, 1991.

29. Dennis, R. A. (METC PM), "Mechanical Analysis of a Cross Flow Filter", METC Gasif. and Gas Stream Cleanup Systems Contractor Review Meeting

30. Chiang, T. K. and Dennis, R. A. (METC), "METC In-House Particulate Cleanup Program"; 11th METC Gasif. and Gas Stream Cleanup Systems Contractor Review Meeting, 1991.

31. Dennis, R. A. and Chiang, T. K. (METC), "Summary of METC's In-house HTHP Particulate Cleanup Research", 10th METC Gasif. and Gas Stream Cleanup Systems Contractor Review Meeting, Aug., 1990.

32. Chiang, T. K. et al (METC), "Generalization of Lab Dust Cake Characteristics for Full-Scale Applications", 8th EPRI Particulate Control Symposium, GS-7050, Nov., 1990.

33. Dennis, R. and Grant M. A. (EPA), "Development and Evaluation of Improved Fine Particulate Filter Systems", EPA Project Summary, Air and Energy Eng. Research Lab, May 1985. 
34. Dennis, R. (GCA), "Mechanics of Aerosol Separations: Basic Concept", Proceedings of the Eng. Foundation Conf., Oct. 30, 1977.

35. Dennis, R. and Klemn, H. (GCA), "Modeling Coal Fly Ash Filtration with Glass Fabrics", p. 13-39, Fabric Filter Symposium, Dec. 5, 1977.

36. Black, C. (Texaco), "TECO's Polk Unit \#1 IGCC Project Update", 12 th EPRI Conf. on Gasification Power Plant, Oct. 27, 1993.

37. Fisackerly, R. (Destec), "The Wabash River Coal Gasif. Repowering Project Update", 12 th EPRI Conf. on Gasification Power Plant, Oct. 27, 1993.

38. Motter, J. (KRW), "Engineering Process Review of the Pinon Pine IGCC Project", 12 th EPRI Conf. on Gasification Power Plant, Oct. 27, 1993.

39. Droog, H. A. (Shell), "IGCC Buggenum Ready for Demonstration", 12 th EPRI Conf. on Gasification Power Plant, Oct. 27, 1993.

40. Sendin, U. (PRENFLO), "Status of the 335 MW IGCC Puertollano Project", 12 th EPRI Conf. on Gasification Power Plant, Oct. 27, 1993.

41. Adlhoch, W. (HTW), "The Rheinbraun HTW Gasification Process - An Update of Development", 12 th EPRI Conf. on Gasification Power Plant, Oct. 27, 1993.

42. Sears, R. (SCS), "The Joint DOE Industry Power Systems Development Facility", 12 th EPRI Conf. on Gasification Power Plant, Oct. 27, 1993.

43. Minchener, A. J. (British Coal), "Development of the CRE Gasifier for Use in Integrated Partial Gasification CC Systems", 12 th EPRI Conf. on Gasification Power Plant, Oct. 27, 1993.

44. Epstein, M. (EPRI), "Overview of Dust Filtration from Coal-Derived Reducing Gases at HT", 2nd EPRI Workshop on Dust Filtration, March 11, 1992.

45. Salter, J. A. (Shell), "SCGP-1 HTHP Filtration Experience", 2nd EPRI Workshop on Dust Filtration, March 11, 1992.

46. Ito, S. (CRIEPI), "Cleaning and Regeneration of Porous Ceramic Filter Applied to a 20 TPD Pilot Plant of Hot Coal Gas Filtration", 2nd EPRI Workshop on Dust Filtration, March 11, 1992.

47. Durst, M. (Schumacher), "Design Alternatives for HG Dust Filtration", 2nd EPRI Workshop on Dust Filtration, March 11, 1992.

48. Isaksson, J. (Ahlstrom), "ACTF-Filter Experiences", 2nd EPRI Workshop on Dust Filtration, March 11, 1992.

49. Laux, S. et al (RWTH), "Performance of Ceramic Filter Elements for HG Filtration", 2nd EPRI Workshop on Dust Filtration, March 11, 1992.

50. Cahill, P. (British Coal), "Durability of Ceramic Filters for the British Coal Topping Cycle", 2nd EPRI Workshop on Dust Filtration, March 11, 1992. 
51. Laux, S. et al (RWTH), "Numerical Modeling of Filters with Ceramic Candle Elements", 2nd EPRI Workshop on Dust Filtration, March 11, 1992.

52. Pitt, R. U. (RWTH), "One-Dimensional Modeling of Candle Filter Systems", 2nd EPRI Workshop on Dust Filtration, March 11, 1992.

53. Pontius, D. H. (SRI), "Characterization of Particles Emitted in Gasification and Combustion Processes", 2nd EPRI Workshop on Dust Filtration, March 11, 1992.

54. Sheckler, C. (Refractron), "Critical Components of Hot Gas Filter Design", 2nd EPRI Workshop on Dust Filtration, March 11, 1992.

55. Leith, D. (Univ of NC), "Fundamentals of Gas-Particle Separation Processes at High Temperature and Pressure", Proceedings of the Separations Technology Workshop for Coal Gasification, Morgantown, WV, Dec. 8, 1988.

56. Leith, D. et al (Harvard U), "Effect of Modified Cleaning Pulses on Pulse Jet Filter Performancen, 3rd symposium on Fabric Filters for Particle Collection, EPA-600/7-78-087, 1977.

57. Sawyer, J. W. (VPI), "Thermal/Chemical Degradation of Ceramic Candle Filter Materials", 11th METC Gasification and Gas Cleanup Systems Contractors Review Meeting, Morgantown, WV, Aug. 13, 1991.

58. Lippert T. E. (WH), "Subpilot-Scale Gasifier Evaluation of Cross-Flow Filters", 11th METC Gasification and Gas Cleanup Systems Contractors Review Meeting, Morgantown, WV, Aug. 13, 1991.

59. Alvin, M. A. (WH), "Thermal/Chemical Stability of Ceramic Cross-Flow Filters Materials", 11th METC Gasification and Gas Cleanup Systems Contractors Review Meeting, Morgantown, WV, Aug. 13, 1991.

60. Robin, A. (Texaco), "Integration and Testing of Hot Desulfurization and Entrained-Flow Gasification", 11th METC Gasification and Gas Cleanup Systems Contractors Review Meeting, Morgantown, WV, Aug. 13, 1991.

61. Rudnick, S. N. et al (Harvard U), "Specific Resistance of filter Dust Cakes", 3rd symposium on Fabric Filters for Particulate collection, Tucson, AZ, Dec. 5, 1977.

62. FWDC Report on Carbonizer Test Runs 1 and 2 on "2nd Generation PFBC R\&D", Feb 27, 1992.

63. FWDC Phase 2 Status Report 66, "2nd Generation PFBC R\&D", Sept., 1993.

64. Zaharchuk, R. and Rutkowski, M. D. (G/C), "Application of Hot Gas Particulate Removal Devices to IGCC Systems", 10th Pittsburgh Coal Conf., Sept. 20, 1993.

65. Roll, M. W. et al (Destec), "The Destec Coal Gasification Process at LGTI", 10 th Pittsburgh Coal Conf., Sept. 20, 1993.

66. Bayens, C. A. et al (Shell), "Update on Projects Using the Shell Coal Gasification Process", 10 th Pittsburgh Coal Conf., Sept. 20, 1993. 
67. Grove, A. and Shenker, J. (TRW/FW), "Combustion of Char in a CC System Based on the Partial Gasification of Coal", 10th Pittsburgh Coal Conf., Sept. 20, 1993.

68. Rehmat, A. and Goyal, A. (IGT), "Performance Characteristics of Advanced Fluidized-Bed Staged Combustion", 10th Pittsburgh Coal Conf., Sept. 20, 1993.

69. Pontius, D. H. (SRI), "Particulate Characterization for PFBC Filter Systems", Coal-Fired Power Systems 93 - Advances in IGCC and PFBC Review Meeting, Morgantown, WV, June 28, 1993.

70. Lippert, T. E. (WH), "Specific Filter Design for PFBC", Coal-Fired Power Systems 93 Advances in IGCC and PFBC Review Meeting, Morgantown, WV, June 28, 1993.

71. Chiang, T. K. and Dennis, R. A. (METC) "Effect of Operating Conditions on Dust Cake Behavior in Filters with High Surface-to-volume Ratio", Coal-Fired Power Systems 93 Advances in IGCC and PFBC Review Meeting, Morgantown, WV, June 28, 1993.

72. Sawyer, J. W. (VPI), "Ceramic Filter Material Issues", Coal-Fired Power Systems 93 Advances in IGCC and PFBC Review Meeting, Morgantown, WV, June 28, 1993.

73. Alvin, M. A. (WH), "Evaluation of Ceramic Filter Material, Selection for Application", Coal-Fired Power Systems 93 - Advances in IGCC and PFBC Review Meeting, Morgantown, WV, June 28, 1993.

74. Robert, D. L. (CeraMem), "Ceramic Filters for Removal of Particles from HG Streams", Coal-Fired Power Systems 93 - Advances in IGCC and PFBC Review Meeting, Morgantown, WV, June 28, 1993.

75. Zievers, J. F. (IF\&P), "Some Ceramic Options", Coal-Fired Power Systems 93 - Advances in IGCC and PFBC Review Meeting, Morgantown, WV, June 28, 1993.

76. Lippert, T. E. (WH), "Westinghouse Filter Update", Coal-Fired Power Systems 93 Advances in IGCC and PFBC Review Meeting, Morgantown, WV, June 28, 1993.

77. Mudd, M. J. (AEP), "Initial Operation of the Tidd PFBC Hot Gas Filter", Coal-Fired Power Systems 93 - Advances in IGCC and PFBC Review Meeting, Morgantown, WV, June 28, 1993.

78. Clift, R. and Seville, J. P. K. (Univ. of Surrey, UK), "Gas Cleaning at High Temperatures", Blackie Academic \& Professional (London), Sept., 1993.

79. Combustion Power Company (CPC), "Granular-Bed and Ceramic Candle Filters in Commercial Plants - A Comparison", Vol. 1, METC topical Report, April, 1993.

80. Southern Company Services, Inc. (SCS), "Assessment of Coal Gasification/Hot Gas Cleanup Based Advanced Gas Turbine systems", DOE/MC/26019-3004, Dec., 1990. 


\subsection{DISCUSSION OF CONCEPTS}

This section presents the results of Subtask 3, Evalùation and Identification of Potential Ceramic Cleaning Filter Techniques. Since the concepts, cases and design bases had to be identified before completing the analyses and modeling of Subtasks 1 and 2, this section is presented first.

The three candle filter cleaning systems that have been evaluated include:

- $\quad$ On-line $400^{\circ} \mathrm{F}$ pulse

- Off-line $400^{\circ} \mathrm{F}$ pulse

- Rapid combustion pulse

Each of the systems has built-in physical characteristics which limit and define the capabilities for producing a pulse of blowback gas. A description of the three systems, including their limitations, is the purpose of this section of the report.

\subsection{ON-LINE $400^{\circ} \mathrm{F}$ PULSE}

This system is essentially the one that is proposed on commercial candle filters and is being used at test facilities such as Tidd, Karhula and Aachen University. It consists of a compressor, air dryer, primary accumulator tank, air filter and several secondary accumulator tanks with $2^{n}$ fast acting back pulse valves. The secondary tanks are also called blowback reservoirs. When the back pulse valves are activated during candle filter blowback a 200 millisecond pulse of cleaning fluid is blown through piping into the candle filter plenum and then into the candle filters. For this evaluation the pulse is blown into a plenum containing up to 74 candles. In some designs tubing is manifolded into each candle. The blowback gas for PFBC is compressed air. For gasifiers and carbonizers the blowback gas is fuel gas taken from the clean fuel gas stream and then cooled and then compressed. Nitrogen has also been proposed.

The $200 \mathrm{~ms}$ pulse is a limitation of the Atkomatic valve used at Tidd. Attempts are being made to develop a faster acting valve since a shorter pulse is believed to be more advantageous. Figure 3.1-1 shows a piping schematic of the blowback system for the Tidd filter. At Tidd the secondary tank is $4 \mathrm{ft}^{3}$ in size and the piping includes redundant valves which would not be needed in a commercial system.

The accumulator tank pressure can be whatever is needed to release the cake from the filter. At Tidd the tank and compressor are rated for 1500 psig. Normally the back pulse pressure has been 800 psig but up to 1200 psig has been needed at times. Because of the very high pressure drop from the tank to the individual candle filters these high tank pressures are required. At the filter only a few psig pressure differential is needed to blow off the filter cake.

In order to prevent thermal shock it is advantageous to use as hot a gas as possible. The maximum operating temperature of the back pulse valve limits the tank gas temperature to $400^{\circ} \mathrm{F}$ for the type of valve that is used at Tidd. Since the pulse is very rapid, attempting to heat the gas in the external pipe after the valve would not be effective. It may be possible that in the future a high temperature, fast acting valve and a properly designed ejector could produce a blowback gas hot enough to prevent thermal shock. For this evaluation a $400^{\circ} \mathrm{F}$ maximum blowback gas will be used in the design.

The criteria for determining at what temperature thermal shock starts occurring for candle filters is based on tests that showed that at temperatures $100^{\circ} \mathrm{F}$ below operating temperature micro cracking of the candle is observed. However, long term test results with candle filters blown back with "cold" air have not shown that micro cracking necessarily leads to candle filter failure.

Westinghouse at the Tidd facility, for example, has made no attempt to use heated blowback gas in 


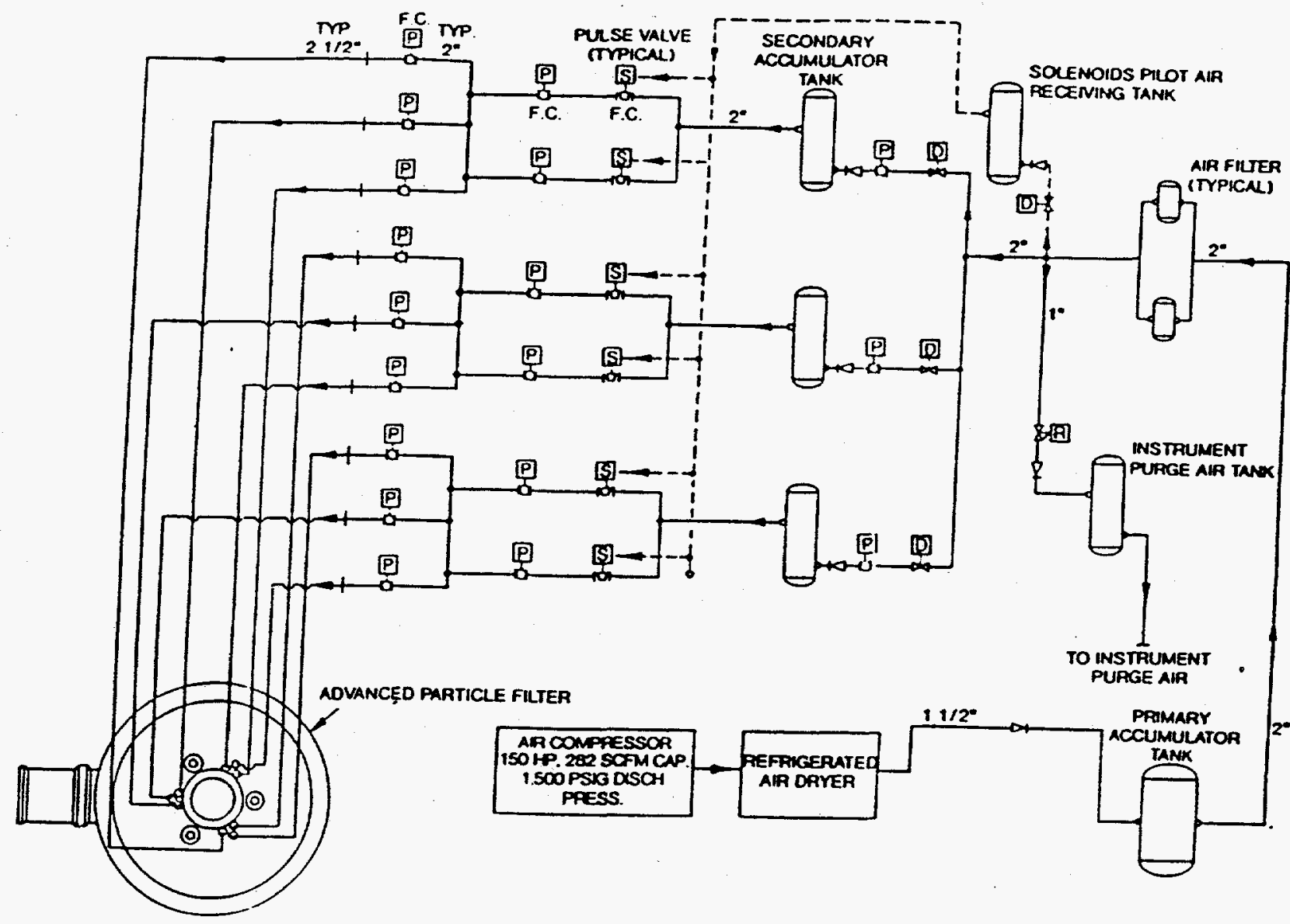

Reference: Westinghouse Tidd Facility

Figure 3.1-1

ON-LINE PULSE DRIVEN 
the reservoir. Candle life data from this facility could provide useful information for blowback system design.

The limitations for this system are thus:

Pressure: $\quad$ no limit but typically $800-1200$ psig

Temperature: $\quad 400^{\circ} \mathrm{F}$ maximum in the reservoir

Pulse duration: minimum 200 millisecond for Atkomatic valve, maximum dependent on tank size

Flow rate: $\quad$ subsonic dependent on pulse tube pressure drop

\subsection{OFF-LINE $400^{\circ} \mathrm{F}$ PULSE}

The advantage to off-line filter cleaning is that the dust ash has an opportunity to fall to the bottom of the filter vessel before it re-attaches to the filter surface. It must be emphasized that removal of ash from the gas stream is actually a result of gravitational settling and this is a relatively ineffective method of particle separation. The ash particles entering the filter are less than 10 microns in size. The size of the particles blown off the candles is not known; therefore, calculations cannot accurately predict the settling time required for a particular case. Since on-line filter blowback systems have worked successfully it can be assumed that the particles being blown off are large enough agglomerates. Off-line cleaning can allow more agglomerates to settle between blowback pulses. This can increase cleaning efficiency and increase the duration of time between blowback resulting in lower consumption of blowback gas and lower compressor power requirements.

Off-line cleaning requires a shut-off valve that can function at high temperature and pressure. This valve would not have to be a positive shut-off valve. Some leakage would be allowable which would lower the valve cost.

In order to prevent high excessive gas flows to other filters when a filter is valved off additional filter vessels would be required in a system. This will add capital cost compared to on-line systems.

Off-line cleaning involves isolating a vessel from the gas stream and then blowing back the candles starting with the top tier of candles then the remainder in succession from top to bottom. For a commercial vessel containing 16 candle clusters and assuming a blowback cycle time of 30 seconds per cluster, the vessel would be off-line 8 minutes. This should allow ample time for settling of agglomerates.

In order to optimize system design, information is needed on the actual particle size of agglomerates blown off candles at various conditions. Also attempts should be made to increase the size of agglomerates formed on candles.

The limitations for this system are the same as for on-line cold pulse cleaning.

\subsection{RAPID COMBUSTION PULSE}

Nakaishi and others of METC have patented a concept using a rapid pulse combustor to produce a hot blowback gas for filter cleaning. This concept is a radical departure from the conventional systems previously described in that the high pressure blowback pulse is generated only when needed by the rapid combustion of fuel in a pressure vessel outside of the filter vessel. After 



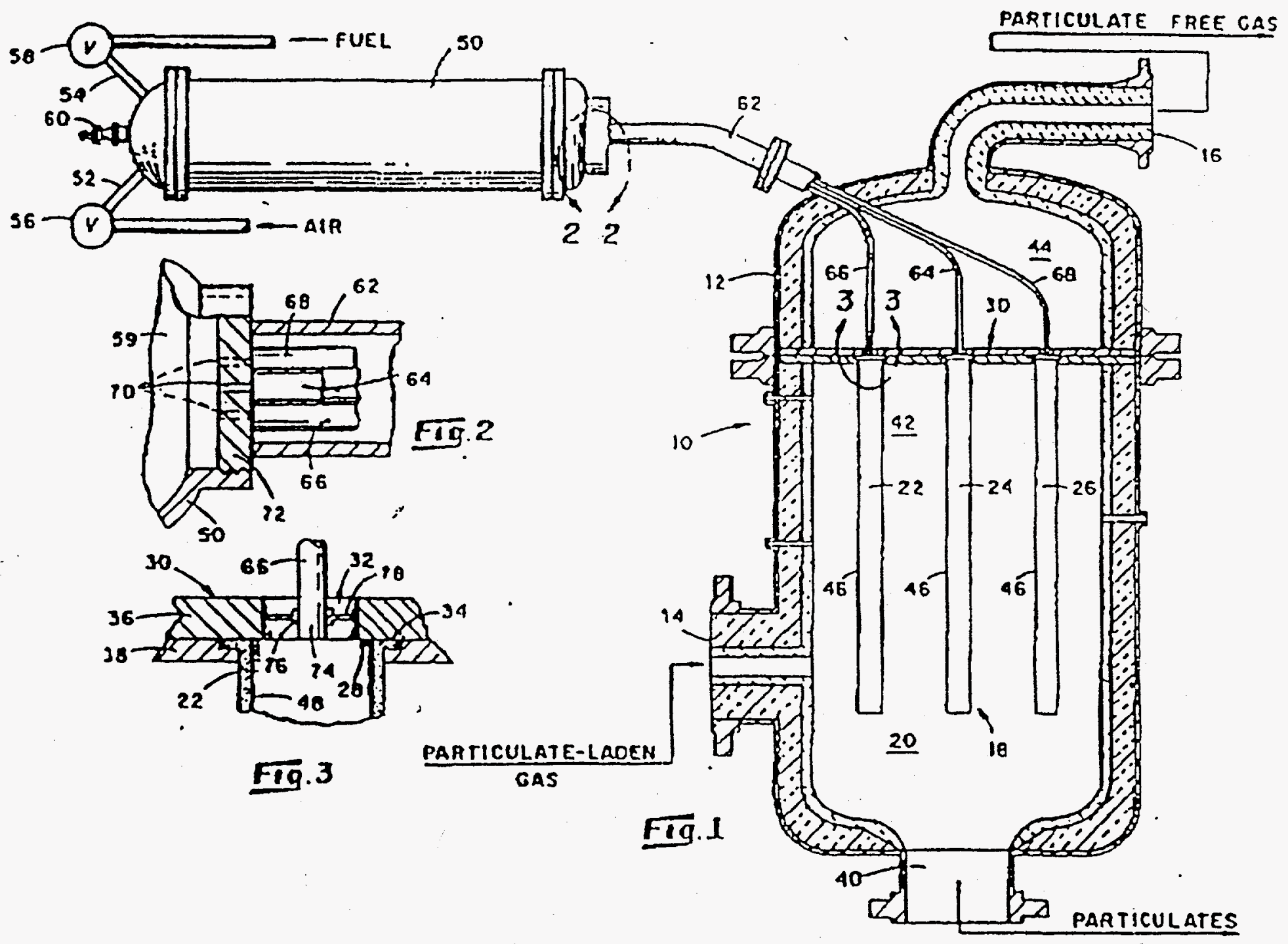

Reference: U.S. Patent $5,167,676$, C. V. Nakaishi etal

Figure 3.3-1

RAPID PULSE DRIVEN 
The CPFBC plant is the Second Generation PFBC design which uses a carbonizer to generate a low BTU combustion gas. The IGCC plant is an air-blown, fluidized bed gasifier.

Input to the model was based on real data from operating systems, laboratory and pilot scale tests, model simulations and information from Westinghouse. Section 4.0 describes the model in detail. 


\subsection{ANALYSIS AND MODELING OF FILTER BLOWBACK SYSTEM}

This section presents the results of Subtask 1 First Principal Analysis of Ceramic Barrier Filter Cleaning Mechanisms and Subtask 2 Operational-Values for Parameters Identified With the Filter Cleaning Mechanisms.

\subsection{ANALYSIS OBJECTIVE AND SCOPE}

One of the objectives of this project is to identify the basic mechanisms and functional relationships governing cake removal as they relate to the ceramic barrier filter cleaning techniques described in the previous section. This involves, for example, analysis of pressure drops through porous media (filter and cake layers), or the pressure level required in the candle filter cavity for effective cake removal. A companion objective is to determine a range of values for operational parameters, such as the flow rate of the cleaning fluid, its pressure and temperature at the pulse lance. The values of these parameters are to be established by taking into consideration the properties of cleaning fluids such as air, nitrogen, or recycled fuel gas as appropriate, and the properties of filter medium and cake that forms on the surface of filter medium.

In short, given a suitable geometrical and process description of the components and constituents involved in the filter blowback system, the analysis and modeling objectives are to establish the necessary design data for the Conceptual Design Task (to be described in Section 5), including:

(1) The required gas flow rate and the associated pressure $P$ and temperature $T$ conditions at various points in the blowback system.

(2) The volume, $P$, and $T$ of the cleaning fluid reservoir and the duration of blowback.

\subsection{ANALYSIS BASIS AND FORMAT}

In carrying out "first principle" analyses to achieve above objectives, it was assumed that the filter is the typical $1.5 \mathrm{~m}$ long, $0.6 \mathrm{~m}$ O.D., $0.3 \mathrm{~m}$ I.D. SiC candle, which is one of the widely tested porous HTHP ceramic filters. The geometrical/physical arrangement of the blowback system (the piping and internals that deliver the pulse gas from reservoir to candle cavity) is assumed to be similar to that used at the Tidd PFBC demonstration plant, i.e., a "cluster" blowback type. In a cluster blowback system, a number of candles are suspended from a common plenum, which is connected to a single ejector through a pulse pipe. When a pressurized gas is discharged through the ejector into the plenum/candle cavities, the clustered filters are cleaned all at once. (See Section 5 for the overall schematics of the blowback piping arrangement.) In contrast, in a "single" or "individual" blowback system, each candle is cleaned individually with a small ejector located directly above the candle opening/cavity. The individual blowback type is suitable for compact pilot plant filtering systems, while the cluster type is more economical for large, commercial-scale applications since it employs a fewer number of ejectors per candle.

The filtrates, i.e., "dirty" gases, considered in the present analysis are the raw dusty gas from the Second Generation PFBC, Second Generation Carbonizer, and a Fluid Bed Gasifier, as described elsewhere. The raw gas, however, may be "pre-cleaned" with cyclones (as required by the overall design optimization) to reduce the dust loading in the raw gas to a lower level so that it is more appropriate for "final cleaning" in the candle filters.

As mentioned in Section 3, these three types of dirty gas in combination with the three filter cleaning techniques give rise to the eight design cases to be studied. While each of these eight cases has its unique process conditions that would lead to a different blowback requirement (see Tables 4.2-1 through 4.2-3 for a summary of common/unique parameters and blowback requirement for each case), it is clear that the analysis procedure itself would be similar, and it can 


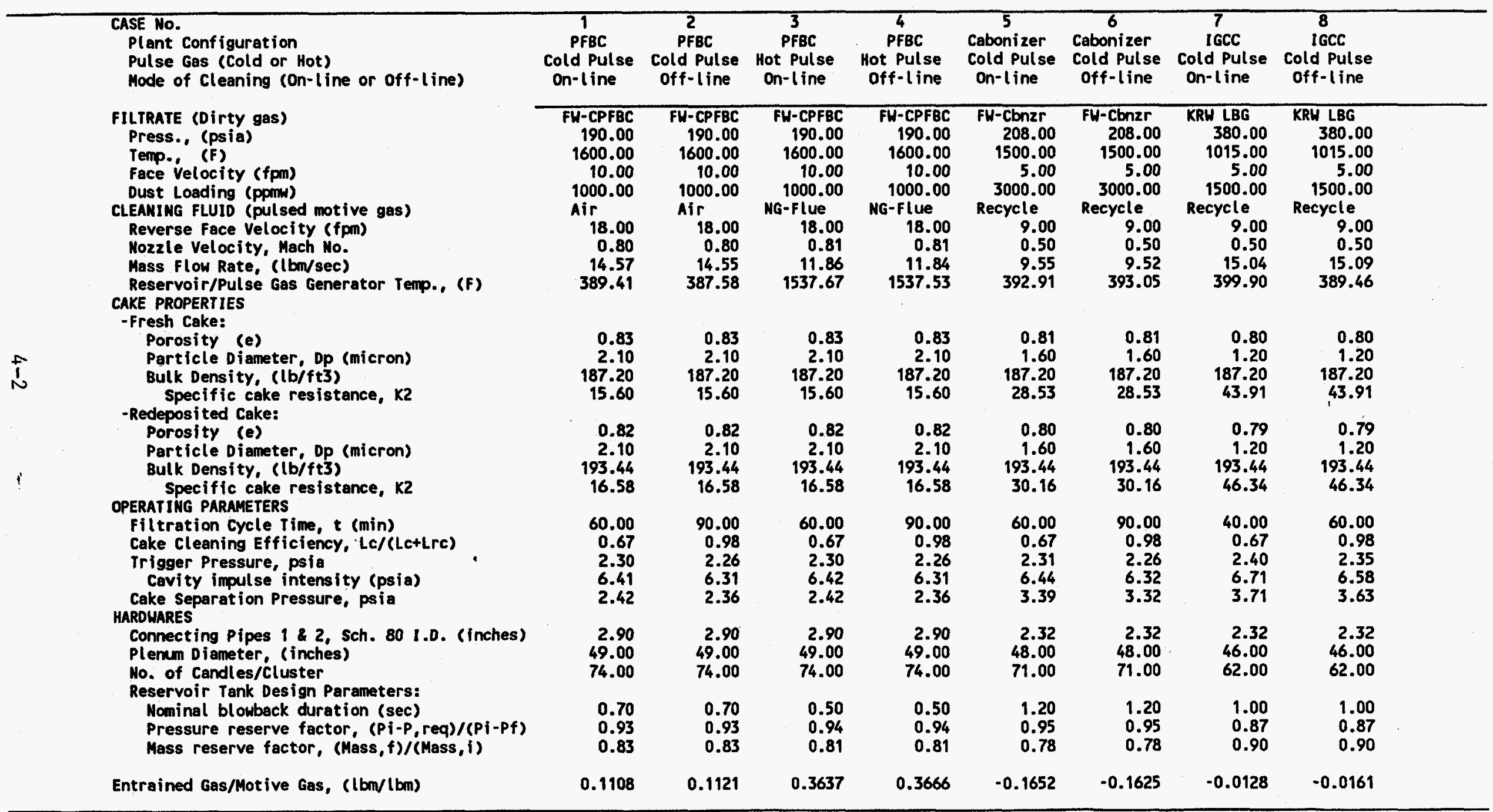

Notes: Specific cake resistance $K 2=($ del $P) /(U) /(W)=($ in. $W) /(\mathrm{fpm}) /(\mathrm{lb} / \mathrm{ft} 2) ; \mathrm{Lc}$, Lrc $=$ thickness of fresh and redeposited cake layers, respectively.

$\mathrm{Pi}, \mathrm{Pf}, \mathrm{P}, \mathrm{Keq}=\mathrm{Initial}$ final and required tank pressures, respectively: Recycle = Recycle process gas (carbonizer gas or KRW low-Btu gas). Cold Pulse = conventional pulse, gas temperature $<400 \mathrm{~F}$; Hot Pulse = rapid combustion generated hot gas $>1500 \mathrm{~F}$; off-line $=0$ irty gas flow interrupted with valve. 
CASE No. 1 through 8

Exceptions as noted.

CERAMIC CANDLE FILTER (Schumacher)

Nominal length, $1.5 \mathrm{~m}$; effective length, $1.425 \mathrm{~m}$ ( $95 \%$ of nominal)

Nominal O.D. $60 \mathrm{~cm} ; 1 . D .30 \mathrm{~cm}$

Effective porosity 0.8 (e); effective particle diameter 80 microns

PULSE GAS DELIVERY SYSTEM ARRANGEMENT (piping from pulse gas reservoir/generator to candle filters):

PULSE GAS RESERVOIR/GENERATOR (feeding pulsed gas to connecting pipe 2):

One unit serves 4 clusters of candles

CONNECTING PIPE 2:

3 in. (Cases 1, 2, 3, 4) or 2.5 in. (Cases 5, 6, 7, 8) nominal, Schedule 80; $15 \mathrm{ft}$ long

One $90 \mathrm{deg}$ elbows, and one ball valve (equivalent total velocity heads $=1.10$ )

CONNECTING PIPE 1 (allowing pipe diameter changes as necessary):

3 in. (Cases 1, 2, 3, 4) or 2.5 in. (Cases 5, 6, 7, 8) nominal, schedule 80; $50 \mathrm{ft}$ long

f Three 90 deg elbows, three 90 deg tees, five ball valves, and one glove-type control valve (equivalent total velocity heads = 19.1 ).

PULSE LANCE (feeding pulsed gas to the ejector (ocated below):

1.5 inch nominal, schedule 40; 75 inches long

Nozzle tip flush with ejector entrance (i.e.., upper diffuser)

EJECTOR (mixing pulsed motive gas and entrained clean gas; pressurizing the mixed gas and feeding it to the pulse pipe below):

Venturi throat, 3.73 inches $1.0 ., 8$ inches long

40 deg opening at the upper diffuser and 20 deg opening at the bottom diffuser

Ejector total length $=17.4$ inches; 6.065 inches I.D. at ends (entrance and exit)

PULSE PIPE (feeding the mixed motive/entrained gas to plenum):

6 incir nominal, schedule 40; 102 inches long

PLENUM (distributing the mixed gas to candles; one plenum per cluster):

7.5 inches in height and 49 (Cases 1,2,3,4), 48 (Cases 5, 6) and 46 (Cases 7, 8) inches in diameter (disk-shaped)

No. Of CANDLES/PLENUM $=74$ (Cases $1,2,3,4) ; 71$ (Cases 5,6$) ; 62$ (Cases 7, 8)

NO. OF CLUSTERS/TIER $=4$

NO. OF TIERS/VESSEL. $=4$

NO. OF VESSELS/PLANT $=10$ (Cases 1, 3); 12 (Cases 2, 4); 2 (Case 5); 3 (Case 6); 4 (Case 7); 5 (Case 8)

PULSE GAS COMPRESSOR

Compression stages $=2$ (with inter-cooler)

Adiabatic efficiency $=90 \%$

Notes: (filter) cavity impulse intensity = Differential filter cavity pressure when the flow is reversed.

(Reservoir tank) mass reserve factor = (mass of gas in tank after pulse)/(mass of gas in tank initially). 


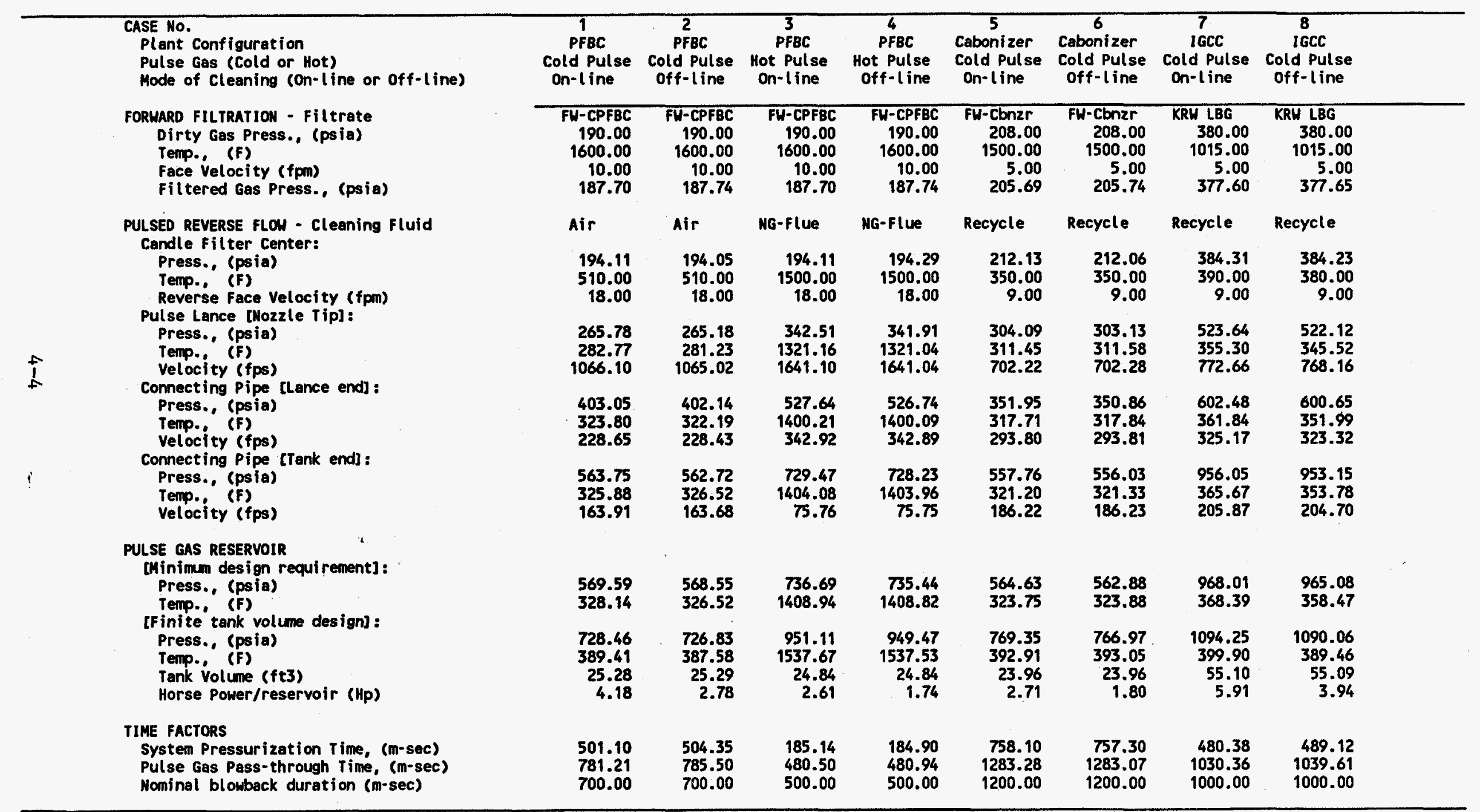


be "copied" from one case and applied to another. For example, the main difference between the "cold pulse" and "hot pulse" cases is the temperature of the cleaning fluid, and the main difference between the "on-line" and "off-line" cases is the settling time available for the separated cake to fall to the bottom of the filter cake. But the first principle that governs cake separation per se is the same for all cases. Furthermore, the relatively large number of physical/process parameters involved in characterizing the systems can often be treated as "inputs" or interchangeably as calculated "outputs" or assigned as common "constants". The analyses, therefore, can be conveniently implemented in a series of spreadsheets using commercially available software. When the spreadsheets are constructed in a tabular format to describe the changes in gas flows from one point to next, they serve simultaneously as "computer programs" to perform mass, momentum, and/or energy balances etc., and as "printouts" or "tables" to display all pertinent local input/output relationships. The spreadsheet format also allows the user to experiment "what if" analyses more easily than any other format.

The following is a summary of key "input" parameters that are required for the spreadsheet modeling that is described in Section 4.3.

\section{Solids (Filter Medium and Cake)}

Physical properties of conditioned filter medium and cake layer(s) such as density, porosity, and mean "effective" particle diameter (which together lead to a definition of permeability or the inversely related specific resistance " $k_{2}$ ); separation pressure/stress that is required to overcome the adhesive/cohesive forces of the cake/filter medium for filter cleaning. When the cake is viewed as one having two sublayers, fresh and redeposited, a value of cake cleaning efficiency is also required to define the relative thickness of dust in the two sublayers.

\section{Gases (Filtrate and Cleaning Fluid)}

The filtrate and cleaning fluid are treated as ideal gases. The only required physical property of the gases is the molar composition, which allows internal calculations for molecular weight, specific heats ( $C_{p}$ and the $C_{p} / C_{v}=k$ ratio) and viscosity, all expressed as a function of locally prevailing temperature and pressure at various points within the blowback system.

\section{Operating Conditions}

Input parameters required for filtering operation include the temperature, pressure, face velocity and dust loading of the incoming dirty gas, filtration cycle time (or the trigger pressure that initiates pulse blowback), cake separation efficiency (which defines the fraction of cake freed by the cleaning pulse), and cake cleaning efficiency (which is related to the fraction of freed cake that would redeposit after the pulse), a geometric description of the piping/internals that interconnect the filters to the gas reservoir (i.e., length/diameter of pipes, number/type of fittings such as elbows, tees, ball and control valves; length/diameters of pulse lance, ejector, pulse pipe, and plenum; effective length/diameter/number of candle filters; relative flow areas available for the motive gas and the filtered gas to entrain/mix at the ejector). Also, indirectly required are characteristics of the pulse control valve such as its opening/closing time (e.g., 50-200 ms) and temperature limitation (e.g., less than $400^{\circ} \mathrm{F}$ ).

\subsection{ANALYSIS AND MODELING OF BLOWBACK SYSTEM}

The general principle of filter cake removal is discussed below, along with an explanation of the mathematical expressions used and design assumptions made in analyzing/modeling the conventional on-line, cold pulse cleaning system. Extensions of concepts to on-line, hot pulse, or off-line cleaning methods involve only minor modifications. Where appropriate, data used in 
Case 1 (conventional on-line, cold pulse) are referred to as numerical examples for clarity. Case 1 as a whole is discussed in more detail in Section 4.4.

The analysis/modeling of the blowback system is presented in a "backward" fashion, i.e., starting with the prerequisite for cake separation at the candle, the required flow conditions of the pulsed gas (at various key points within the blowback system) are established in reverse from the cake layer on the filter surface to the gas reservoir where the cleaning fluid is stored. (Note: In writing mathematical expressions, typical spreadsheet notations are used, that is, the symbol / means division, ${ }^{*}$ multiplication, and ${ }^{\wedge}$ exponentiation.)

\section{Pulse Cleaning Principle}

When the pulse valve in a filter blowback system is opened to discharge the compressed cleaning fluid from the reservoir, the gas accelerates itself through the connecting pipes and enters the ejector mixing zone at a high velocity (see Section 5.4, Figure 5.4-5; for an ejector schematic). Here, the motive gas mixes and entrains a portion of the clean filtered gas at the ejector opening. As the mixed gas slows down in the ejector diffuser, the momentum of the gas is converted back to pressure energy, raising the pressure of the mixed gas at the exit. The ejector, in effect, functions as a fluid "pump" which increases the gas pressure and brings about flow reversal.

The reverse flow initiated by the ejector causes the pressure in the downstream pulse pipe, plenum space and filter cavities to increase which, in turn, stops the forward filtration of the dirty gas through the porous media. As the pressure in the candle cavity continues to increase, the reverse flow and the "reverse pressure drops" of the mixed gas through the filter/cake increases. The pressure drop through the cake layer is actually a manifestation of the (viscous) drag force exerted by the moving gas onto the stationary cake particles. Thus, when the applied "separation pressure" associated with the reverse flow (or, equivalently, the tensile stress across the cake layer) exceeds the tensile strength of the cake as represented by either

(1) the internal cohesive force among the cake particles, or

(2) the adhesive force between the cake and the filter medium,

the cake layer detaches. The detached cake typically assumes the form of flakes or agglomerates in falling down to the bottom of filter vessel.

\section{Quasi-Steady State Square-Wave Flow Approximation}

The idealized cake separation process described above actually takes place in a very short period of time - typically, in a fraction of a second. There are reports in the literature (RWTH, CRIEPI) that describe the pulse cleaning of candle filter in an individual blowback system as essentially a quasi-steady state process with an extremely short initial unsteady phase. That is, once the pulse valve is opened, the pressure and the reverse flow increase rapidly to the steady state values, and the cake detaches within the first $50 \mathrm{~ms}$ (milliseconds) or less, which is very short compared to the overall pulse duration time of 400 to $1,000 \mathrm{~ms}$ or more. This is understandable since, in a single blowback system, the ejector is located right above the candle cavity and the pulse gas reservoir is often located in close proximity. For practical purposes, then, the pressure rise and the attendant flow reversal in a single blowback system can be viewed as an instantaneous "square wave" process.

In a cluster blowback system, the quasi-steady state square-wave approximation may be less perfect. This is because the ejector in a cluster blowback system is located some distances away from the filters, and it should take longer for the reversing gas to pressurize the extra volume of pulse pipe and plenum that interconnect the ejector and candles. In addition, the reservoir may also be located some distance away from the ejector in a larger system. Therefore, the increase in 
pressure in the candle cavity and the attendant flow reversal through the filter may be more gradual than in an individual blowback system. Nevertheless, the square wave approximation can be and is used in the spreadsheet model to provide a conservative estimation of the gas flow/pressure requirements so long as the candle-cavity is pressurized to the critical "separation pressure" level. To ensure this, the pulse duration should be sufficiently long to allow the system to attain the quasi-steady state values. This required minimum pulse duration time is a function of the blowback system volume and the gas flow rate, and it should be set at least equal to the system "pressurization" time. This latter parameter is established as an output in the model for the purpose of determining the minimum pulse duration time and the reservoir volume. More on this later.

\section{Cake Separation Pressure and Separation Efficiency}

The critical "separation stress" at which cake can be removed is clearly the fundamental data required for effective design of a blowback system, regardless of the cleaning technology type (onor off-line, cold or hot pulse). Yet there is paucity of information on separation stresses in the literature, even though they should have been tested, compiled, and made available for various cake types to be separated under a variety of operating conditions.

The separation stress is a complex function of material, temperature, pressure, and the manner by which the cake is deposited. There is apparently no reliable method to predict a priori the critical separation stress, del $P_{\text {sep }}$ (in units of, e.g., psia) based solely on the mechanical properties of cake and/or filter medium. [Note: "del" means "delta" or "difference".] For reliable results, direct experimental measurement of the separation stress by coupon testing for each cake/medium combination under actual conditions is apparently the only dependable method.

Still, there are suggestions that the separation stress may be roughly proportional to the inverse of particle diameter $D_{p}$ and/or to a decreasing function of porosity $e$ :

$$
\operatorname{del} P_{\text {sep }}=(\text { constant }) / D_{p}
$$

or,

$$
\operatorname{del} P_{\text {sep }}=(\text { constant }) / D_{p}{ }^{*}((1-e) / e)
$$

These relationships suggest that a cake having smaller diameter particles and/or smaller porosity may be relatively more difficult to remove. They also allow a rough estimation of the required separation stress to be made for the same kind of cake but one having a different particle diameter and/or porosity. It should also be commented that, at least in the above relations, the apparent separation stress is not a function of cake thickness, which implies that a thick cake may be easier to remove than a thin one since the former provides a greater pressure drop under (otherwise) identical flow condition.

In actual filtering practice, neither the applied separation pressure nor the cohesive/adhesive strength of the cake/filter medium is ever uniformly distributed over the entire filter surface. Therefore, "patch cleaning" as opposed to "uniformly layered cleaning" is likely to develop, i.e., the cake is completely detached in some areas and completely retained in some other areas. To quantify such partial cleaning, a "separation efficiency" $E_{\text {sep, }}$, may be defined to indicate the fractional weight of cake freed by a cleaning pulse. This separation efficiency is not only a function of cake properties but may also be a strongly skewed function of the applied separation pressure. For example, the separation stress required to remove the entire cake is reportedly twice that necessary to remove $90 \%$ of the cake, and may be as much as ten times that necessary to remove 50\% (Koch et al, p. 337, "Filtration \& Separation", July, 1992). Clearly, the two separation parameters, $P_{\text {sep }}$ and $E_{\text {sep }}$, should be used together to be meaningful but, once again, there is 
paucity of such paired data. Often, the separation pressure (e.g., $\mathbf{P}_{\text {sep }}=2.4$ psia used in Case 1) is available without the corresponding separation efficiency clearly defined. In such case, the only recourse is to assume that it is for full cake separation, i.e., $\mathrm{E}_{\mathrm{sep}}=1$, as is assumed in our case studies.

\section{Impulse Intensity in Filter Cavity}

In order to create a sufficiently strong back flow for cake separation, the candle cavity must be pressurized to a certain minimum level during the blowback. The required Cavity Impulse Intensity (CII) is the sum of the pressure drops across the cake/filter medium in the forward filtration and those during the reverse flow periods:

$$
\begin{gathered}
\text { Cavity Impulse Intensity }=(\operatorname{del} P)_{\text {forward }}+(\operatorname{del} P)_{\text {reverse }} \\
\text { or } \quad C I I=\left(\operatorname{del} P_{\text {cake }}+\operatorname{del} P_{\text {filter }}\right)_{\text {for }}+\left(\operatorname{del} P_{\text {cake }}+\operatorname{del} P_{\text {filter }}\right)_{\text {rev }}
\end{gathered}
$$

In above, the term (del $\mathrm{P}_{\text {cake) }}$ rev is the cake layer pressure drop that must be developed during the reverse flow period to equal to or exceed the critical cake separation stress, del $\mathbf{P}_{\text {sep }}$, which is presumed known/specified.

For example, the pressure drops through the cake and filter during the forward filtration period may be 1.3 psia and 1 psia, respectively, for a total of 2.3 psia pressure drops. (This is the "trigger" pressure drop that initiates a pulse blowback). If the reverse flow is such that the pressure drops through the cake and filter are 2.4 psia and 1.7 psia, respectively, then the cavity impulse intensity is equal to $(1.3+1)+(2.4+1.7)=6.4$ psia. This 6.4 psia increase in pressure is that which must be developed in the filter cavity in order to create a separation pressure of 2.4 psia across the cake layer. If the known critical cake stress is equal to 2.4 psia or less, then the cake is blown off; conversely, if the critical stress is greater than 2.4 psia, the cake would remain attached.

The above "relative pressure" conditions can be described alternatively in terms of "absolute pressure". If the absolute pressure of the dirty gas at the filter surface is 190 psia, then the clean filtered gas in the filter cavity is $190-2.3=187.7$ psia when the pulse cleaning is triggered. During the reverse flow period, the cavity pressure must reach at least $190+4.1=194.1$ psia in order to effect cake separation. Of the 4.1 psia differential, 2.4 psia are that due to the cake layer. The mass flow rate of the pulsed gas that generates this pressure differential of 2.4 psia across the cake layer is that required for characterizing the rest of blowback system.

\section{Pressure drops Through Porous Media}

In order to model the distribution of pressure drops through the porous media (filter and cake layers) a suitable pressure drop correlation equation is required. The correlation equation we selected for this purpose is the Ergun's equation which is a super set of the more familiar Carman-Kozeny equation and Burke-Plummer equation. The general Ergun equation can be expressed as:

$$
\operatorname{del} P / L=f_{p} / g_{c} / D p^{*}\left((1-e) / e^{\wedge 3}\right)^{*} R_{h o} * u^{\wedge 2}
$$

where the friction coefficient $\mathrm{f}_{\mathrm{p}}$ is given by:

$$
\begin{aligned}
& \mathrm{f}_{\mathrm{p}}=\mathrm{C}_{1} / \operatorname{Re}, \mathrm{p}+\mathrm{C}_{2}=150 / \operatorname{Re}, \mathrm{p}+1.75 \\
& \operatorname{Re}, \mathrm{p}=\mathrm{Dp} \mathrm{p}^{*} \mathrm{u}^{*} \mathrm{Rho} / \mathrm{Mu} /(1-\mathrm{e})
\end{aligned}
$$


In above, Rho is gas density, $\mathrm{Mu}$ gas viscosity, $\mathrm{u}$ gas velocity, $\mathrm{g}_{\mathrm{c}}$ a conversion factor, and $\mathrm{C}$ 's constants. The Ergun's equation asymptotically reduces to the Carman-Kozeny equation when the particle Reynolds number is small ( $\operatorname{Re}, \mathrm{p}<<10)$, i.e.,

$$
\operatorname{del} \mathrm{P} / \mathrm{L}=150 / \mathrm{g}_{\mathrm{c}} / \mathrm{Dp}^{\wedge 2 *}\left((1-\mathrm{e})^{\wedge 2} / \mathrm{e}^{\wedge \overline{3}}\right)^{*} \mathrm{Mu}^{*} \mathrm{u}
$$

and to the Burke-Plummer equation when the particle Reynolds number is large ( $\operatorname{Re}, p>>1000)$, i.e.,

$$
\operatorname{del} \mathrm{P} / \mathrm{L}=1.75 / \mathrm{g}_{\mathrm{c}} / \mathrm{Dp} \mathrm{p}^{*}\left((1-\mathrm{e}) / \mathrm{e}^{\wedge^{3}}\right)^{*} \mathrm{Rho}^{*} \mathrm{u}^{\wedge}
$$

To apply Ergun's equation in determining pressure drops, one needs to know (in addition to the gas flow rate and gas properties) the effective porosities (e) of both filter and cake, their effective mean particle diameters $\left(D_{p}\right)$, the thickness $(L)$, density Rho,cake, etc. These can be either directly specified (if known), or estimated indirectly relative to other available information. For example, effective diameter $\mathrm{D}_{\mathrm{p}}$ and porosity e may be "estimated" (i.e., treated as "fitted" parameters) from known permeability coefficient, B, permeability B/L, and/or specific resistance $\mathrm{k}_{2}$, since they are related to each other through the equation (in the Carman-Kozeny form), by:

$$
\begin{gathered}
\operatorname{del} P / L=M u^{*} u / B=C_{1} / g_{c} / D p^{\wedge} *\left((1-e)^{\wedge 2} / e^{\wedge 3}\right)^{*} M u^{*} u \\
\text { i.e., } B=g_{c} / C_{1} * e^{\wedge 3} /(1-e)^{\wedge 2 *} D p^{\wedge 2}
\end{gathered}
$$

or,

$$
\begin{gathered}
\operatorname{del} P / L=k_{2}^{*} \text { Rho,cake }{ }^{*} u^{*}(1-e)=C_{1} / g_{c} / D p^{\wedge 2 *}\left((1-e)^{\wedge 2} / e^{\wedge 3}\right)^{*} M^{*} u \\
\text { i.e., } \quad k_{2}=C_{1} / g_{c} / D p^{\wedge 2 *}\left((1-e) / e^{\wedge}\right)^{*} M u / R h o, \text { cake }
\end{gathered}
$$

The cake thickness in the model may be treated as one consisting of two sublayers, a fresh layer $\mathrm{L}_{\mathrm{c}}$ and a redeposited layer $\mathrm{L}_{\mathrm{cr}}$, although in assessing the cake separation stress they are considered together. The fresh cake layer $\mathrm{L}_{c}$ is that related to the amount of dust removed from the dirty gas at steady state: its value can be determined directly from known gas flow rate, dust loading (or areal density), filtration cycle time (or trigger pressure), effective filter surface area, cake porosity and cake density.

The redeposited layer $\mathrm{L}_{\mathrm{cr}}$ represents the dust that is "recycled" from the previous cycle of filtration operation. It is generally known that even if the cake is completely blown off in a pulse, a fraction of it would redeposit to the filter surface because, in an on-line blowback system, there is simply not enough time for all the detached cake flake or "agglomerates" to settle by free-falling to the bottom of filter vessel. The redeposited layer thickness, therefore, is more of a function of filter vessel design (e.g., cluster/tier arrangement, height of tiers/vessel) and other operational factors external to the blowback system. In the model, different values of porosity, particle diameter, and/or cake density may be assigned to the redeposited layer to simulate the different manner by which this sublayer is formed. For example, particle diameters in the redeposited layer may assume a smaller value because, with their relatively slower free-fall terminal velocity, smaller particles are more likely to be recaptured than larger particles in the redeposited layer. The porosity of the redeposited layer may also be smaller because it is the inner sublayer which is likely to be more compacted.

The true redeposited layer thickness is not easy to quantify even if all details of the cake settling/redeposition process are known. Nevertheless, in order to provide a capability to approximately account for this effect in the pressure drop calculation, a "cake cleaning" efficiency is defined as: 


$$
\mathrm{E}_{\text {clean }}=\mathrm{L}_{\mathrm{c}} /\left(\mathrm{L}_{\mathrm{c}}+\mathrm{L}_{\mathrm{cr}}\right)
$$

which may be specified as an input in the model to provide an estimation of $\mathrm{L}_{c r}$ from known $\mathrm{L}_{c}$. The "cleaning" efficiency $E_{\text {clean }}$ (not to be confused with the cake "separation" efficiency discussed earlier) represents the fractional thickness of the fresh cake layer relative to the total thickness, and is assumed to be 0.667 for all on-line cleaning cases and 0.98 for off-line cleaning cases in the analysis. Off-line cleaning cases should have higher cleaning efficiency because, by design, they provide a longer settling time for the cake flakes or agglomerates to more completely fall to the bottom of the vessel. When $\mathrm{E}_{\text {clean }}=1$, there would be no separate redeposited layer; all the cake is considered "fresh" and the two layer distinction disappears.

\section{Pressure Drops Through Pipes and Fittings}

Once the pressure drops through the porous media are determined as above, the pressure drops through out the rest of blowback system may be determined in a step-by-step fashion starting from the center of candle cavity to the reservoir, using pressure drop correlations for pipes and fittings.

Conventionally, the pressure drops in a pipe containing expansion/contraction sections, and various type of fittings are determined by:

$$
\begin{aligned}
\operatorname{del} P & =\left(4^{*} \mathrm{f}^{*} \mathrm{~L}_{\mathrm{e}} / \mathrm{D}\right) * \mathrm{Rho}^{*} \mathrm{u}^{\wedge} / 2 / \mathrm{g}_{\mathrm{c}} \\
& =\left(4^{*} \mathrm{f}^{*} \mathrm{~L} / \mathrm{D}+\mathrm{K}_{\mathrm{e}}+\mathrm{K}_{\mathrm{c}}+\mathrm{K}_{\mathrm{f}}\right) \mathrm{Rho}^{*} \mathrm{u}^{\wedge} / 2 / \mathrm{g}_{\mathrm{c}}
\end{aligned}
$$

where $u$ is the applicable local gas velocity, and

$f=$ Fanning's coefficient for "skin" friction; approximately, $f=0.04^{*}(\operatorname{Re})^{\wedge 0.16}$, where $\operatorname{Re}=$ $D^{*} u^{*} \mathrm{Rho} / \mathrm{Mu}$ is the Reynolds number

$\mathrm{D}=$ Diameter of pipe

$\mathrm{L}=$ Actual linear length of pipe

$K_{e}=$ Expansion loss coefficient $=\left(1-A_{1} / A_{2}\right)^{\wedge 2} ; A^{\prime}$ s are flow areas, with $A_{1}<A_{2}$

$\mathrm{K}_{\mathrm{c}}=$ Contraction loss coefficient $=0.4^{*}\left(1-\mathrm{A}_{1} / \mathrm{A}_{2}\right) ; \mathrm{A}^{\prime}$ 's are flow areas, with $\mathrm{A}_{1}<\mathrm{A}_{2}$

$\mathrm{K}_{\mathrm{f}}=$ Fitting loss coefficients for elbows, tees, valves, etc. (see Table 4.4-2 for numerical values)

$\mathrm{L}_{\mathrm{e}}=$ Equivalent length of pipe including the $\mathrm{K}$ terms

It should be commented that the $\mathrm{K}$ coefficients in above represent the so called "velocity head" losses; they are numerically constants once the types/number of fittings are specified. The $f$ coefficient is a weak variable function of the Reynolds number (and hence a function of velocity $u$ as well as $\mathrm{P}$ and $\mathrm{T}$ ), but often can be assumed constant for simplicity.

In our blowback system, there are two distinctive groups of "piping/internals" for which the pressure drops are to be determined:

(1) The pressure drops from the center of candle cavity through plenum, pulse pipe (located below the ejector), to the lower diffuser/throat area of the ejector; and

(2) The pressure drops from the nozzle tip of the pulse lance (located above the ejector) through the interconnecting pipes and fittings/valves to the gas reservoir. 
The gas flow in the first group downstream of the ejector is relative low in velocity and so are the pressure drops relative to the absolute pressure. In determining the pressure drops caused by frictions the conventional correlations can be applied using only "representative" local properties (e.g., mean gas velocity or density) as if the gas were incompressible.

Within the second group of piping upstream of the ejector, the gas velocity is generally very high and so are the pressure drops due to friction. As a consequence, the absolute pressure and density of the gas change greatly and rapidly from one section to another. Furthermore, not all of the del $P$ is due to friction; part of the change is due to the conversion of pressure energy to kinetic energy when the gas is accelerated. Therefore, in this group of piping, the gas is best treated as a true compressible fluid and the pressure changes determined by equations that account for such effects.

For an adiabatic frictional flow of a compressible gas in a pipe with known diameter D (see, for example, MaCabe, Smith, and Harriott, "Unit Operation of Chemical Engineering", Fifth Ed., P. 133-135), the "equivalent" length $\mathrm{L}_{e}$ between any two points $a$ and $b$ is related to the gas velocities $V_{a}$ and $V_{b}$ (expressed in terms of Mach number) at points $a$ and $b$ by:

$$
4 * \mathrm{f}^{*} \mathrm{~L}_{\mathrm{e}} / \mathrm{D}=\left(1 / \mathrm{V}_{\mathrm{a}}{ }^{\wedge}-1 / \mathrm{V}_{\mathrm{b}}{ }^{2}-(\mathrm{k}+1) / 2^{*} \ln \left(\left(\mathrm{V}_{\mathrm{b}}{ }^{\wedge} / \mathrm{V}_{\mathrm{a}}{ }^{2}\right)^{*}\left(\mathrm{G}_{\mathrm{a}} / \mathrm{G}_{\mathrm{b}}\right)\right)\right) / \mathrm{k}
$$

where $f$ is the Fanning's coefficient for skin friction as before, and

$$
\begin{aligned}
& \mathrm{k}=\mathrm{C}_{\mathrm{p}} / \mathrm{C}_{\mathrm{v}} \\
& \mathrm{G}_{\mathrm{a}}=1+(\mathrm{k}-1) / 2 * \mathrm{~V}_{\mathrm{a}}{ }^{2} \\
& \mathrm{G}_{\mathrm{b}}=1+(\mathrm{k}-1) / 2 * \mathrm{~V}_{\mathrm{b}}{ }^{2}
\end{aligned}
$$

The Mach number $V$ is of course the ratio of linear gas velocity $u$ to that of local sonic velocity $c$, i.e., $\mathrm{V}=\mathrm{u} / \mathrm{c}$, and $\mathrm{c}$ is given by:

$$
c=\left(k^{*} g_{c} * T^{*} R / M W\right)^{\wedge 0.5}
$$

in which $\mathrm{T}$ is the absolute temperature, $\mathrm{R}$ the universal gas constant, $\mathrm{MW}$ molecular weight of gas.

Assuming the gas velocity $\mathrm{V}_{\mathrm{a}}$ and the properties of gas at point a are "known" from a previous calculation, the above equation can be evaluated for the $4^{*} \mathrm{f}^{*} \mathrm{~L}_{\mathrm{e}} / \mathrm{D}$ term on the left hand side if a value for $V_{b}$ is "guessed". From the computed equivalent pipe length $L_{e}$, a value for the linear pipe length $L$ can be determined by subtracting the effects of velocity head losses due to contraction, expansion, and/or fittings. If the computed $L$ matches the specified value for the pipe length, the guessed $\mathrm{V}_{\mathrm{b}}$ is accepted. If not, the trial-and-error is repeated until they match within a desired accuracy.

Once $V_{b}$ is determined as above, the pressure and temperature of the gas at point $b$ can be determined by the following relations:

$$
\begin{aligned}
& P_{a} / P_{b}=V_{b} / V_{a}^{*}\left(G_{b} / G_{a}\right)^{\wedge 0.5} \\
& T_{a} / T_{b}=\left(G_{b} / G_{a}\right)
\end{aligned}
$$

This whole procedure can be repeated to determine the condition of gas for velocity, pressure and temperature at point $c$ in the-next segment of pipe using point $b$ as the reference where gas conditions are known. If that next segment of pipe is different in pipe diameter, a contraction or expansion loss is assessed in determining the pressure drop at the interface. Similarly, if fittings in 
that segment are different in type/number, the velocity head loss effects are adjusted accordingly. However, in the very last and "short" section of the pipe that is connected to the reservoir tank, the gas flow is assumed isentropic and friction is ignored.

\section{Ejector Design}

The schematic of the ejector postulated in our blowback system is illustrated in Figure 5.4-5. The ejector is physically located below the pulse lance and is connected to the pulse pipe.

As mentioned earlier, the ejector functions as a fluid pump to increase the pressure of the mixed gas in the ejector mixing zone (opening/upper diffuser). Typically, the motive gas enters the mixing zone at a high velocity, entraining a portion of the clean filtered gas in forming the mixed gas. The pressurized gas then flows through the throat, lower diffuser, and pulse pipe into the candle cavity, where it ultimately causes the cake to separate. In our "backward" design procedure, the flow rate and pressure/temperature of the mixed gas required to effect cake separation have already been determined, as previously explained. What needs to be determined presently at the ejector are the flow rate and pressure/temperature of the motive gas leaving the pulse lance nozzle. The pressure and temperature of the clean filtered gas are "known" (from forward filtration calculations) but not the rate of entrainment, if any.

The following mass, momentum, and total energy equations around the ejector mixing zone are solved simultaneously to determine the flow rate and P/T condition of the motive gas. In the mathematical expressions below, terms with subscripts 1,2, and 3 refer to the motive gas, clean filtered gas, and mixed gas, respectively.

\section{Mass Balance}

$$
m_{1}+m_{2}=m_{3}
$$

The mass flow rate of the mixed gas $\mathrm{m}_{3}$ is known from previous calculations for the pressure drop through porous media. It is the critical mass flow rate required to produce a sufficiently large pressure drop across the cake layer to overcome the cake adhesive or cohesive forces. When $\mathrm{m}_{1}<\mathrm{m}_{3}$, the mass flow $\mathrm{m}_{2}$ is necessarily positive, meaning a portion of the clean filtered gas is being entrained. Conversely, when $m_{1}>m_{3}$, the mass flow $m_{2}$ is negative and there would be no entrainment of the clean filtered gas. Instead, the portion of excess motive gas would overflow into the space above the mixing zone.

\section{Total Energy Balance}

$$
\begin{aligned}
& \left(m^{*} C p^{*} T+m^{*} u^{\wedge 2} / 2 / g_{c}\right)_{1}+\left(m^{*} C p^{*} T+m^{*} u^{\wedge} / 2 / g_{c}\right)_{2}= \\
& \left(m^{*} C p^{*} T+m^{*} u^{\wedge} / 2 / g_{c}\right)_{3}
\end{aligned}
$$

In the above equation, the potential energy or effect of elevation is neglected. The mass flow rate $m$ and velocity $u$ are generally related by $m=R h o^{*} u^{*} A$, in which $A_{1}$ would be the nozzle flow area for motive gas, $A_{2}$ the annular flow area for clean filters gas, and $A_{3}$ the throat area for the mixed gas. The reference temperature $T_{\text {ref }}$ in the enthalpy term $m^{*} C^{*}\left(T-T_{\text {ref }}\right)$ is set equal to zero for brevity but any other convenient temperature may be used instead. It should be also noted that any frictional effects would be automatically accounted for as an increase in temperature although they do not explicitly appear in the equation. 
Momentum Balance

For simplicity, one dimensional flow is assumed in the ejector momentum balance. In general, the $\mathrm{x}$-directional (downward direction in the ejector schematics) momentum balance around the upper diffuser may be written as:

$$
\text { (sum of all surface forces) })_{x}=\text { (sum of } x \text {-momentums) out }- \text { (sum of } x \text {-momentums) in }
$$

or, in more detail,

$$
\begin{aligned}
& P_{1}{ }^{*} A_{1}+P_{2}^{*} A_{2}-P_{3}^{*} A_{3}-P_{a v e}{ }^{*}\left(\left(A_{1}+A_{2}\right)-A_{3}\right)-F_{f}= \\
& \left(m_{3}{ }^{*} u_{3}-\left(m_{1}^{*} u_{1}+m_{2}{ }^{*} u_{2}\right)\right) / g_{c}
\end{aligned}
$$

where

$$
P_{\text {ave }}=\left(P_{2}+P_{3}\right) / 2 \quad \text { (approximation) }
$$

and $A$ 's are flow areas as described earlier. The term $P_{\text {ave }}{ }^{*}\left(\left(A_{1}+A_{2}\right)-A_{3}\right)$ represents approximately the $x$-directional force acting on the side wall of the upper diffuser. The term $F_{f}$ represents any frictional force, which is normally small and may be ignored for simplicity. However, if desired, various inefficiencies may be empirically approximated by the following expressions, although only the last term is a true "surface" force:

$$
\begin{aligned}
F_{\mathrm{f}}= & \left(\mathrm{K}_{\mathrm{e}}{ }^{*} \mathrm{Rho}^{*} \mathrm{u}^{\wedge} / 2 / \mathrm{g}_{\mathrm{c}}^{*} \mathrm{~A}\right)_{1} & & \text { Expansion loss } \\
& +\left(\mathrm{K}_{\mathrm{c}}{ }^{*} \mathrm{Rho}^{*} \mathrm{u}^{\wedge} / 2 / \mathrm{g}_{\mathrm{c}}{ }^{*} \mathrm{~A}\right)_{2} & & \text { Contraction loss } \\
& +\left(4^{*} \mathrm{f}^{*} \mathrm{~L} / \mathrm{D}^{*} \mathrm{Rho}^{*} \mathrm{u}^{\wedge} / 2 / \mathrm{g}_{\mathrm{c}}{ }^{*} \mathrm{~A}\right)_{3} & & \text { Skin friction }
\end{aligned}
$$

It should be noted that the effect of $P$ and $T$ enter indirectly into the energy and momentum balances through density $R$ ho, specific heat $C_{p}$ and velocity $u$.

The above three equations may be solved for $\mathrm{u}_{1}, \mathrm{P}_{1}$, and $\mathrm{T}_{1}$ (of the nozzle gas) by any suitable iterative procedure such as the modified direct substitution method used in the spreadsheet model. Basically, one guesses a set of $P_{1}$ and $T_{1}$, and specifies a Mach number $V_{1}$ for the nozzle gas, e.g., 0.8 for a high velocity but subsonic flow. This allows a determination of $u_{1}$ and $m_{1}$ and, whence, $m_{2}$ and $u_{2}$ via the mass balance. From these, a new set of $P_{1}$ and $T_{1}$ can be solved from the energy and momentum balances and compared with the guessed set. If they are not sufficiently close to each other, an averaged value of $\mathrm{P}$ and $\mathrm{T}$ are used as the revised guess. The process is repeated until the re-computed set of $P / T$ is very close to the previous set of $P / T$.

When $P_{1}$ and $T_{1}$ are determined as above, the ratio of $P_{1}$ and $P_{2}$ is tested against the critical pressure ratio $P_{\text {crit }}$ to determine if indeed the flow is subsonic or sonic, i.e.,

$$
\mathrm{P}_{1} / \mathrm{P}_{2}<\mathrm{P}_{\text {crit }} \quad \text { for subsonic flow }
$$

and

$$
\mathrm{P}_{1} / \mathrm{P}_{2}=\text { or }>\mathrm{P}_{\text {crit }} \quad \text { for sonic flow }
$$

where

$$
\mathbf{P}_{\text {crit }}=((\mathbf{k}+1) / 2)^{\wedge}(\mathbf{k} /(\mathbf{k}-1))
$$


If the result differs from what was assumed, the value of $\mathrm{V}_{1}$ is re-specified as appropriate and the whole process of determining $\mathrm{P}_{1}$ and $\mathrm{T}_{1}$ iterated until a set of feasible and acceptable $\mathrm{u}_{1}, \mathrm{P}_{1}$, and $\mathrm{T}_{1}$ is found. It should be added that there may be other operational constraints that must be accommodated in establishing the feasibility. For example, in Case 1 , the nozzle temperature $T_{1}$ is necessarily kept below $400^{\circ} \mathrm{F}$ because of the temperature limitation of the reservoir pulse valve (< $400^{\circ} \mathrm{F}$ ) which is located upstream of the pulse lance.

It should be commented that an effective ejector may be designed with the motive gas velocity in the range of Mach 0.2 to 1.0. The effectiveness of momentum-to-pressure energy conversion depends strongly on the nozzle/annular flow area ratio and other hardware dimensions, because a pulse jet having same momentum can be created either with a large nozzle/low pressure gas or with a small nozzle/high pressure combination. In fact, depending on the particular combination of nozzle/annular space dimensions and the velocity of the nozzle gas, entrainment of the clean filtered gas may or may not occur. If the motive gas has excess mass and momentum, a portion of the motive gas can overflow and escape through the annular space as negative entrainment. This occurs in some of the study cases.

\section{Reservoir Sizing}

Once the $\mathrm{P} / \mathrm{T}$ and flow rate of the cleaning fluid $\left(\mathrm{m}_{\mathrm{cl}}=\right.$ mass of motive gas exiting the lance nozzle) are determined as above, the previously described pressure drop calculation procedure may be used to establish the $P / T$ profile of the gas along the interconnecting pipes from the pulse lance nozzle to the gas reservoir. The required minimum pressure $P_{r}$ and temperature $T_{r}$ of the cleaning fluid in the reservoir is therefore known. What remains to be established is the volume of the reservoir tank.

Sizing of the blowback reservoir is very much a function of one's attitude as to how conservatively the tank should be designed/operated. If energy losses in the form of pressure drops and the costs of reservoir/cleaning fluid are not a concern, an effective gas reservoir can always be realized by making it arbitrarily high in pressure and arbitrarily large in volume relative to the rest of blowback system. On the other hand, once the cake is blown off, any excess amount of "cold" gas passing through the hot filter would serve only to cool the ceramic materials, thereby increasing the risk of thermal shock. In actuality, costs of gas/tank/compression energy are not negligible and, hence, compromises on reliability/benefits vs. costs/risks must be made in specifying the pressure and volume of the reservoir.

If the reservoir is maintained at the minimum design condition of $P_{r}$ and $T_{r}$, the volume of tank would have to be infinitely large. For a finite size reservoir, it is clear that the cleaning fluid must be stored at $\mathrm{P} / \mathrm{T}$ above that required as minimum. It is also clear that the smaller the tank volume the higher the initial value of $P_{1}, T_{1}$ must be so that, at the end of gas discharge, the final value of $P_{2}, T_{2}$ would be close or at the minimum level (i.e., $P_{r}$ and $T_{r}$ ). In the spreadsheet model, the gas discharge from the reservoir is modeled as an isentropic process so the $\mathrm{P} / \mathrm{T}$ condition before and after the discharge are related by:

$$
\begin{aligned}
& \mathrm{T}_{2} / \mathrm{T}_{1}=\left(\mathrm{M}_{2} / \mathrm{M}_{1}\right)^{\wedge(\mathrm{k}-1)} \\
& \mathrm{P}_{2} / \mathrm{P}_{1}=\left(\mathrm{T}_{2} / \mathrm{T}_{1}\right)^{\wedge(\mathrm{k} /(\mathrm{k}-1))}
\end{aligned}
$$

where $M_{1}$ and $M_{2}$ are the initial and final mass of gas in the reservoir, and $k$ the specific heat ratio $\mathrm{C}_{\mathrm{p}} / \mathrm{C}_{\mathrm{v}}$. The mass difference $\left(\mathrm{M}_{1}-\mathrm{M}_{2}\right)$ is the amount of gas discharged during the pulse and is related to the pulse duration time, $t_{p}$, by

$$
t_{p}=\left(M_{1}-M_{2}\right) / m_{c l}
$$


where $\mathrm{m}_{\mathrm{cl}}$ is the quasi-steady state flow rate of cleaning fluid determined earlier. For a specified value of pulse duration time $t_{p}$, the mass difference $\left(M_{1}-M_{2}\right)$ is therefore known. In addition to this, a value of the mass ratio $M_{2} / M_{1}$ may be specified so that both $M_{1}$ and $M_{2}$ can be fixed to determine the size of tank. The ratio $\mathrm{M}_{2} / \mathrm{M}_{1}$ is an indicator of the tank size: the closer it is to 1 the larger the tank becomes and, conversely, the closer it is to 0 , the smaller the tank becomes. (However, the impact of this parameter on the tank pressure is exactly opposite: the closer it is to 1 , the lower the pressure, and vice versa.) In the spreadsheet model, the ratio $\mathbf{M}_{2} / \mathbf{M}_{1}$ is set at about 0.78 (Case 5) to 0.90 (Case 7) by trial in such a way that the initial P/T values is deemed not excessively "high".

Finally, an explanation is in order as to how the pulse duration time $t_{p}$ may be specified. As mentioned earlier, a system "pressurization" time can be determined once the P/T profile is established for the whole blowback system. For Case 1, the system pressurization time can be shown to be about 500 milliseconds (ms). The "minimum pulse duration time" $t_{p, m i n}$ must therefore be at least $500 \mathrm{~ms}$ to effect cake separation; however, the "actual pulse duration time" $t_{p}$ may be set at any higher values for other reasons. In Case $1, t_{p}$ is set at a higher value of $700 \mathrm{~ms}$; this is done to allow an extra margin of fluid flow and time to reach the quasi-steady state values. With the added margin, the initial value of $P / T$ in the reservoir could also be beneficially lowered (to minimize compression work). More on this shortly.

\subsection{EXAMPLE OF SPREADSHEET MODELING - CASE 1}

We now turn to the explanation and discussion of the numerical results from the spreadsheet modeling, using Case 1 as example. Case 1 results for conventional on-line, cold pulse cleaning of FW/PFBC cake are tabulated in Spreadsheet Table 4.4-1 through 4.4-6 in the following pages; the corresponding tables for the other seven cases (Case 2 through Case 8) are presented in Appendix B.

Table 4.4-1 serves as the depository of gas properties that are required in spreadsheet modeling, such as molar (volumetric) composition, molecular weight (MW), density (Rho), viscosity (Mu), specific heat $\left(C_{p}\right)$, the specific heat ratio $k=C_{p} / C_{v}$, and sonic velocity, among others. Up to 9 gases can be accommodated in the table for this purpose; they are stored as available gases in Column 1 to 9. The last two columns are reserved for the two currently active gases that are designated as the filtrate and cleaning fluid, since the "formulas" for viscosity, specific heat, etc. stored in the last two columns are directly linked to other corresponding "cells" in Tables 4.4-2 through 4.4-6.

Table 4.4-1A is one of the two support tables where the viscosity "formula" for a specified mixed gas is prepared from their pure components and "copied" back to Table 4.41 for later use. As can be seen, the gas viscosity is expressed as a 3-coefficient polynomial function of $T$, and the mixed gas may consist of up to 12 pure components. As shown in the "Sample Data", the gas viscosities can vary 2 to 3 times in the temperature range of interest $\left(77-1,600^{\circ} \mathrm{F}\right)$ and, hence, the viscosity has a very strong impact on pressure drop calculations.

Table 4.4-1B is the other support table where "formulas" for specific heat $\mathrm{C}_{\mathrm{p}}$ are generated and "copied" back to Table 4.4-1. The specific heat $C_{p}$ is computed via a 4-coefficient polynomial function of $T$. Because of the ideal gas assumption, $C_{v}$ may be computed as $\left(C_{p}-R\right)$, where $R$ is the gas constant. The ratio $k=C_{p} / C_{v}$ is computed accordingly, which is then used to compute the sonic velocity $c=\left(g_{c}{ }^{*} k^{*} R^{*} T / M W\right)^{\wedge}{ }^{\prime}$, etc. All these formulas (not the fixed numerical values) are constructed in such a way that they can be readily "copied" to any other tables, if the relative positions of the "cells" are not altered.

Table 4.4-2 deals with the pressure drop calculations at the end of forward filtration period. All inputs required to establish the distribution of pressure drops through filter and cake are specified 


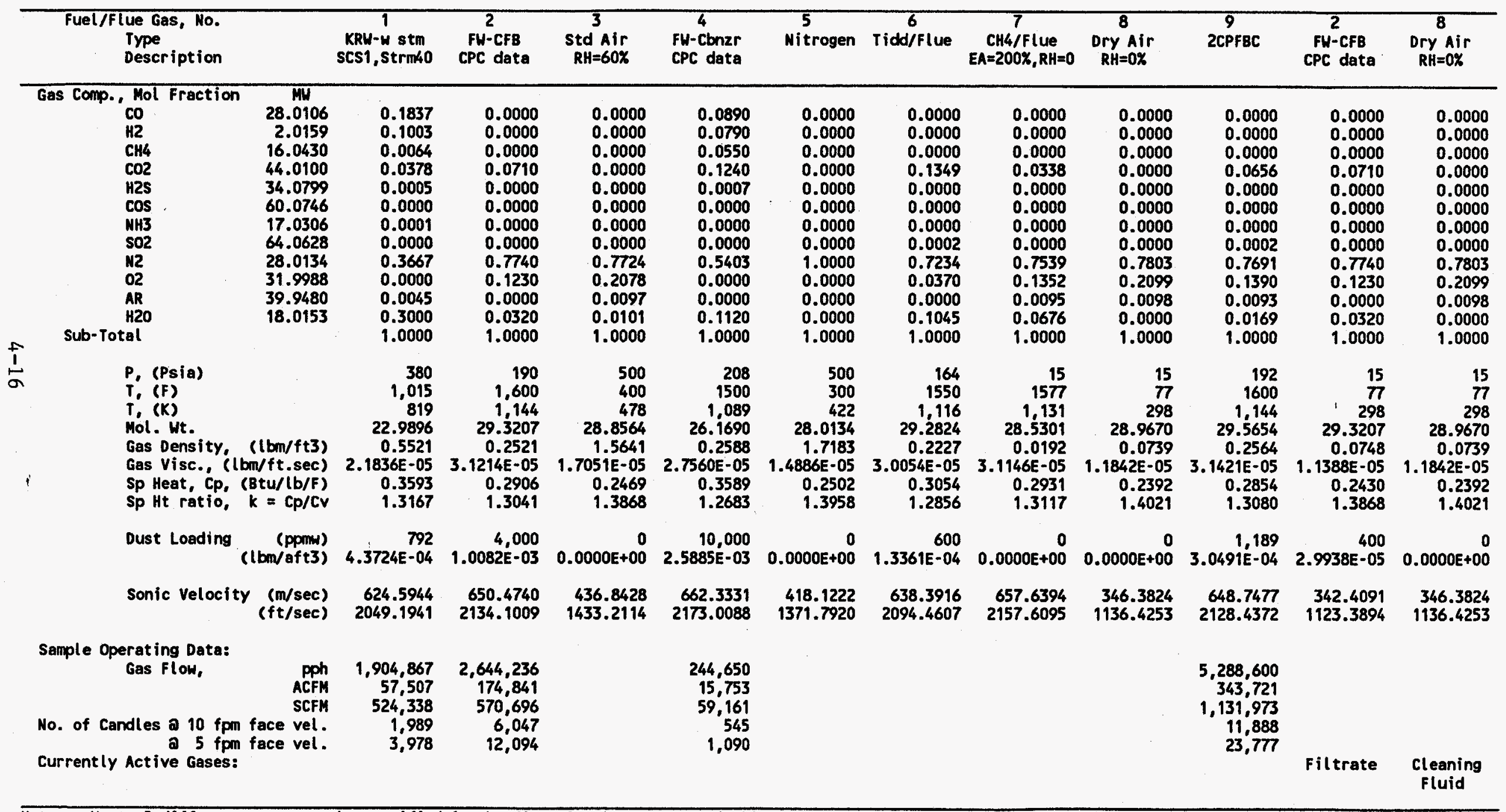

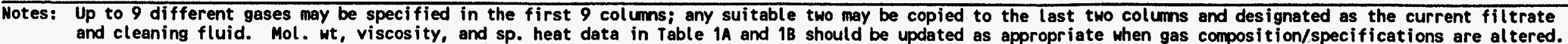




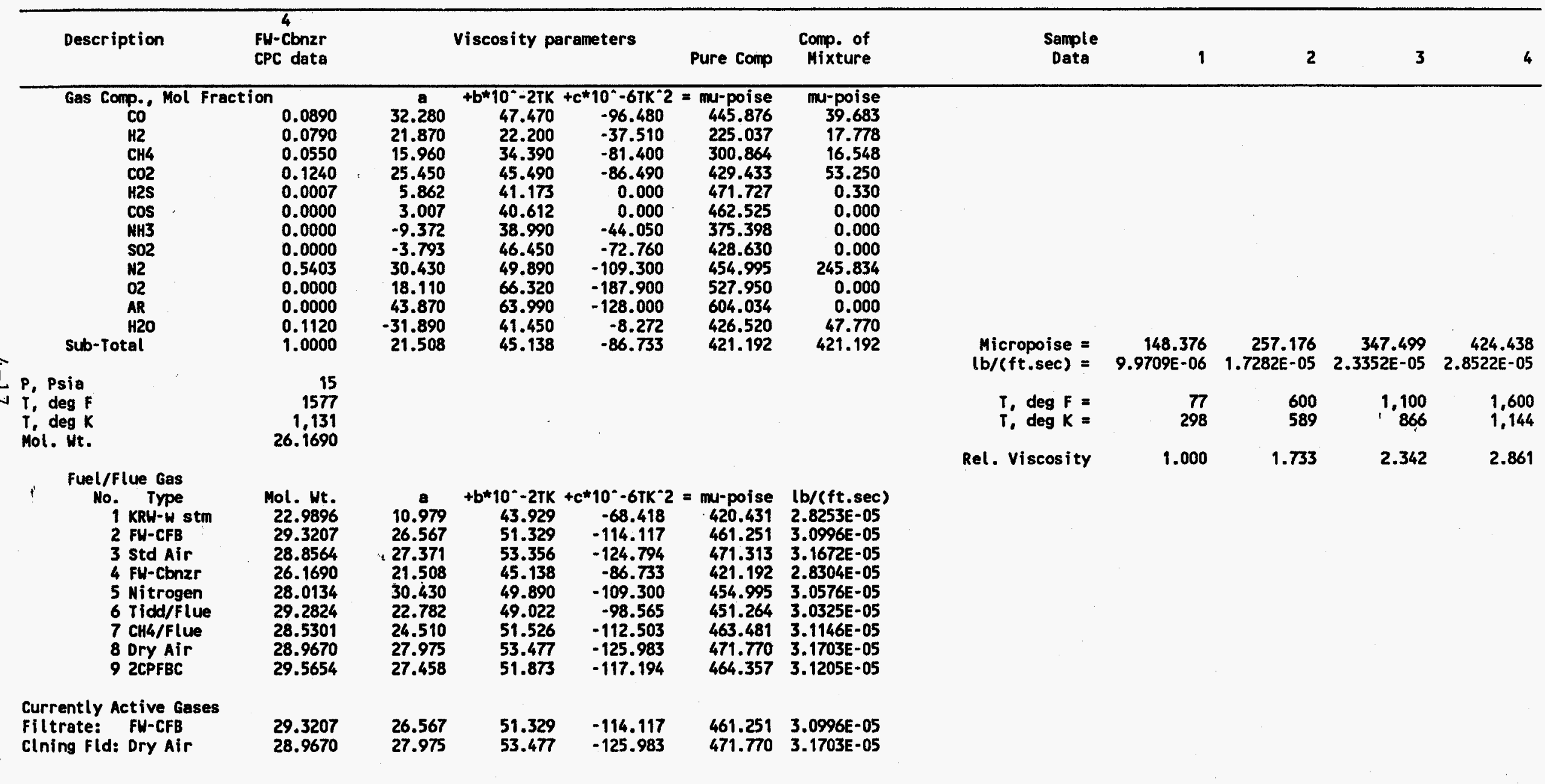

Hotes: Micro-poise $=$ Mu-poise $=0.000001 *$ poise; 1 poise $(P)=100$ centi-poise $(c p)=0.0672 \quad(\mathrm{bm} /(\mathrm{ft}-\mathrm{sec})=242 \mathrm{lbm} /(\mathrm{ft}-\mathrm{h})$.

When a new gas is designated as the current filtrate or cleaning fluid, be sure to update the corresponding viscosity data in the bottom two rows. 


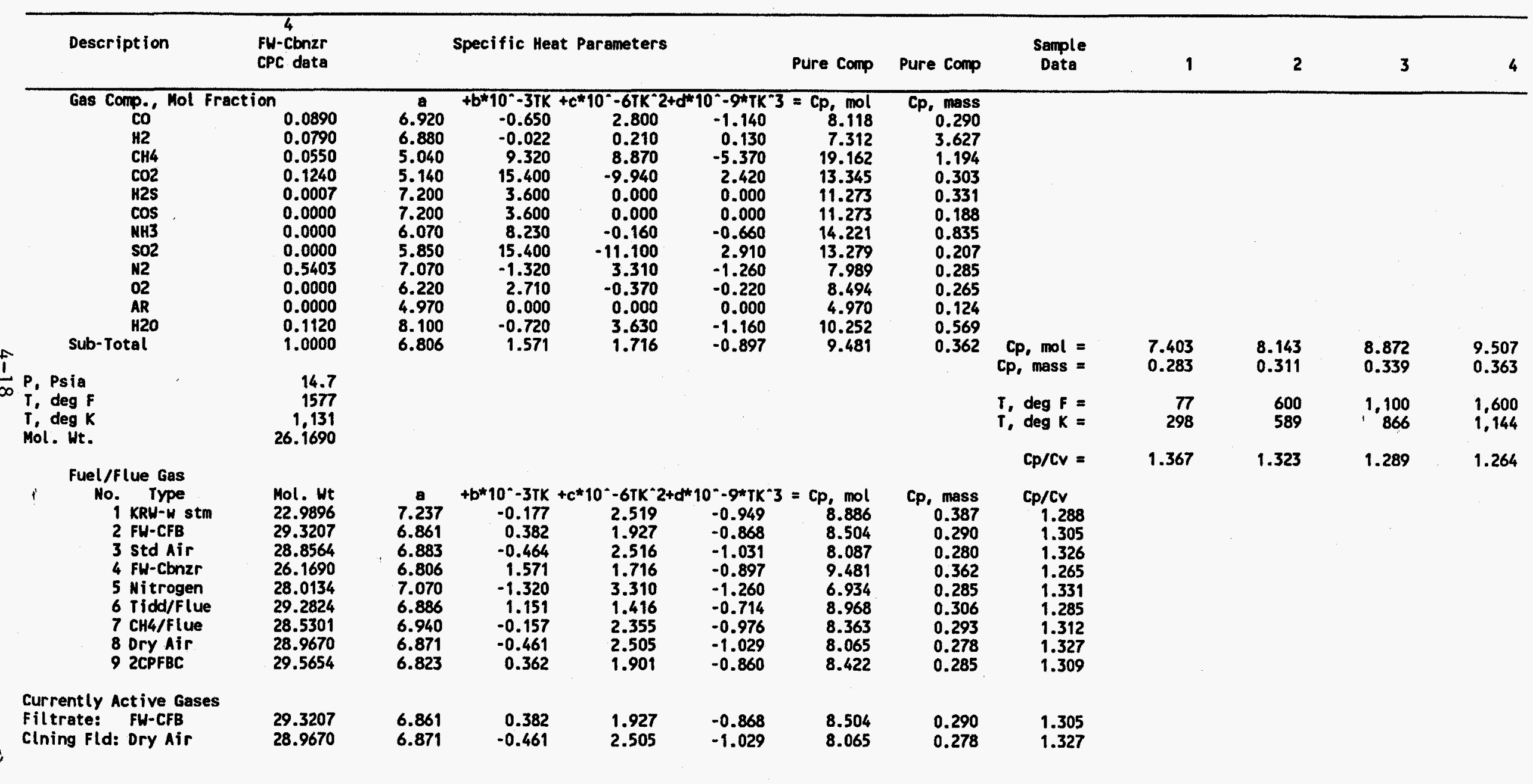

Hotes: $C_{p}$ mol $=$ Btu/(lb-mole)/F; Cp, mass $=B$ tu/lbm/F. 


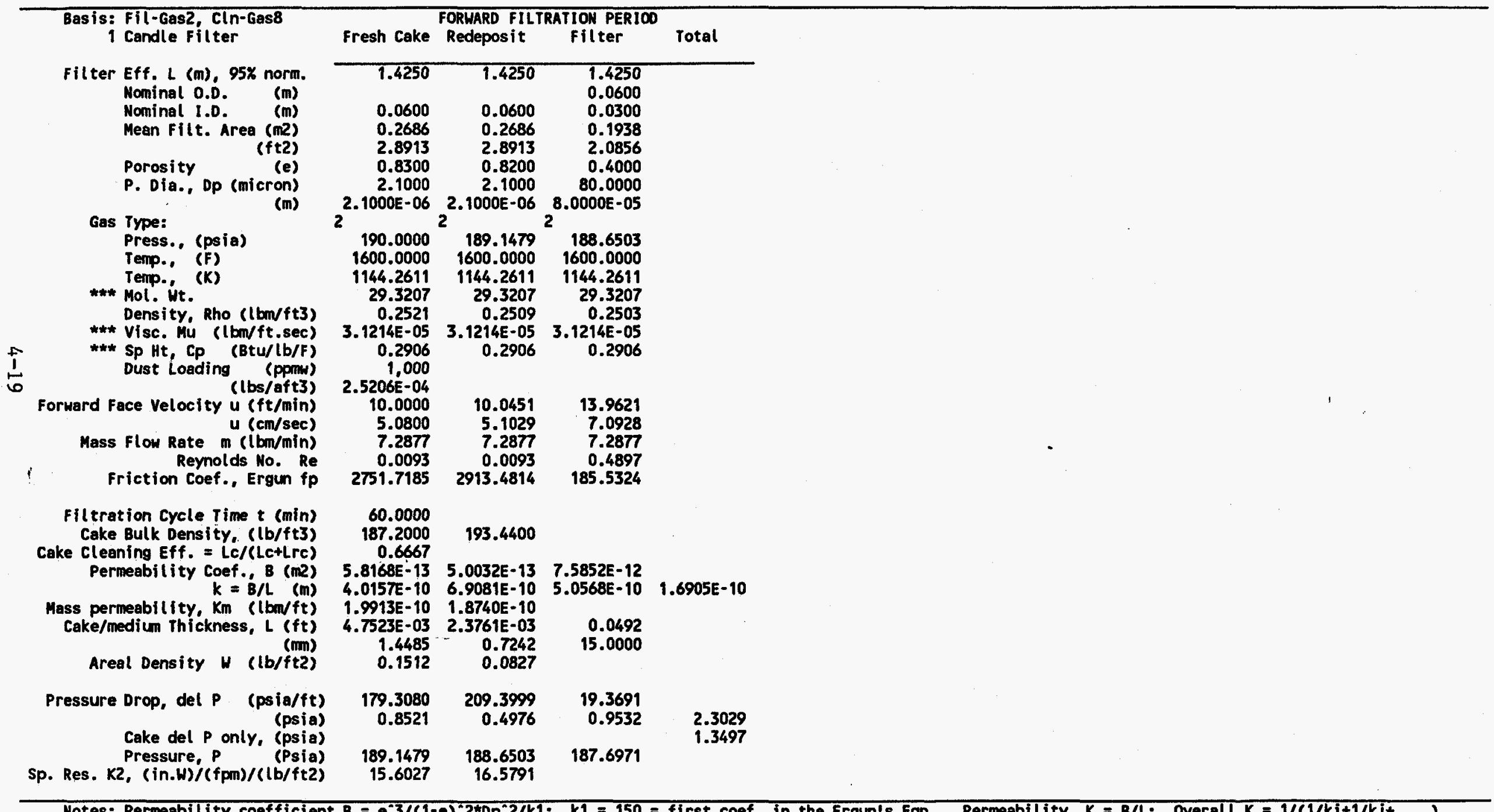

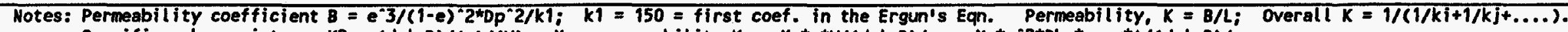

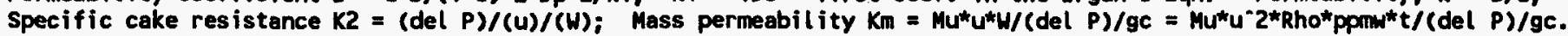




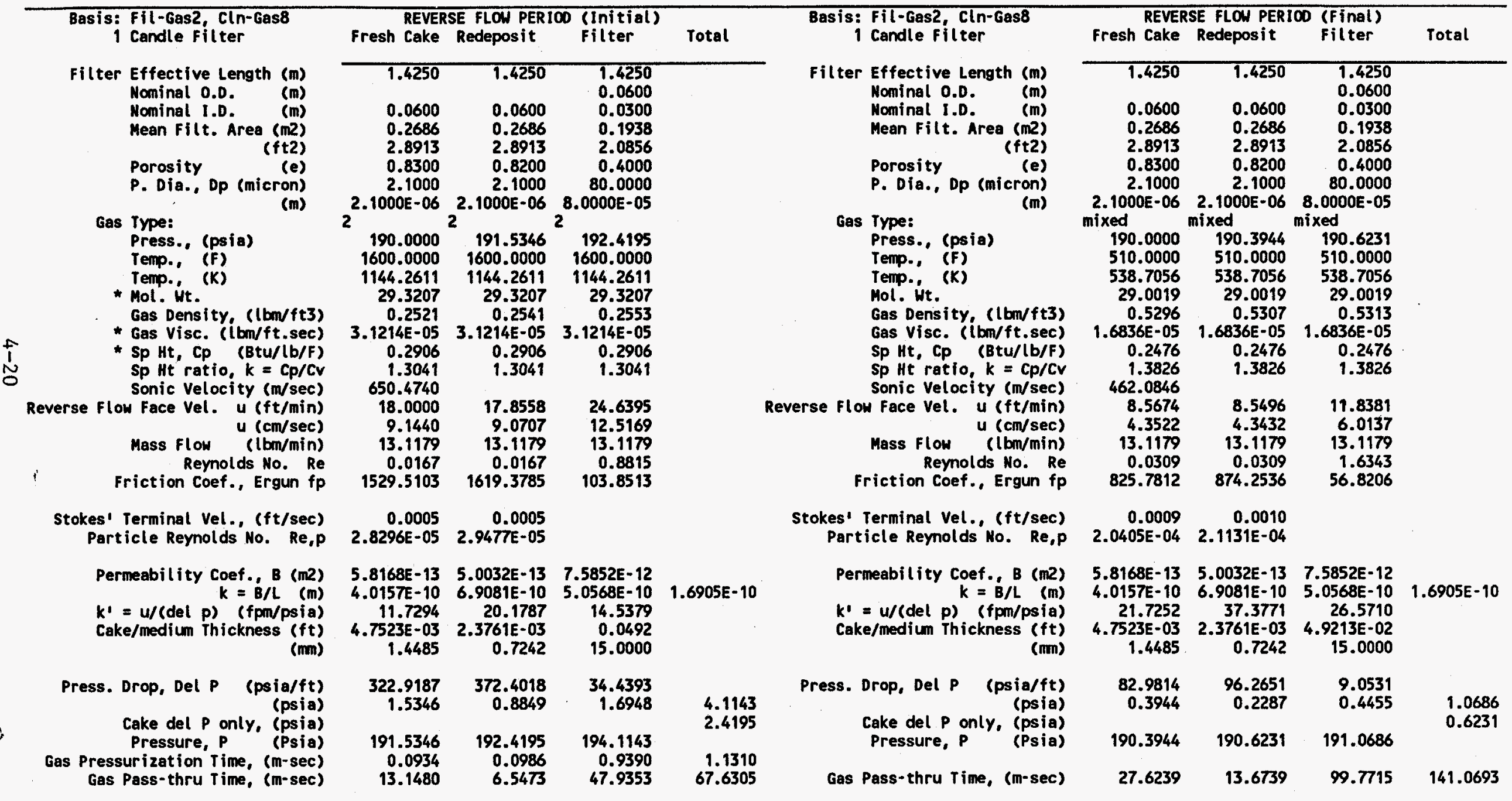

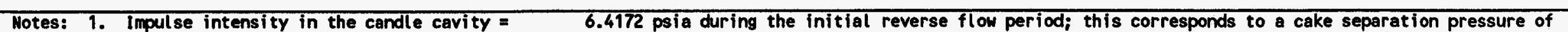
2.4195 psia if the reverse flow face velocity is set to 


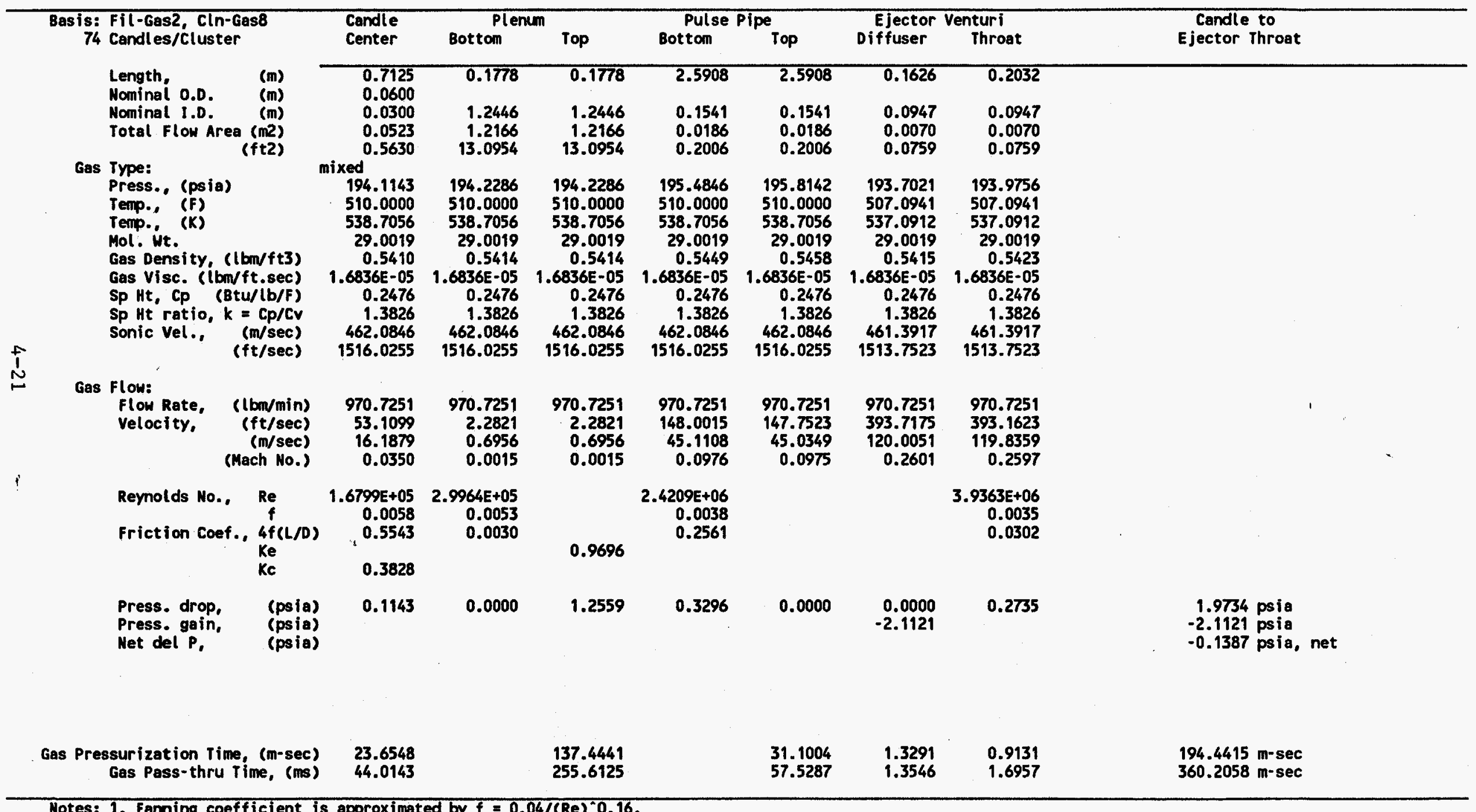

Notes: 1. Fanning coefficient is approximated by $f=0.04 /(\mathrm{Re}){ }^{4} 0.16$.

2. Flow is assumed isothermal from candle to pulse pipe; flow in the diffuser is assumed isentropic. 


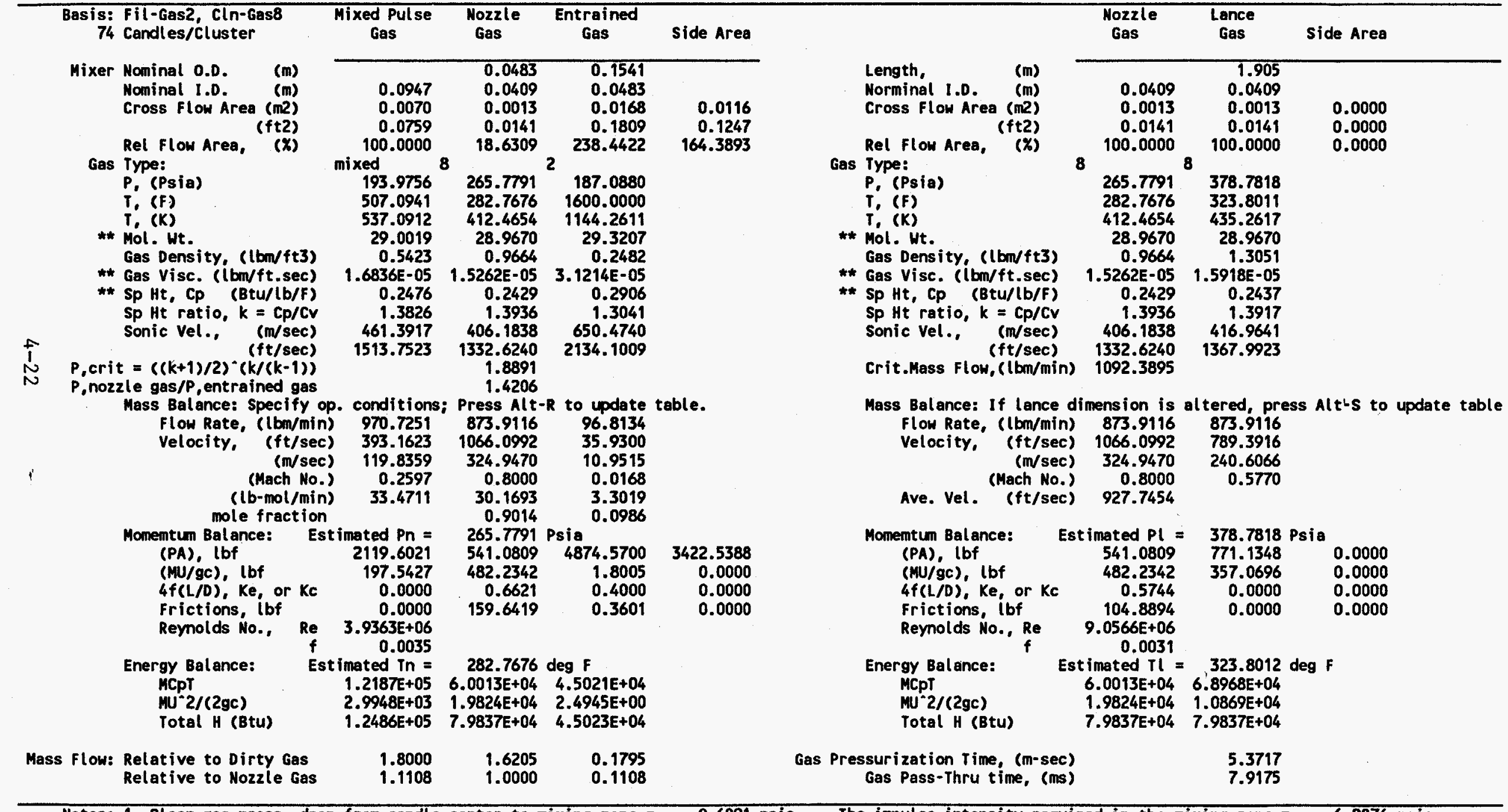
Notes: 1. Clean gas press. drop from candle center to mixing zone $=0.6091$ psia. The impulse intensity required in the mixing 20 . $=0.6 .8876$ psi
2. Mixed pulse gas viscosity and specific heat are molar-averaged values of nozzle and entrained gases. Ejector venturi area ratio $=$
0.6150 


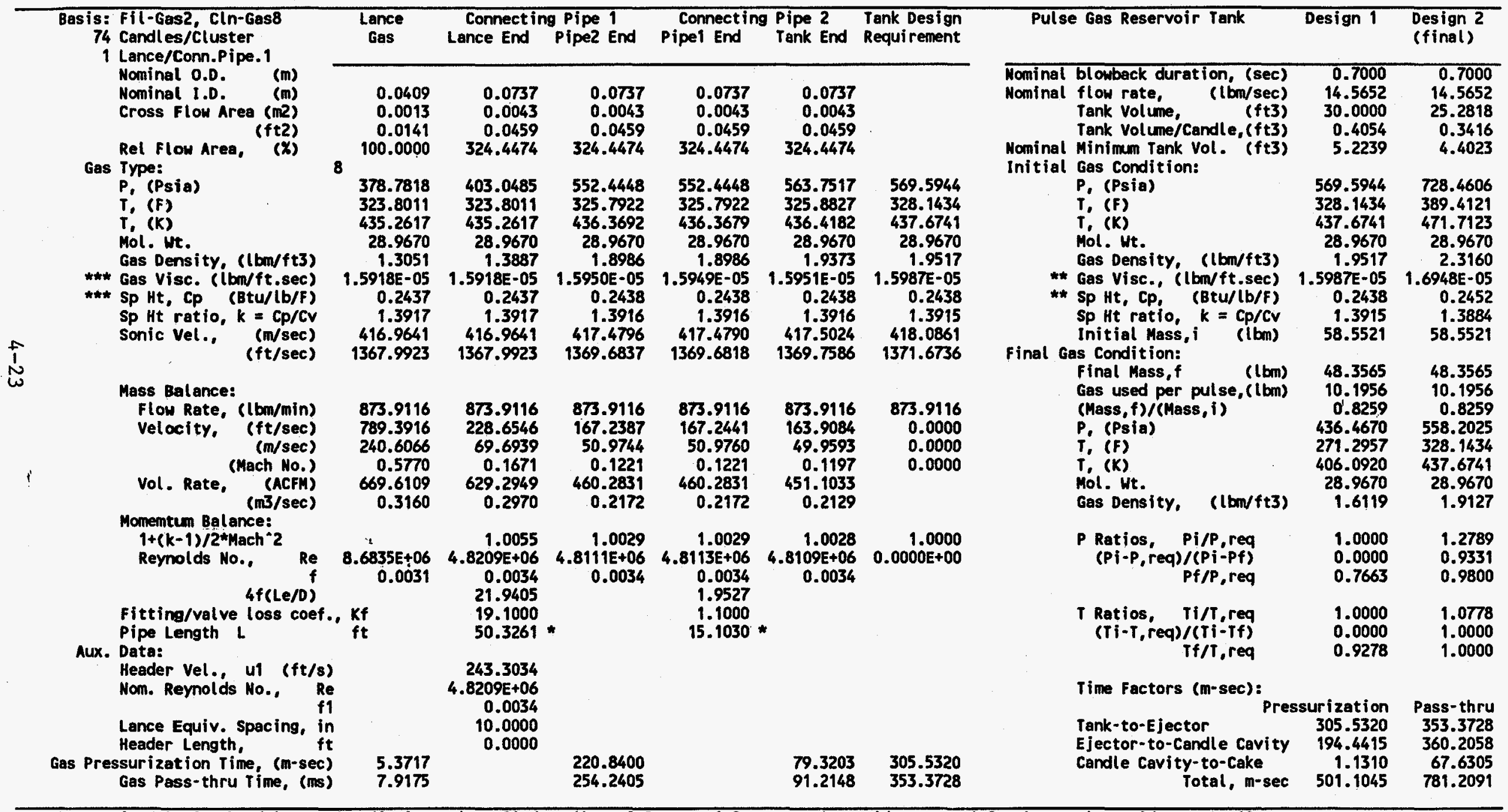

Notes: 1. Velocity head losses for fitting/valve: 90 deg elbow, $0.9 ;$ tee, 1.8; gate valve (wide open), $0.2 ;$ glove valve (wide open), 10.
2. Flow in connecting pipes is Fanno (adiabatic \& frictional); last section of pipe2 to reservoir tank is assumed frictiontess. 
Basis: Fil-Gas2, Cln-Gas8

74 Candles/Cluster

4 Clusters served/Reservoir

\section{PULSE GAS COMPRESSION WORK/PONER:}

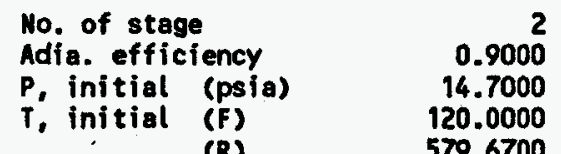

$\begin{array}{lr}P \text {, initial (F) } & 14.7000 \\ T & 120.0000\end{array}$

(R) $\quad 579.6700$

P. final (psia) 728.4606

$\begin{array}{llr}T \text {, final } & \text { (F) } & 652.1539 \\ & \text { (R) } & 1111.8239\end{array}$

$\begin{array}{lr}\text { (R) } & 1111.8239 \\ \text { Compr. work, (Btu/(b) } & 260.9740 \\ \text { (Kwh/lb) } & 0.0765\end{array}$

$\begin{array}{ll}\text { (Kwh/pulse) } 0.7796 & 0.076\end{array}$

I compressor Power/reservoir:

$\begin{array}{lr}\text { No. of pulse/hr } & 4.0000 \\ \text { Pulse gas flow, Ib } & 40.7825\end{array}$

Kw/Reservoir $\quad 3.1184$

Hp/Reservoir $\quad 4.1819$

Total No. of Reservoirs $\quad 4.0000$

Pulse gas flow, Ibm/hr 163.1302

Total KW $\quad 12.4737$

Total Hp $\quad 16.7275$

Notes: 1. Compressor work/power calculations based on simple multi-stage adiabatic compression with inter-coolers; data for preliminary estimations only. 
or estimated as shown. For example, the effective porosity of fresh cake (0.83) and its effective particle diameter (2.1 microns) are "fitted" to the known specific cake resistance data of 15.60 (in.W) $/(\mathrm{fpm})\left(\mathrm{lb} / \mathrm{ft}^{2}\right)$ listed at the bottom. As shown, at a face velocity of $10 \mathrm{fpm}$ and after 60 minutes of filtration, the dirty gas that enters the candle at 190 psia would leave as clean filtered gas from the candle cavity at 187.6971 psia. If pulse cleaning is initiated at this point, the "trigger" pressure would be the difference, or 2.3029 psia. The thickness of the fresh cake layer is 1.4485 $\mathrm{mm}$ which sits on top of a redeposited cake layer of $0.7242 \mathrm{~mm}$ ("recycled" from previous cycle of filtration), assuming the cake cleaning efficiency is $66.67 \%$.

Table 4.4-3 is analogous to Table 4.4-2 but is for the reverse flow period after the pulse cleaning has been initiated. The left half of the table pertains to the initial phase of reverse flow when the gas has just reversed its direction but the gas is still hot at $1,600^{\circ} \mathrm{F}$. The total pressure drop is 4.1143 psia (from 194.1143 psia, clean gas side, to 190 psia, dirty gas side) although the pressure drop across the cake layers is only 2.4195 psia. This figure, which is restated in the footnote, is the separation pressure that is required to overcome the tensile strength of cake under the HTHP condition. If the cake is detached during this initial phase, the impulse intensity of the gas in the filter cavity that is developed to activate cake separation is $=6.4172 \mathrm{psia}$, which is the sum of the trigger pressure drop ( 2.3029 psia) and the pressure drop in the initial reverse flow period (4.1143 psia). As shown in the table, in order to generate this condition, the pulsed gas must enter the clean side of the filter at $18 \mathrm{fpm}$ with a mass flow of $13.1179 \mathrm{lb} / \mathrm{min}$. This critical mass rate is the quasi-steady flow that must be developed through out the system.

The right hand side of Table 4.4-3 provides similar analysis but is for the final phase of the reverse flow period when the "colder" mixed gas at $510^{\circ} \mathrm{F}$ flows through the filter and the cake, assuming the cake is still attached. (The mixed gas is at $510^{\circ} \mathrm{F}$ because the cleaning fluid is stored at $400^{\circ} \mathrm{F}$ or less in the reservoir.) As can be seen in the table, the pressure drops at $510^{\circ} \mathrm{F}$ are drastically smaller than those in the initial phase because of lower gas viscosity and lower linear gas velocity $(8.5674 \mathrm{fpm}$ ) even though the mass flow rate is identical at $13.1179 \mathrm{lbm} / \mathrm{min}$. The total pressure drop has now decreased to 1.0686 psia and the pressure drop across the cake layer would be only 0.6231 psia, if the cake is still attached. Because of the much lower separation pressure exerted by the cold gas, it is very unlikely that the cake separation would take place in this phase, unless the tensile strength of the cake is improbably lower in the lower temperature range. It can be postulated therefore that what actually blows off the cake is the hot gas that reversed its flow direction during the initial phase and is not the cold gas that follows it in a later phase. This is consistent with experimental observations that cake tends to detach early and quickly, not later and slowly.

Table 4.4-4 deals with the pressure drop calculations for the entire cluster containing 74 candles in the piping section from the center of candle to the ejector venturi area. The mass flow rate is 74 times 13.1179 or $970.7251 \mathrm{lb} / \mathrm{min}$. As noted earlier, the pressure drops in this section (downstream of the ejector) are relatively small because of the relatively low gas velocity. The process here is assumed isothermal except the lower diffuser which is assumed isentropic. It should be noticed that there is small pressure gain through the diffuser and, as a result, there is little overall change in pressure and temperature from the candle to the venturi throat area.

The left hand side (LHS) of Table 4.4-5 deals with the calculations in the ejector mixing zone using the successive substitution procedure described earlier. The results of the simultaneous mass, total energy, and momentum balances show that, in the mixing zone, the "cold" cleaning fluid ("nozzle gas" = dry air, Gas 8) at 265.7791 psia and $282.7676^{\circ} \mathrm{F}$ would entrain/mix with the clean filtered gas ("entrained gas" = Gas 2) at 187.0880 psia and $1,600^{\circ} \mathrm{F}$ to form a "mixed pulse gas" at $193.9756 \mathrm{psia}$ and $507.0941^{\circ} \mathrm{F}$. For the specified Mach number of 0.8 (or $1,066 \mathrm{ft} / \mathrm{sec}$ ) at the nozzle tip, $873.9116 \mathrm{lb} / \mathrm{min}$ of cleaning fluid would entrain $96.8134 \mathrm{lb} / \mathrm{m} / \mathrm{min}$ of the clean filtered gas in forming $970.7251 \mathrm{lb} / \mathrm{min}$ of the mixed gas at the $\mathrm{P} / \mathrm{T}$ conditions that are required for cake separation. 
The RHS of Table 4.4-5 deals with the $P / T$ changes that take place in the pulse lance. A similar iterative procedure is applied here to determine the $\mathrm{P} / \mathrm{T}$ conditions for the pulse lance which is $1.905 \mathrm{~m}$ in length. The cleaning fluid would enter the pulse lance at 378.7818 psia and $323.8011^{\circ} \mathrm{F}$, but because of the high velocity flow, it would lose pressure and temperature rapidly (to $265.7791 \mathrm{psia}$ and $282.7676^{\circ} \mathrm{F}$ ) as the gas is accelerated from $771 \mathrm{ft} / \mathrm{sec}$ at the inlet to $1,066 \mathrm{ft} / \mathrm{sec}$ at the nozzle tip.

The LHS of Table 4.4-6 deals with the pressure drops in the pipe section upstream of the ejector. Above the pulse lance there are two main interconnecting pipes which can be different in length and/or diameter: for Case 1, the lengths are assumed to be $50 \mathrm{ft}$ and $15 \mathrm{ft}$ respectively for Connecting Pipes 1 and 2, but the inside diameter is same at $0.0737 \mathrm{~m}$ ( 2.90 inches) for both. There are a number of fittings/valves in Pipe 1 that create a total "velocity head" losses of 19.1, of which 10 is attributable to the control valve alone. (In contrast, there is a total of only 1.1 "velocity head" losses for Pipe 2.) Using the equations for compressible fluid discussed in the previous section, the overall pressure drops in Pipe 1 and Pipe 2 are found to be 149 psia and 11 psia, respectively, most of which due directly to fitting/valve frictions. The final "short" pipe connected to the reservoir is considered frictionless and, hence, the change in pressure here is entirely due to acceleration of the gas from 0 to $163.9084 \mathrm{ft} / \mathrm{sec}$. The minimum tank design requirement, i.e., the lowest $\mathrm{P} / \mathrm{T}$ for storing the cleaning fluid, is $569.5944 \mathrm{psia}$ and $328.1434^{\circ} \mathrm{F}$. At this minimum level, however, the tank volume is infinitely large unless $\mathrm{P} / \mathrm{T}$ is allowed to drop.

The complete $\mathrm{P} / \mathrm{T}$ profile data along the blowback system from the filter surface to the reservoir tank can be found in the above referenced spreadsheets. For quick reference, a simplified $\mathrm{P} / \mathrm{T}$ profile is compiled from these and presented below (Table 4.4-7).

The RHS of Table 4.4-6 deals with reservoir sizing. "Design 1" shown in Column 1 of the table is a temporary design for a tank with a finite volume in which the initial gas condition is arbitrarily set equal to the minimum condition. When the gas is discharged from this minimum condition, the final P/T naturally drops to a lower level that is not effective for cake separation; however, by varying the tank volume (which affects the final/initial mass ratio), the effect of $P / T$ drops can be studied. Using a suitable mass ratio learned in Design 1, "Design $2^{\text {" }}$ is performed with the initial $\mathrm{P} / \mathrm{T}$ set at a higher level so that, when the gas is discharged for the same pulse duration, the final $\mathrm{P} / \mathrm{T}$ would be equal to the minimum required or nearly so.

For Case 1, our final design choice is to set the final-to-initial mass ratio at 0.8259 and the tank volume at 25.2818 cubic feet. Under this condition, it is found that the pulsed gas can be discharged for 0.7 second from initial $P=728.4606$ psia and initial $T=389.4121^{\circ} \mathrm{F}$ to arrive at final $\mathrm{P}=558.2025 \mathrm{psia}$ and final $\mathrm{T}=328.1434^{\circ} \mathrm{F}$. In general, the tank volume and the initial $\mathrm{P} / \mathrm{T}$ values are very strongly related to each other, as is evident in the following sensitivity analysis (Table 4.4-8).

Clearly, the tank pressure can be several hundred psia higher than the minimum required, depending on the design philosophy or constraints. It should be noted in this conjunction that, had the initial temperature $\mathrm{T}$ for the design case exceeded the specified upper limit of $400^{\circ} \mathrm{F}$ for the pulse control valve, the temperature of pulse gas passing through the cake (i.e., $510^{\circ} \mathrm{F}$ specified in Table 4.4-4) would have to be lowered and the whole calculations repeated. The final tank pressure for the design case ( 558.20 psia) is slightly lower than the required minimum (569.59 psia) but this is compensated for by the positive effect of longer pulse duration ( 0.7 second rather than the minimum required time of 0.5 second), as discussed below.

The "pressurization" time as defined in the model is the time required to pressurize the system with the cleaning fluid to the pressure profile necessary to blow off the cake without replacing the hot gas pre-existing in the system. This parameter is listed for all major system segments in the 
TABLE 4.4-7 REVERSE FLOW P/T PROFILE

(From Filter Surface to Reservoir Tank)

\begin{tabular}{|r|r|r|r|r|}
\hline LOCATION & $\mathrm{P}, \mathrm{psia}$ & $\mathrm{T},{ }^{\mathrm{O}} \mathrm{F}$ & Velocity & Notes \\
\hline Dirty gas side & 190.00 & 1600.00 & $18.00 \mathrm{fpm}$ & \\
\hline Cake/filter & 192.42 & 1600.00 & $17.86 \mathrm{fpm}$ & $\mathrm{P}_{\text {sep }}=2.42 \mathrm{psia}$ \\
\hline Candle center & 194.11 & 510.00 & $53.11 \mathrm{fps}$ & \\
\hline Plenum top & 194.23 & 510.00 & $2.28 \mathrm{fps}$ & \\
\hline Pulse pipe top & 195.81 & 510.00 & $147 \mathrm{fps}$ & \\
\hline Lower diffuser & 193.70 & 507.09 & $393 \mathrm{fps}$ & \\
\hline Ejector venturi throat & 193.97 & 507.09 & $393 \mathrm{fps}$ & \\
\hline Pulse lance, nozzle & 265.78 & 282.77 & $1066 \mathrm{fps}$ & Mach $=0.80$ \\
\hline Pulse lance, top & 378.78 & 323.80 & $789 \mathrm{fps}$ & \\
\hline Pipe 1 (lance end) & 403.05 & 323.80 & $228 \mathrm{fps}$ & \\
\hline Pipe 1 (pipe2 end) & 552.44 & 325.79 & $167 \mathrm{fps}$ & \\
\hline Pipe 2 (pipe1 end) & 552.44 & 325.79 & $167 \mathrm{fps}$ & \\
\hline Pipe 2 (tank end) & 563.75 & 325.88 & $164 \mathrm{fps}$ & \\
\hline Tank (min. req.) & 569.59 & 328.14 & $0 \mathrm{fps}$ & Vol. $=$ infinity \\
\hline Tank (actual) & 728.46 & 389.41 & $0 \mathrm{fps}$ & Vol. $=25.3 \mathrm{ft}^{3}$ \\
\hline
\end{tabular}

TABLE 4.4-8 SENSITIVITY OF TANK VOLUME VS. INITIAL TANK P/T

\begin{tabular}{|rr|r|r|}
\hline TANK VOLUME, & $\mathbf{F t}^{3}$ & Initial $\mathbf{P}, \mathrm{psia}$ & Initial $^{\mathbf{0}}{ }^{\mathrm{o}} \mathrm{F}$ \\
\hline 4.9 & 1561 & 592 \\
\hline 15.1 & 851 & 427 \\
\hline (Final Design) & 25.3 & 728 & 389 \\
\hline 35.5 & 678 & 373 \\
\hline 45.7 & 651 & 363 \\
\hline 96.7 & 601 & 345 \\
\hline 198.8 & 579 & 336 \\
\hline (very large) & 569 & 328 \\
\hline
\end{tabular}


bottom row of Tables 4.4-3 through 4.4-6. The gas "pass-through" time, which is also listed at the bottom of the tables, is the time required for the "cold" cleaning fluid to reach the cake layer, assuming the flow is plug flow through out the system. In other words, it is the time needed for the cold gas to completely replace or purge the hot gas from the blowback system. Both parameters are a function of the gas flow rate and the volume of blowback system and, by definition, the pass-through time is longer than the pressurization time. The following table which is compiled from the spreadsheets illustrates the differences:

TABLE 4.4-9 BLOWBACK SYSTEM TIME FACTORS

\begin{tabular}{|r|r|r|}
\hline SYSTEM COMPONENT & PRESSURIZATION TIME, ms & PASS-THROUGH TIME, ms \\
\hline Filter/Cake layers & 1.13 & 67.63 \\
\hline Candle cavity & 23.65 & 44.01 \\
\hline Plenum & 137.44 & 255.61 \\
\hline Pulse pipe & 31.10 & 57.53 \\
\hline Ejector venturi & 0.91 & 1.70 \\
\hline Pulse lance & 5.37 & 7.91 \\
\hline Pipe 1 & 220.84 & 254.24 \\
\hline Pipe 2 & 79.32 & 91.21 \\
\hline & 501.10 & 781.21 \\
\hline Total Time (ms) & & \\
\hline
\end{tabular}

As explained in Section 4.3, the cake is most likely blown-off by the time the cold gas arrives at the cake layer. Therefore, a suitable pulse duration time may be selected using these two time parameters as a guidance. It is clear that the actual pulse duration time should be at least equal to the pressurization time but it may be shorter or longer than the pass-through time, depending on other operational considerations. For example, a longer pulse may be justified because it can provide a longer cake free-fall time for more complete cake cleaning. Another reason might be that the initial P/T in the reservoir can be lowered to minimize the gas compression work or to avoid reaching an uncomfortably high level. This is a design trade-off because the final P/T may have to be allowed to fall below the minimum level. In Case 1, the actual pulse duration time is set at 0.7 second which lies between the pressurization time of 0.5011 second and gas pass-through time of 0.7812 second. However, the final pressure is allowed to drop to $98 \%$ of the minimum required pressure of 569.5944 psia $\left(=\mathrm{P}_{\mathrm{r}}\right)$ or 558.2025 psia as shown in the last column of Table 4.4-6. It is estimated that this would reduce the useful driving force (the "Pressure Reserve Factor" listed in Table 4.2-1) to about $93.3 \%$ of the time when the gas is discharging or the effective pulse duration time to about 0.65 second.

It is interesting to note that the total pressurization time in the piping segments below the ejector is 0.1944 second, of which 0.1374 second is that required for pressurizing the plenum alone (see Table 4.4-4). Similarly, the pressurization time in the piping above the ejector is 0.3055 second, of which 0.2208 second is due to Connecting Pipe 1 (see Table 4.4-6). The plenum and Pipe 1 thus represent most of the "volume" that must be "filled up" before the cake separation could be effected. Since the amount of cleaning fluid consumed per pulse is a function of system volume, 
the time parameter can be used to identify the piping segments (here, plenum and Pipe 1) where the system volume could be minimized to save power and cost.

Finally, Table 4.4-6A is a short table wherein the compression work/power needed to compress the cleaning fluid is determined. The compressor is assumed to be 2-stage with intercooling and its adiabatic efficiency is assumed to be $90 \%$. Since pulse discharges are infrequent, the pulse gas can be resupplied by a "slow" compressor and, hence, the nominal power required (as shown) is not great. In practice, when one wishes to do the compression "quickly" in a short period of time, the power requirement would be many times greater.

\subsection{SUMMARY FOR OTHER CASES}

An overall comparison of the reverse flow condition and $P / T$ requirements (at various key points in the blowback system) for all study cases are presented in Table 4.2-3. A brief explanation of Tables 4.2-1 and 4.2-3 follows:

The major difference in operating conditions between off-line cases (Cases 2, 4, 6, and 8) and on-line cases (Cases 1, 3, 5, and 7) is that a cake cleaning efficiency of $98 \%$ is assumed for the off-line cases vs. only $66.67 \%$ for the on-line cases. Because of the better cleaning efficiency, the off-line cases can be operated with a longer filtering cycle time: $90 \mathrm{~min}$ vs. $60 \mathrm{~min}$ for the on-line cases. As a result, their power requirements are only two thirds of the power requirement for the on-line cases, which is the chief advantage.

The major difference in operating conditions between the contrasting cold pulse and hot pulse cases is that the reservoir temperature for cold pulse cases is limited to $400^{\circ} \mathrm{F}$ or less but there is none for the hot pulse reservoir. It should pointed out that the two hot pulse cases (Cases 3 and 4 ) as modeled here are hypothetical in that the hot cleaning fluid is "stored" at $1,537^{\circ} \mathrm{F}$, which is not entirely realistic. They are shown here only to demonstrate the impacts of temperature on the operating conditions for the two pairs of corresponding cases namely, Case 1 vs. Case 3 and Case 2 vs. Case 4. (Later, the design of reservoirs for these cases will be replaced by more feasible "Rapid-Combustors" as designed by METC. See Section 5 for details). In general, the hot pulse cases tend to require higher pressure in the tank but the hot fluid can entrain more of the clean filtered gas. (However, entrainment is not a virtue here: the cleaning fluid itself is already hot and, hence, entrainment of clean filtered gas is not required at all from the view point of preventing thermal shock.) Another interesting observation regarding the hot pulse cases is that their pressurization time at about $185 \mathrm{~ms}$ is much shorter than the 500-750 ms required for the cold pulse cases. This follows since there is less mass in the system when the gas is hot.

One of the major differences in operating conditions among the PFBC cake, carbonizer cake, and gasifier cake is the relative cake resistance. The specific cake resistances $k_{2}$, are assumed to be about 15.60-16.58, 28.53-30.16, and 43.91-46.34 (inches of water)/(fpm) $/\left(\mathrm{lb} / \mathrm{ft}^{2}\right)$, respectively, so that they are approximately in the relative order of 1 to 2 to 3 for the three types of cakes. Partly because of their higher cake resistances, the face velocity for the carbonizer and gasifier cases is set at $5 \mathrm{fpm}$ vs. $10 \mathrm{fpm}$ for the PFBC cases. Due to lack of reliable data, cake separation pressures are somewhat arbitrarily graded in the range of 2.36-2.42 psia for the PFBC cake (base case), 3.32-3.39 psia for carbonizer cake, and 3.63-3.71 psia for the gasifier cake to reflect the relative difficulties of separating these cakes. The gasifier case requires the cleaning fluid to be stored at the highest pressure (1,090-1,094 psia in $55-\mathrm{ft}^{3}$ reservoirs) partly because of its higher system pressure (384.23 psia) and partly because of its higher separation pressure requirement. The 25 $\mathrm{ft}^{3}$ reservoirs for the PFBC and carbonizer cases require a storage pressure in the range of 726-769 psia for the cold pulse and about 950 psia for the hot pulse technology. (Note: The reservoir volume for the gasifier cases is made larger than the PFBC/carbonizer cases in order to keep the storage pressure at a "relatively low" level of 1,090-1,094 psia; if the tank volume were 24 
to $25 \mathrm{ft}^{3}$, the pressure would have been about 1,280-1,290 psia which were deemed too "high". This is a design/cost trade-off issue.)

It should be remarked that the "hardwares" (ejector, pulse lance, pipings, etc.) as specified in the present study are not necessary optimal for each individual case. In fact, for the sake of maintaining uniform comparison, most of the hardware components are kept the same as possible (to Case 1) for all other cases. As a result, some of the blowback conditions may not be entirely optimum. For example, in the cases for the carbonizer, the entrainment is negative, meaning there is overflow of excess motive gas which is wasted. For the gasifier cases, there is essentially no entrainment. (Note: However, entrainments of clean filtered gas for these cases can always be achieved by changing/optimizing the ejector configuration.)

Another point regarding the hardware is that practically all of the pressure changes take place in the piping upstream of the ejector. Most of the pressure drops due to skin friction occurs in the pulse lance immediately above the ejector and in the interconnecting Pipe 1, where gas velocity is very high. Within Pipe 1, most of the friction losses can be attributed to fittings and valves, especially the control valve. The diameters of piping segments also have very strong effects on the pressure drops. Any changes in these components can easily cause a large difference in pressure at the end of the interconnecting pipes. The pressure of the gas reservoir itself is a strong function of tank volume and/or pulse duration: depending on the design philosophy applied in sizing the reservoir, the tank pressure can easily be increased or decreased by a hundred psia or more. In summary, the final P/T condition determined for a reservoir must be so understood in light of the unique hardware components and geometric configuration of each specific blowback system. The conventional wisdom of simply assuming the reservoir pressure being in the range of "two to three" times of the system pressure may or may not be sufficiently accurate nor revealing (as to why so much pressure is needed) in many cases.

\subsection{CONCLUDING REMARKS}

The spreadsheet model described above can be used to assist conceptual design of a blowback systems or used as an analytical tool to compare performance of different filter cleaning techniques. The model can be applied to carry out "what-if" analyses to provide guidance in optimizing system parameters - especially in determining the dimensions or geometrical configuration of hardware such as ejector and pipes. While optimization was not one of the basic objectives (and therefore not specifically done for each individual system), it was found that the reservoir pressure (and, to some extent, temperature) depend strongly on the hardware setups (length/diameter of pipes, type/number of fitting/valves) of the blowback system. Often, there are numerous seemingly equally good alternatives that can achieve the same result: for example, at the ejector, a pulse with the same momentum can be generated with a large nozzle/low pressure gas or with a small nozzle/high pressure combination. In a future work, an optimization study could be carried out to investigate the performances of the blowback system with different configurations.

It also becomes clear during the model development that one of the fundamental process parameter required for effective design of blowback system is the cake "separation stress". This separation stress is nominally in the order of a few psia, and once it is specified or known, all the rest of pressure and temperature distribution of the pulsed gas within the blowback system can be established in a step-by-step fashion. [It is refreshing to realize here that the essential purpose of storing the cleaning fluid under a very high pressure of several hundred psia or even in excess of a thousand psia is to generate only a few psia of pressure drop across the cake layer. All the rest of pressure energy is expended in accelerating the gas or in overcoming the system friction and is eventually lost.] Unfortunately, the data on cake separation stress is not commonly available in the literature nor easily estimated by theoretical means; it appears that the only reliable method is by direct experimental measurements. 
Other important parameters that need to be developed or compiled include cake separation and cake cleaning efficiencies. The former is the parameter closely associated with cake separation stress, and the latter is a function of the properties of cake flakes which are not well characterized. For instance, it is the particle size distribution of the cake flakes or agglomerates after separation that determines the effective terminal velocity during free-fall which, in turn, determines the cake cleaning efficiency. The mean particle size of the cake flakes during free falling is definitely greater (by, perhaps, two to three orders of magnitude) than the mean particle diameter of the cake on the candle filter or that found in the bottom of filter vessel, but there is no reliable measured data. It is recommended that more $R \& D$ effort be directed in establishing/compiling this class of information (separation stress, cake flake properties, etc.) for all types of cakes under their actual operation conditions.

Originally, the quasi-steady state method of analysis as developed here was meant for use with the single or individual blowback systems. The quasi-steady state assumption and the "square wave" approximation should be nearly perfect for small filter systems but perhaps less so for the large cluster type for which the analysis work was later extended. For a large cluster type the responses to a pulse can be expected to be more "gradual" than in a small system. While the concepts of pressurization time and gas pass-through time can help in estimating key design parameters such as the minimum pulse duration required for effective cake separation, a suitable unsteady state formulation should be able to determine this more directly. Such options could be explored in future work on blowback system modeling and analysis. 


\subsection{CONCEPTUAL DESIGN}

In this section the conceptual designs of the three filter blowback systems are described. This will include brief descriptions of the IGCC and CPFBC power plants, operating parameters of these plants, rationale for design cases, modeling results, and design details of the filter systems. Based on the conceptual designs an economic comparison was completed and is presented in Section 6.0.

The conceptual design includes system and component descriptions, general arrangement diagrams and material and energy balances. The conceptual designs were done for eight different cases as agreed upon by the project participants described as follows:

- Case 1: $\mathrm{CPFBC}$ with conventional on-line cleaning, $400^{\circ} \mathrm{F}$ pulse.

- Case 2: CPFBC with conventional off-line cleaning, $400^{\circ} \mathrm{F}$ pulse.

- Case 3: $\mathrm{CPFBC}$ with rapid combustion $1500^{\circ} \mathrm{F}$ pulse, on-line cleaning.

- Case 4: $\mathrm{CPFBC}$ with rapid combustion $1500^{\circ} \mathrm{F}$ pulse, off-line cleaning.

- Case 5: Carbonizer with conventional on-line cleaning, fuel gas $400^{\circ} \mathrm{F}$ pulse.

- Case 6: Carbonizer conventional off-line cleaning, fuel gas $400^{\circ} \mathrm{F}$ pulse.

- Case 7: IGCC with conventional on-line cleaning, fuel gas $400^{\circ} \mathrm{F}$ pulse.

- Case 8: IGCC with conventional off-line cleaning, fuel gas $400^{\circ} \mathrm{F}$ pulse.

\subsection{PLANT DESCRIPTIONS}

DOE/METC has selected the KRW air blown gasifier and Foster Wheeler's second generation PFBC for the candle filter cleanup system conceptual designs. Following are brief descriptions of the two power plants.

\subsubsection{Foster Wheeler Second Generation PFBC}

Information and data about this advanced power generating concept was from a FWDC report titled "Second Generation Pressurized Fluidized Bed Combustion Plant Conceptual Design and Optimization of a Second-Generation PFB Combustion Plant, Phase 1, Task 1, Volume 1" September, 1989, and a report written by Combustion Power Company for DOE/METC titled "Granular-Bed and Ceramic Candle Filters in Commercial Plants-A Comparison" April, 1993.

In this concept, coal is pyrolized to produce a low-Btu fuel gas that is burned in a topping combustor by mixing it with high excess air exhaust gas from a PFBC. The coal char residue from the pyrolizer/carbonizer is burned in the PFBC along with the balance of plant coal, if any. Lime sorbent is added to the carbonizer and PFBC to minimize carbonizer tar yield and to control sulfur oxide emissions from both units.

The fuel gas leaving the carbonizer flows to cyclones where particulates are removed and then enters the candle filter vessels for final particulate removal. The gas from the PFBC is also precleaned with cyclones before entering the candle filter vessels. Table 5.1-1 provides candle filter vessel parameters for the PFBC and carbonizer, and also the KRW gasifier. 


\subsubsection{KRW Air Blown Fluidized Bed Gasifier}

The data for the KRW gasifier was taken from a report titled "Assessment of Coal Gasification/Hot Gas Cleanup Based Advanced Gas Turbine Systems" December, 1990 written for DOE by Southern Company Services, Inc. and others.

The KRW gasifier operates by mixing steam and air with coal at a high temperature to produce a low BTU fuel gas. The fuel gas is cooled to $1,056^{\circ} \mathrm{F}$ and then partially cleaned with cyclones. The cooled, clean gas passes through a candle filter before entering a high temperature desulfurization device. The candle filter cleans the gas of the remaining particulates in order to protect the fixed bed desulfurization device. The conditions shown in Table 5.1-1 are for the fuel gas as it enters the candle filter.

Table 5.1-1

Candle Filter Vessel Parameters

No. Parameter

1. MWe net

2. Pressure, inlet, PSIA

3. Temp., inlet, ${ }^{\circ} \mathrm{F}$

4. Flow, inlet, lb/hr gas

5. Flow, inlet, ACFM

6. Inlet particulate loading, ppmw

7. Particle size, microns, D50

8. Particle loading, lbs/hr

9. Candle filter data

Size O.D., mm

Size I.D., $\mathrm{mm}$

Length, $\mathbf{m}$

Material

10. Candle filter vessel design

Diameter, ft. O.D.

Height, ft.

Total candles needed

No. of candles per vessel

No. of vessels

No. of tiers

No. of candles per blowback cluster

Design face velocity, fpm

Flow, ACFM per vessel

\begin{tabular}{|c|c|c|}
\hline $\begin{array}{l}\text { KRW } \\
\text { IGCC } \\
\end{array}$ & $\begin{array}{c}\text { Foster Wheeler } \\
\text { Second } \\
\text { Generation } \\
\text { PFBC } \\
\end{array}$ & Carbonizer \\
\hline 458 & 453 & 453 \\
\hline 380 & 192 & 208 \\
\hline 1,015 & 1,600 & 1,500 \\
\hline $1,904,867$ & $5,288,600$ & 492,562 \\
\hline 57,507 & 343,721 & 31,811 \\
\hline 1,500 & 1,000 & 3,000 \\
\hline 1.2 & 2.1 & 1.6 \\
\hline 2,857 & 5,289 & 1,478 \\
\hline 60 & 60 & 60 \\
\hline 30 & 30 & 30 \\
\hline 1.5 & 1.5 & 1.5 \\
\hline $\mathrm{SiC}$ & $\mathrm{SiC}$ & $\mathrm{SiC}$ \\
\hline 16 & 16 & 16 \\
\hline 67 & 67 & 67 \\
\hline 3,978 & 11,888 & 2,272 \\
\hline 995 & 1,188 & 1,136 \\
\hline 4 & 10 & 2 \\
\hline 4 & 4 & 4 \\
\hline 62 & 74 & 71 \\
\hline 5 & 10 & 5 \\
\hline 14,377 & 34,372 & 15,906 \\
\hline
\end{tabular}

\subsection{SELECTION OF CONCEPTUAL DESIGN CASES}

Eight design cases have been chosen for evaluation. The rationale for these choices is discussed in this section. The selection was a combined effort of the project participants and was based on the results of work done under Tasks 1,2 and 3. 


\subsubsection{Pros and Cons of Potential Cleaning Techniques}

The three filter cleaning techniques under evaluation are:

- Conventional on-line, pulse-driven reverse flow using a blowback gas stored under pressure in a reservoir.

- Conventional off-line cleaning using shut-off valves to isolate the candle filter vessel during blowback. Blowback can be cold pulse or rapid combustion pulse.

- Novel rapid combustion pulse cleaning technique using a high temperature, high pressure combustion product as the cleaning fluid.

More detailed descriptions for each of these methods appear in Section 3.0. This section addresses only the aspects of pros and cons for each method which provided input for the conceptual design choices.

\subsubsection{On-line $400^{\circ} \mathrm{F}$ Pulse}

Pros: The strongest point in favor of this technique is its commercial availability and its operational experience (irrespective of success or failure). The associated hardware has been widely tested under various HTHP conditions and the basic operating data/information are much more readily available than any other method. Generic PFBC and IGCC operating points are reasonably well established and reported/described in the literature.

Cons: The major drawback of the conventional method is its apparent inability to prevent thermal shock from occurring when the relatively "cold" blowback gas passes through the hot candle filter element even for a very short period of time. The pressurized cleaning fluid is normally stored "cold" near the ambient condition since the control valve is typically designed for a maximum of only $400^{\circ} \mathrm{F}$. Although the temperature of the blowback gas (motive pulse gas plus entrained hot clean gas) may be made higher with a properly designed pulse tube, the mixed gas temperature is usually still several hundred degrees Fahrenheit below that of ceramic material. As a result, thermal shock inevitably occurs.

Another weak point of the conventional technique is that, due to its reliance on a quick acting valve (200-400 ms) for its blowback operation, there is insufficient time for the separated cake particles from falling off and away from the filter surface. The end effect is that a large fraction of the cake particles that are just blown off tend to redeposit again onto the filter surface, resulting in poor overall filter cleaning efficiency.

\subsubsection{Off-line $400^{\circ} \mathrm{F}$ Pulse}

Pros: The principle advantage of the off-line cleaning method is that it can provide an opportunity for the dust particles to fall to the bottom of the filter vessel thus improving filter cleaning efficiency and lowering compressor operating costs. A secondary advantage is that because additional vessels are needed this allows a filter to be off line for a lengthy period of time to remove difficult cakes formed during upset conditions.

Cons: If a $400^{\circ} \mathrm{F}$ blowback gas is used then thermal shock will occur as described in the previous system. A major disadvantage are the additional capital costs associated with the shut-off valves and the extra candle filters needed to prevent high face velocities to the other filters when the filter being cleaned is valved off. 


\subsubsection{Rapid Combustion Pulse}

Pros: Basically, the combustion-driven filter cleaning method generates its own cleaning fluid as required by combustion of a fuel with an oxidant. - The HTHP combustion product exits through a sonic orifice and is piped and manifolded to the individual filter tubes as in the conventional method. The advantages include: (1) the pulsed gas is at a high temperature thus eliminating thermal shock effects, (2) a high-temperature quick opening valve is not needed, (3) the pulse duration and peak pressure can be controlled by selecting a particular fuel and a suitably designed combustor, and (4) the composition of combustion production can be modified to produce either a reducing or oxidizing gas to suit the need of a given application (IGCC or PFBC); however, for short pulses, the difficulty in controlling precise amounts of fuel and oxidant for a reducing atmosphere is such that at this time it is not being considered for gasifiers.

Cons: While there are no serious limitations for the combustion-driven technique for producing a blowback pulse with the required temperature, pressure, and flow characteristics, the single pulse generated by the combustion technique may not be able to provide a sufficient reverse flow duration for the detached cake dust to fall to the bottom the filter vessel. In order to minimize the cake redeposition problem, more than one combustion pulse (or longer burning combustion process) may be necessary to achieve a high cake cleaning efficiency. The design of the combustor (initiated with spark plug ignition) may be more complicated for this case. This system, however, can be used with off-line cleaning eliminating this concern.

\subsection{SPREADSHEET MODELING RESULTS}

In Section 4 the complete spreadsheet data for Case 1 is presented and discussed. In addition, a summary of data for Cases 2 through 8 are provided in Tables 4.2-1, 4.2-2 and 4.2-3. The complete spreadsheets for all of the cases are in Appendix B. The information from the spreadsheets was used for the conceptual designs detailed in the following Section 5.4. Some of the spreadsheet data is repeated in the tables shown in Section 5.4 so that the data can be easily accessed and compared while reading the text.

\subsection{CONCEPTUAL DESIGN DETAILS}

In this section conceptual design details are presented for the three blowback techniques as used in the two power plants described in Section 5.1: second generation PFBC and an air blown fluidized bed gasifier. The conceptual designs include eight cases for comparison of the three blowback techniques providing necessary information for the economic assessment. Descriptions of each case are given including equipment size, process flow conditions and operating parameters. Process design data for the eight designs was provided by the model/spreadsheet described in Section 4.0. Summaries of the candle filter vessel designs and the blowback system designs for the eight cases are shown in Table 5.4-1 and 5.4-2. Figure 5.4-1 illustrates the filter design and Figures 5.4-2, 5.4-3 and 5.4-4 show typical blowback piping arrangements.

Before descriptions of each case are given some design criteria/philosophy will be discussed:

- The candle filter vessel is based on a Westinghouse design. Candles are attached to plenums which are blown back by a single pulse using compressed air or fuel gas stored in a reservoir. 
TABLE 5.4-1

CANDLE FILTER VESSEL DESIGN

\begin{tabular}{|c|c|c|c|c|c|c|c|c|}
\hline & \multicolumn{6}{|c|}{ FW Second Generation PFBC } & \multicolumn{2}{|c|}{ KRW Gasifier } \\
\hline & $\begin{array}{c}\text { Case } 1 \\
\text { CPFBC } \\
\text { Conv. }\end{array}$ & $\begin{array}{c}\text { Case } 2 \\
\text { CPFBC } \\
\text { Off-Line }\end{array}$ & $\begin{array}{c}\text { Case } 3 \\
\text { CPFBC } \\
\text { RP }\end{array}$ & $\begin{array}{c}\text { Case } 4 \\
\text { CPFBC } \\
\text { RP. } \\
\text { Off-Line }\end{array}$ & $\begin{array}{c}\text { Case } 5 \\
\text { Carbonizer } \\
\text { Conv. }\end{array}$ & $\begin{array}{c}\text { Case } 6 \\
\text { Carbonizer } \\
\text { Off-Line }\end{array}$ & $\begin{array}{l}\text { Case } 7 \\
\text { IGCC } \\
\text { Conv. }\end{array}$ & $\begin{array}{c}\text { Case } 8 \\
\text { IGCC } \\
\text { Off-Line }\end{array}$ \\
\hline Plant Size, MWe & 453 & 453 & 453 & 453 & 453 & 453 & 458 & 458 \\
\hline Flow Total, ACFM & 343,721 & 343,721 & 343,721 & 343,721 & 31,811 & 31,811 & 57,507 & 57,507 \\
\hline Filter Velocity, FPM & 10 & 10 & 10 & 10 & 5 & 5 & 5 & 5 \\
\hline Filter Vessel Diam., Ft. & 16 & 16 & 16 & 16 & 16 & 16 & 16 & 16 \\
\hline Filter Vessel Height, Ft. & 67 & 67 & 67 & 67 & 67 & 67 & 67 & 67 \\
\hline Number of Filter Vessels & 10 & 12 & 10 & 12 & 2 & 3 & 4 & 5 \\
\hline Candles per Vessel & 1,184 & 1,184 & 1,184 & 1,184 & 1,136 & 1,136 & 992 & 992 \\
\hline Candles per System & 11,840 & 14,208 & 11,840 & 14,208 & 2,272 & 3,408 & 3,968 & 4,960 \\
\hline Number of Tiers in Vessel & 4 & 4 & 4 & 4 & 4 & 4 & 4 & 4 \\
\hline Plenums per Tier & 4 & 4 & 4 & 4 & 4 & 4 & 4 & 4 \\
\hline Candles per Plenum & 74 & 74 & 74 & 74 & 71 & 71 & 62 & 62 \\
\hline Plenum Diam., In. & 49 & 49 & 49 & 49 & 48 & 48 & 46 & 46 \\
\hline Pulse Reservoirs Required per Vessel & 4 & 4 & 4 & 4 & 4 & 4 & 4 & 4 \\
\hline Number of HT Valves per System & 0 & 12 & 0 & 12 & 0 & 3 & 0 & 5 \\
\hline
\end{tabular}


TABLE 5.4-2

BLOWBACK SYSTEM DESIGN

\begin{tabular}{|c|c|c|c|c|c|c|c|c|}
\hline & \multicolumn{6}{|c|}{ FW Second Generation PFBC } & \multicolumn{2}{|c|}{ KRW Gasifier } \\
\hline & $\begin{array}{c}\text { Case } 1 \\
\text { CPFBC } \\
\text { Conv. }\end{array}$ & $\begin{array}{l}\text { Case } 2 \\
\text { CPFBC } \\
\text { Off-Line }\end{array}$ & $\begin{array}{c}\text { Case } 3 \\
\text { CPFBC } \\
\text { Rapid Comb. }\end{array}$ & $\begin{array}{c}\text { Case } 4 \\
\text { CPFBC } \\
\text { Rapid Comb. } \\
\text { Off-Line }\end{array}$ & $\begin{array}{c}\text { Case } 5 \\
\text { Carbonizer } \\
\text { Conv. }\end{array}$ & $\begin{array}{c}\text { Case } 6 \\
\text { Carbonizer } \\
\text { Off-Line }\end{array}$ & $\begin{array}{l}\text { Case } 7 \\
\text { IGCC } \\
\text { Conv. }\end{array}$ & $\begin{array}{c}\text { Case } 8 \\
\text { IGCC } \\
\text { Off-Line }\end{array}$ \\
\hline Dust Part Size, Micron & 2.1 & 2.1 & 2.1 & 2.1 & 1.6 & 1.6 & 1.2 & 1.2 \\
\hline Dust Loading, PPMW & 1,000 & 1,000 & 1,000 & 1,000 & 3,000 & 3,000 & 1,500 & 1,500 \\
\hline Reservoir Volume, FT ${ }^{3}$ & 25 & 25 & 11 & 11 & 24 & 24 & 55 & 55 \\
\hline Blowback Pressure, PSI & 729 & 727 & 450 & 450 & 769 & 767 & 1,094 & 1,090 \\
\hline Initial Res. Temp, ${ }^{\circ} \mathbf{F}$ & 389 & 388 & 1,600 & 1,600 & 393 & 393 & 400 & 389 \\
\hline Rapid Comb. Temp, ${ }^{\circ} \mathbf{F}$ & - & - & 3,540 & 3,540 & - & - & - & - \\
\hline Blowback Gas & Air & Air & Combustion Gas & Combustion Gas & Fuel Gas & Fuel Gas & Fuel Gąs & Fuel Gas \\
\hline Candles per Pulse & 74 & 74 & 74 & 74 & 71 & 71 & 62 & 62 \\
\hline Required Pulse Pressure in Candle, PSI & 194 & 194 & 194 & 194 & 212 & 212 & 384 & 384 \\
\hline Time Between Pulses, Min. & 60 & 90 & 60 & 90 & 60 & 90 & 40 & 60 \\
\hline Nozzle Gas per Pulse, lbs. & 10.2 & 10.2 & 5.9 & 5.9 & 11.5 & 11.4 & 15.0 & 15.1 \\
\hline Pulse Temp. at Candle Filter, ${ }^{\circ} \mathrm{F}$ & 510 & 510 & 1,500 & 1,500 & 350 & 350 & 390 & 380 \\
\hline Blowback Duration, Sec. & 0.7 & 0.7 & 0.055 & 0.055 & 1.2 & 1.2 & 1.0 & 1.0 \\
\hline Cleaning Efficiency, \% & 66.7 & 98.0 & 66.7 & 98.0 & 66.7 & 98.0 & 66.7 & 98.0 \\
\hline Specific Cake Resistance, K2 & 15.6 & 15.6 & 15.6 & 15.6 & 28.5 & 28.5 & 43.9 & 43.9 \\
\hline Rapid Comb. Fuel, lbs/pulse & - & - & 0.25 & 0.25 & - & - & - & - \\
\hline Rapid Comb. Air, lbs/pulse & - & - & 5.65 & 5.65 & - & - & - & - \\
\hline Compressor Requirements, Total, HP & 167 & 111 & 104 & 69 & 22 & 14 & 94 & 63 \\
\hline
\end{tabular}




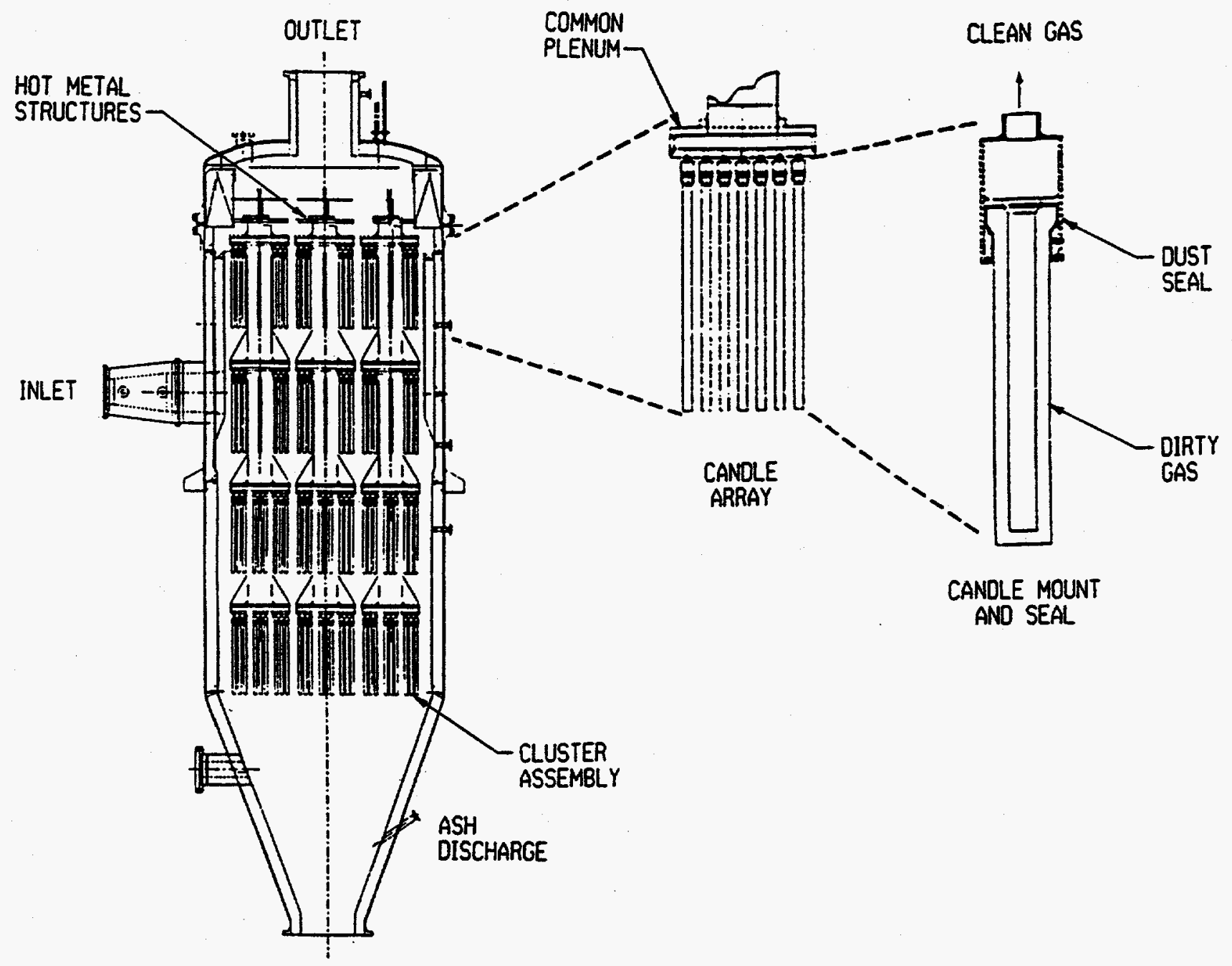

FILTER SYSTEM

Lippert, T.E., "Specific Filter Design for PFBC",

Coa1-Fired Power Systems-93. Advances for IGCC and PFBC

Review Meeting, Morgantown, WV, June 28, 1993

FIGURE 5.4-1

COMMERCIAL CANDLE FILTER DESIGN 


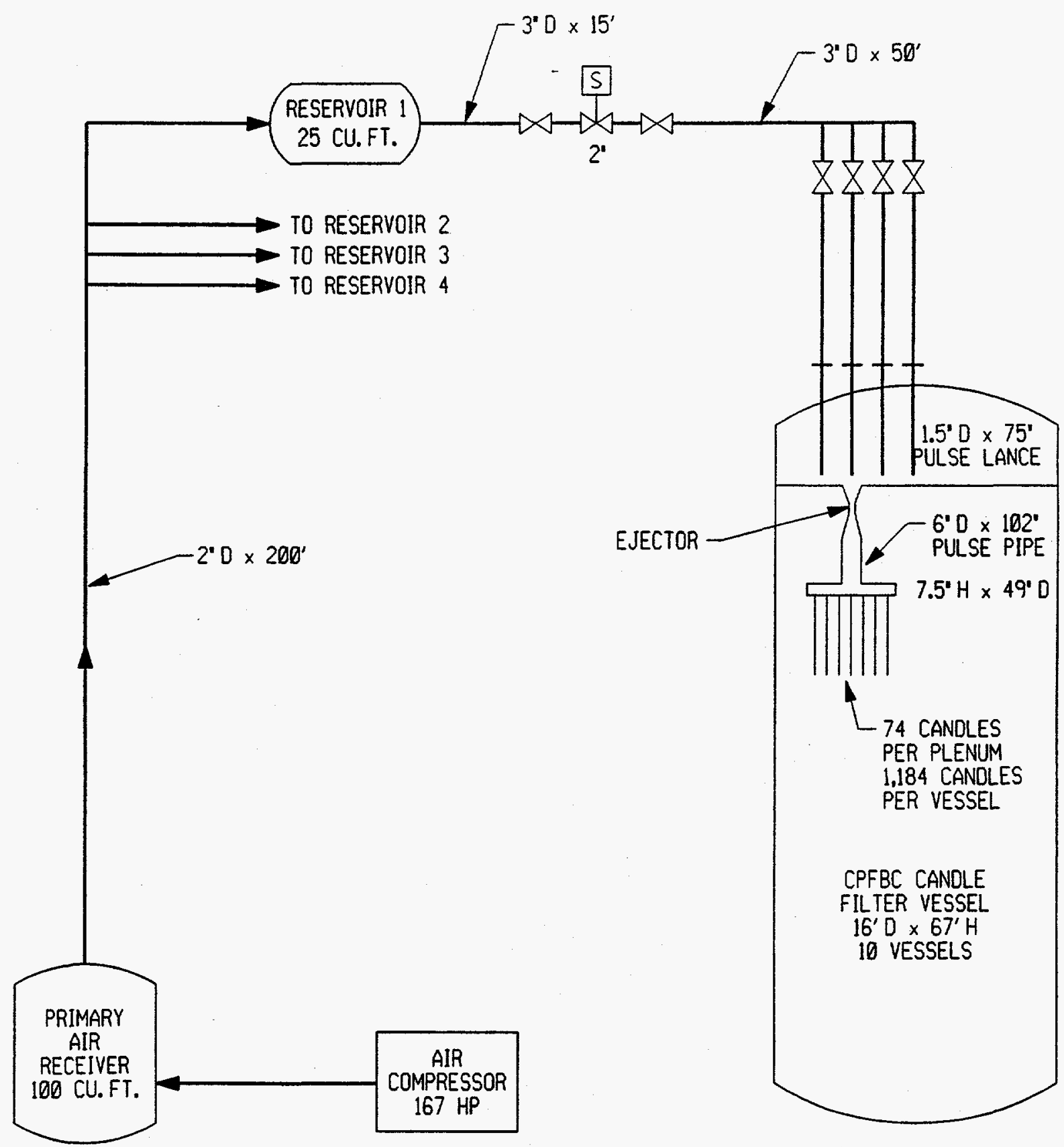

FICURE 5.4-2

CASE 1 BLOWBACK SYSTEM

CPFBC SIMPLIFIED SCHEMATIC 


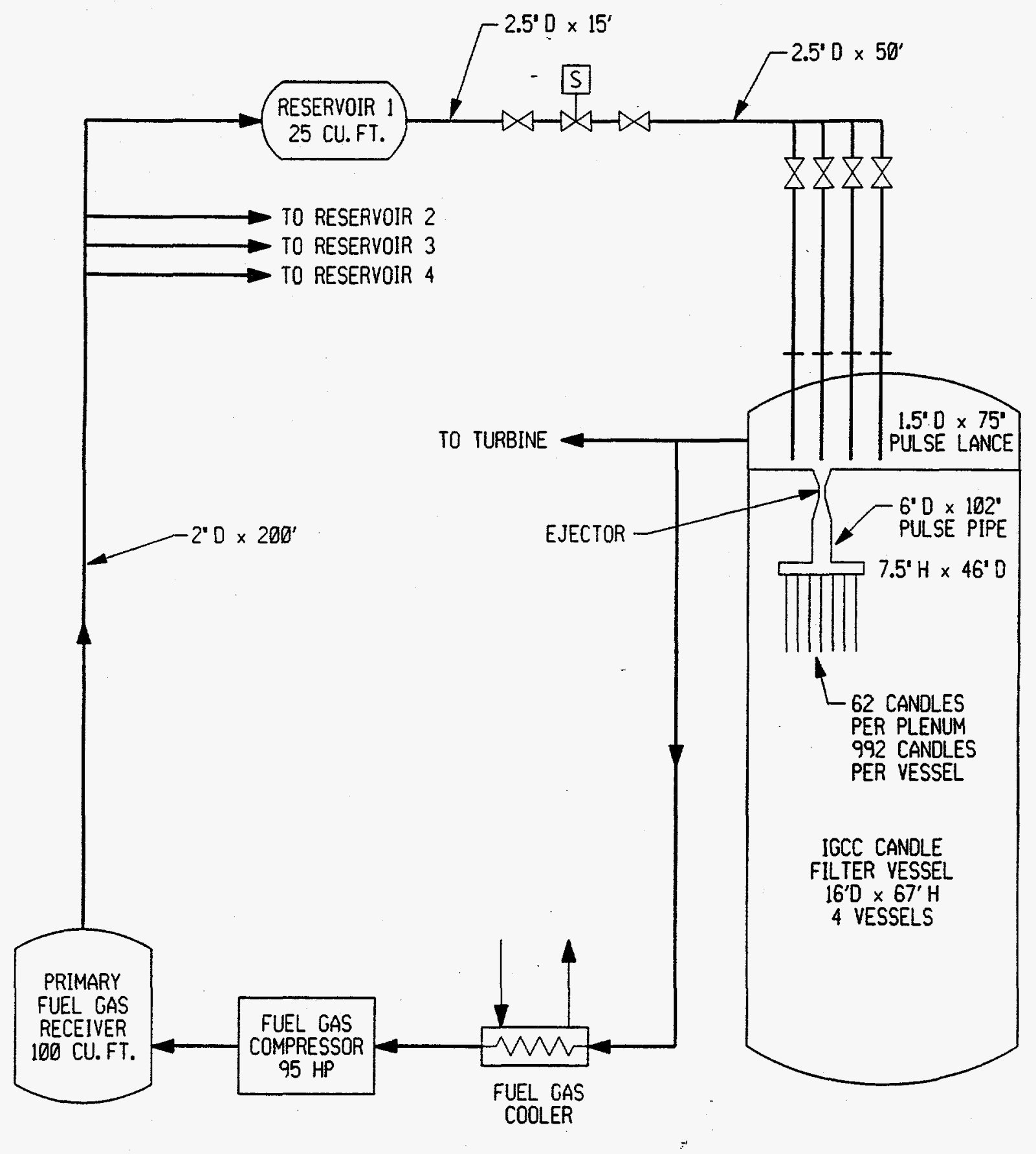

FIGURE $5.4-3$

CASE 7 BLOWBACK SYSTEM

IGCC SIMPLIFIED SCHEMATIC 


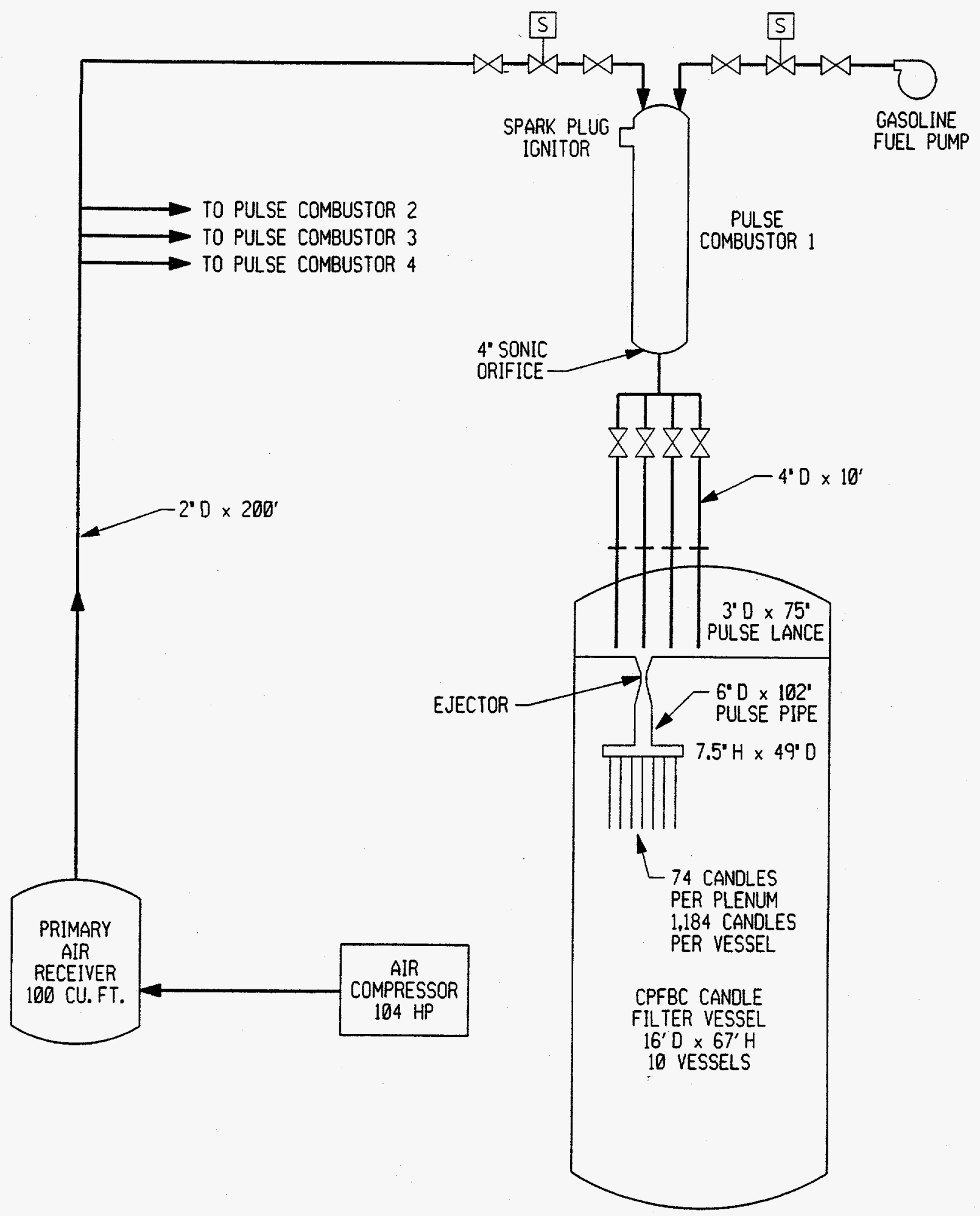

FIGURE $5.4-4$

CASE 3 BLOWBACK SYSTEM

CPFBC RAPID COMBUSTION PULSE 


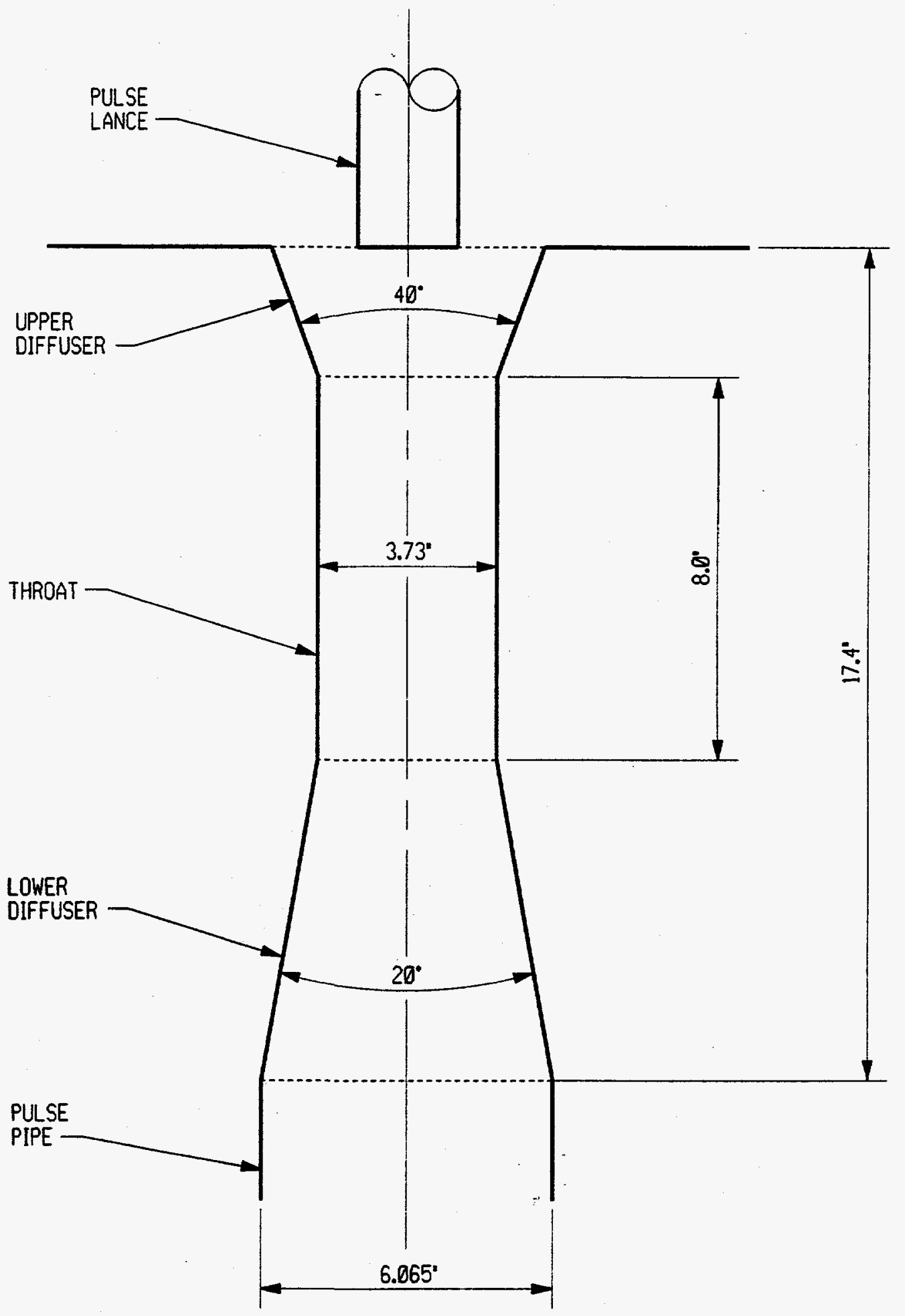

FIGURE 5.4-5

VENTURI DETAILS 
- To reduce the harmful effects of thermal shock it is desirable to blowback with the highest temperature gas as possible. With a $400^{\circ} \mathrm{F}$ temperature limitation on the currently availablé fast-acting valve it is not possible to entrain enough hot, clean gas to produce a blowback gas which is $100^{\circ} \mathrm{F}$ lower than operating temperature. As a result no effort was made to maximize the blowback gas temperature.

- The candle filter vessels for the eight cases are the same size, $16 \mathrm{ft} . \mathrm{D} \times 67 \mathrm{ft} . \mathrm{H}$, and have the same number of tiers and clusters. The different power plant flows are accommodated by the number of vessels and somewhat by the number of candles per vessel. This was done to simplify the process design for blowback requirements and also to lessen the amount of effort to cost the vessels.

- Reasonable face velocities were chosen to size the filter vessels based on published reports: $10 \mathrm{fpm}$ for the PFBC and $5 \mathrm{fpm}$ for the gasifier and carbonizer.

- A difference from the Westinghouse design is that the assumed design blowback reservoirs are larger in capacity. At Tidd a $4 \mathrm{ft}^{3}$ vessel is used to blowback 38 candles. For Case $1 \mathrm{a}$ $25 \mathrm{ft}^{3}$ vessel is used for blowing back 74 candles. The larger vessels were designed to lower the required blowback pressure.

- Compressor horsepower requirements, as calculated in the model, were not rounded off to reasonable numbers because this study is concerned more with system comparisons rather than detailed design of equipment.

\subsubsection{Case 1 - FW CPFBC with On-line Conventional Blowback}

This is essentially a base case since it is the only blowback system that has been used at what can be considered a commercial size. For the $453 \mathrm{MWe}$ power plant, ten candle filter vessels were required using a $10 \mathrm{fpm}$ design. This is a reasonable face velocity assuming a cake specific resistance of 15.6 (in.w)/(fpm) $/\left(\mathrm{lb} / \mathrm{ft}^{2}\right)$. In practice the face velocity would be based on actual cake properties determined by accepted standards. The dust loading to the filter is $1,000 \mathrm{ppmw}$. Cyclones precede the candle filter.

The reservoir blowback pressure required to blow off the cake every 60 minutes is 729 psi as calculated using spreadsheet. The blowback pressure is very sensitive to the hardware between the reservoir and the candle filter. Because the filter designed by Westinghouse for the Tidd facility has had the most operating experience this design was used as a basis for input to the G/C spreadsheet. Table 4.2-2 in Section 4.0 summarizes the pipe arrangements from the reservoir to the candle for all the eight cases. For Case 1 the design is as follows:

\author{
Reservoir capacity \\ Pipe to Atkomatic valve \\ Atkomatic valve \\ Valve to pulse lance \\ Pulse lance \\ Ejector/venturi \\ Pulse pipe \\ Plenum \\ Number of candles in plenum
}

$$
\begin{aligned}
& 25 \mathrm{ft}^{3} \\
& 3^{\prime \prime} \mathrm{D} \text {., Schedule } 80,15 \mathrm{ft} \text {. long } \\
& 2^{\prime \prime D} \text {. } \\
& 3^{\prime \prime} \mathrm{D} \text {., Sched. } 80,50 \mathrm{ft} \text {. long } \\
& 1.5^{\prime \prime} \mathrm{D} \text {., Sched. } 40,75^{\prime \prime} \text { long } \\
& 17.4^{\prime \prime} \text { long, 3.73" I.D. } \\
& 6^{\prime \prime} \mathrm{D} \text {., Sched. 40, } 102^{n} \text { long } \\
& 7.5^{\prime \prime} \text { high, } 49^{\prime \prime} \text { Diam. } \\
& 74
\end{aligned}
$$

Figure 5.4-2 shows the piping arrangement and 5.4-5 is a detail sketch of the venturi. Compressed air at $400^{\circ} \mathrm{F}$ is supplied to the reservoir by a reciprocating compressor with intercoolers. Brake horsepower required is 167 . 
When the trigger pressure is reached in the plenum, the atkomatic valve is opened and the candles are blown back with $10.2 \mathrm{lb}$ of air in a time frame of $700 \mathrm{~ms}$. According to the model the cake is blown off in $500 \mathrm{~ms}$.

In order to lessen the amount of re-attachment the candles are blown back starting with the top tier and in sequence until the 16 plenums in the vessel are cleaned.

During the blowback the reservoir pressure drops from 729 to 558 psi which is a conservative design for the reservoir volume. Simultaneously the blowback gas temperature drops from $389^{\circ} \mathrm{F}$ to $328^{\circ} \mathrm{F}$ in the reservoir. The motive gas at the ejector entrains hot, clean gas at a rate of $11 \%$ producing a blowback gas temperature in the candle of $510^{\circ} \mathrm{F}$. From a thermal shock standpoint this is not a desirable condition; however, no amount of entrainment would alleviate this. The limiting factor is that the reservoir gas temperature cannot be higher than $400^{\circ} \mathrm{F}$ because the fast acting Atkomatic valve has a maximum design temperature of $400^{\circ} \mathrm{F}$. Until a higher temperature fast acting valve is available the potential for candle filter damage due to thermal shock will be a drawback for this blowback system.

The total amount of blowback air is $1,631 \mathrm{lb} / \mathrm{hr}$. This is an insignificant amount when compared to the total flue gas flow of $5,288,600 \mathrm{lb} / \mathrm{hr}$; therefore, the dilution effect can be ignored.

\subsubsection{Case 2 - FW CPFBC with Off-line Conventional Blowback}

Referring to Tables 5.3-1 and 5.3-2 Case 2 design is identical to Case 1 except for the following:

- Twelve candle filter vessels are required instead of ten for Case 1.

- Twelve filter vessel shut-off valves are required to isolate the filters during blowback.

- The time between pulses for Case 2 is 90 minutes versus 60 minutes for Case 1.

- $\quad$ The cleaning efficiency for Case 2 is $98 \%$ versus $66.7 \%$ for Case 1 .

- Horsepower requirement for Case 2 is 111 versus 167 for Case 1.

As discussed in Section 3.2, the main advantage of off-line cleaning is that dust particles have sufficient time to fall to the bottom of the filter vessel before re-depositing. It is assumed for this design that the cleaning efficiency could reach $98 \%$. With this assumption the time between pulses increases to 90 minutes resulting in lower blowback air consumption and therefore lower compressor horsepower.

There is another possible off-line cleaning advantage that could increase time between pulses. During on-line cleaning the particles that re-deposit first are smaller than the mean particle size. Smaller particles produce a cake which will either penetrate the candle filter or form a cake with a higher pressure drop. Off-line blowback would prevent the re-deposition of fine particles and, potentially, result in a lower pressure drop cake and longer times between blowback. When blowing back with cold gases this would mean less thermal shock.

What is unknown at this time is the amount of time needed to allow $98 \%$ cleaning efficiency. There is no quantitative data on the mean particle size of dust blown off of a candle filter. Some reports state that the dust falls off in sheets or flakes. Some photos shown a rapid disintegration. Samples of particles taken from filter vessels are invariably less than ten microns which would have terminal velocities so slow that a significant amount of settling time, perhaps 15 minutes, would be needed. The fact that on-line filter cleaning is effective in actual practice indicates that the dust blown off must have a mean agglomerate size of at least 200 microns. 
The costs of the two additional filter vessels and the shut-off valves are evaluated in Section 6.0. The valves could be either butterfly valves or slide gate valves. Three manufacturers of high

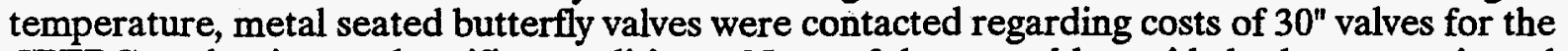
CPFBC, carbonizer and gasifier conditions. None of them would provide budget costs since the valves would be custom designed because their standard designs were not suitable. While it has not been established that valves are commercially available for the power plant conditions, it is assumed that they could be designed and fabricated and would function satisfactorily as filter véssel shut-off valves.

As in Case 1, the potential for thermal shock damage to the candle filters is present, and, because the filter vessel is off-line for larger periods, additional cooling will occur. This has not been quantified.

\subsubsection{Case 3 - FW CPFBC with On-line Rapid Combustion Pulse Blowback}

For Case 3 the spreadsheet was not used for the blowback system design. DOE METC was given data and based on this sized the combustor vessel, the sonic orifice and downstream piping. In Appendix B there are Case 3 and Case 4 spreadsheet designs for a hypothetical rapid combustor that would be needed for a system containing blowback hardware similar to Case 1 . The pressure needed for these cases cannot be attained with the combustor as designed by DOE METC; therefore, the DOE design will be described. The candle filter vessel design however is the same as for Case 1, and the number of vessels needed, ten, is also the same.

The rapid combustion blowback system is unique and has not yet been tested at any scale. As proposed for this case the combustion vessel is a refractory lined vessel $20 \mathrm{ft}$. long with a $10^{\text {"t I.D. }}$ $\left(11 \mathrm{ft}^{3}\right.$ in volume). At one end are inlets for gasoline injection and combustion air. At the opposite end is a $4^{\mathrm{H} D} \mathrm{D}$ sonic orifice fabricated of Tungsten. Ignition is started with a spark plug.

When the filter trigger pressure is reached, $0.25 \mathrm{lbs}$. of gasoline is injected into the combustor along with a measured amount of air. The gasoline is combusted rapidly. In the first $20 \mathrm{~ms}$ the required pressure for blowback, $450 \mathrm{psi}$, is reached. This pressure is sustained for $35 \mathrm{~ms}$ and $5.9 \mathrm{lbs}$ of pulse air is discharged to the candle filter plenum. In order to reduce friction losses and maintain sonic velocity a 4 " pipe goes from the sonic orifice to a manifold outside of the vessel. The pipe diameter is reduced to $3^{\prime \prime}$ inside the filter vessel and it is this pulse lance which provides the required momentum to the candle plenum. After the pulse the combustor pressure is equalized with clean gas from the filter vessel. There is no fast acting valve at the combustor but each pulse lance has a ball valve which is opened prior to a pulse. Refer to Figure 5.4-3 for the piping arrangement.

The ignition temperature of the combustion gas is $3,540^{\circ} \mathrm{F}$ which generates the pressure. Since this gas is hot enough to eliminate any chance of thermal shock, there is no need for an ejector in the candle plenum. The actual temperature of the blowback gas at the candle filter has not been determined. It may be too hot in which case the system design must allow for cooling the motive gas.

Except for the sonic orifice, which is fabricated from tungsten, the combustor, fuel pump/injector and air compressor are commercial items and not technical drawbacks. Precise feed control of the fuel and air into the combustor may require fast acting valves and a sophisticated control system. There is a limitation on the maximum pressure achievable in the combustor which at this time is estimated to be three times operating pressure. For gasifiers it may be possible to use this system but it would require different arrangements not yet resolved. As a result, for this study, it is being used only in the CPFBC. 


\subsubsection{Case 4 - FW CPFBC with Off-line Rapid Combustion Pulse Blowback}

If technically and economically feasible Case 4 provides the optimum blowback system. The rapid combustion pulse eliminates candle filter thermal-shock damage and off-line cleaning achieves the highest cleaning efficiency. Since the G/C spreadsheet could not be used for process design data, all of the effects of the increase in efficiency on operating costs for off-line cleaning could not be determined quantitatively; however, based on Case 2 costs versus Case 1 similar reductions could be expected. Increased capital costs for two extra filter vessels and 12 shut-off valves are determined in Section 6.0 along with the reduced amount of fuel and air costs because of longer times between pulses. As in Case 2 a $98 \%$ cleaning efficiency is assumed.

The blowback technique is the same as for Case 3. At trigger pressure, gasoline is injected into the combustor and ignited to produce a predetermined amount of pulse gas, in this case $5.9 \mathrm{lbs}$. Candle plenums are blown back in sequence from the top tier to the bottom. The blowback cycle time will depend on the time needed for the particles to settle, approximately 8 to 12 minutes.

\subsubsection{Case 5 - FW Carbonizer with On-line Conventional Blowback}

The FW carbonizer produces a low Btu fuel gas which is highly reactive therefore compressed air cannot be used for cleaning the candle filters. Either nitrogen or recycled clean fuel gas are options but for this design fuel gas is used. A slip stream of clean gas is cooled and then compressed to the required blowback pressure. From the blowback reservoir the blowback system hardware is identical to that described in Cases 1 through 4.

The particulates leaving the carbonizer are different than CPFBC particulates and this has an effect on the candle filter design and blowback requirements. The mean particle size is smaller, 1.6 microns, and the cake specific resistance is 28.5 (in.w) $/(\mathrm{fpm}) /\left(\mathrm{lb} / \mathrm{ft}^{2}\right)$, twice that of CPFBC cake. Dust loading entering the filter vessel is $3,000 \mathrm{ppmw}$ which results in a blowback time between pulses of 60 minutes.

A filter face velocity of $5 \mathrm{fpm}$ was arbitrarily chosen. This is a reasonable face velocity for a gasifier particulate filter. Two filter vessels are needed with four tiers of candles and four candle clusters per tier.

The blowback system consists of a $24 \mathrm{ft}^{3}$ reservoir which contains fuel gas compressed to 769 psi, a $2^{\prime \prime} \mathrm{D}$ fast acting valve, $2.5^{\prime \prime} \mathrm{D}$ pipe from the reservoir to the filter vessel, a $1.5^{\prime \prime} \mathrm{D}$ pulse lance and a candle plenum containing 71 candles. The fuel gas compressor requirement is $22 \mathrm{Hp}$. Each pulse requires $11.5 \mathrm{lbs}$ of fuel gas but this is recycled not consumed. Cleaning efficiency is $66.7 \%$ and the plenums are blown back in sequence from top tier to bottom tier. The blowback gas temperature at the candle is $350^{\circ} \mathrm{F}$ presenting a thermal shock problem unavoidable for this system because of the fast acting valve temperature limitations of $400^{\circ} \mathrm{F}$.

\subsubsection{Case 6 - FW Carbonizer with Off-line Conventional Blowback}

For off-line cleaning an additional filter vessel is required ( 3 total) and 30" shut-off valves for each filter vessel. The blowback system described for Case 5 is the same except that a smaller compressor is needed, $14 \mathrm{Hp}$ versus $22 \mathrm{Hp}$ for Case 5.

Off-line cleaning will increase the cleaning efficiency from $66.7 \%$ to $98 \%$ and the blowback time between pulses is now 90 minutes as compared to 60 minutes for Case 5 . Thermal shock is still likely since the blowback gas temperature at the candle is $350^{\circ} \mathrm{F}$. 


\subsubsection{Case 7 - KRW IGCC with On-line Conventional Blowback}

An important input to the $G / C$ spreadsheet is the cake specific resistance. For the CPFBC it is 15.6 (in.w) $/(\mathrm{fpm}) /(\mathrm{lb} / \mathrm{ft} 2)$ and this is considered reasonable. The carbonizer cake is double this, 28.5 , and again there is confidence in using this. For the gasifier, however, the specific resistance has been reported as high as ten times that of CPFBC. For comparing on-line versus off-line blowback this does not present a problem, but, for an absolute cost of blowback, the specific resistance becomes important.

An arbitrary choice of 43.9, three times that of CPFBC, was made for gasifier Cases 7 and 8 . This has still resulted in the highest blowback pressure of the eight cases, 1,094 psi, and the shortest time between pulses.

Referring to Tables 5.4-1 and 5.4-2 the filter system consists of 4 filter vessels operating at a face velocity of $5 \mathrm{fpm}$. Inlet loading is $1,500 \mathrm{ppmw}$ and mean particle size is 1.2 microns. Figure $5.4-4$ shows the piping arrangement.

Similar to the carbonizer system, clean fuel gas is cooled then compressed and stored in the blowback reservoir until needed. Reservoir size is $55 \mathrm{ft}^{3}$ double that of the CPFBC reservoir in order to keep the reservoir pressure below 1000 psig. Pipe size is $2.5^{\prime \prime} \mathrm{D}$ from the reservoir to the filter, the pulse lance is $1.5^{\mathrm{m}} \mathrm{D}$ and the candle plenum holds 62 candles. Blowback pressure is 1,094 psia and time between pulses is 40 minutes. $15 \mathrm{lbs}$ of fuel gas is used per pulse. As with the other on-line systems, the cleaning efficiency is $66.7 \%$. Fuel gas compressor requirement is $94 \mathrm{Hp}$, relatively high because of the pulse pressure and quantity needed for blowback.

Thermal shock remains a potential problem since the blowback gas temperature is $390^{\circ} \mathrm{F}$.

\subsubsection{Case 8 - KRW IGCC with Off-line Conventional Blowback}

Case 8 off-line cleaning requires five filter vessels instead of four. The blowback hardware and pressure/volume requirements are the same as for Case 7. Time between blowback pulses increases from 40 to 60 minutes and compressor horsepower is reduced from 94 to 63 . An assumed $98 \%$ cleaning efficiency is used for spreadsheet calculations.

Gasifier particles are smaller and tend to be more irregular. They may take longer to settle but this is not known. Very little data is available concerning filtration of gasifier particulates at the temperature and pressure conditions used for this study. In any case, the time required to settle $98 \%$ of the particles does not have an effect on costs. The only impact might be a longer time for the candles to cool and perhaps suffer thermal shock damage. The blowback gas temperature is $380^{\circ} \mathrm{F}$ similar to on-line cleaning.

\subsection{CONCLUSIONS}

During the selection of the design cases and subsequently the conceptual designs several observations become apparent:

- Thermal shock

Conventional on-line and off-line cold pulse blowback systems clean the filters with about $400^{\circ} \mathrm{F}$ air or gas. This is well below 100 less than operating temperature which is required to prevent thermal shock. Only the rapid combustion pulse system satisfies this requirement. 
- Ancillary Equipment

The conventional systems use equipment that is commercial. The fast acting valve may be considered developmental especially if a larger valve is desired. A larger valve would decrease pressure drop and therefore blowback reservoir pressure requirements. For the carbonizer and gasifier, fuel gas must be cooled and recompressed but, again, the heat exchangers and compressors are standard equipment.

The rapid combustion system, on the other hand, is, at this time, only a concept. While somewhat similar combustion systems have been built and operated none were designed to deliver a precise amount of gas at a certain temperature, pressure and flow rate. A significant amount of test work will be needed before this concept can be considered commercial. The work will include fuel selection, fuel and oxidant feed control, firing mechanism and sonic orifice design.

- Dilution Effects on the Process Gas

The carbonizer and gasifier systems use recycled fuel gas therefore do not suffer a blowdown dilution effect. The other systems using compressed air use such small amounts dilution is not a concern. The amounts shown in Table 5.4-2 are for blowback cycles of 60 minutes but even if the blowback cycle was reduced to an unlikely ten minutes dilution would not be a factor to be concerned about.

- On-line versus Off-line Cleaning

At best off-line cleaning would increase cleaning efficiency from $67 \%$ to $98 \%$. Operating costs would drop but not enough to be significant based on compressor horsepower requirements. The additional vessels and shut-off valves needed will add what may be prohibitive capital costs that may not be justified by lower operating costs or longer candle life due to less pulsing. Comparative costs are discussed specifically in the cost section of this report.

As has been mentioned previously, the efficient separation of particulates from the gas stream depends on how fast particles fall to the bottom of the filter vessel after blow back. Attempts should be made to see if the particles/cake can be altered with an additive so that they are blown off as large flakes, sheets or agglomerates without making the cake too "sticky" to be blown off with a reasonable pressure differential. Alternately, the candle filter itself might be designed to promote discharge of the cake as a sheet or large agglomerates.

- Feasibility

At this period in the development of blowback systems for CPFBC and gasifier environments, feasibility rather than comparative costs may be the determining factor for choosing one system over another. This is because capital costs and operating costs based on these conceptual designs will not vary much between the eight cases except for on-line versus off-line comparisons. The feasibility of even the conventional system being tested at Tidd has not been demonstrated for long term periods especially the effect of the low temperature blowback on candle filter stability. There is even less experience for systems tested under gasifier conditions at high temperature and pressure. 


\subsection{ECONOMIC ANALYSIS}

The economics of the ceramic barrier filter hot gas cleanup (HGCU) systems were developed on the basis of consistently defining the capital and operating costs and then performing an economic analysis based on the incremental cost of electricity (COE) as the figure of merit. The conceptual cost estimate was determined on the basis of system scope as described in Section 5.0, equipment quotes, the PFBC reference plant, and inhouse cost data.

Table 6.1 Itemizes the Total Plant Cost (TPC) and the component COE costs for each of the eight estimated cases. Cases 1 - 4 represent HGCU systems as applied to Circulating Pressurized Fluidized Bed Combustors, cases 5 - 8 represent HGCU systems applied to carbonizers and gasifiers. The face velocities for these applications as well as particle loading determine the number of vessels required for each system. As shown in Table 6.1, the COE of the systems with similar applications are equivalent. As expected, the cases with off-line cleaning are slightly higher than the same system with on-line cleaning, since additional vessels are required. All but cases 7 and 8 have the same working pressure so the TPC is equivalent on a cost per vessel level. Cases 7 and 8 have a higher working pressure, more costly vessels, thus a higher TPC's on a per vessel basis. The cost difference between the $1500^{\circ} \mathrm{F}$ and $400^{\circ} \mathrm{F}$ pulse on-line cleaning technique is negligible. Technical feasibility and not cost will determine which is used.

Table 6.1

HGCU SYSTEMS COST SUMMARY

\begin{tabular}{|c|c|c|c|c|c|c|c|c|}
\hline & $\begin{array}{c}\text { Case } 1 \\
\text { PFBC } \\
400^{\circ} \mathrm{F} \\
\text { Pulse } \\
\text { On-Line }\end{array}$ & $\begin{array}{c}\text { Case } 2 \\
\text { PFBC } \\
400^{\circ} \mathrm{F} \\
\text { Pulse } \\
\text { Off-Line }\end{array}$ & $\begin{array}{c}\text { Case } 3 \\
\text { PFBC } \\
1500^{\circ} \mathrm{F} \\
\text { Pulse } \\
\text { On-Line }\end{array}$ & $\begin{array}{c}\text { Case } 4 \\
\text { PFBC } \\
1500^{\circ} \mathrm{F} \\
\text { Pulse } \\
\text { Off-Line }\end{array}$ & $\begin{array}{c}\text { Case } 5 \\
\text { Carbonizer } \\
400^{\circ} \mathrm{F} \\
\text { Pulse } \\
\text { On-Line }\end{array}$ & $\begin{array}{c}\text { Case } 6 \\
\text { Carbonizer } \\
400^{\circ} \mathrm{F} \\
\text { Pulse } \\
\text { Off-Line }\end{array}$ & $\begin{array}{c}\text { Case } 7 \\
\text { IGCC } \\
400^{\circ} \mathrm{F} \\
\text { Pulse } \\
\text { On-Line }\end{array}$ & $\begin{array}{c}\text { Case } 8 \\
\text { IGCC } \\
400^{\circ} \mathrm{F} \\
\text { Pulse } \\
\text { Off-Line }\end{array}$ \\
\hline MW & 453 & 453 & 453 & 453 & 453 & 453 & 458 & 458 \\
\hline TPC - $\$ / \mathrm{kW}$ & 132.7 & 158.3 & 130.8 & 157.5 & 26.5 & 39.1 & 62.1 & 75.6 \\
\hline \# of Vessels & 10 & 12 & 10 & 12 & 2 & 3 & 4 & 5 \\
\hline TPC/Vessel & 13.3 & 13.2 & 13.1 & 13.1 & 13.3 & 13.0 & 15.5 & 15.1 \\
\hline $\begin{array}{l}\text { Fixed O\&M - } \\
\text { mills/kWh }\end{array}$ & 1.6 & 1.9 & 1.6 & 1.9 & 0.5 & 0.6 & 0.8 & 1.0 \\
\hline $\begin{array}{l}\text { Variable O\&M } \\
\text { mills/kWh }\end{array}$ & 0.9 & 1.0 & 0.9 & 1.0 & 0.2 & 0.3 & 0.4 & .5 \\
\hline $\begin{array}{l}\text { Carrying } \\
\text { Charge } \\
\text { mills/kWh }\end{array}$ & 4.1 & 4.8 & 4.0 & 4.8 & 0.8 & 1.2 & 1.9 & 2.3 \\
\hline $\begin{array}{l}\mathrm{COE}^{(1)} \\
\text { mills/kWh }\end{array}$ & 6.5 & 7.7 & 6.5 & 7.7 & 1.5 & 2.1 & 3.2 & 3.8 \\
\hline
\end{tabular}

(1) No consumables were large enough to be recognized on a unit cost basis, although the costs are included in the annual costs. No fuel cost difference was recognized. 
The cost of the ceramic barrier filter system for the advanced PFBC plant is about 2.5 times the cost for the IGCC plant. The PFBC plant requires two filter systems, one for the combustor and * one for the carbonizer, and has a much higher gas volume. The cost of the cleanup system as compared to the total plant cost, however, is small, 10-12\% for the advanced PFBC and 4-5\% for the IGCC.

The emphasis of this effort was placed on obtaining good cost results at the TPC level for the HGCU systems. To highlight the cost of the HGCU systems, the battery limits of the estimate are from the inlet piping of the filter vessels to the inlet of the ash coolers. The capital costs at the Total Plant Cost (TPC) level include equipment, materials, labor, indirect construction costs, engineering and contingencies. Table 6.2 lists the TPC components and Appendix $C$ contains the Total Plant Cost Summary Sheets.

Table 6.2

TOTAL PLANT COST COMPARISON M\$

\begin{tabular}{|l|c|c|c|c|c|c|c|c|}
\hline & $\begin{array}{c}\text { Case 1 } \\
\text { PFBC } \\
400^{\circ} \mathrm{F} \\
\text { Pulse } \\
\text { On-Line }\end{array}$ & $\begin{array}{c}\text { Case 2 } \\
\text { PFBC } \\
400^{\circ} \mathrm{F} \\
\text { Pulse } \\
\text { Off-Line }\end{array}$ & $\begin{array}{c}\text { Case 3 } \\
\text { PFBC } \\
1500^{\circ} \mathrm{F} \\
\text { Pulse } \\
\text { On-Line }\end{array}$ & $\begin{array}{c}\text { Case 4 } \\
\text { PFBC } \\
1500^{\circ} \mathrm{F} \\
\text { Pulse } \\
\text { Off-Line }\end{array}$ & $\begin{array}{c}\text { Case 5 } \\
\text { Carbonizer } \\
400^{\circ} \mathrm{F} \\
\text { Pulse } \\
\text { On-Line }\end{array}$ & $\begin{array}{c}\text { Case 6 } \\
\text { Carbonizer } \\
400^{\circ} \mathrm{F} \\
\text { Pulse } \\
\text { Off-Line }\end{array}$ & $\begin{array}{c}\text { Case 7 } \\
\text { IGCC } \\
400^{\circ} \mathrm{F} \\
\text { Pulse } \\
\text { On-Line }\end{array}$ & $\begin{array}{c}\text { Case 8 } \\
\text { IGCC } \\
400^{\circ} \mathrm{F} \\
\text { Pulse } \\
\text { Off-Line }\end{array}$ \\
\hline Filter Vessel & 45.1 & 54.1 & 45.1 & 54.1 & 8.5 & 12.8 & 20.4 & 25.5 \\
\hline $\begin{array}{l}\text { Hot Gas } \\
\text { Piping }\end{array}$ & 0.9 & 2.5 & 0.9 & 2.5 & 0.1 & 0.6 & 0.3 & 1.0 \\
\hline $\begin{array}{l}\text { Blow Back } \\
\text { System }\end{array}$ & 3.2 & 3.5 & 3.4 & 4.0 & 1.2 & 1.6 & 3.3 & 3.3 \\
\hline Ash Handling & 6.0 & 7.2 & 6.0 & 7.2 & 1.2 & 1.8 & 2.4 & 3.0 \\
\hline Electrical & 4.9 & 4.3 & 3.8 & 3.4 & 1.0 & 1.0 & 2.0 & 1.8 \\
\hline TPC & 60.1 & 71.7 & 59.3 & 71.3 & 12.0 & 17.7 & 28.4 & 34.6 \\
\hline
\end{tabular}

The cost driver of the TPC are the vessel costs. The vessel costs represents approximately $75 \%$ of the total plant cost. Thus a HGCU system configuration for on-line cleaning is less costly than the same application with off-line cleaning. The blow back systems including gas compression represent a small percentage of the total system cost.

Operation and maintenance (O\&M) cost values were determined on a first year basis and subsequently levelized over the 30 year plant life to form a part of the economic analysis. Consumables were evaluated on the basis of the quantity required, operation cost was determined on the basis of the number of operators, and maintenance was evaluated on the basis of maintenance costs required for each major plant section. These operating costs were then converted to unit values of $\$ / \mathrm{kW}$-yr or mills $/ \mathrm{kWh}$.

The capital and operating costs of the plant are combined with plant performance in the comprehensive evaluation of cost of electricity(COE). 
In summary, the following economic assumptions were made:

- Plant book life is 30 years

- Capacity factor is 65 percent

- Plant inservice date is January 1995

- COE determined on a levelized, current dollar basis

- COE methodology was based on EPRI TAG methodology

\subsection{METHODOLOGY}

This section describes the approach, basis, and methods that were used to perform capital and operating cost evaluations of the HGCU system. Included in this section are descriptions of the capital costs, the operating cost and expenses, and the economic evaluation.

The capital costs, operating costs, and expenses were established consistent with EPRI Technical Assessment Guide (TAG) methodology and the plant scope identified in Section 6.0. The cost of each component was quantitatively developed to enhance credibility and establish a basis for subsequent comparisons and modification as the technology is further developed.

- Total plant cost values are expressed in December 1994 dollars.

- The estimates represent mature technology plant, or " ${ }^{\text {th }}$ plant" (i.e., it does not include costs associated with a first-of-a-kind plant).

- The estimate represent HGCU systems from the filter vessel inlet to the ash cooler inlet..

Site is located within the Ohio River Valley, southwestern Pennsylvania/eastern Ohio, but not specifically sited within the region except that it is considered to be located on a major navigable water way.

- Terms used in connection with the estimate are consistent with the EPRI TAG.

- The basis for equipment, materials, and labor costing is described in Section 6.2.

- Design engineering services, including construction management and contingencies basis, are examined in Section 6.2.2.

- The operating and maintenance expenses and consumables costs were developed on a quantitative basis.

- The operating labor cost was determined on the basis of the number of operators required.

- The maintenance cost was evaluated on the basis of relationships of maintenance cost to initial capital cost.

- The cost of consumables, including fuel, was determined on the basis of individual rates of consumption, the unit cost of each consumable, and the plant annual operating hours.

- The by-product credit for the gypsum is considered to be zero. 
Each of these expenses and costs is determined on a first-year basis and subsequently levelized over the life of the plant through application of a levelizing factor to determine the value that forms a part of the economic evaluation. This amount when combined with fuel cost and capital charges results in the figure of merit, $\mathrm{COE}$.

\subsection{CAPITAL COSTS}

The capital cost, specifically referred to as Total Plant Cost (TPC) for the HGCU system, was estimated using the EPRI structure. The major components of TPC consist of bare erected cost, engineering and home office overheads and fee plus contingencies.

The capital cost was determined through the process of estimating the cost of every significant piece of equipment, component, and bulk quantity.

\subsubsection{Bare Erected Cost}

The bare erected cost level of the estimate, also referred to as the sum of process capital and general facilities capital, consists of the cost of: factory equipment, field materials and supplies, direct labor, indirect field labor, and indirect construction costs Other process equipment, minor secondary systems, and materials were estimated by G/C on the basis of the PFBC reference plant and in-house data consisting of other cost data and relationships, catalog data, and standard utility unit cost data.

The piping system costs for the HGCU systems were estimated on the basis of the corresponding systems in the PFBC reference plant, and the AFBC reference plant.

The electrical and I\&C portion of the estimate was developed using material and equipment cost relationships to the electrical and I\&C costs for similar systems.

In most cases the costs for bulk materials for this estimate were derived from recent vendor or manufacturer's quotes for similar items on other projects. Where actual or specific information regarding equipment specifications was available, that information was used to size and quantify material and equipment requirements. Where information was not furnished or was not adequate, requirements were assumed and estimated based on information available from project estimates of similar type and size.

The labor cost to install the equipment and materials was estimated on the basis of labor manhours. Labor costing was determined on a multiple contract labor basis with the labor cost including direct and indirect labor costs plus fringe benefits and allocations for contractor expenses and markup. This was supplemented in limited cases, as required, with equipment labor relationship data to determine the labor cost. The relationships used were based on the in-house historical data and the source plants.

The indirect labor cost was estimated at 7 percent of direct labor to recognize the cost of construction services and facilities not provided by the individual contractors. The latter cost represents the estimate for miscellaneous temporary facilities such as construction road and parking area construction and maintenance; installation of construction power; installation of construction water supply and general sanitary facilities; and general and miscellaneous labor services such as jobsite cleanup and construction of general safety and access items.

\subsubsection{Total Plant Cost (TPC)}

The TPC level of the estimate consists of the bare erected cost plus engineering and contingencies. 
The engineering costs represent the cost of architect/engineer services for design, drafting, and project construction management services. The cost was determined at 12 percent applied to the ${ }^{*}$ bare erected cost on an individual account basis. The cost for engineering services provided by the equipment manufacturers and vendors is included directly in the equipment costs.

Allowances for process and project contingencies are also considered part of the TPC. The process contingency covers the uncertainty in the technical development of specific equipment. A process contingency of 10 percent was added to the estimated cost of the filter vessels due primarily to the uncertainty of the cluster blow back system. Also, a 5 percent contingency was added to ash handling system due to the uncertainty in the physical characteristics of the ash. No other process contingency was included.

Consistent with conventional power plant practices, the general project contingency was added to the total plant cost to cover project uncertainty and the cost of any additional equipment that could result from a detailed design. Based on EPRI criteria, the cost estimate contains elements of Classes I, II, and III level estimates. As a result, on the basis of the EPRI guidelines, a nominal value of 15 percent was used to arrive at the plant nominal cost value. This project contingency is intended to cover the uncertainty in the cost estimate itself. The contingencies represent costs that are expected to occur.

In addition to the TPC cost level, the Total Plant Investment (TPI) and Total Capital Requirement (TCR) were determined.

TPI at date of start-up includes escalation of construction costs and allowance for funds used during construction (AFDC), formerly called interest during construction, over the construction period. TPI is computed from the TPC which is expressed on an "overnight" or instantaneous construction basis. For the construction cash flow, a uniform expenditure rate was assumed, with all expenditures taking place at the end of the year. The construction period is estimated to be 1 year. For a one year construction period, TPI $=$ TPC.

The apparent escalation rate and the weighted cost of capital (discount rate) are the standard values currently proposed by EPRI.

The TCR includes all capital necessary to complete the entire project. TCR consists of TPI, prepaid royalties, preproduction (or start-up) costs, inventory capital, initial chemical and catalyst charge, and land cost:

- Royalties costs are assumed inapplicable to the mature PFBC plant and thus are not included.

- Preproduction U.S. costs are intended to cover operator training, equipment checkout, major changes in plant equipment, extra maintenance, and inefficient use of fuel and other materials during plant start-up. They are estimated as follows:

- 1 month fixed operating costs - operating and maintenance labor, administrative and support labor, and maintenance materials.

- 1 month of variable operating costs as full capacity (excluding fuel) - includes chemicals, water, and other consumables and waste disposal charges.

- $\quad 25 \%$ of full capacity fuel cost for 1 month - covers inefficient operation that occurs during the start-up period. 
- $\quad 2 \%$ of TPI - covers expected changes and modifications to equipment that will be needed to bring the plant up to full capacity.

- Inventory capital is the value of inventories-of fuel, other consumables, and by-products, which are capitalized and included in the inventory capital account. The inventory capital is estimated as follows: Fuel inventory is based on full-capacity operation for 60 days. Inventory of other consumables (excluding water) is normally based on full-capacity operation at the same number of days as specified for the fuel. In addition, an allowance of $1 / 2 \%$ of the TPC equipment cost is included for spare parts.

- Initial catalyst and chemical charge covers the initial cost of any catalyst or chemicals that are contained in the process equipment (but not on storage, which is covered in inventory capital). No value is shown because costs are minimal and included directly in the component equipment capital cost.

- Land cost is not applicable to this estimate and is not included.

Each of the TCR cost components, as well as the summary TPC components and the TPI, is included in this section on the Capital Investment \& Revenue Summary sheets. In addition, a summary for the capital cost for each case is included in Appendix B.

\subsubsection{Capital Cost Estimate Exclusions}

Although the estimate is intended to represent a complete HGCU system, there remain several qualifications/exclusions as follows:

- Sales tax is not included (considered to be exempt).

- On-site fuel transportation equipment (such as barge tug, barges, yard locomotive, bulldozers) is not included.

- Allowances for unusual site conditions (such as piling, extensive site access, excessive dewatering, extensive inclement weather) are not included.

- Royalties are not included.

\subsection{OPERATING COSTS AND EXPENSES}

The operating costs and related maintenance expenses (O\&M) described in this section pertain to those charges associated with operating and maintaining the HGCU system over its expected life.

The costs and expenses associated with operating and maintaining the plant include:

- Operating labor
Maintenance
- Material

The values for these items were determined consistent with EPRI TAG methodology. These costs and expenses are estimated on a first-year basis, in December 1994 dollars. The first-year costs assume normal operation and do not include the initial start-up costs.

The operating labor, maintenance material and labor, and other labor-related costs are combined and then divided into two components; fixed O\&M, which is independent of power generation, 
and variable O\&M, which is proportional to power generation. The first-year operating and maintenance cost estimate allocation is based on the plant capacity factor.

The other operating costs, consumables and fuel, are determined on a daily 100-percent operating capacity basis and adjusted to an annual plant operation basis.

The development of the actual values was performed on a $\mathrm{G} / \mathrm{G}$ model that is consistent with TAG. The inputs for each category of operating costs and expenses are identified in the succeeding subsections along with more specific discussion of the evaluation processes.

\subsubsection{Operating Labor}

The cost of operating labor was estimated on the basis of the number of operating jobs (OJ) required to operate the plant (on an average-per-shift basis). The operating labor charge (OLC) expressed in first year $\$ / \mathrm{kW}$ was then computed using the average labor rates:

$$
\text { OLC }=\frac{(\mathrm{OJ}) \times(\text { labor rate } \times \text { labor burden }) \times(8760 \mathrm{~h} / \mathrm{yr})}{\text { (net capacity of plant at full load in } \mathrm{kW})}
$$

The operating labor requirements were determined on the basis of in-house representative data for the plant section.

\subsubsection{Maintenance}

Since the development of the maintenance labor and maintenance material costs are so interrelated in this methodology, their cost bases are discussed together. Annual maintenance costs are estimated as a percentage of the installed capital cost. The percentage varies widely, depending on the nature of the processing conditions and the type of design.

On the basis of G/C in-house data and EPRI guidelines for determining maintenance costs , representative values expressed as a percentage of system cost were specified for each major system. The rates were applied against individual estimate values. Using the corresponding TPC values, a total annual (first-year) maintenance cost was calculated, including both material and labor components. The rate applied to the filter vessels includes the cost of candle replacement once every three years.

Since the maintenance costs are expressed as maintenance labor and maintenance materials, a maintenance labor/materials ratio of 40/60 was used for this breakdown. The operating costs, excluding consumable operating costs, are further divided into fixed and variable components. Fixed costs are essentially independent of capacity factor and are expressed in $\$ / \mathrm{kW}-\mathrm{y}$. Variable costs are incremental, directly proportional to the amount of power produced, and expressed in mills/kWh (\$/MWh). The equations for these calculations are:

$$
\begin{aligned}
& \text { Fixed O\&M = Capacity Factor (CF) } \times \text { Total O\&M }(\$ / \mathrm{kWy}) \\
& \text { Variable O\&M }=\frac{(1-\mathrm{CF}) \times \text { Total O\&M }(\$ / \mathrm{kW}-\mathrm{yr}) \times 1000 \mathrm{mills} / \$}{(\mathrm{CF} \times 8760 \mathrm{~h} / \mathrm{yr})}
\end{aligned}
$$

\subsubsection{Consumables}

The feedstock and disposal costs are those consumable expenses associated with power plant operation. Consumable operating costs are developed on a first-year basis and subsequently levelized over the 30-year life of the plant. The consumables category consists of water and chemicals, auxiliary power, other consumables, and waste disposal. 
The "water" and chemicals component pertains to the water acquisition charge for water required for the plant steam cycle, and for miscellaneous services and composite water makeup and treating chemicals and liquid effluent chemical category, representing the composite chemical requirement for wastewater treating. These commodities are negligible for the HGCU system and are not included.

The auxiliary power component consists of the electricity required to drive the blow back gas compressors. The charge rate of $.05 \$ / \mathrm{kWh}$ is based on current in-house information for internal power costs.

The "other consumables" component consists of startup fuel, gases, primarily the nitrogen required for transport and blanketing and steam but does not contain any significant quantities. For cases 3 and 4 this component represents the gasoline costs for the pulse combustors.

The "waste disposal" component pertains to the cost allowance for off-site disposal of plant solid wastes. This commodity is not applicable to the HGCU systems and is not included.

\subsection{COST OF ELECTRICITY (COE)}

The revenue requirement method of performing an economic analysis of a prospective power plant is widely used in the electric utility industry. This method permits the incorporation of the various dissimilar components for a potential new plant into a single value that can be compared to various alternatives. The revenue requirement figure-of-merit is COE that is the levelized (over plant life) coal pile-to-busbar cost of power expressed in mills/kWh. The value, based on EPRI definitions and methodology, includes the TCR, which is represented in the levelized carrying charge (sometimes referred to as the fixed charges), levelized fixed variable operating and maintenance costs, levelized consumable operating costs, and the levelized fuel cost.

The levelized carrying charge, applied to TCR, establishes the required revenues to cover return on equity, interest on debt, depreciation, income tax, property tax, and insurance. Levelizing factors are applied to the first year fuel, O\&M costs, and consumable costs to yield levelized costs over the life of the project. A long-term inflation rate of $4.1 \% / y r$. was assumed in estimating the cost of capital and in estimating the life cycle revenue requirements for other expenses. To represent these varying revenue requirements for fixed and variable costs, a "levelized" value was computed using the "present worth" concept of money based on the assumptions shown in the basis table resulting in a levelized carrying charge of $16.9 \%$ and levelization factor of 1.541.

By combining costs, carrying charges, and levelizing factors, a levelized busbar COE for the $65 \%$ design capacity factor was calculated along with the levelized constituent values. The format for this cost calculation is:

$$
\text { Power Cost }(\text { COE })=\frac{(\mathrm{LCC}+\mathrm{LFOM}) \times 1000 \mathrm{mills} / \$}{\mathrm{CF} \times 8760 \mathrm{~h} / \mathrm{y}}+\mathrm{LVOM}+\mathrm{LCM}-\mathrm{LB}+\mathrm{LFC}
$$


where:

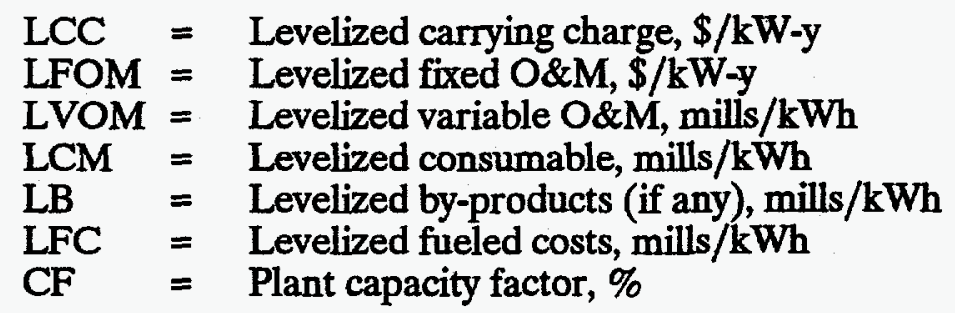

The consolidated basis for calculating capital investment and revenue requirements is given in the succeeding table titled Estimate Basis/Financial Criteria for Revenue Requirement Calculations. The principle cost and economics output for this study, the Capital Investment and Revenue Requirement summary presents key TPC values and other significant capital costs, operating costs, maintenance costs, consumables, fuel cost and the levelized busbar COE.

\subsection{CONCLUSIONS}

Off-line cleaning has a slightly higher cost than on-line cleaning even though more efficient. This was due primarily to the extra vessels required. The cost difference between rapid combustion and $400^{\circ} \mathrm{F}$ on-line cleaning is negligible. Technical feasibility and not cost will determine which technique is chosen.

The cost driver of the total system cost are the vessel costs. The vessel costs represent approximately $75 \%$ of the total plant cost. Thus a HGCU system configuration for on-line cleaning is less costly even though less efficient than the same application with off-line cleaning. The blow back systems including gas compression represent a small percentage of the total system cost.

The cost of the ceramic barrier filter system for the advanced PFBC plant is about 2.5 times the cost for the IGCC plant. The PFBC plant requires two filter systems, one for the combustor and one for the carbonizer, and has a much higher gas volume. The cost of the cleanup system as compared to the total plant cost, however, is relatively small, 10-12\% for the advanced PfBC and $4-5 \%$ for the IGCC. 
TITLE/DEFINITION

Case:

Plant Size:

Fuel(type):

Design/Construction:

TPC(Plant Cost) Year:

Capacity Factor:

CAPITAL INVESTMENT

Process Capital \& Facilities

Engineering(incl.C.M.,H.O.\& Fee)

Process Contingency

Project Contingency

TOTAL PLANT COST(TPC)

TOTAL CASH EXPENDED

AFDC

TOTAL PLANT INVESTMENT(TPI)

Royalty Allowance

Preproduction Costs

Inventory Capital

Initial Catalyst \& Chemicals(w/equip.)

Land Cost

TOTAL CAPITAL REQUIREMENT(TCR)

OPERATING \& MAINTENANCE COSTS(First Year)

Operating Labor

Maintenance Labor

Maintenance Material

Administrative \& Support Labor

TOTAL OPERATION \& MAINTENANCE(1st yr.)

FIXED $O$ \& $M$ (1st yr.)

VARIABLE O \& $M$ (1st yr.)

CONSUMABLE OPERATING COSTS(less Fuel)

Water \& Chemicals

Auxilliary Power

$\$ 60,093$

Other Consumables

Waste Disposal

TOTAL CONSUMABLES(1st yr.,-fuel)

BY-PRODUCT CREDITS(First Year)

FUEL COST(First Year)

LEVELIZED OPERATION \& MAINTENANCE COSTS

Fixed $O$ \& $M$

Variable $O$ \& $M$

Consumables

By-product Credit

Fuel

LEVELIZED CARRYING CHARGES(Capital)

LEVELIZED BUSBAR COST OF POWER 30 Year at a Capacity Factor of:

Case 1 - CPFBC with Conventional Blowback $65(\%)$

453.0 (MW, net) HeatRate: 7,822 (Btu/kWh) Cost: $\quad 1.60$ (\$/MMBtu) 30 (years)

1995 (Jan.)

$\$ \times 1000$

1,548
187

$\$ 60,093$

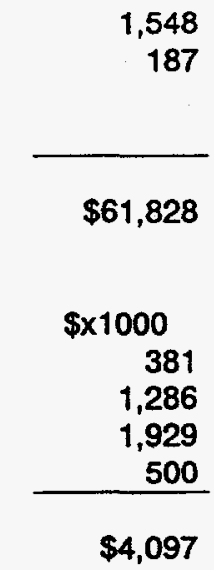

$\$ 1000$

44,424

4,943

7,838

$\$ 60,093$

35

$\$ 35$
$\$ / k W$

98.1

6.4

10.9

17.3

132.7

132.7

3.4

0.4

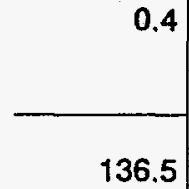

$\$ / k W-y r$

0.8

2.8

4.3

1.1

9.0

$5.88 \$ / k W-y r$

$0.56 \mathrm{mills} / \mathrm{kWh}$

mills/kWh

0.01

$9.1 \$ / k W-y r=$

$23.1 \$ / k W-y r=$

$4.1 \mathrm{mills} / \mathrm{kWh}$

6.5 mills/kWh
1.6 mills $/ \mathrm{kWh}$

0.9 mills $/ \mathrm{kWh}$

0.0 milis $/ \mathrm{kWh}$

mills/kWh

mills/kWh

0.01 


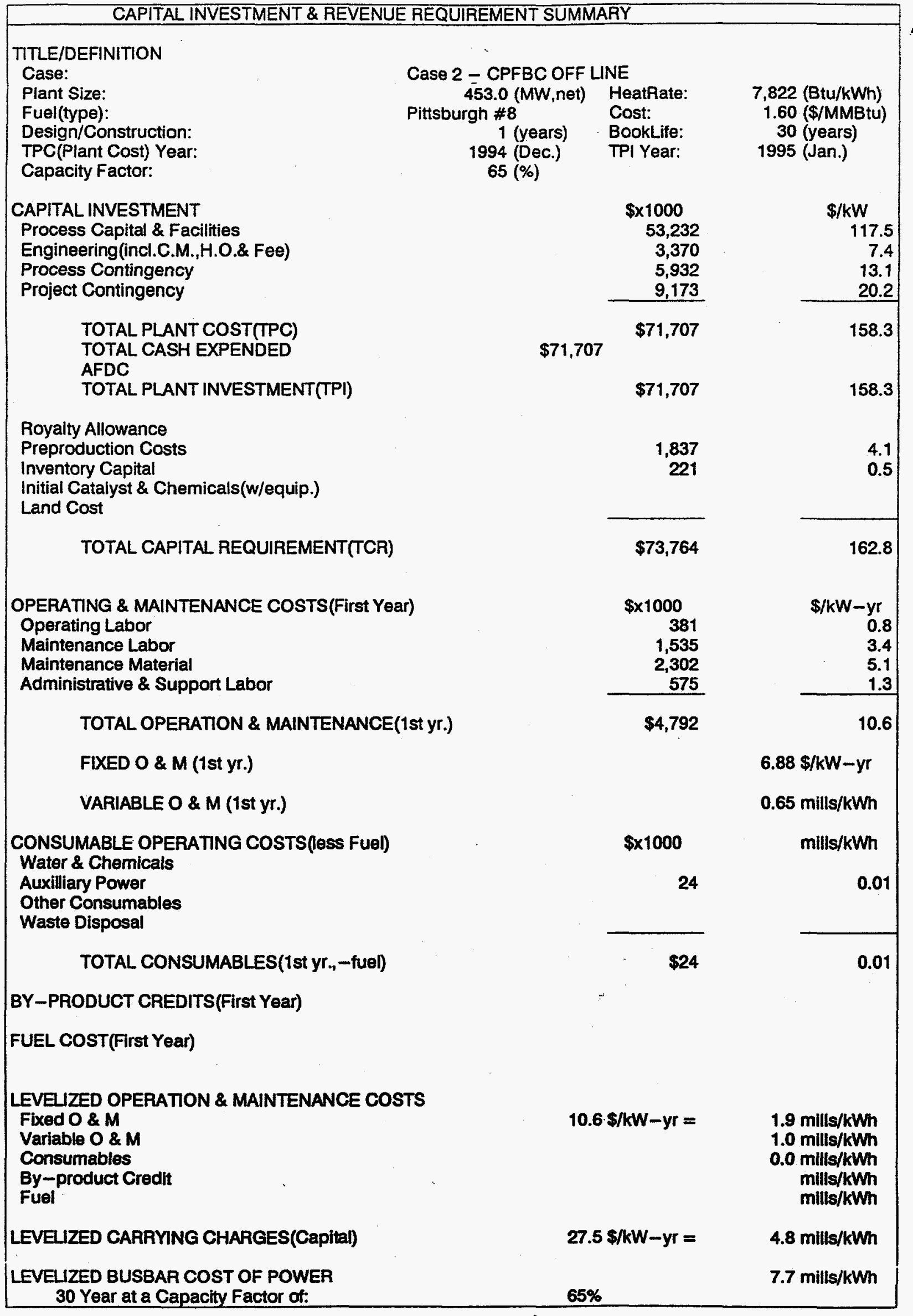




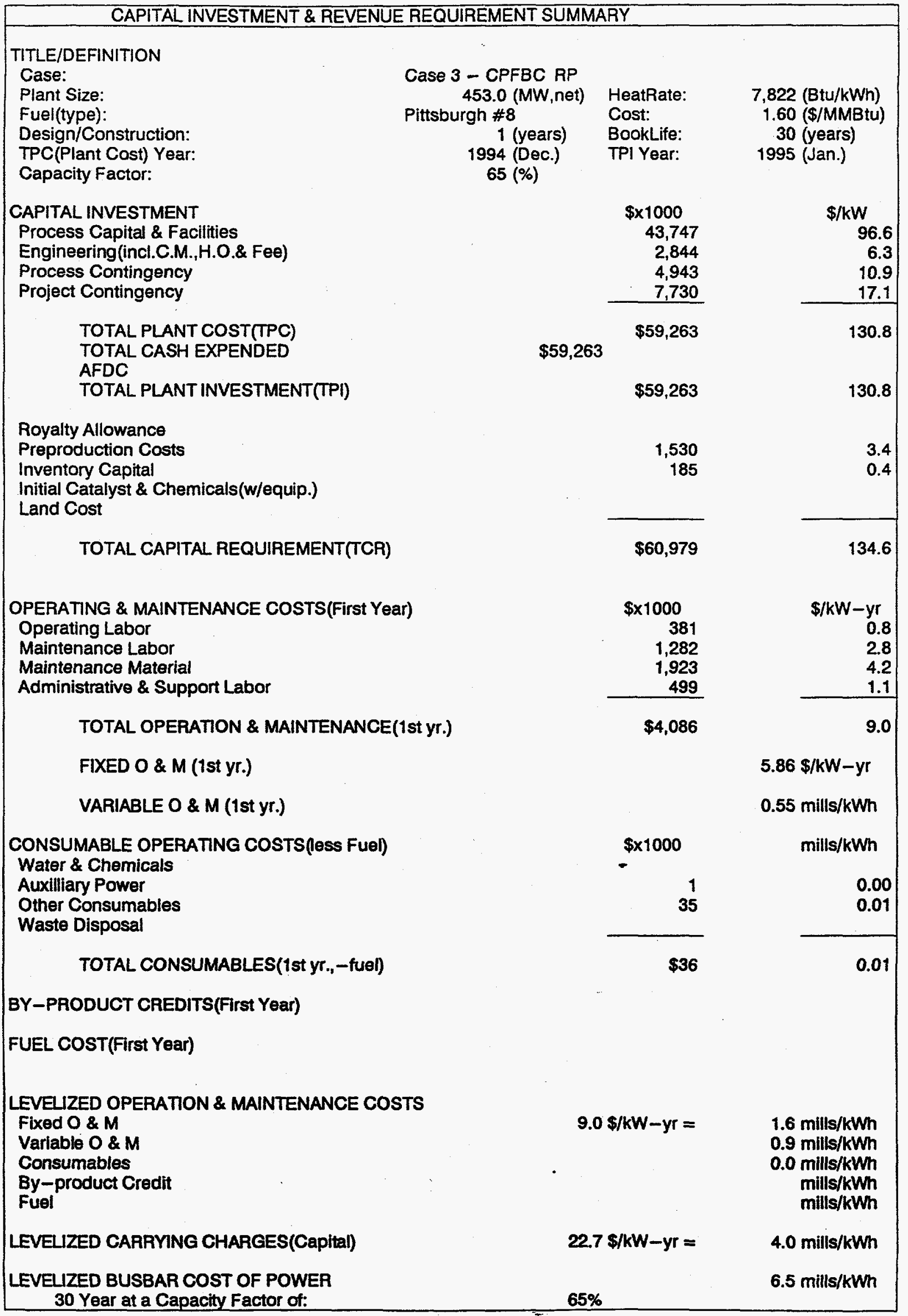




\section{TITLE/DEFINITION \\ Case: \\ Plant Size: \\ Fuel(type): \\ Design/Construction: \\ TPC(Plant Cost) Year: \\ Capacity Factor:}

CAPITAL INVESTMENT

Process Capital \& Facilities

Engineering(incl.C.M.,H.O.\& Fee)

Process Contingency

Project Contingency

TOTAL PLANT COST(TPC)

TOTAL CASH EXPENDED

AFDC

TOTAL PLANT INVESTMENT(TPI)

Royalty Allowance

Preproduction Costs

Inventory Capital

Initial Catalyst \& Chemicals(w/equip.)

Land Cost

TOTAL CAPITAL REQUIREMENT(TCR)

OPERATING \& MAINTENANCE COSTS(First Year)

Operating Labor

Maintenance Labor

Maintenance Material

Administrative \& Support Labor

TOTAL OPERATION \& MAINTENANCE(1st yr.)

FIXED 0 \& $M$ (1st yr.)

VARIABLE O \& $M$ (1st yr.)

CONSUMABLE OPERATING COSTS(less Fuel)

Water \& Chemicals

Auxilliary Power

Other Consumables

Waste Disposal

TOTAL CONSUMABLES(1st yr.,-fuel)

BY-PRODUCT CREDITS(First Year)

FUEL COST(First Year)

LEVELIZED OPERATION \& MAINTENANCE COSTS

Flxed $O$ \& $M$

Variable $O$ \& $M$

Consumables

By-product Credit

Fuel

LEVELIZED CARRYING CHARGES(Capital)

LEVELIZED BUSBAR COST OF POWER 30 Year at a Capacity Factor of:

\section{Case 4 - CPFBC RP-OFF LINE \\ 453.0 (MW, net) HeatRate: \\ Pittsburgh \#8 \\ Cost:

$$
\begin{array}{ll}
1 \text { (years) } & \text { BookLife: } \\
1994 \text { (Dec.) } & \text { TPI Year: }
\end{array}
$$ \\ $65(\%)$}

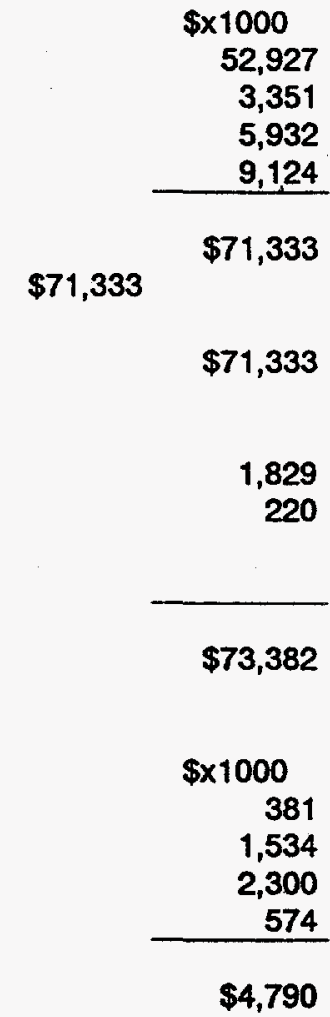

381

1,534

2,300

$\$ 4,790$

7,822 (Btu/kWh)

1.60 (\$/MMBtu)

30 (years)

1995 (Jan.)

$\$ / \mathrm{kW}$

116.8

7.4

13.1

20.1

157.5

157.5

4.0

0.5

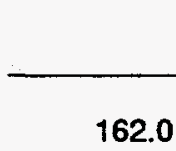

$\$ / k W-y r$

0.8

3.4

5.1

1.3

10.6

$6.87 \$ / k W-y r$

0.65 mills/kWh

$\$ \times 1000$

mills/kWh

1.9 mills/kWh

1.0 mills/kWh

0.0 mills $/ \mathrm{kWh}$

mills/kWh

mills/kWh

$27.4 \$ / k W-y r=$

4.8 mills/kWh

7.7 mills/kWh 


\section{TITLE/DEFINITION}

Case:

Plant Size:

Fuel(type):

Design/Construction:

TPC(Plant Cost) Year:

Capacity Factor:

CAPITAL INVESTMENT

Process Capital \& Facilities

Engineering(incl.C.M.,H.O.\& Fee)

Process Contingency

Project Contingency

TOTAL PLANT COST(TPC)

TOTAL CASH EXPENDED

AFDC

TOTAL PLANT INVESTMENT(TPI)

Royalty Allowance

Preproduction Costs

Inventory Capital

Initial Catalyst \& Chemicals(w/equip.)

Land Cost

TOTAL CAPITAL REQUIREMENT(TCR)

OPERATING \& MAINTENANCE COSTS(First Year)

Operating Labor

Maintenance Labor

Maintenance Material

Administrative \& Support Labor

TOTAL OPERATION \& MAINTENANCE(1st yr.)

FIXED $O$ \& $M$ (1st yr.)

VARIABLE O \& $M$ (1st yr.)

CONSUMABLE OPERATING COSTS(less Fuel)

Water \& Chemicals

Auxilliary Power

Other Consumables

Waste Disposal

TOTAL CONSUMABLES(1st yr.,-fuel)

BY-PRODUCT CREDITS(First Year)

FUEL COST(First Year)

LEVELIZED OPERATION \& MAINTENANCE COSTS

\section{Fixed $O$ \& $M$}

Variable $O$ \& $M$

Consumables

By-product Credit

Fuel

LEVELIZED CARRYING CHARGES(Capital)

LEVELIZED BUSBAR COST OF POWER

30 Year at a Capacity Factor of:
Case 5 - Carbonizer Conv.

453.0 (MW, net) HeatRate:

Pittsburgh \#8

Cost:

1 (years) $\quad$ BookLife:
1994 (Dec.)

$65(\%)$

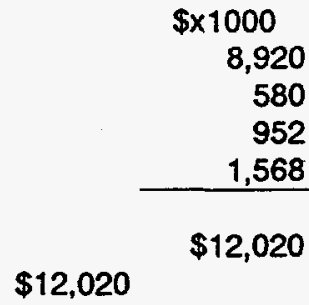

$\$ 12,020$

340

37

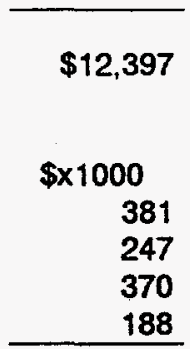

$\$ 1,187$

$\$ \times 1000$

$2.6 \$ / \mathrm{kW}-\mathrm{yr}=$

$4.6 \$ / \mathrm{kW}-\mathrm{yr}=$
$1.70 \$ / \mathrm{kW}-\mathrm{yr}$

0.16 mills $/ k W h$

5

mills/kWh

7,822 (Btu/kWh)

1.60 (\$/MMBtu)

30 (years)

1995 (Jan.)

$\$ / k W$

26.5

26.5

0.8

0.1

27.4

$\$ / k W-y r$

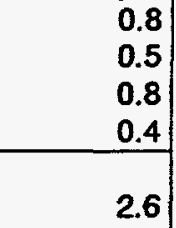

2.6

$\$ 5$

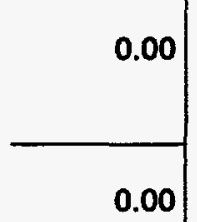

0.5 mills/kWh

0.2 mills/kWh

0.0 mills $/ \mathrm{kWh}$

mills/kWh

mills/kWh

$0.8 \mathrm{mills} / \mathrm{kWh}$

1.5 mills/kWh 


\begin{tabular}{|c|c|c|c|}
\hline \multicolumn{4}{|c|}{ CAPITAL INVESTMENT \& REVENUE REQUIREMENT SUMMARY } \\
\hline $\begin{array}{l}\text { TITLE/DEFINITION } \\
\text { Case: } \\
\text { Plant Size: } \\
\text { Fuel(type): } \\
\text { Design/Construction: } \\
\text { TPC(Plant Cost) Year: } \\
\text { Capacity Factor: }\end{array}$ & $\begin{array}{c}\text { Case } 6 \text { = Carbonizer } ~ \\
453.0 \text { (MW,net) } \\
\text { Dittsburgh \#8 } \\
1 \text { (years) } \\
1994 \text { (Dec.) } \\
65 \text { (\%) }\end{array}$ & $\begin{array}{l}\text { f-Line } \\
\text { HeatRate: } \\
\text { Cost: } \\
\text { BookLife: } \\
\text { TPI Year: }\end{array}$ & $\begin{array}{c}7,822(\text { Btu/kWh) } \\
1.60 \text { ( } \$ \text { /MMBtu) } \\
30 \text { (years) } \\
1995 \text { (Jan.) }\end{array}$ \\
\hline $\begin{array}{l}\text { CAPITAL INVESTMENT } \\
\text { Process Capital \& Facilities } \\
\text { Engineering(incl.C.M.,H.O.\& Fee) } \\
\text { Process Contingency } \\
\text { Project Contingency }\end{array}$ & & $\begin{array}{r}\$ \times 1000 \\
13,167 \\
833 \\
1,428 \\
2,262 \\
\end{array}$ & $\begin{array}{r}\$ / \mathrm{kW} \\
29.1 \\
1.8 \\
3.2 \\
5.0 \\
\end{array}$ \\
\hline \multicolumn{2}{|l|}{$\begin{array}{l}\text { TOTAL PLANT COST(TPC) } \\
\text { TOTAL CASH EXPENDED } \\
\text { AFDC } \\
\text { TOTAL PLANT INVESTMENT(TPI) }\end{array}$} & $\$ 17,691$ & $\begin{array}{l}39.1 \\
39.1\end{array}$ \\
\hline \multicolumn{2}{|l|}{$\begin{array}{l}\text { Royalty Allowance } \\
\text { Preproduction Costs } \\
\text { Inventory Capital } \\
\text { Initial Catalyst \& Chemicals(w/equip.) } \\
\text { Land Cost }\end{array}$} & $\begin{array}{r}481 \\
54\end{array}$ & $\begin{array}{l}1.1 \\
0.1\end{array}$ \\
\hline \multicolumn{2}{|l|}{ TOTAL CAPITAL REQUIREMENT(TCR) } & $\$ 18,226$ & 40.2 \\
\hline \multicolumn{2}{|l|}{$\begin{array}{l}\text { OPERATING \& MAINTENANCE COSTS(First Year) } \\
\text { Operating Labor } \\
\text { Maintenance Labor } \\
\text { Maintenance Material } \\
\text { Administrative \& Support Labor }\end{array}$} & $\begin{array}{r}\$ \times 1000 \\
381 \\
367 \\
550 \\
224 \\
\end{array}$ & $\begin{array}{r}\$ / \mathrm{kW}-\mathrm{yr} \\
0.8 \\
0.8 \\
1.2 \\
0.5 \\
\end{array}$ \\
\hline \multicolumn{2}{|l|}{ TOTAL OPERATION \& MAINTENANCE(1st yr.) } & $\$ 1,523$ & 3.4 \\
\hline \multicolumn{2}{|l|}{ FIXED 0 \& $M($ (1st yr.) } & & $2.19 \$ / k W-y r$ \\
\hline \multicolumn{2}{|l|}{ VARIABLE $O \& M$ (1st yr.) } & & 0.21 mills/kWh \\
\hline \multicolumn{2}{|l|}{$\begin{array}{l}\text { CONSUMABLE OPERATING COSTS(less Fuel) } \\
\text { Water \& Chemicals } \\
\text { Auxilliary Power } \\
\text { Other Consumables } \\
\text { Waste Disposal }\end{array}$} & $\$ \times 1000$ & $\begin{array}{r}\text { mills/kWh } \\
0.00\end{array}$ \\
\hline \multicolumn{2}{|l|}{ TOTAL CONSUMABLES(1st yr.,-fuel) } & $\$ 3$ & 0.00 \\
\hline \multicolumn{2}{|l|}{ BY-PRODUCT CREDITS(First Year) } & & \\
\hline \multicolumn{4}{|l|}{ FUEL Cost(First Year) } \\
\hline \multicolumn{3}{|l|}{$\begin{array}{l}\text { LEVELIZED OPERATION \& MAINTENANCE COSTS } \\
\text { Fixed O \& M } \\
\text { Variable O \& M } \\
\text { Consumables } \\
\text { By-product Credit } \\
\text { Fuel }\end{array}$} & $\begin{array}{l}0.6 \mathrm{mills} / \mathrm{kWh} \\
0.3 \mathrm{mills} / \mathrm{kWh} \\
0.0 \mathrm{mills} / \mathrm{kWh} \\
\mathrm{mills} / \mathrm{kWh} \\
\mathrm{mills} / \mathrm{kWh}\end{array}$ \\
\hline \multicolumn{2}{|l|}{ LEVELIZED CARRYING CHARGES(Capital) } & $\$ / \mathbf{k W}-\mathbf{y r}=$ & 1.2 mills/kWh \\
\hline $\begin{array}{l}\text { LEVELIZED BUSBAR COST OF POWER } \\
30 \text { Year at a Capacity Factor of: }\end{array}$ & \multicolumn{2}{|c|}{$65 \%$} & $2.1 \mathrm{mills} / \mathrm{kWh}$ \\
\hline
\end{tabular}


TITLE/DEFINITION

Case:

Plant Size:

Fuel(type):

Design/Construction:

TPC(Plant Cost) Year:

Capacity Factor:

CAPITAL INVESTMENT

Process Capital \& Facilities

Engineering(incl.C.M.,H.O.\& Fee)

Process Contingency

Project Contingency

TOTAL PLANT COST(TPC)

TOTAL CASH EXPENDED

AFDC

TOTAL PLANT INVESTMENT(TPI)

Royalty Allowance

Preproduction Costs

Inventory Capital

Initial Catalyst \& Chemicals(w/equip.)

Land Cost

TOTAL CAPITAL REQUIREMENT(TCR)

OPERATING \& MAINTENANCE COSTS(First Year)

Operating Labor

Maintenance Labor

Maintenance Material

Administrative \& Support Labor

TOTAL OPERATION \& MAINTENANCE(1st yr.)

FIXED O \& M (1st yr.)

VARIABLE $O \& M$ (1st yr.)

CONSUMABLE OPERATING COSTS(lesS FUel)

Water \& Chemicals

Auxilliary Power

Other Consumables

Waste Disposal

TOTAL CONSUMABLES(1st yr.,-fuel)

BY-PRODUCT CREDITS(First Year)

FUEL COST(First Year)

LEVELIZED OPERATION \& MAINTENANCE COSTS

Fixed $O$ \& $M$

Variable $O$ \& $M$

Consumables

By-product Credit

Fuel

LEVELIZED CARRYING CHARGES(Capital)

LEVELIZED BUSBAR COST OF POWER

30 Year at a Capacity Factor of:
Case 7 - IGCC Conv. 458.0 (MW,net) Pittsburgh \#8 1 (years) 1994 (Dec.) $65(\%)$

HeatRate:

Cost:

BookLife:

TPI Year:

$\$ \times 1000$

21,197

1,378

2,153

3,709

$\$ 28,437$

$\$ 28,437$

$\$ 28,437$

750

87

$\$ 29,275$

$\$ \times 1000$

381

590

886

291

$\$ 2,149$

$\$ \times 1000$

20

$\$ 20$

$4.7 \$ / k W-y r=$

$10.8 \$ / k W-y r=$
$3.05 \$ / k W-y r$

0.29 mills/kWh

mills/kWh

1.60 (\$/MMBtu)

30 (years)

1995 (Jan.)

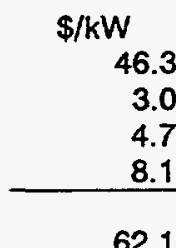

62.1

1.6

0.2

63.9

\$/kW-yr

0.8

1.3

0.6

4.7

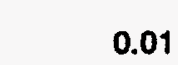

0.01
$0.8 \mathrm{mills} / \mathrm{kWh}$

0.4 mills/kWh

0.0 mills $/ \mathrm{kWh}$

mills/kWh

mills/kWh

1.9 mills $/ k W h$

3.2 mills/kWh 


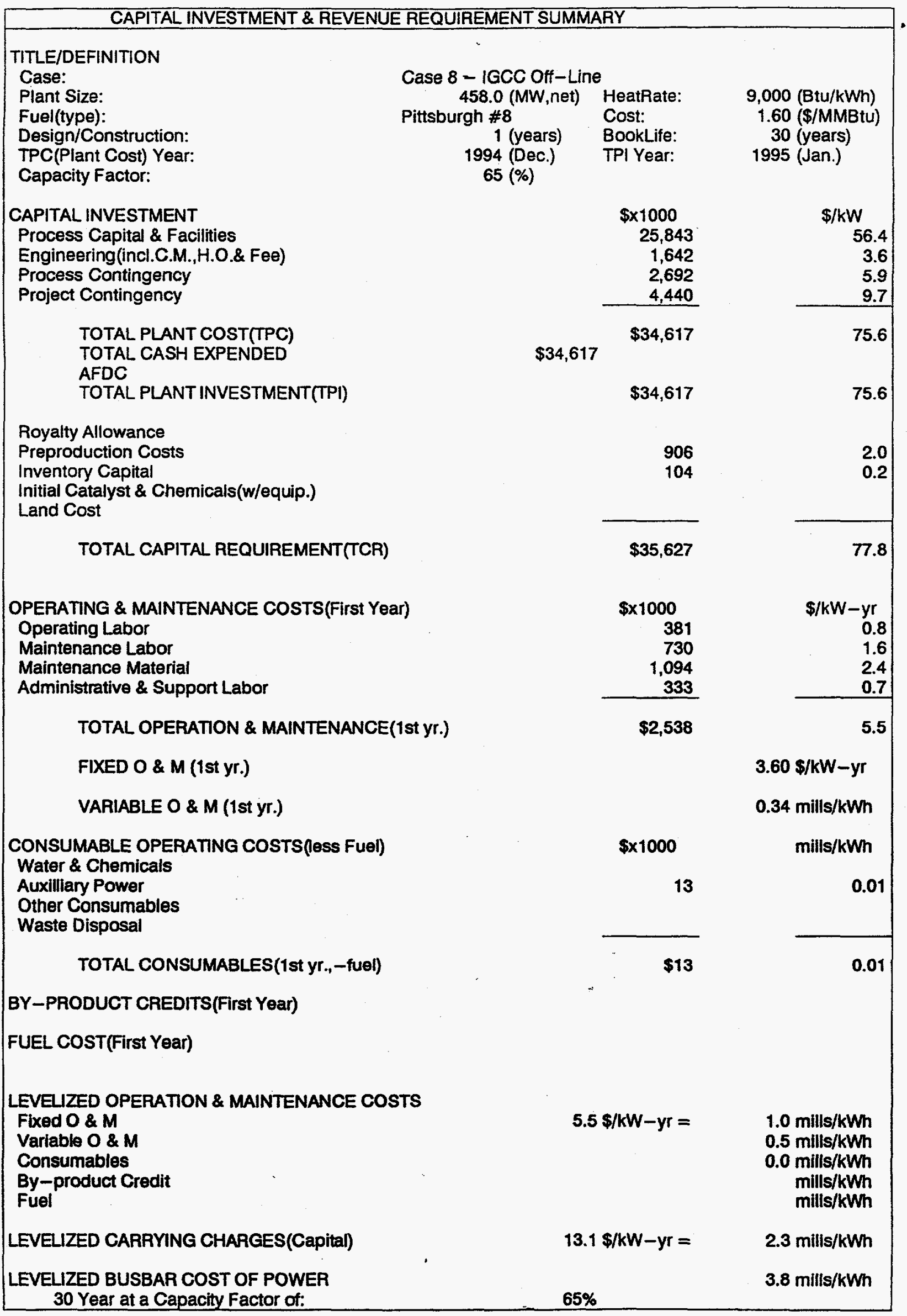




\subsection{CONCLUSIONS AND R\&D RECOMMENDATIONS}

The objective of study task was to assess and evaluate the effectiveness, appropriateness and economics of three different ceramic barrier filter cleaning techniques. These techniques included conventional on-line pulse driven reverse gas filter cleaning, off-line reverse gas filter cleaning and rapid pulse driven filter cleaning.

The cleaning techniques were evaluated from a first principles approach. This analysis was then used to understand the basic mechanisms and functional relationships governing cake removal and to establish the necessary design data for the conceptual design and economic analysis. The result of this analysis was a spreadsheet computer model which was turned over to METC and is a powerful tool for identifying and directing future R\&D developments.

Within individual sections of this report critical design and operational issues were evaluated against the application and conclusions were identified. This section presents some overall key findings on the issues followed by conclusions and recommendations for R\&D design challenges.

\subsection{FINDINGS}

\subsubsection{Analyses and Modeling of the Filter Blowback Systems}

The spreadsheet model can be used to assist conceptual design of a blowback system or used as an analytical tool to compare performance of different filter cleaning techniques. The model can be applied to carry out "what-if" analyses to provide guidance in optimizing system parameters especially in determining the dimensions or geometrical configuration of hardware such as ejector and pipes. While optimization was not one of the basic objectives (and therefore not specifically done for each individual system), it was found that the reservoir pressure (and, to some extent, temperature) depend strongly on the hardware setups (length/diameter of pipes, type/number of fitting/valves) of the blowback system. Often, there are numerous seemingly equally good alternatives that can achieve the same result: for example, at the ejector, a pulse with the same momentum can be generated with a large nozzle/low pressure gas or with a small nozzle/high pressure combination. In a future work, an optimization study could be carried out to investigate the performances of the blowback system with different configurations.

It also becomes clear during the model development that one of the fundamental process parameters required for effective design of blowback systems is the cake "separation stress". This separation stress is nominally in the order of a few. psia, and once it is specified or known, all the rest of pressure and temperature distribution of the pulsed gas within the blowback system can be established in a step-by-step fashion. Unfortunately, the data on cake separation stress is not commonly available in the literature nor easily estimated by theoretical means; it appears that the only reliable method is by direct experimental measurements.

Other important parameters that need to be developed or compiled include cake separation and cake cleaning efficiencies. As explained in an earlier section, the former is the parameter closely associated with cake separation stress, and the latter is a function of the properties of cake flakes which are not well characterized. For instance, it is the particle size distribution of the cake flakes or agglomerates after separation that determines the effective terminal velocity during free-fall which, in turn, determines the cake cleaning efficiency. The mean particle size of the cake flakes during free falling is definitely greater (by, perhaps, two orders of magnitude or more) than the mean particle diameter of the cake on the candle filter or that found in the bottom of filter vessel, but there is no reliable measured data. It is recommended that more R\&D effort be directed in establishing/compiling this class of information (separation stress, cake flake properties, etc.) for all types of cakes under their actual operation conditions. 
The diameters of piping segments have very strong effects on the pressure drops. Any changes in these components can easily cause a large difference in pressure at the end of the interconnecting pipes. The pressure of the gas reservoir itself is a strong function of tank volume and/or pulse duration: depending on the design philosophy applied in sizing the reservoir, the tank pressure can easily be increased or decreased by a hundred psia or more. In summary, the final $\mathrm{P} / \mathrm{T}$ condition determined for a reservoir must be so understood in light of the unique hardware components within each specific blowback system. The conventional wisdom of simply assuming the reservoir pressure being in the range of "two to three" times of the system pressure may or may not be sufficiently accurate nor revealing (as to why so much pressure is needed) in many cases. [It is refreshing to realize here that the essential purpose of storing the cleaning fluid under a very high pressure of several hundred psia or even in excess of a thousand psia is to generate only a few psia of pressure drop across the cake layer. All the rest of pressure energy is expended in accelerating the gas or in overcoming the system friction and is eventually lost.] Future filter designs must pay careful attention to the design of the piping system between the gas reservoir and the filters.

\subsubsection{Conceptual Design}

The conventional systems use equipment that is commercial. The fast acting valve may be considered developmental especially if a larger valve is desired. A larger valve would decrease pressure drop and therefore blowback reservoir pressure requirements. For the carbonizer and gasifier, fuel gas must be cooled and recompressed but, again, the heat exchangers and compressors are standard equipment.

In order to prevent thermal shock it is advantageous to use as hot a gas as possible. The maximum operating temperature of the back pulse valve limits the tank gas temperature to $400^{\circ} \mathrm{F}$ for the type of valve that is used at Tidd. Since the pulse is very rapid, attempting to heat the gas in the external pipe after the valve would not be effective. It may be possible that in the future a high temperature, fast acting valve and a properly designed ejector could produce a blowback gas hot enough to prevent thermal shock. For this evaluation a $400^{\circ} \mathrm{F}$ maximum blowback gas was used in the design. The development of higher temperature, fast acting valves could alleviate this situation.

The criteria for determining at what temperature thermal shock starts occurring for candle filters is based on tests that showed that at temperatures $100^{\circ} \mathrm{F}$ below operating temperature micro cracking of the candle is observed. However, long term test results with candle filters blown back with "cold" air have not shown that micro cracking necessarily leads to candle filter failure. Westinghouse at the Tidd facility, for example, has made no attempt to use heated blowback gas in the reservoir. Candle life data from this facility could provide useful information for blowback system design.

The rapid combustion system, while at this time only a concept, has the potential to reduce thermal shock significantly with present technology. While somewhat similar combustion systems have been built and operated none were designed to deliver a precise amount of gas at a certain temperature, pressure and flow rate. A significant amount of test work will be needed before this concept can be considered commercial. This work will include fuel selection, fuel and oxidant feed control, firing mechanism and sonic orifice design.

The carbonizer and gasifier systems use recycled fuel gas therefore do not suffer a blowdown dilution effect. The other systems using compressed air use such small amounts dilution is not a concern. The amounts shown in Table 5.4-2 are for blowback cycles of 60 minutes but even if the blowback cycle was reduced to an unlikely ten minutes dilution would not be a factor to be concerned about. 
Since the cleaning of multiple elements in a plenum has the potential to reduce the complexity of the blowback system, most of the vendors are pursuing this approach. More data is needed on this approach to verify the uniformity of the gas distribution and cleaning. Testing at Tidd should answer some of these questions.

At this period in the development of blowback systems for CPFBC and gasifier environments, feasibility rather than comparative costs may be the determining factor for choosing one system over another. This is because capital costs and operating costs based on these conceptual designs do not vary much between the eight cases except for on-line versus off-line comparisons. The feasibility of even the conventional system being tested at Tidd has not been demonstrated for long term periods especially the effect of the low temperature blowback on candle filter stability. There is even less experience for systems tested under gasifier conditions at high temperature and pressure.

The separation of particles is a result of gravitational settling after blowback. In addition to demonstrating blowback techniques it will be important to determine that the particles blown off can settle in a reasonable amount of time. Ways of achieving rapid settling by additives, blowback technique or filter design should be explored.

\subsubsection{Economic Analysis}

Off-line cleaning has a slightly higher cost than on-line cleaning even though more efficient. This was due primarily to the extra vessels required. The cost difference between rapid combustion $400^{\circ} \mathrm{F}$ cold on-line cleaning is negligible. Technical feasibility and not cost will determine which technique is chosen.

The cost driver of the total system cost are the vessel costs. The vessel costs represents approximately $75 \%$ of the total plant cost. Thus a HGCU system configuration for on-line cleaning is less costly even though less efficient than the same application with off-line cleaning. The blow back systems including gas compression represent a small percentage of the total system cost.

The cost of the ceramic barrier filter system for the advanced PFBC plant is about 2.5 times the cost for the IGCC plant. The PFBC plant requires two filter systems, one for the combustor and one for the carbonizer, and has a much higher gas volume. The cost of the cleanup system as compared to the total plant cost, however, is relatively small, $10-12 \%$ for the advanced PFBC and $4-5 \%$ for the IGCC.

\subsection{CONCLUSIONS}

- The on-line $400^{\circ} \mathrm{F}$ pulse blowback system is commercially available and has been widely tested under both PFBC and IGCC conditions. Potential limitations include thermal shock and particle redeposition resulting in poor overall filter cleaning efficiency.

- The off-line $400^{\circ} \mathrm{F}$ pulse blowback system should provide an improved filter cleaning efficiency by allowing the dust particles to fall to the bottom of the filter vessels. However, this has yet to be demonstrated and quantified through large scale tests. The greater efficiency will come with a higher capital costs associated with additional valve and vessels. As with the on-line system, thermal shock could also be a potential limitation.

- The rapid combustion pulse blowback system, while at this time only a concept, has the potential to eliminate thermal shock in a cost effective manner. A significant amount of test work will be needed before this concept can be considered viable. The rapid combustion 
pulse system was not included for the carbonizer and IGCC cases due to concerns about producing a reducing gas pulse for these applications.

- The criteria for determining at what temperature thermal shock starts occurring for candle filters is based on tests that showed that a temperatures $100^{\circ} \mathrm{F}$ below operating temperature micro cracking of the candle is observed. However, long term test results with candle filters blown back with "cold" air have not shown that micro cracking necessarily leads to candle filter failure.

- The off-line cleaning system has a higher cost due primarily to the extra vessels required to maintain a constant face velocity. However, if testing shows that off-line cleaning can sustain a higher face velocity this cost differential will disappear. These costs, however, were a small portion of the entire plant costs. Technical feasibility and not cost will determine which technique is chosen.

- The cost driver for the ceramic barrier filter cost are the vessel costs. The blowback systems including gas compression represent a small percentage of total system costs.

- The spreadsheet model developed for this task can be used to assist conceptual design of a blowback system or used as an analytical tool to compare performance of different filter cleaning techniques. It became clear during the model development that many of the fundamental process parameters required for the effective design of blowback systems are not commonly available in the literature nor easily estimated by theoretical means.

- Based on calculations for plenum blowback using G/C's spreadsheet model, it appears that a fast acting valve may not be needed. If this is the case, a less expensive, high temperature valve may be used and the reservoir gas temperature could be heated to alleviate thermal shock.

\subsection{R\&D RECOMMENDATIONS}

- Several fundamental parameters (such as cake separation stress) required for the effective design of blow back systems are not commonly available in the literature nor easily estimated by theoretical means. It is recommended $R \& D$ effort be directed in establishing/compiling this class of information.

- The main advantage of off-line cleaning is that dust particles have sufficient time to fall to the bottom of the filter vessel before redepositing. However, there is no quantitative data on the mean particle size of dust blown off candle filters. This needs to be determined and ways of achieving rapid settling by additives, blow back techniques or filter and vessel design should be explored.

- In order to prevent thermal shock it is advantageous to use as hot a gas as possible. The operating temperature of the back pulse valve is the present limit on blow back temperature. The development of higher temperature, fast acting valves could alleviate this situation.

- The rapid combustion system has the potential to eliminate thermal shock effects in a cost effective manner. A significant amount of development work is needed including fuel selection, fuel and oxidant feed control, firing mechanism and sonic orifice design.

- More data is needed on the plenum cleaning technique to verify the uniformity of gas distribution and cleaning. These concerns should be addressed during the testing at Tidd. 
- The piping system between the gas reservoir and the filters has a very strong impact on the pressure drop of the blow back system. Much more attention in the future needs to be paid to the design, testing and standardization of this system. 


\section{APPENDIX A}

This appendix contains complete correspondence with our consultant Dr. David Leith of the University of North Carolina. 
February 22, 1994

To: $\quad$ M. G. Klett

From: $\quad$ R. Zaharchuk

Subject: $\quad$ Meeting with David Leith, HGCU Blowback Project

During the afternoon of February 16, 1994, a meeting was held at the University of North Carolina. In attendance were:

H. Chen

R. Zaharchuk

David Leith, Director, Air, Radiation and Industrial Hygiene Program

Peter C. Raynor, Doctoral Student

The purpose of this meeting was to discuss the spreadsheet model for filter cleaning developed by $H$. Chen and to determine how best $D$. Leith and $P$. Raynor could assist $G / C$ in the DOE project concerning the evaluation of three blowback systems for candle filters. Prior to the meeting $D$. Leith was sent Task 1 and 2 progress report and spreadsheet information. During the meeting G/C gave D. Leith the METC report on candle filter tests, SRI particle analyses and other papers concerning candle filter cleaning. The meeting agenda was in three parts as follows:

1. The three blowback systems were explained by R. Zaharchuk to ensure that $D$. Leith fully understood the advantages and disadvantages of each system. He was told that conceptual designs would be done but at this time $G / C$ was not sure which systems DOE would choose. The DOE would be given our recommendations in Task 3 of the project. Although D. Leith had not been involved in hot gas cleanup since 1988, it was fairly obvious he understood the systems because of his past work on bag filters.

2. In the next portion of the meeting $\mathrm{H}$. Chen went through the blowback model spreadsheet in detail providing his rationale and basic assumptions. D. Leith agreed that using the Ergun equation was acceptable. He also admitted that he was involved in producing many models himself and was skeptical about their usefulness. He said that he would like to have a copy of our model in order to perform sensitivity studies with various parameters. $H$. Chen claimed that it would be difficult to do this since he had not written instructions on how to run the model.

During the model discussion, cake removal efficiency, cake tensile strength, cake porosity, particle size and other parameters were talked about.

3. The last portion of the meeting concerned the areas where $D$. Leith and $P$. Raynor could help $G / C$. $G / C$ requested that a letter report by Leith should be completed by the first week in March so that their input could be presented to DOE at a meeting in mid-March. The report would contain comments and potential efforts by Leith and Raynor. The areas suggested by $G / C$ were: 
- Search sources of data that may not have been published. This should include work being done by S. Rudnick who is currently a consultant for CeraMem.

- Comment on the G/C spreadsheet model.

- Comment on off-line cleaning versus on-line. D. Leith has done work on this at atmospheric conditions.

- Comment on the three blowback systems being investigated.

- Comment on dust cake characteristics such as tensile strength, pressure drop, porosity.

- Comment on blowback pressure versus time.

- Comment on re-entrainment during on-line cleaning, i.e., cake removal efficiency.

- Comment on whether data collected for pulse jet cleaning at atmospheric conditions applies to high temperature, high pressure rigid ceramic filters.

This was a very good first meeting. It is our impression that Leith and Raynor have a good understanding of the theoretical fundamentals of filter cleaning and of our current concerns and needs. This should become apparent in their first letter report. They were requested to reserve hours for a later review or additional work.

After the meeting a short tour was taken through D. Leith's test lab. He is currently doing work on industrial oil aerosol filtrations, determination of aerosol content in work areas and testing of HEPA type filters.

\section{RZ:als}

cc: $\quad$ H. T. Chen 
3 May 1994

Mr. Roman Zaharchuk

Advanced Technology Services

Gilbert/Commonwealth, Inc.

P.O Box 1498

Reading, PA 19603-1498

Dear Roman:

Following is my report on the questions you asked me recently. I will put the originals in the mail today, and include copies of several articles that you may not have but that are listed in the references.

Please let me know if you have any questions.

Sincerely yours,

Dewind

David Leith 


\section{May 1994}

Mr. Roman Zaharchuk

Advanced Technology Services

Gilbert/Commonwealth, Inc.

P.O Box 1498

Reading, PA 19603-1498

Dear Roman:

During our telephone conversation on April 21, you asked me to consider two questions regarding the cleaning of ceramic candle filters:

- Estimate the effectiveness of off-line cleaning with the plenum-pulse system, assuming the size distribution of the removed dust is given in the report by Snyder and Pontius of Southern Research Institute, SRI (1).

- Estimate the effect of taking one vessel off-line for cleaning on the performance of the vessels that remain on-line.

This letter will give you my thoughts on these questions.

\section{Effectiveness of Off-Line Cleaning}

To address this question, I made several assumptions.

1. Immediately after the plenum pulse, dust removed from the ceramic candles is spread in uniform concentration throughout the vessel tier cleaned.

This assumption seems reasonable. The action of the plenum pulse should drive dust away from the candles and mix it thoroughly with the gas in the vessel tier cleaned. I am not assuming the dust remains in uniform concentration, see point 3 below, only that it has uniform concentration immediately after the plenum pulse.

2. The size distribution of the removed dust is given by the data in the SRI report.

Several size distributions are presented in this report. I did separate calculations for several of the size distributions presented there. In general, the size distributions presented for the filter cake are finer than the size distributions for the hopper ash.

3. Gas in the vessel is partially mixed due to convection after the plenum pulse. 
The degree of gas mixing in the vessel will affect how the dust settles. I did separate calculations for gas fully and continuously mixed due to convection, and for gas that is stagnant and not mixed at all. Reality should lie between these two extremes. As shown below, there is little difference in these two cases unless enough time passes to remove a significant fraction of the dust.

4. This work makes no assumption about the fraction of the dust cake on the ceramic filters that the plenum pulse separates.

The fraction of dust on the ceramic candles that is removed from the system by a plenum pulse will deperd on the product or the fiaction of dust un the candles that is sepurated by the pulse, multiplied by the fraction of dust removed that settles out by gravity over time, after the pulse. This letter does not consider the fraction of dust that is separated. It addresses the fraction of removed dust that scttles out hy gravity.

Theory

The fraction of dust particles of a given size that settle from a closed chamber when the gas within the chamber is continuously stirred or mixed by convection is given by Eq. (1). The fraction of these same particles that settle from the chamber if the gas within is stagnant is given by $\mathrm{Eq}$. (2). These equations can be readily derived; let me know if you would like the derivations.

$\eta_{\text {mixad }}=1-\exp \left[\frac{-v_{1} t}{H}\right]$

$\eta_{\text {manem }}=\frac{v_{1} t}{H}$

where
$v_{t}$ is the particle's terminal settling velocity,
$t$ is time, and
$H$ is the height of the chamber.

Equations for terminal velocity and its dependence on temperature and pressure are given in the Appendix.

For particles with a size distribution, the overall removal efficiency for the dust is given by

$\eta_{\text {ovendi }}=\int_{0}^{1} n(d) d G \approx \sum_{1}^{n} n(d) \Delta G$

where $n$ (d) is efficiency as a function of particle size as given by Eq. (1) or Eq. (2) abnve, and dC is the differential fraction of all particles in the distribution with size " $\mathrm{d}$ ". For a discrete frequency distribution, as given in the SRI dalu, the diMerential "dO" van be replaced by " $\Delta G$ ". Eq. (3) was used to determine the fraction of dust in the vessel removed by gravitational settling in time " $t$ ". 


\section{Method}

Size distributions for Tidd hopper ash, ID\#2998, Tidd filter cake ash, ID $\$ 4012$, and EPRU/Grimethorpe filter cake ash, DD\$2896 were taken from the SRI report and used in a spreadsheet that utilized the above equations to determine fly ash removal by settling from the vessel. In all these calculations, the height of the tier cleaned was assumed to be 3 meters. Gas temperature was iaken to be $1550 \mathrm{~F}$; pressure was taken to be ten atmospheres. Under these conditions, gas viscosity was taken to be $3.0 \times 10^{-5} \mathrm{lb} /(\mathrm{ft}-\mathrm{s})$ from the spreadsheet compiled by $\mathrm{Dr}$. Herbert Chen of your firm (2).

Results

Results of these calculations are given in the spreadsheets on the three pages at the end of this letter. Of most interest are the plots in the lower left corners of each spreadsheet, which show the fraction of dust that settles out against time since the cleaning pulse. Two lines are shown on each plot, one for the well-mixed case where removal efficiency is given by Eq. (1), and one for the stagnant case where removal efficiency is given by Eq. (2). For low removal cfficiencies, these lines converge.

If we assume that the size distribution for the separated ash is most like that given by the sample from the Tidid hopper, ID $\$ 2998$, it appears that after ten seconds less than $1 \%$ of the ash will have settied from the vessel. After about two minutes, about $10 \%$ will have settled out. The Tidd hopper ash is the coarsest ash considered in this analysis.

If we assume that the size distribution of the separated ash is most like that given by the sample from the EPRU/Grimethorpe or Tidd filter cakes, then the time necessary for $1 \%$ of the ash to settle out is 20 to 70 seconds, respectively. Similarly, the time necessary for $10 \%$ of the ash to settle becomes about 250 to 1000 seconds, respectively. The EPRI/Grimethorpe and Tidd filter cake ashes are finer than the Tidd hopper ash, and so take longer to settle.

\section{Discussion}

Regardless of which ash we assume represents most accurately the size distribution of the dust separated from the ceramic candles by a plenum pulse, these calculations suggest that the pressure vessel will have to remain off-line for a significant amount of time if much of the dust is to settle out. Dust that does not settle out completely will redeposit on the candle filters when they come back on line, increasing the mass of the clust cake on the filters and the subsequent pressure drop.

The key assumption in these calculations is that the size distribution of the dust freed from the candles by a plenum pulse is the same as the size distribution of the dust cake on the filters or in the hopper. We can hope that the dust freed from the candles by the plenum pulse will be coarser than the distributions for cake or hopper dust measured by SRI. This freed dust may contain agglomerates that would settle relatively quickly. If these agglomerates are fragile, they might be broken apart in the process of measuring the size distribution of the hopper dust. The fact that the hopper dust had a coarser size distribution than the filter cake dust shows that agglomeration does occur, as otherwise the size distributions of these two dusts would be the same. 
Although we might be hopeful that settling will be more effective than is calculated here, in my view we should not plan on it. Experiments with pulse-jet cleaned fabric filters that collected fly ash with size distributions similar to those expected in pfbc operations had removal efficiencies that generally were about $10 \%$ for on-line cleaning at filtration velocities lower than about 10 $\mathrm{cm} / \mathrm{s}(3,4)$. Removal efficiencies for off-line cleaning were slightly higher, but comparable (5).

We can also use these results to estimate the fraction of dust that should settle to the bottom of the vessel during on-line cleaning. This can be done by realizing that the mean residence time for the gas in the vessel, $t$, is given by

$t=\frac{V}{Q}$,

where the dusty-side volume of the pressure vessel is given by " $\mathrm{V}$ ", and the gas flow through the vessel is given by " $Q$ ". Thus, if these two parameters are known, we can calculate mean residence time in the vessel and enter the same spreadsheet plots discussed above to determine the fraction of separated dust that should fall to the hopper after an on-line pulse. The complement of this fraction will redeposit on the candle filters. Although I do not have data for V and Q, I would expect that the mean residence time for the gas in the vessels would be less than ten seconds. These calculations suggest that only a very small fraction of the separated dust should settle out by gravity during this time.

These resulis can also be used to help determine the minimum mass of dust per unit area that will remain on a candle after pulse cleaning, $w$. This is given (4) by

$w=\frac{w_{0}}{\eta y}$,

where $w_{\theta}$ is the mass per unit area added to the candle between cleaning pulses and is given by $w_{0}=c v$ tinleval, where $c$ is inlet mass concentration, $v$ is filtration velocity, and $t_{\text {ineoval }}$ is the time between cleaning pulses. Here, $\gamma$ is the fraction of the dust cake that is freed by the cleaning pulse, and $\eta$ is the fraction of removed dust that settles to the hopper after a pulse as calculated according to the methods in this letter. In the optimistic event that the cleaning pulse removes all dust from the candle, $\gamma=1$, and Eq. (5) can be solved to give the mass per unit area of the dust cake after a pulse. This calculation could be done for reasonable operating values for the ceramic candle filters, to determine the expected mass of dust that would remain on the filters for modeling pressure drop.

\section{Effect of Taking One Vessel Orf Line on Remaining Vessels}

If one vessel is taken off-line for cleaning, the flow that previously passed through that vessel would have to be diverted to the vessels that remain on-line. The increase in flow thorough the vessels that remain on-linc would be given by

$Q_{\text {during oleming }}=Q_{\text {nocleming }}\left(\frac{N}{N-1}\right)$. 
where $Q$ is gas flow to any single vessel and $N$ is the total number of vessels. Clearly, as the total number of vessels increases, the effect on flow through a vessel that remains on-line is minimized.

The effect on pressure drop of increased flow through a vessel can be checked using $D r$. Chen's model. I would expect that most but not all of the pressure drop through a candle filter would be laminar; and in that case pressure drop is proportional to flow. Thus, as a minimum, we could expect that pressure drop through the on-line vessels would increase by the value given in the parenthetic expression in Bq. (6) above.

Some second-order effects may also occur. The added pressure drop caused by higher velocity during cleaning has the potential to cause some cake collapse on the candle filters that handle the extra flow. The effect of this collapse would be to decrease cake porosity, further increasing pressure drop which could cause further collapse, etc. Thus, the net effect of off-line cleaning on the pressure drop for the remaining vessels might be to cause higher pressure drops than expected on the basis of flow diversion alone. Whether the collapsed cake would be easier or more difficult to clean from the candle filter than cake that did not collapse is difficult to say.

Because these calculations suggest that a vessel will have to remain off-line for a considerable length of time before appreciable dust settles out, it may be necessary to consider designing a system in which one vessel is always off-line for cleaning. The particular vessel off-line would rotate through all vessels used. In this case, cleaning of any given vessel would be more frequent if fewer vessels are used. Calculations could be done to determine the feasibility of this concept.

I hope these comments will be useful. Please let me know if you have questions about the points raised here, or if you have additional questions. I am enjoying working with you on these problems.

Sincerely yours,

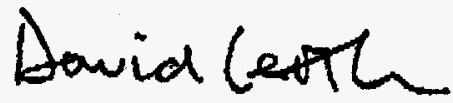

David Leith, Sc.D. 
References

1. Snyder, T.R and D.H. Pontus, "Assessment of Ash Characteristics from Gas Stream Cleanup Facilities", report SRI-ENV-93-904-6938-T1, prepared for T.P. Dorchak, USDOE, Morgantown, WV 1993.

2. Chen, H.T., "Properties of Fuel Gas and Flue Gas", spreadsheet output dated 2/15/94.

3. Leith, D., M.W. First and H. Feldan, "Performance of a Pulse-Jet Filter at High Filtration Velocity II. Filter Cake Redeposition", JAPCA 27: 636 (1977).

4. Ellenbecker, M.J. and D. Leith, "Dust Removal Characteristics of Fabrics Used in Pulse-Jet Filters", Powder Technology, 36: 13 (1983).

5. Templin, B.R. and D. Leith, "Effect of Operating Conditions on Pressure Drop in a Pulse-Jet Cleaned Fabric Filter", Plant/Operations Progress, 7: 215 (1988).

A-9 
APPENDIX - EQUations FoR TERMINAL SETTLING VELOCITY

Equations in this section are taken from Reist (1)

Terminal velocity is given by Stokes's law,

$v_{t}=\frac{d_{s}^{2} C_{e} g}{18 \mu}$

where

d. is the particle's aerodynamic diameter,

$\mathrm{C}_{c}$ is the Cunningham slip correction factor,

$g$ is the accelcration of gravity, and

$\mu$ is gas viscosity

Slip correction factor, $C_{0}$, depends on the gas mean free path, $\lambda$, which in turn depends on temperature and pressure.

$C_{q}=1+\frac{2 \lambda}{d}\left[1.257+0.400 \exp \left(\frac{-1.10 d}{2 \lambda}\right)\right]$

$\lambda=\frac{1}{\sqrt{2} \mathrm{n} \pi \mathrm{d}_{\mathrm{m}}^{2}}$

where $d_{m}$ is the mean molecular diameter, given by $3.6 \times 10^{-8} \mathrm{~cm}$ for air, and assumed the same for the combustion gases present here. The value for $\boldsymbol{n}$ is the number of molecules per mole, and can be found from

$$
n=\frac{6.02 \times 10^{23}\left(\frac{293}{T}\right)\left(\frac{\mathrm{P}}{1}\right)}{22,400}
$$

where $6.02 \times 10^{23}$ is Avogadro's number, 22,400 is the number of $\mathrm{cm}^{3}$ per mole at $20^{\circ} \mathrm{C}, \mathrm{T}$ is absolute temperature in ${ }^{\circ} \mathrm{K}$, and $\mathrm{P}$ is absolute pressure in atmospheres.

1. Reist, Parker C., Introduction to Aerosol Science, MacMillan, New York, 1984. 
का

\begin{tabular}{|c|c|c|c|c|c|c|c|c|c|c|c|}
\hline Settlin & ng Time & 98 for $P F E$ & 3 FIy As & sh During & g Off-Lin & e Clean & ng & & & & \\
\hline Tidd hor & pper ash & $(1 \mathrm{D} * 2928)$ & & & & & & & & & \\
\hline & & & & & & & & & & & \\
\hline viscosity & $y, g /(\mathrm{cm}-5$ & s), $1 \mathrm{bm} /(\mathrm{A}-\mathrm{s})$ & $=$ & 4.47E-04 & $3.00=-05$ & & & & & & \\
\hline Pressur & $\mathrm{re}, \mathrm{atm}=$ & & & 10 & 10 & & & & & & - \\
\hline Temper & rature, oc & . OF $=$ & & 843 & 1550 & & & & & & \\
\hline Tier Hei & ight, cm & $=$ & & 300 & & & & & & & \\
\hline lambda, & $1, \mathrm{~cm}=$ & & & 0.000002 & & & & & & & \\
\hline & & & & & & & & & & & \\
\hline & Sizo biat & tribution In & formatior & $n$ & & & & & & & \\
\hline & & & & & & & & & & & \\
\hline $\operatorname{size}$ & $\%$ & Ran & & & Fracin & Ad] Frec & & & vi & & \\
\hline & & Iow & high & Midpt & Range & In Range & $\mathrm{Cc}$ & & $\mathrm{cm} / \mathrm{s}$ & & \\
\hline 0.55 & 0.0 & 0.0 & 0.6 & 0.000028 & 0.000 & 0.000 & & 1.225 & 0.00011 & & \\
\hline 0.70 & 0.0 & 0.6 & 0.7 & 0.000063 & 0.000 & 0.000 & & 1.009 & 0.00052 & & \\
\hline 1.00 & 0.0 & 0.7 & 1.0 & 0.000085 & 0.000 & 0.000 & & 1.073 & 0.00095 & & \\
\hline 1.3 & 1.2 & 1.0 & 1.3 & 0.000115 & 0.012 & 0.012 & & 1.054 & 0.00170 & & \\
\hline 1.8 & 3.0 & 1.3 & 1.8 & 0.000155 & 0.018 & 0.018 & & 1.040 & 0.00305 & & \\
\hline 2.3 & 7.0 & 1.8 & 2.3 & 0.000205 & 0.040 & 0.040 & & 1.030 & 0.00528 & & \\
\hline 3.1 & 14.0 & 2.3 & 3.1 & 0.000288 & 0.070 & 0.070 & & 1.023 & 0.00893 & & \\
\hline 4.1 & 26.0 & 3.1 & 4.1 & 0.000358 & 0.120 & 0.120 & & 1.017 & 0.01586 & & \\
\hline 5.5 & 48.0 & 4.1 & 5.5 & 0.000480 & 0.200 & 0.200 & & 1.013 & 0.02848 & & \\
\hline 7.3 & 70.0 & 5.5 & 7.3 & 0.000640 & 0.240 & 0.240 & & 1.010 & 0.05044 & & \\
\hline 10 & 74.0 & 7.3 & 10.0 & 0.000865 & 0.040 & 0.040 & & 1.007 & 0.09191 & & \\
\hline 13 & 77.0 & 10.0 & 13.0 & 0.001150 & 0.030 & 0.030 & & 1.005 & 0.16217 & & \\
\hline 18 & 84.0 & 13.0 & 18.0 & 0.001550 & 0.070 & 0.070 & & 1.004 & 0.29418 & & \\
\hline 22 & 90.0 & 18.0 & 22.0 & 0.002000 & 0.060 & 0.080 & & 1.003 & 0,48037 & & \\
\hline 31 & 94.5 & 22.0 & 31.0 & 0.002850 & 0.045 & 0.045 & & 1.002 & 0.85850 & & \\
\hline 41 & 98.0 & 31.0 & 41.0 & 0.003600 & 0.035 & 0,035 & & 1.002 & 1.58338 & & \\
\hline 501 & 100.0 & 41.0 & 50.0 & 0.004550 & 0.020 & 0.020 & & 1.001 & 2.52841 & & \\
\hline & & & & Total & 1.000 & 1.000 & & & & & \\
\hline & & & & & & & & & & & \\
\hline Fractio & nal Rem & loval by Gr & vitationa & al settling & & & & & & & \\
\hline & & & & & & & & & & & \\
\hline & well $m \mid x$ & stagnant & & & & & & & & & \\
\hline $\operatorname{tine}$ & otg_mix & ote_ster & & & Frac & of $t$ & & & ttlas Ou & & \\
\hline 1 & 0.0007 & 0.0007 & 1.0000 & $x$ & & & & & & & \\
\hline 2 & 0.0015 & 0.0015 & & & & & & & & & \#政 \\
\hline 4 & 0.0030 & 0.0030 & & & & \#\# & & tet & & Af & Itn \\
\hline 8 & 0.0059 & 0.0080 & & & & & & & & & \\
\hline 16 & 0.0116 & 0.0119 & & & & & & & & & \\
\hline 32 & 0.0224 & 0.0230 & 7 & & & & & & +1 & & \\
\hline 64 & 0.0423 & 0.0477 & 8 & & & ( & & & 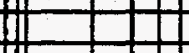 & $\mathrm{m}$ & ifttit \\
\hline 125 & 0.0746 & 0.0032 & & & & & & & & & $11 \mathrm{II}$ \\
\hline 250 & 0.1252 & 0.1864 & & & 我事 & 弗 & & & $\equiv$ & & \\
\hline 500 & 0.1081 & 0.3720 & & & & 冊 & & $72+$ & $7=$ & & a_mix 册 \\
\hline 1000 & 0.2768 & & E & & & & & $H$ & +4 & & 曲 \\
\hline 2000 & 0.3769 & & & & & $171]$ & & & & ]- & - eta_cteg | \\
\hline 4000 & 0.4984 & & & & & 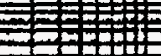 & & & 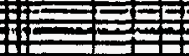 & & 曲曲 \\
\hline 8000 & 0.6434 & & & & & 册冊 & & 井 & 7 & & $2+$ 册 \\
\hline 16000 & 0.7862 & & & & & +t-m & & Ditt & & m & 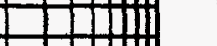 \\
\hline & & & 0,0004 & & & 1101 & & 11111 & & & 1011 \\
\hline & & & & 1 & 10 & 10 & & & 1000 & 10000 & 100000 \\
\hline & & & & & & & Time, & secondt & & & \\
\hline & & & & & & & & & & & \\
\hline
\end{tabular}




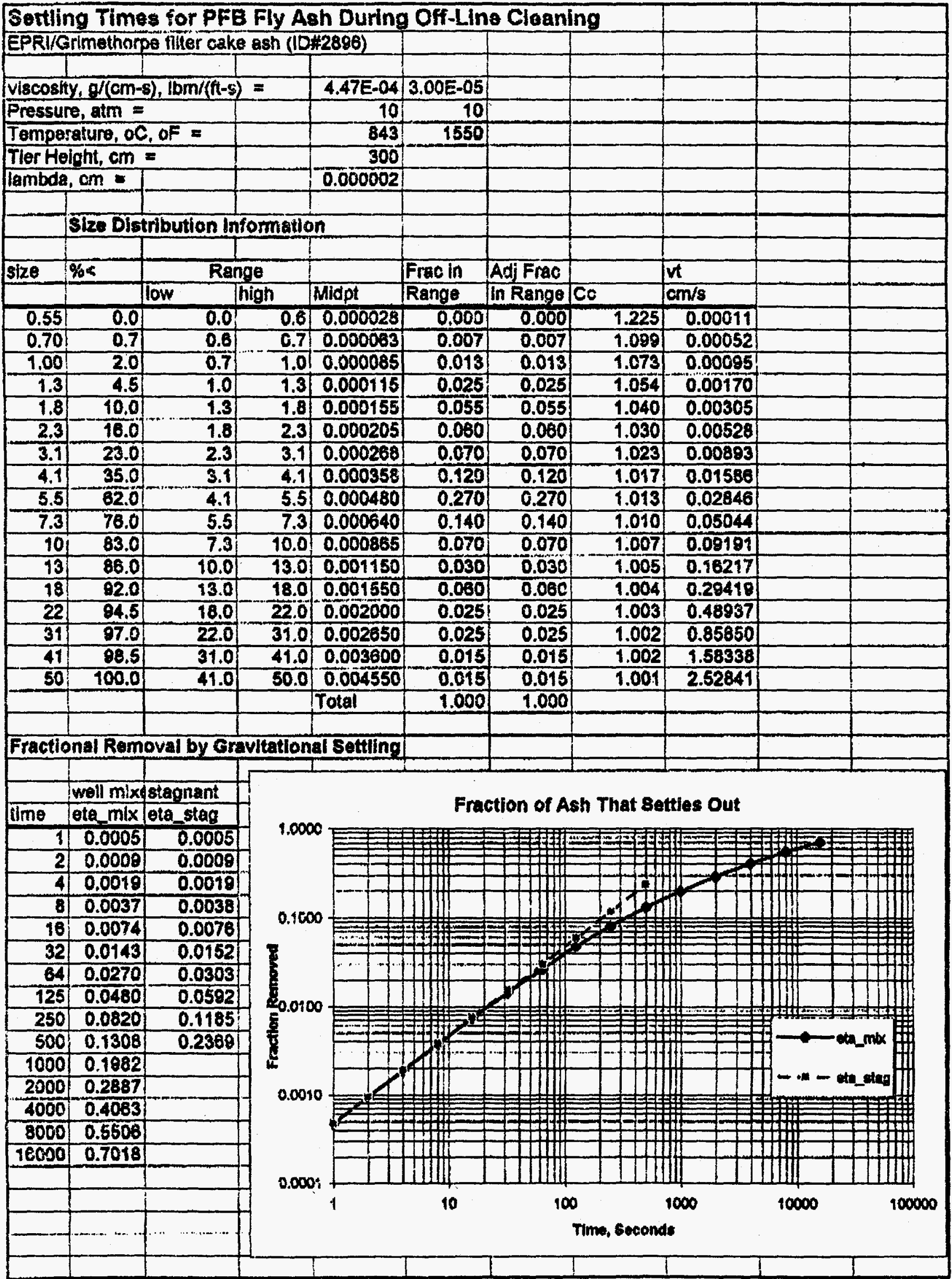


Sheet1

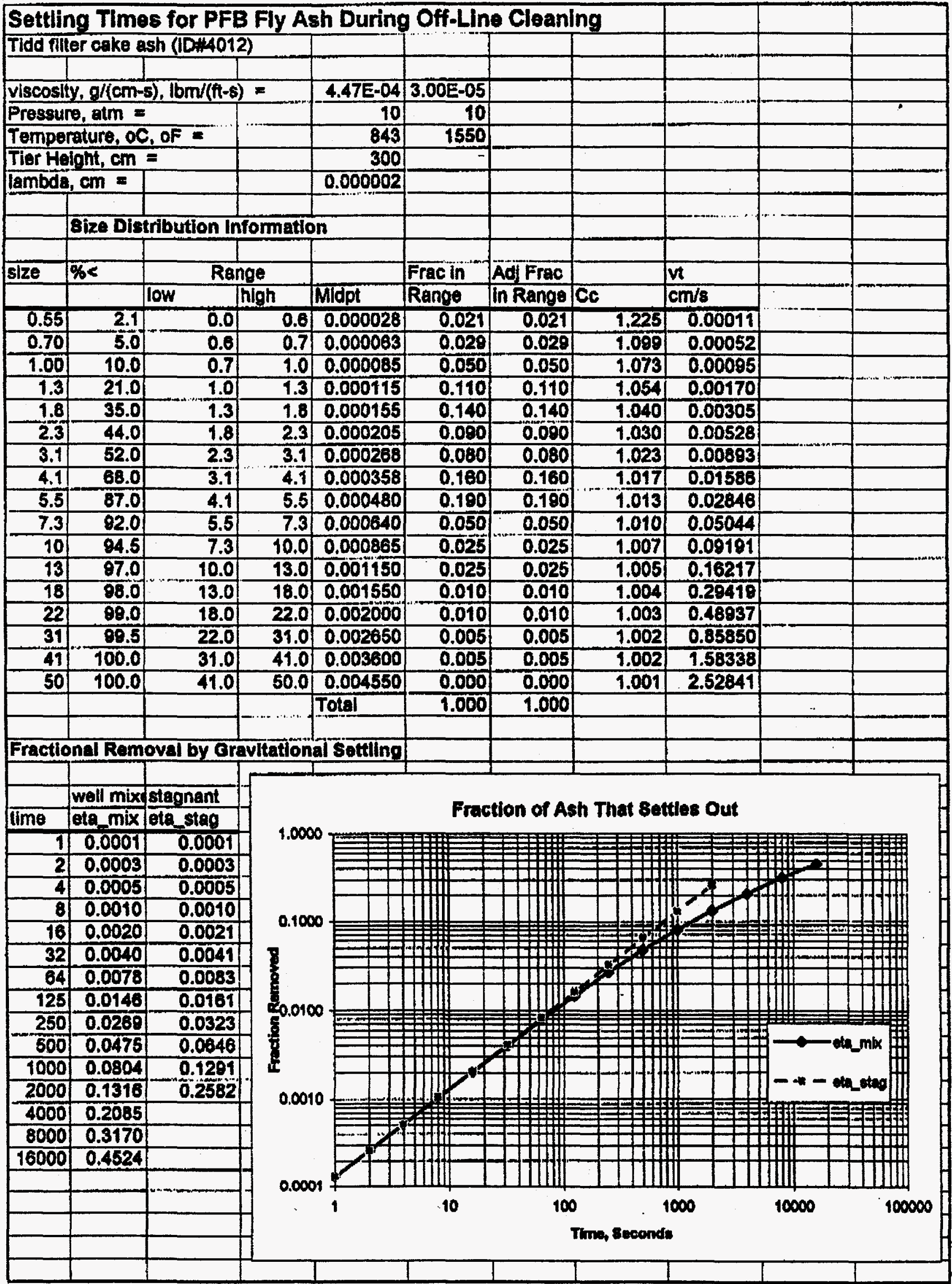


Mr. Roman Laharchuk

Advanced Technology Services

Gilbert/Commonwealth, Inc.

P.O Box 1498

Reading, PA 19603-1498

Dear Roman:

On 5 May you asked me to do some calculations to determine how long it would take for ash to settle from a vessel if the ash particles are all $200 \mathrm{~km}$ in aerodynamic diameter. You asked me to determine this relationship for a single tier of candle filters 3 meters high, and aiso for a bank of four tiers a total of 12 meters high.

\section{Method}

To make this calculation, we must first determine the settling velocity for $200 \mathrm{Hm}$ particles under high temperature and pressure conditions. Unfortunately, Stokes's law cannot be used as we are out of the Stokes drag region. Thus, we must first calculate $\mathrm{C}_{\mathrm{D}} \mathrm{Re}^{2}$, where

$C_{D} \operatorname{Re}^{2}=\frac{4 d^{3} \rho_{r}\left(\rho_{t}-\rho_{p}\right) \mathrm{g}}{3 \mu^{2}}$

and:

CD is drag coefficient,

Re is Reynolds number,

d is particle diameter,

of is fluid density,

$\rho_{p}$ is particle density,

8 is the acceleration of gravity, and

$\mu \quad$ is gas viscosity

For this calculation, I used $\rho_{f}=0.00315 \mathrm{~g} / \mathrm{cm}^{3}, \rho_{p}=1 \mathrm{~g} / \mathrm{cm}^{3}$, and $\mu=0.000447 \mathrm{~g} /(\mathrm{cm} \mathrm{s})$, where the values are for $1550 \mathrm{~F}$ and 10 atmospheres. For these conditions, $\mathrm{C}_{\mathrm{D}} \mathrm{Re}^{2}=165$.

From Figure 4.3 on pagc 48 of Reist (1), we find the corresponding value of Reynolds number, $R c$, is 5 , from which 
$v_{t}=\frac{\operatorname{Re} \mu}{d \rho_{f}}=35 \mathrm{~cm} / \mathrm{s}$

The value for settling velocity from Eq. (2) was then substituted into the spreadsheet used previously and described in iny letter to you dated 2 May 1994 for calculating removal by settling.

Further spreadsheet calculations were carried out for settling heights of 12 meters, both for the $200 \mu \mathrm{m}$ ash particles and for ash particles with the size distributions analyzed previously.

\section{Results}

Results of these calculations are shown in the tables attached. The first table shows settling for $200 \mu \mathrm{m}$ particles in a 3 meter vessel. It shows that over $10 \%$ of the ash will settle out in less than one second using either the fully mixed or the stagnant gas models. Essentially all of the ash will settle out after ten seconds.

The second table attached shows the results for $200 \mu \mathrm{m}$ particles where the settling distance is 12 meters instead of 3 meters. It shows that nearly $20 \%$ of the ash will settle out atter 10 seconds, and that removal will he essentially complele gfer one minute.

The third, fourth, and fifth tables show settling data for a 12 meter settling height, where the size distribution of the ash is assumed to be that of EPRI/Grimethorpe ash \#2996. Tidd filter cake ash \#4012, and 17idd hopper ash \#2998. These tables show that several minutes are necessary for only a few percent of the ash to settle out, and that even after an hour of settling a substantial fraction of the freed ash will remain in suspension in the gas.

\section{Discussion}

These calculations stiow that setling estinutes are very serisitive to assunptions about the size distribution of the ash freed from the ceramic candle fillers during cleaning. If we assume that the ash particles are all $200 \mu \mathrm{m}$ in diameter, then complete settling occurs relatively quickly. On the other hand, if we use available data to estimate the size distribution of the ash, it appears that settling will be much slower. The data suggest that the mean size of the ash is several orders of magnitude smaller than the $200 \mu$ im assumption.

Data from pulse-jet cleaned fabric filters that I have sent you previously suggest that settling will be slower rather than faster. My own view is that we should think very carefully before disregarding the data on size distribution that we already have, in favor of assumptions about what the size distribution might be.

\section{Additional Thought}

It seems to me that the candle filters have two jobs here. The first job is to separate the particles from the gas stream. The second job is to coalesee these collected particles into agglomerates large enough to settle out quickly when the filters are cleaned. Actual removal of 
the ash from the gas stream occurs due to gravitational settling of the agglomerates, as it is settling that actually removes the particles from the process gas. A great deal of attention has been given to the effectiveness with which the filters do their first job, and separate the particles from the gas. Perhaps too little attention has been given to their ability to build large agglomerates.

The problem we are running into is that gravitational settling is a relatively ineffective method to remove particles from gas. If the filters do their second job poorly and are relatively ineflicient as agglomerators, the agglomerated ash will remain fine and settle out slowly, even with off-line cleaning.

Thus, some additional work may be warranted to determine what can be done to foster ash agglomeration by candle filters. At the same time, we might consider methods other than gravitational settling to remove agglomerated ash. As you know, I have great interest in cyclones for ash collection. Perhaps ' $N$ should consider using a secondary cyclone to remove the agglomerates from the back-pulsed gas. Because a cyclone is nuch more efficient than gravity at removing particles, the gas in the vessel after filter pulse cleaning could be cleaned of agglomerates in a few seconds rather than requiring minutes or even hours.

I hope these thoughts will be helpful. Please let me know if you have questions or comments.

Sincerely yours,

David Leith, Sc.D.

\section{Reference}

1. Reist, P.C., Introduction to Acrosol Science, Macmillan, New York, 1984. 
Sheal

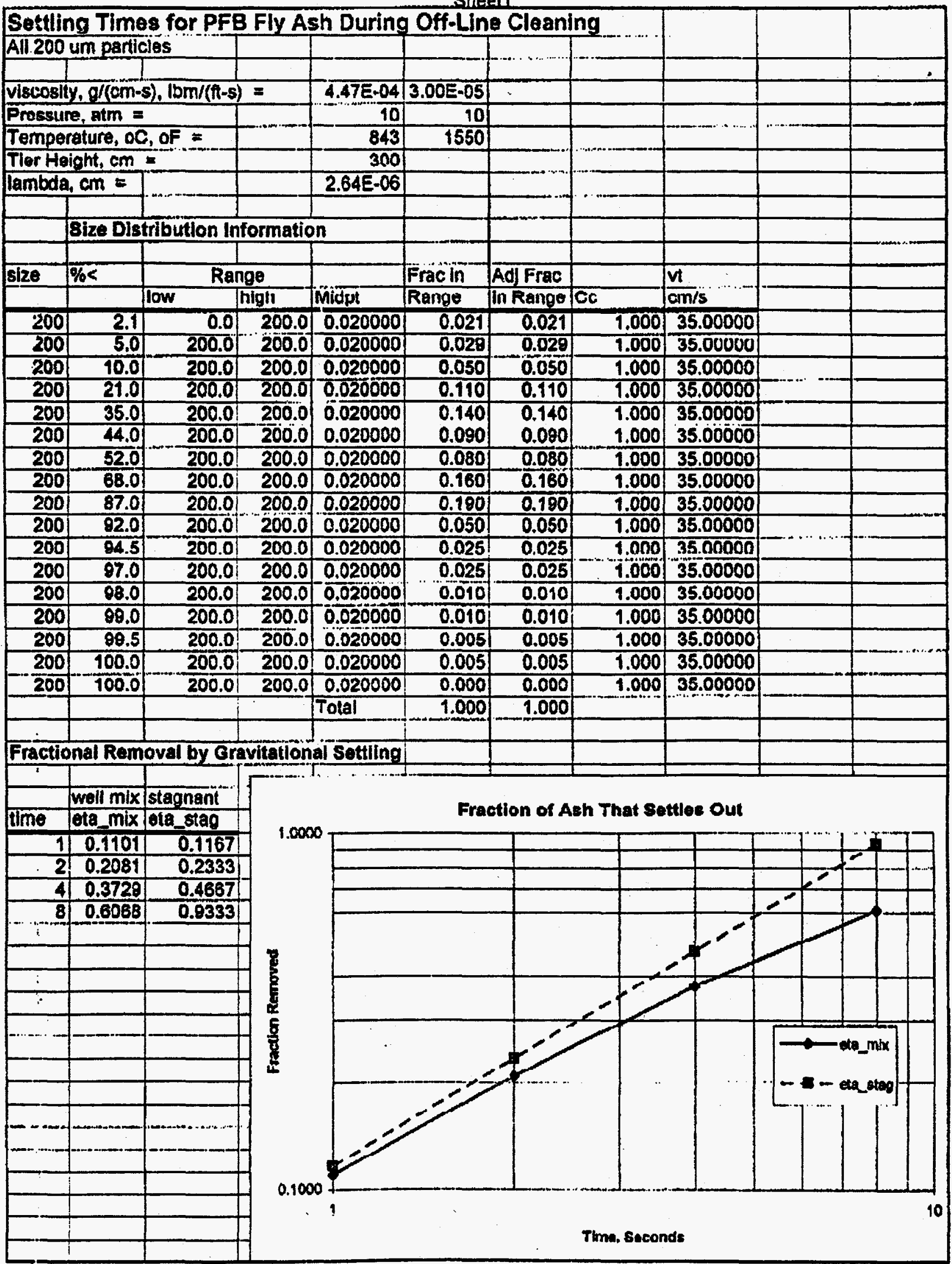


Sheet1

Settling Times for PFB Fly Ash During Off-Line Cleaning All 200 um particles

vlscosily, $g /(\mathrm{cm}-\mathrm{s}), \mathrm{lbm} /(\mathrm{ft}-\mathrm{s})=$

Pressure, atm =

Temperature, oc of $=$

Tlor Helght, $\mathrm{cm}=$

Iarnbda, $\mathrm{cm}=$

4.47E-04 3.00E-05

\begin{tabular}{r|r|}
\hline 10 & 10 \\
\hline
\end{tabular}

843

1200

8ize Distribution Information

$2.64 \mathrm{E}-06$

\begin{tabular}{|c|c|c|c|c|c|c|c|c|}
\hline & 20 & & & & & & & \\
\hline & & & & & & & & \\
\hline size & $\%<$ & $\mathbf{R a}$ & inge & & Frac in & Adl Frac & & $v t$ \\
\hline & & How & Thigh & Midpt & Range & in Range & $\mathrm{Cc}$ & $\mathrm{cm} / \mathrm{s}$ \\
\hline 200 & 2.1 & 0.0 & 200.0 & 0.020000 & 0.021 & 0.021 & 1.000 & 35.00000 \\
\hline 200 & 5.0 & 200.0 & 200.0 & 0.020000 & 0.028 & 0.029 & 1.000 & 35.00000 \\
\hline 200 & 10.0 & 200.0 & 200.0 & 0.020000 & 0.050 & 0.050 & 1.000 & 35,00000 \\
\hline 200 & 21.0 & 200.0 & 200.0 & 0.020000 & 0.110 & 0.110 & 1.000 & 35.00000 \\
\hline 200 & 35.0 & 200.0 & 200.0 & 0.020000 & 0.140 & 0.140 & 1.000 & 35.00000 \\
\hline 200 & 44.0 & 200.0 & 200.0 & 0.020000 & 0.090 & 0.090 & 1.000 & 35.00000 \\
\hline 200 & 52.0 & 200.0 & 200.0 & 0.020000 & 0.080 & 0.080 & 1.000 & 35.00000 \\
\hline 200 & 68.0 & 200.0 & 200.0 & 0.020000 & 0.160 & 0.160 & 1.000 & 35.00000 \\
\hline 200 & 87.0 & 200.0 & 200.0 & 0.020000 & 0.180 & $0.18 \overline{0}$ & 1.000 & 35.00000 \\
\hline 200 & 92.0 & 200.0 & 200.0 & 0.020000 & 0.050 & 0.050 & 1.000 & 35.00000 \\
\hline 200 & 84.5 & 200.0 & 200.0 & 0.020000 & 0.025 & 0.025 & 1.000 & 35.00000 \\
\hline$\overline{200}$ & 97.0 & 200.0 & 200.0 & 0.020000 & 0.025 & 0.025 & 1.000 & 35.00000 \\
\hline 200 & 98.0 & 200.0 & 200.0 & 0.020000 & 0.010 & 0.010 & 1.000 & 35.00000 \\
\hline 200 & 89.0 & 200.0 & 200.0 & 0.020000 & 0.010 & 0.010 & 1.000 & 35.00000 \\
\hline 200 & 98.5 & 200.0 & 200.0 & 0.020000 & 0.005 & 0.005 & 1.000 & 35.00000 \\
\hline 200 & 100.0 & 200.0 & 200.0 & 0.020000 & 0.005 & 0.005 & 1.000 & 35.00000 \\
\hline 200 & 100.0 & 200.0 & 200.0 & 0.020000 & 0.000 & 0.000 & 1.000 & 35.00000 \\
\hline & & & & Total & 1.000 & 1.000 & & \\
\hline & & & & & & & & \\
\hline act & & & & & & & & \\
\hline
\end{tabular}

\begin{tabular}{|r|r|r|}
\hline & & \\
\hline & well mlx & stagnant \\
\hline time & ota_mix & ota_stag \\
\hline 1 & 0.0287 & 0.0292 \\
\hline 2 & 0.0567 & 0.0583 \\
\hline 4 & 0.1101 & 0.1167 \\
\hline 1.8 & 0.2081 & 0.2333 \\
\hline 16 & 0.3729 & 0.4667 \\
\hline 32 & 0.6068 & 0.9333 \\
\hline & & \\
\hline & & \\
\hline & & \\
\hline & & \\
\hline & & \\
\hline & & \\
\hline & & \\
\hline & & \\
\hline & & \\
\hline & & \\
\hline
\end{tabular}

Fraction of Ash That Bettles Out

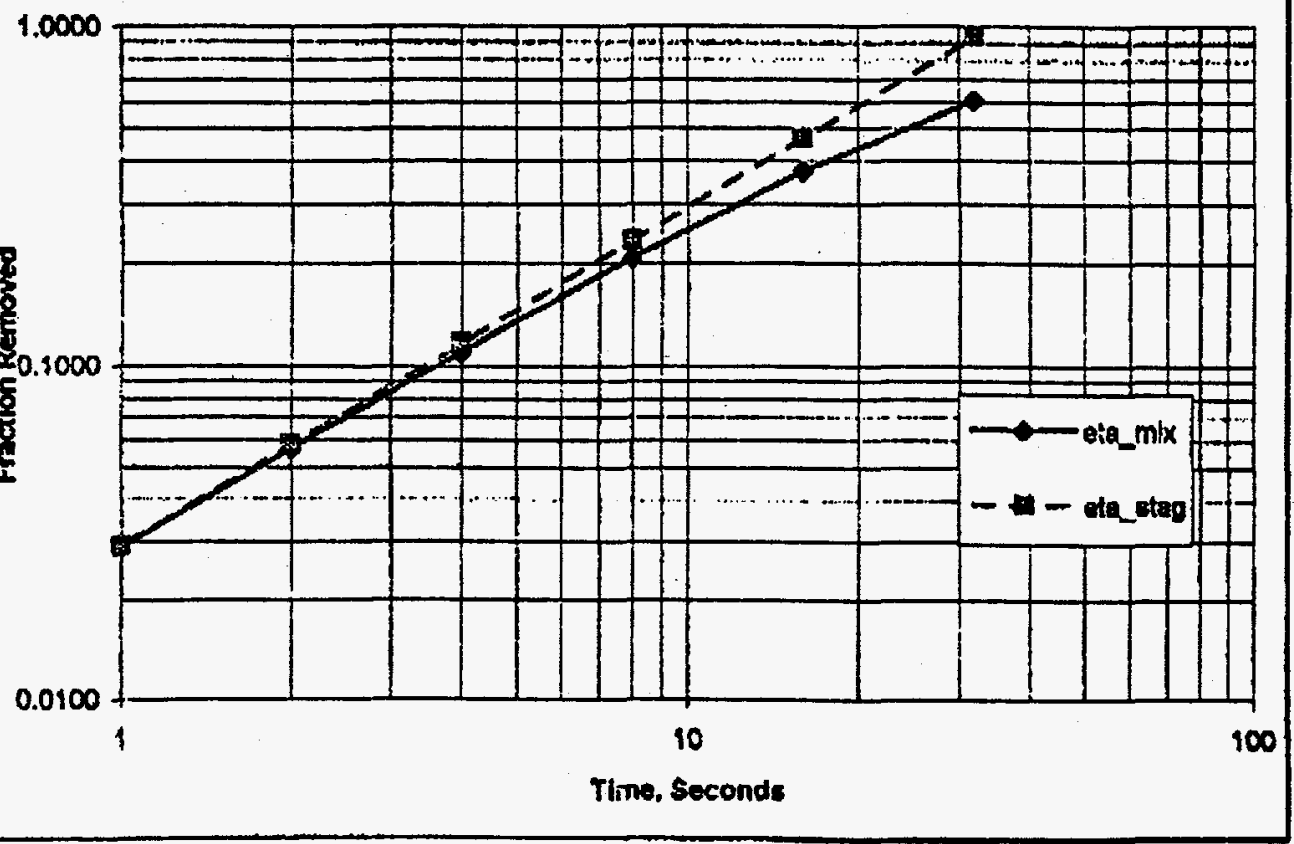




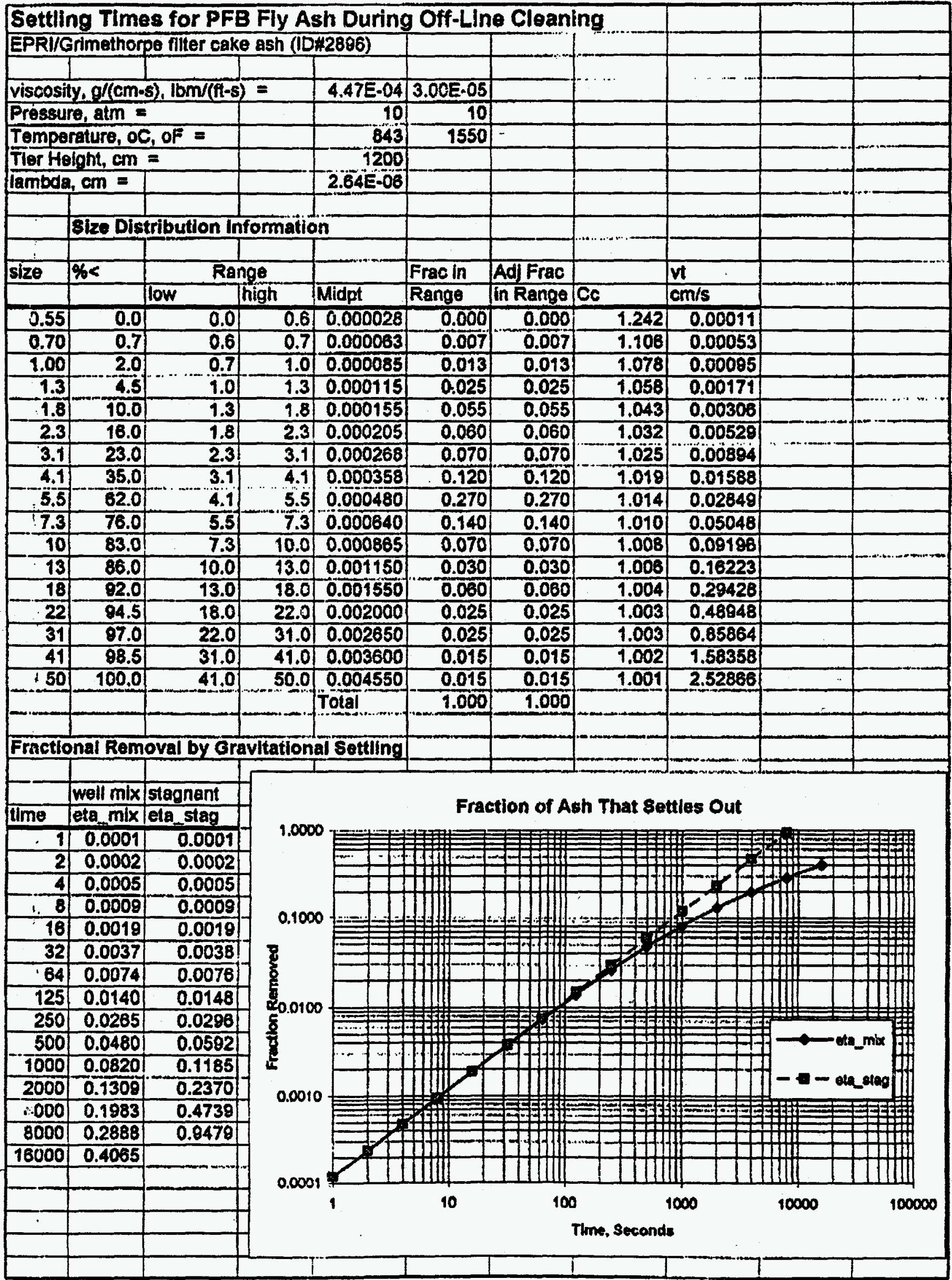


Settling Times for PFB Fly Ash During Off-Line Cleaning

\begin{tabular}{|c|c|c|}
\hline \multicolumn{3}{|c|}{ Tidd hopper ash (1D\#2988) } \\
\hline Viscoslty, g/(cm-s), $1 \mathrm{bm} /(\mathrm{ft}-\mathrm{s})=$ & $447 E-04$ & $300 E .05$ \\
\hline Préssure, atm = & $\frac{-10}{10}$ & 10 \\
\hline Teinperature, oC, of = & 843 & 1550 \\
\hline Tier Helght, $\mathrm{cm}=$ & 1200 & \\
\hline lambda, $\mathrm{cm}=$ & 2.64E-0. & \\
\hline
\end{tabular}

\begin{tabular}{|c|c|c|c|c|c|c|c|c|c|c|c|}
\hline & Size Dis! & tribution ir & Iformatio & & & & & & & & \\
\hline$?$ & & & & & & & & & & & \\
\hline $\operatorname{size}$ & $\%<$ & $\mathbf{R a}$ & mge & & Frac in & Adj Frac & & & vt & & \\
\hline & & Low & high & Mldpt & Range & In Range & Cc & & $\mathrm{cm} / \mathrm{s}$ & & \\
\hline 0.55 & 0.0 & 0.0 & 0.6 & 0.000028 & 0.000 & 0.000 & & 1.242 & 0.00011 & & \\
\hline 0.70 & 0.0 & 0.6 & 0.7 & 0.000063 & 0.000 & 0.000 & & 1.106 & 0.00053 & & \\
\hline 1.00 & 0.0 & 0.7 & 1.0 & 0.000085 & 0.000 & 0.000 & & 1.078 & 0.00095 & & \\
\hline 1.3 & 1.2 & 1.0 & 1.3 & 0.000115 & 0.012 & 0.012 & & 1.058 & 0.00171 & & \\
\hline 1.8 & 3.0 & 1.3 & 1.8 & 0.000155 & 0.018 & 0.018 & & 1.043 & 0.00300 & & \\
\hline 2.3 & 7.0 & 1.8 & 2.3 & 0.000205 & 0.040 & 0.040 & & 1.032 & 0.00528 & & \\
\hline 3.1 & 14.0 & 2.3 & 3.1 & 0.000268 & 0.070 & 0.070 & & 1.025 & 0.00894 & & \\
\hline 4.1 & 26.0 & 3.1 & 4.1 & 0.000358 & 0.120 & 0.120 & & 1.019 & 0.01588 & & \\
\hline 5.5 & 46.0 & 4.1 & 5.5 & 0.000480 & 0.200 & 0.200 & & 1.014 & 0.02849 & & \\
\hline 77.3 & 70.0 & 5.5 & 7.3 & 0.000640 & 0.240 & 0.240 & & 1.010 & 0.05048 & & \\
\hline 10 & 74.0 & 7.3 & 10.0 & 0.000865 & 0.040 & 0.040 & & 1.008 & 0.09196 & & \\
\hline 13 & 77.0 & 10.0 & 13.0 & 0.001150 & 0.030 & 0.030 & & 1.006 & 0.16223 & & \\
\hline 718 & 84.0 & 13.0 & 18.0 & 0.001550 & 0.070 & 0.070 & & 1.004 & 0.29428 & & \\
\hline$: 22$ & 80.0 & 18.0 & 22.0 & 0,002000 & 0.060 & 0.060 & & 1.003 & 0.48948 & & \\
\hline 31 & 94.5 & 22.0 & 31.0 & 0.002850 & 0.045 & 0.045 & & 1.003 & 0.85864 & & \\
\hline 41 & 98.0 & 31.0 & 41.0 & 0.003600 & 0.035 & 0.035 & & 1.002 & 1.58358 & & \\
\hline 150 & 100.0 & 41.0 & 50.0 & 0.004550 & 0.020 & 0.020 & & 1.001 & 2.52866 & & \\
\hline & & & & Total & 1.000 & 1.000 & & & & & \\
\hline & & & & & & & & & & & \\
\hline Fractic & onal Rem & gual by cr & avitation & al Settling & & & & & & & \\
\hline & & & & & & & & & & & \\
\hline & well $\mathrm{mix}$ & stagnant & & & & & & & & & \\
\hline time & ete_mix & eta_stag & & & & & & . & & & \\
\hline & 0.0002 & 0.0002 & 1.000 & & & & & & & 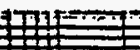 & 車 \\
\hline & 0.0004 & 0.0004 & & & & & & & & 2 & Af \\
\hline & 0.0007 & 0.0007 & & & & & & & & & tIn \\
\hline & 0.0015 & 0.0015 & & & & & & & & & \\
\hline 16 & 0.0030 & 0.0030 & 0.700 & & & & & 7 & 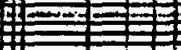 & & f \\
\hline 32 & 0.0058 & 0.0060 & 8 & & & & & & & & \#\# \\
\hline$\longdiv { 6 4 }$ & 0.0116 & 0.0118 & & & & & & III & & m & Dtm \\
\hline 125 & 0.0219 & 0.0233 & & & & 1410 & & & & 1001 & 10010 \\
\hline 250 & 0.0414 & 0.0466 & & & & & & $1=$ & & & 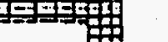 \\
\hline 500 & 0.0748 & 0.0932 & & & & 册 & $\cdots$ & 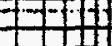 & $\because 4$ & $\rightarrow$ & $m x=$ \\
\hline 1000 & 0.1252 & 0.1865 & 는 & & $Z$ & HAt & - & 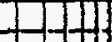 & 71 & & III \\
\hline 2000 & 0.1931 & 0.3730 & 0.0010 & & 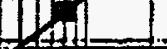 & & & & & -6 & _cteg|| \\
\hline 4000 & 0.2768 & $0.74 \overline{459}$ & & & 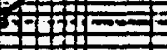 & 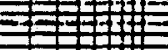 & $\equiv$ & 71 & $\equiv$ & \# & 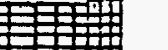 \\
\hline 8000 & 0.3770 & & & & 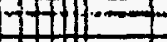 & & & & $\rightarrow$ & & Ifm \\
\hline 18000 & 0.4986 & & & & & & & & 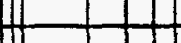 & Hil & III \\
\hline & & & 0.0001 & $1+11$ & 20114 & 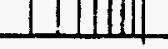 & & LHIII & 1 & 1110 & IIIIII \\
\hline & & & & .1 & 10 & 100 & & & 1000 & 10000 & 100000 \\
\hline ‘ & & & & & & & Tirne. & Secondt & & & \\
\hline & & & & & & & & & & & \\
\hline
\end{tabular}


Sheet1

Settling Times for PFB Fly Ash During Off-Line Cleaning

Tidd filter cake ash (ID 4012)

vlscosity, $g /(\mathrm{cm}-\mathrm{s}), \mathrm{lbm} /(\mathrm{n}-\mathrm{s})=$

Pressure, atm -

Temperature, OC, of $=$

Trer Height, $\mathrm{cm}=$

lambda, $\mathrm{cm}=$

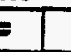

Size Distribution Information

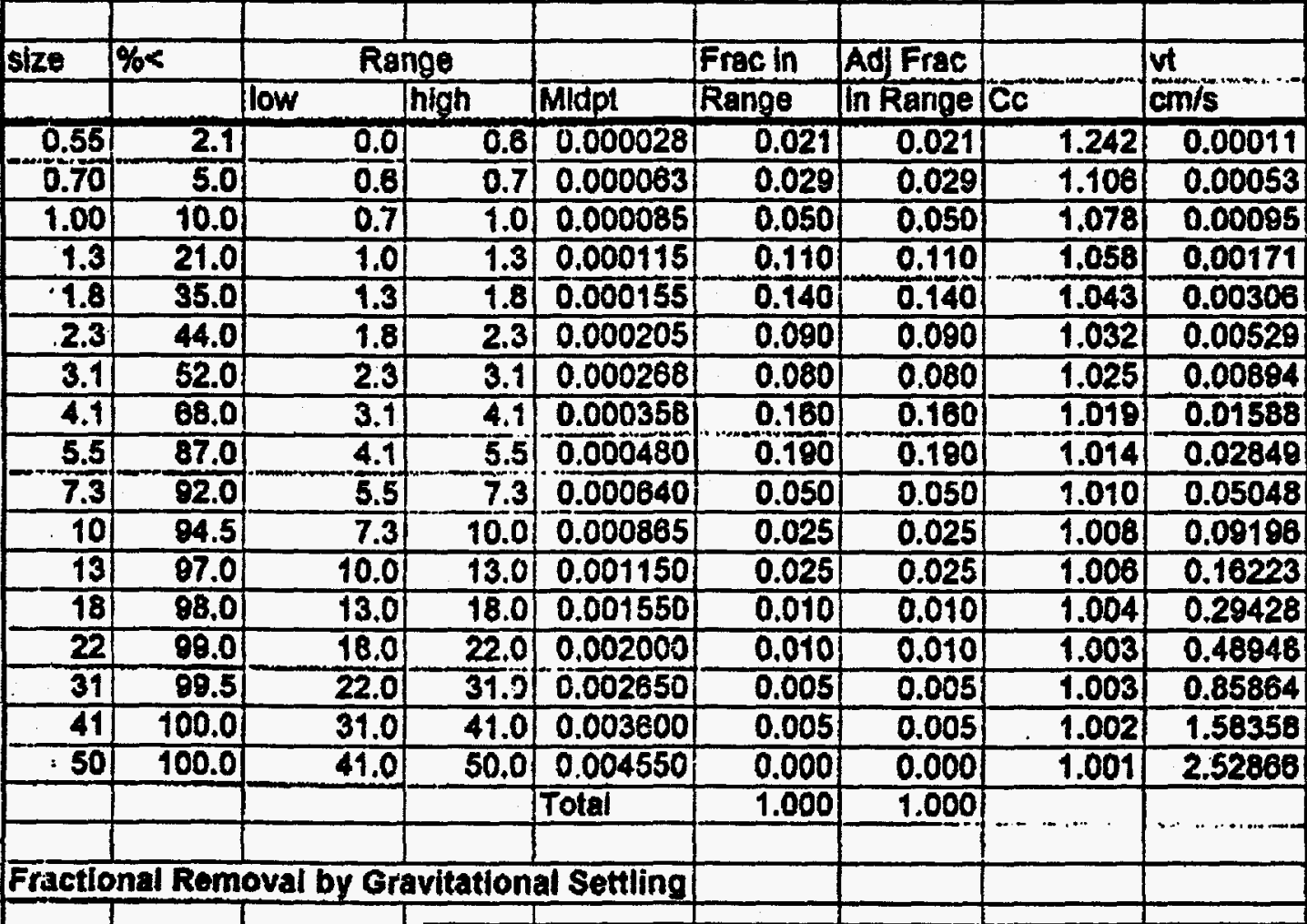

4.47E-04 3.00E-05

\begin{tabular}{r|r|}
\hline 10 & 10 \\
\hline 843 & 1550 \\
\hline
\end{tabular}

1200

2.64E-06

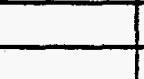

\begin{tabular}{|l|l|l|}
\hline & & \\
\hline & well mix & stagnant \\
\hline
\end{tabular}

time lota_mix ota_stag

Fraction of Ash That settles Out

\begin{tabular}{|r|r|r|}
\hline 1 & 0.0000 & 0.0000 \\
\hline 2 & 0.0001 & 0.0001 \\
\hline 4 & 0.0001 & 0.0001 \\
\hline 8 & 0.0003 & 0.0003 \\
\hline 16 & 0.0005 & 0.0005 \\
\hline 32 & 0.0010 & 0.0010 \\
\hline 64 & 0.0020 & 0.0021 \\
\hline 125 & 0.0039 & 0.0040 \\
\hline 250 & 0.0077 & 0.0081 \\
\hline 500 & 0.0146 & 0.0161 \\
\hline 1000 & 0.0269 & 0.0323 \\
\hline 2000 & 0.0475 & 0.0646 \\
\hline 4000 & 0.0804 & 0.1292 \\
\hline 8000 & 0.1317 & 0.2584 \\
\hline 16000 & 0.2087 & 0.5167 \\
\hline 32000 & 0.3172 & \\
\hline & & \\
\hline
\end{tabular}

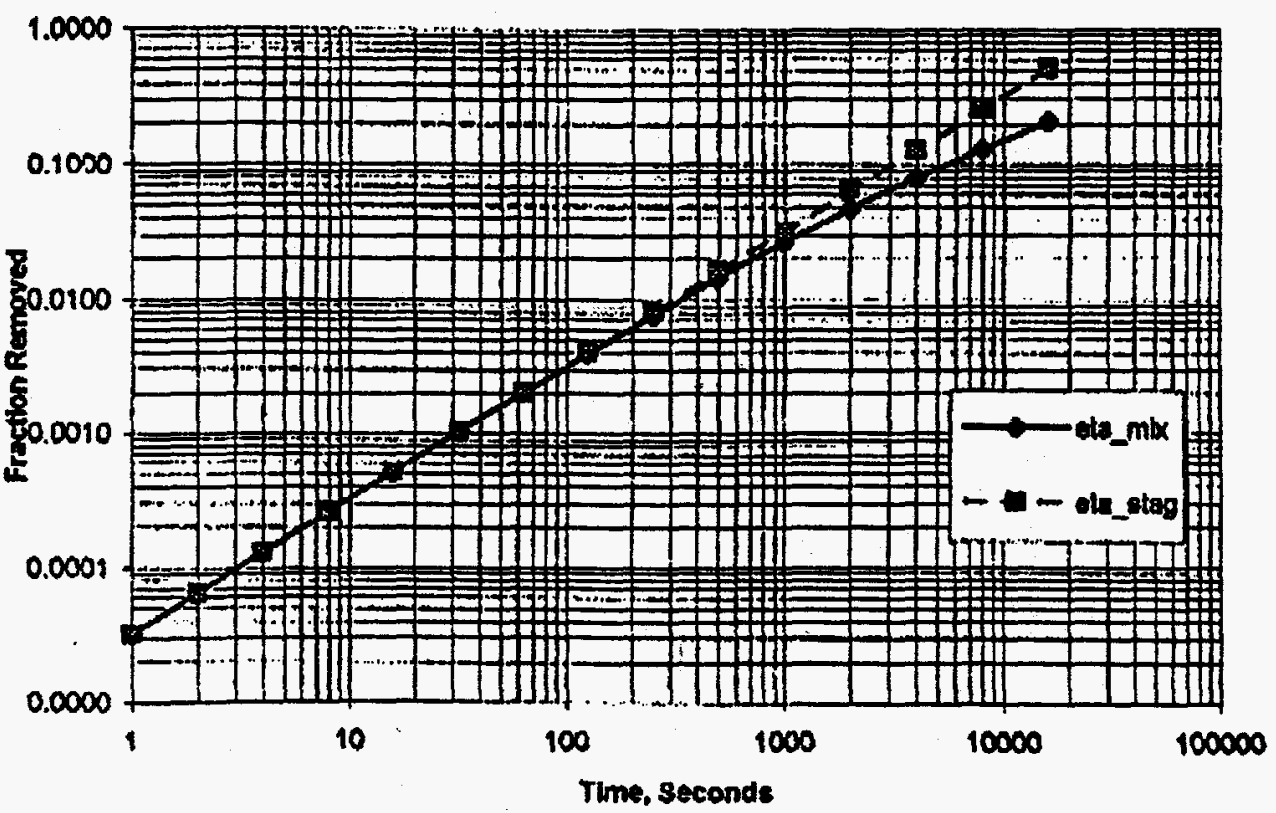


(919) $968-4960$

May 26, 1994

Dr. Herbert T. Chen

Advanced Technology Services

Gilbert/Commonwealth, Inc.

P. O. Box 1498

Reading, PA 19603

Dear Herbert:

This letter summarizes the findings from my search for literature that may assist your design of a ceramic barrier filter cleaning system. To begin, I report my general findings. Then, I provide a brief summary of each paper before finishing with a few comments on where to look for literature in the future. The papers which I summarize are included in this mailing. You will notice that several of the papers are ones which you have already included as references in your "Progress Report 1 and 2". These papers and my comments on them are included for completeness.

\section{Findings from Literature Survey}

Several themes became apparent as literature was reviewed. First, the studies described by the papers, in general, are not systematic; each tends to be focused on a particular filtration installation. Consequently, the results from the studies tend to be anecdotal. Furthermore, the information collected from a given filter installation is difficult to apply in new situations. However, systematic studies may not be helpful to designers of new ceramic filter installations either. As mentioned in several of the papers, the effectiveness of a particular filter design can not generally be evaluated except under actual operating conditions (temperatures, pressures, feed composition, etc...). Therefore, it should be expected that new ceramic filter units will not work exactly as designed.

Secondly, many of the papers indicate that there is a significant increase in residual pressure drop (the pressure drop across a filter immediately after cleaning) as a ceramic filter is used over time. The papers show that filter permeability tends to decrease to a steady-state value that is between 15 and $40 \%$ of the initial permeability. This decrease in permeability means that an increase in residual pressure drop of between $2.5 \mathrm{X}$ and $6 \mathrm{X}$ should be expected as the candle filters are used. The cause of this pressure drop increase is the thin layer of filter cake that remains attached to the ceramic candle filter during pulse cycles. The model developed at Gilbert/Commonwealth underestimates the contribution of the permanent filter cake to the residual pressure drop. 
Another observation common to most papers is that the dust cake separates from the filter primarily as large agglomerates. This finding suggests that the increase in residual pressure drop as the filter operates is not due to reentrainment of separated particles.

Lastly, the papers provide some operating data that may be useful for comparison to the Gilbert/Commonwealth model:

(1) The face velocities mentioned in these papers range from 1.6 to $6.5 \mathrm{~cm} / \mathrm{s}$. However, there seems to be some concern that velocities at the high end of this range may cause particles to penetrate far enough into the ceramic filter surface to cause an unacceptably large increase in the residual pressure drop. In the Gilbert/Commonwealth model, the face velocity is greater than $6 \mathrm{~cm} / \mathrm{s}$. Lowering this design velocity may be prudent.

(2) The largest pulse reservoir mentioned in any of these papers is 37 bar ( 538 psia). This is less than half of the reservoir pressure of $1236 \mathrm{psia}$ in the Gilbert/Commonwealth model. It appears that the Gilbert/Commonwealth pulse system may be overdesigned, though such an approach may be appropriate when so many design parameters are uncertain.

These papers probably include other data that can be used for comparison to the Gilbert/Commonwealth model. Though the operating conditions will invariably change from unit to unit, these data will at least indicate if the model is "in the ballpark".

\section{Summary of Literature Provided}

In this section, the information in each of the papers is summarized. Copies of the papers are attached:

(1) Butcher, C., "Hot News in Ceramic Filters", The Chemical Engineer, No. 505, 1991, pp. 27-29.

This article is fairly general. However, it mentions that face velocities for ceramic filters are typically $3 \mathrm{~cm} / \mathrm{s}$, but can range to as much as $6 \mathrm{~cm} / \mathrm{s}$ or more. In addition, the article quotes researcher Jonathan Seville as saying that, although surface filtration accounts for most particle capture, some particles may penetrate into the filter element to cause a pressure increase that cannot be reversed by cleaning. Also, Seville states that cleaning can be patchy. The difficulty in predicting pressure drops without trials is also mentioned.

(2) Butcher, C., "The Unstoppable Cleanup Machine", The Chemical Engineer, No. 536, 1993, pp. 17-18. 
This article reports on practical operating experience which includes buildup of large amounts of dust on filter elements. The article quotes researcher Roland Clift as saying that the selection of face velocity is important; if the velocity is too high, too many particles will penetrate into the filter element. Clift also stresses the importance of running trials under actual operating conditions to understand a particular cleaning process. Furthermore, it is reported that cleaning is patchy and that the cake usually detaches to leave only a thin layer of dust attached to the filter element.

(3) Callis, R., "Practical Application of High Temperature Filters", Filtration and Separation, Vol. 28, No. 4, 1991, pp. 231-232.

In this article, face velocities for ceramic filters are reported to be 1.5 to 2 times greater than for fabric filters. The author states that any face velocity can be chosen depending on the pressure drop that is affordable. Dust released by cleaning is reported to leave the filter surface in agglomerated form so that reentrainment is not extensive.

(4) Clark, R., Holbrow, P., Oakey, J. E., Burnard, K. and Stringer, J., "Some Recent Experiences with the EPRI Hot Gas Rigid Ceramic Filter at Grimethorpe PFBC Establishment", 12th International Conference on Fluidized Bed Combustion, Vol. 2, 1993, pp. 1251-1258.

This paper is one which you have already reviewed. Its results indicate that residual permeance in a ceramic filter may decrease to $15-30 \%$ of the original permeance as the filter is used and repeatedly cleaned by pulsing. The paper also shows profiles of pressure increases associated with the pulsing cycle. The authors found that the pulse duration must be long enough to allow a maximum pressure drop to be achieved. In their system, a fully open valve time of $120 \mathrm{~ms}$ was not long enough whereas $240 \mathrm{~ms}$ probably was sufficiently long. Optimum filtration velocity was found to be between 3.3 and 6.5 $\mathrm{cm} / \mathrm{s}$ and was probably closer to the upper value.

(5) Koch, D., Cheung, W., Seville, J. P. K. and Clift, R., "Effects of Dust Properties on Gas Cleaning Using Rigid Ceramic Filters", Filtration and Separation, Vol. 29, No. 4, 1992, 337-341.

The authors emphasize the importance of experimental work to select operating conditions. For instance, cake porosity is difficult to estimate. Cleaning is described as patchy for ceramic filters. In addition, the paper mentions that the cleaning stresses required for fabric filters are usually two orders of magnitude smaller than those needed for ceramics. However, the stresses can not be accurately predicted.

(6) Laux, S., Schiffer, H.-P. and Renz, U., "Performance of Ceramic Filter Elements for Combined Cycle Power Plant High Temperature Gas Clean-up", 11th International Conference on Fluidized Bed Combustion, Vol. 2, 1991, pp. 959-969. 
This is also a paper that you have seen before. The residual dust layer in tests conducted for this paper reduced filter permeability to about $30-40 \%$ of the initial permeability. The authors spend some time discussing on-line pulse cleaning. They point out that high momentum jets can be created with a large pipe diameter and a low pulse pressure or with a small pipe diameter and a large pulse pressure. They also present data that show that an increase in pulse pressure increases long-term permeability. With a solenoid valve controlling the start of a cleaning pulse, the authors claim that pressure increases rapidly inside the filter cavity so that "steady-state" conditions are achieved in 10-15 ms. The paper also includes a photograph that shows the break-up of a filter cake during pulsing. The authors state that the cake breaks off into large flakes that immediately fall into the hopper; only a small fraction of the cake is detached as dust particles.

(7) Laux, S., Glernoth, B., Bulak, H. and Renz, U., "Hot Gas Filtration with Ceramic Filter Elements", 12th International Conference on Fluidized Bed Combustion, Vol. 2, 1993, pp. 1241-1250.

Again, this is a paper which you have previously reviewed. The authors report that residual dust causes permeability to decrease to between 20 and $40 \%$ of initial values. They also point out that pulse pressure may need to be increased according to operating conditions, particularly if the pressure drop during normal operation is increasing. These authors suggest that accurate predictions of filter permeability can not be made except with experience at actual operating conditions. The authors also present some profiles of pressure in a pulse-jet system (from the reservoir to the nozzle) that are based on modeling work.

(8) Lehtovaara, A. and Mojtahedi, W., "Ceramic-Filter Behavior in Gasification", Bioresource Technology, Vol. 46, 1993, pp. 113-118.

These authors, after describing the process at the Tampella plant in detail, devote a relatively small portion of their paper to ceramic filters. They mention that their pulse durations were typically between 100 and $300 \mathrm{~ms}$. In one of the filter performance examples the authors present, the baseline pressure drop was 70 mbar whereas the trigger pressure drop was $140 \mathrm{mbar}$. In another example, these pressure drops were somewhat lower. For various example cases, the face velocities ranged from 1.6 to $1.9 \mathrm{~cm} / \mathrm{s}$ and the pulse reservoir pressure ranged from 17 to 37 bar.

(9) Pitt, R. U. and Leitch, A. J., "A Simple Method to Predict the Operation of Flue Gas Filter Pulse Cleaning Systems", 11th International Conference on Fluidized Bed Combustion, Vol. 3, 1991, pp. 1267-1281.

Despite the title, this paper is fairly complicated. The "simple" method described in the paper mentions a couple of iterative FORTRAN routines. Nonetheless, the extensive description of the assumptions made in the model may be useful. In addition, the conclusions reached by the authors may be helpful. They state that critical losses 
occur during pulsing if the candle cavity is not designed to prevent "choking", if pipe diameters are too small, if there are too many flow-dividing junctions, and if there are too many valves in the external piping.

(10) Pontius, D. H., "Attributes of Particles and Dust Cakes Resulting from Hot Gas Cleanup in Advanced Processes for Coal Utilization", Advances in Filtration and Separation Technology, Vol. 2, 1990, pp. 291-294.

This paper states that, once the dust cake forms, the cake does the filtration work. The author also says that the tensile strength of the cake is weak compared to the strength of the filter material; as a result, the filter cake will break away during pulsing very close to the filter surface. Important factors of the dust that affect filtration include particle size distribution, particle shape, particle chemical composition, and mass loading.

(11) Schiffer, H.-P., Renz, U. and Tassicker, O. J., "Hot Gas Filtration at the RWTH Aachen PFBC Facilities", 10th International Conference on Fluidized Bed Combustion, Vol. 1, 1989, pp. 487-494.

The authors describe operating conditions and observations from their tests. Pulse jet pressure was varied from 3 to 5 bar. Pulse jet duration was nominally $300 \mathrm{~ms}$.

Residual permeability decreased to about $1 / 3$ of the initial permeability during the course of operation. Not surprisingly, test results indicate that pulses of short duration cause smaller temperature decreases than longer pulses. The authors measured the residual dust cake to be between 0.3 and $0.5 \mathrm{~mm}$ thick.

(12) Seville, J. P. K., Legros, R., Brereton, C. M. H., Lim, C. J. and Grace, J. R, "Performance of Rigid Ceramic Filters for CFBC Gas Cleaning", 11th International Conference on Fluidized Bed Combustion, Vol. 1, 1991, pp. 279-286.

This is a good paper. The authors found that, due to retained dust, flow resistance (pressure drop) increased during the course of the test to between 2.3 and 2.9 times the initial value. They state that a filter cake is broken when tensile stresses caused by pulsing overcome the adhesive or cohesive forces in the cake. However, the authors state that the critical tensile stress cannot be predicted easily. Data are presented that indicate that the removal stresses measured for ceramic filters are an order of magnitude larger than typical stresses measured for fabric filters. Photographs are shown which demonstrate that pulse cleaning for ceramic filters is patchy and that the filter cake is brittle.

(13) Stringer, J. and Leitch, A. J., "Ceramic Candle Filter Performance at the Grimethorpe (UK) Pressurized Fluidized Bed Combustor", Journal of Engineering for Gas Turbines and Power, Vol. 114, 1992, pp. 371-379.

This paper is another that you have already read. The authors suggest that a slow pressure increase when the pulse valve opens may lead to a decrease in efficiency. They state, however, that this contention has yet to be proven. Reductions in the use of pulse- 
cleaning gas can be achieved by decreasing cleaning frequency, using faster-acting valves, . using valves that require a lower differential pressure, and by having more filter elements per manifold. The authors found little evidence of dust penetration into the filter. They present two mechanisms by which the filter cake may be separated. First, the cake may separate when the pressure drop increase across the cake exceeds the tensile strength of the cake. Second, a shock wave caused by the sudden pressure increase may serve to separate the cake. The authors do not know which mechanism is more dominant. Also, the authors show that permeance decreases to about $20 \%$ of the initial permeance over the course of operation.

(14) Tassicker, O. J., Burnard, G. K., Leitch, A. J. and Reed, G. P., "Performance of a Large Filter Module Utilizing Porous Ceramics on a Pressurized Fluidized Bed Combustor", 10th International Conference on Fluidized Bed Combustion, Vol. 1, 1989, pp. 479-486.

These authors show that permeance decreases during operation to about $20 \%$ of the initial value. They present data which indicate that, in their system, the pressure increase in the candle cavity is not sharp. In addition, the pressure increases inside the candles may vary from candle to candle depending on the distance along a manifold. The authors also present data on temperature fluctuations inside candles during pulses. These temperature changes also differ between candles.

(15) Withers, C. J., West, A. A., Twigg, A. N., Courtney, R. S., Seville, J. P. K. and Clift, R., "Improvements in the Performance of Filtration of Hot Gases", Filtration and Separation, Vol. 27, No. 1, 1990, pp. 32-37.

The data in this paper indicate that the residual pressure drop increases from 3.0 $\mathrm{kPa}$ to $11.2 \mathrm{kPa}$ by the end of the tests. The authors also contend that pulse cleaning is patchy and that an increase in pulse pressure improves cleaning effectiveness.

(16) Zeh, C. M., Chiang, T.-K. and Strickland, L. D., "Evaluation of Ceramic CandleFilter Performance in a Hot Particulate-Laden Stream", Advances in Filtration and Separation Technology, Vol. 2, 1990, pp. 295-298.

In the tests discussed in this paper, pressure drop increased rapidly to a relatively constant value in the first 10 to 24 hours of testing. The authors found that the residual dust has slightly lower permeability than newly captured dust.

(17) Zievers, J. F., Eggerstedt, P., Zievers, E. C. and Nicolai, D., "What Affects the Cost of Hot Gas Filter Stations?", Journal of Engineering for Gas Turbines and Power, Vol. 115,1993, pp. 652-657.

This paper is also one which you have looked at. The paper is fairly elementary; little detail is provided. One piece of data presented is that jet pulse volume is typically 25-30 liters per $\mathrm{m}^{2}$ of filter surface. 


\section{Availability of Other Literature}

In general, there is not a wealth of information available on ceramic candle filters in the open literature. Much of the best available literature comes from conference proceedings rather than journals. The International Conferencés on Fluidized Bed Combustion were the source for many of the papers provided here. Other conference proceedings that have been noted as references, but have not been located, include the International Symposium on Gas Cleaning at High Temperatures (1993), the 4th International Fluidised Bed Combustion Conference (1988), and the 5th World Filtration Congress (1990). Also, many of the references listed in various papers are reports that have been written as parts of projects. Such reports are not be widely available.

I hope that these papers and my comments are useful to you. If you have any questions, please get in touch with me.

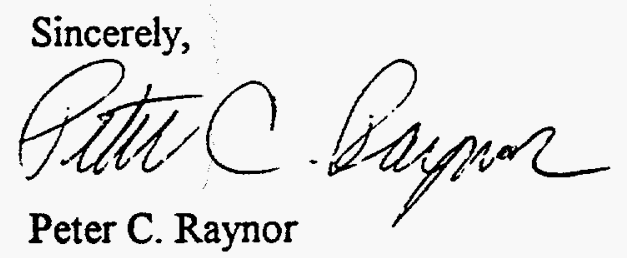


The School of Public Health Department of

Environmental Sciences and Engineering
CHAPEL HILL

The University of North Carolina at Chapel Hill $C B \# 7400$, Rosenau Hall Chapel Hill, N.C. 27599-7 $\$ 10$

919 966-3851

21 July, 1994

Mr. Roman Zaharchuk

Advanced Technology Services

Gilbert/Commonwealth, Inc.

P.O Box 1498

Reading, PA 19603-1498

Dear Roman:

When in Germany several weeks ago, I visited the University of Karlsruhe. There I met Mr. Stephan Berbner, who is a doctoral student working in the laboratory headed by Prof. Friedrich Löffler until his death late last year. Mr. Berbner is studying filtration at high temperature by ceramic candle filters as his thesis dissertation.

You might wish to write him or speak to him about his work. He has a nice experimental rig, where he can load ceramic candle filters with dust, then test their performance. This can all be done at high temperature. He has some good data about filter performance, including what happens due to pulse cleaning.

His address is:

Dipl. - Ing. S. Berbner

Institut für Mechanische Verfahrenstechnik und Mechanik

Universität Karlsruhe (TH)

Postfach 6980

D-76128 Karlsruhe 1

Germany

His telephone is (0721) 608-2415. He speaks excellent English. If you mention my name and say I was there for Marc Plinke's doctoral defense on 18 June, he will make the connection.

Hope your work is going well.

Sincerely yours,

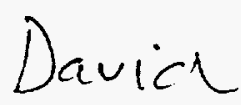

David Leith 


\section{APPENDIX B}

This appendix contains complete spreadsheet tables for Case 2 through 8 , which are presented in the same format as Case 1 discussed in Section 4. 


\section{CASE 2}

\section{Plant Configuration: PFBC \\ Pulse Gas: Cold Pulse \\ Mode of Cleaning: Off-Line}

B-1 


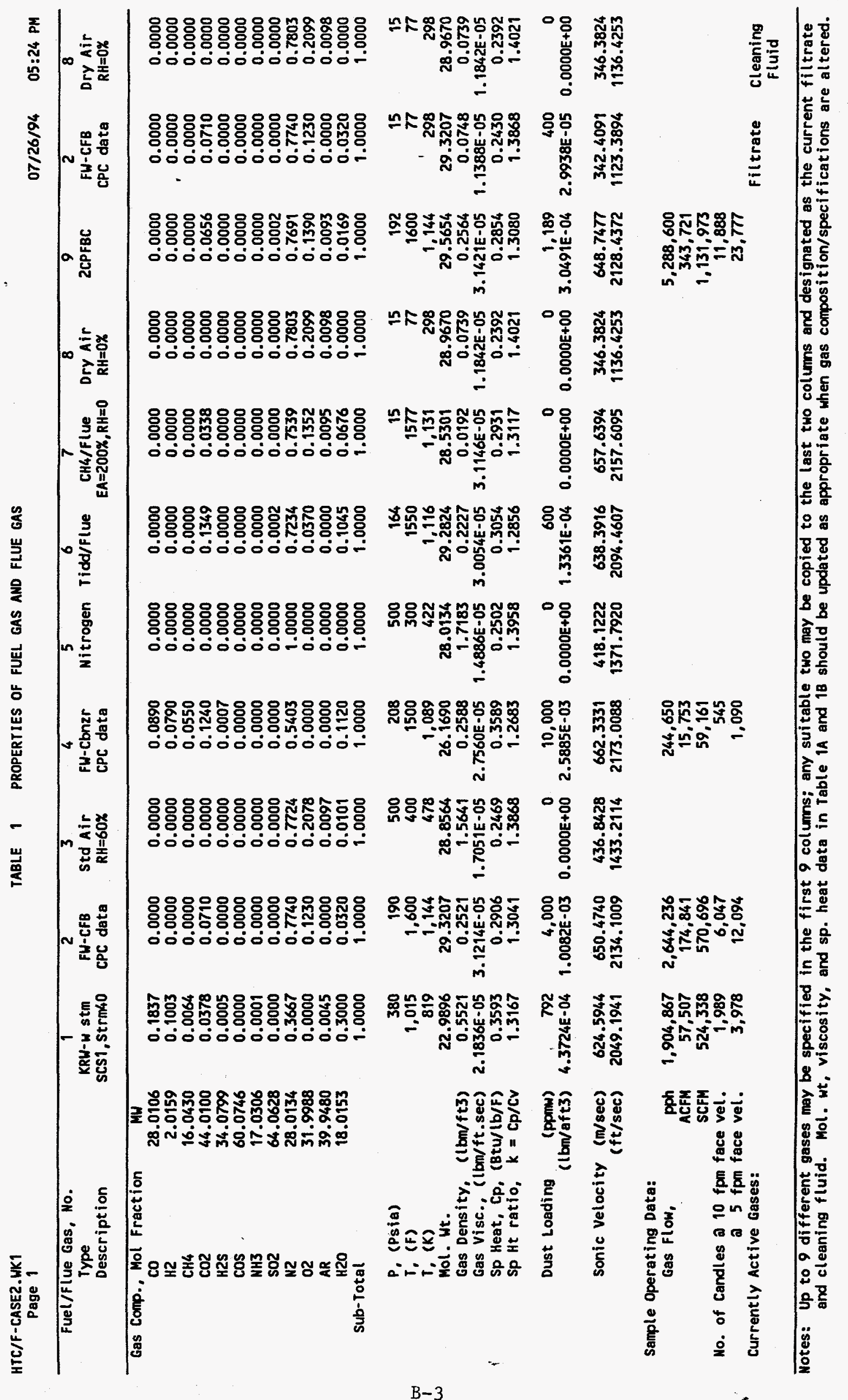




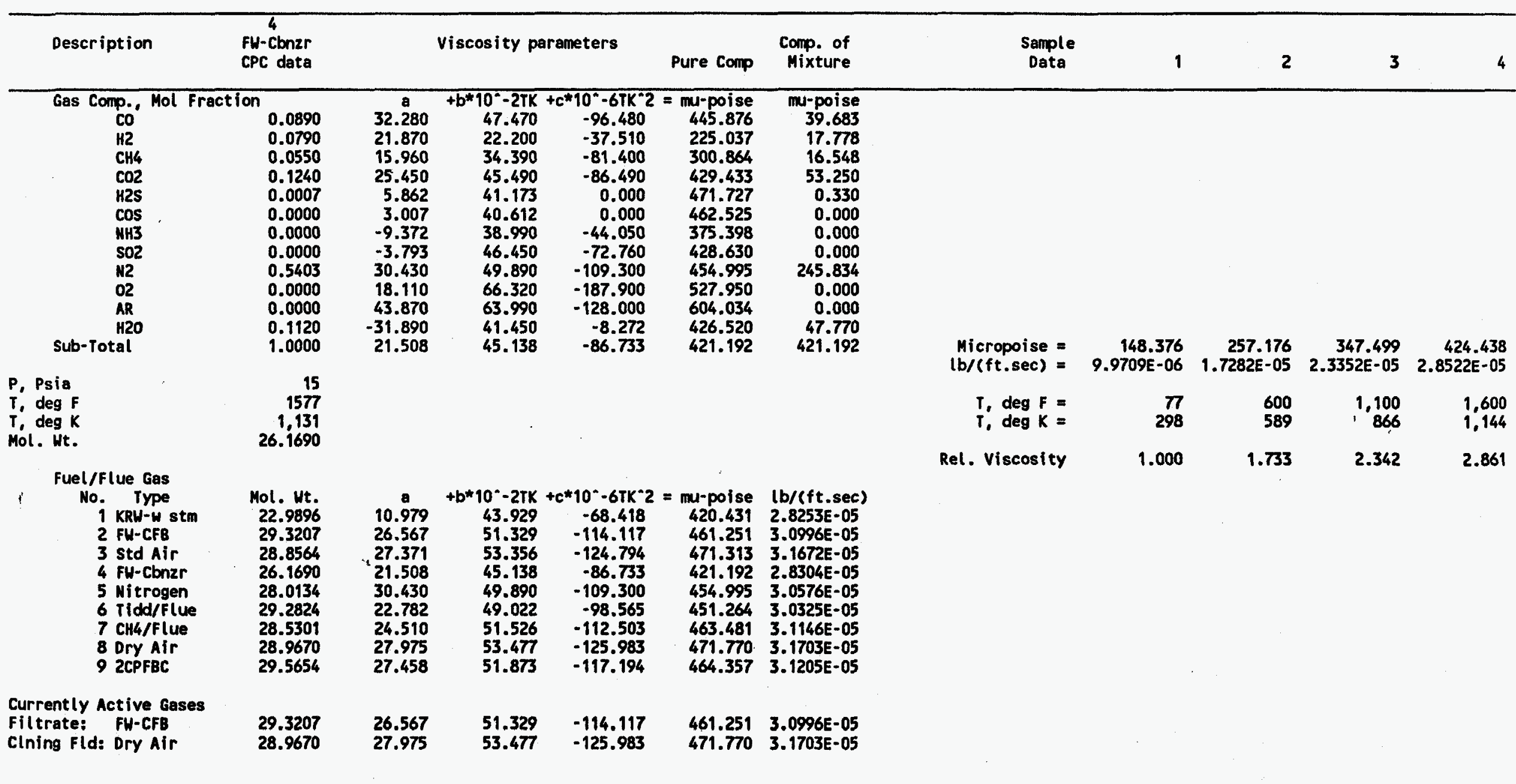

Notes: Micro-poise $=$ Mu-poise $=0.00000 T^{*}$ poise; 1 poise $(P)=100$ centi-poise (cP) $=0.0672$ lbm/(ft-sec) $=242$ (bm/ ft-h).

When a new gas is designated as the current filtrate or cleaning fluid, be sure to update the corresponding viscosity data in the bottom two rows. 


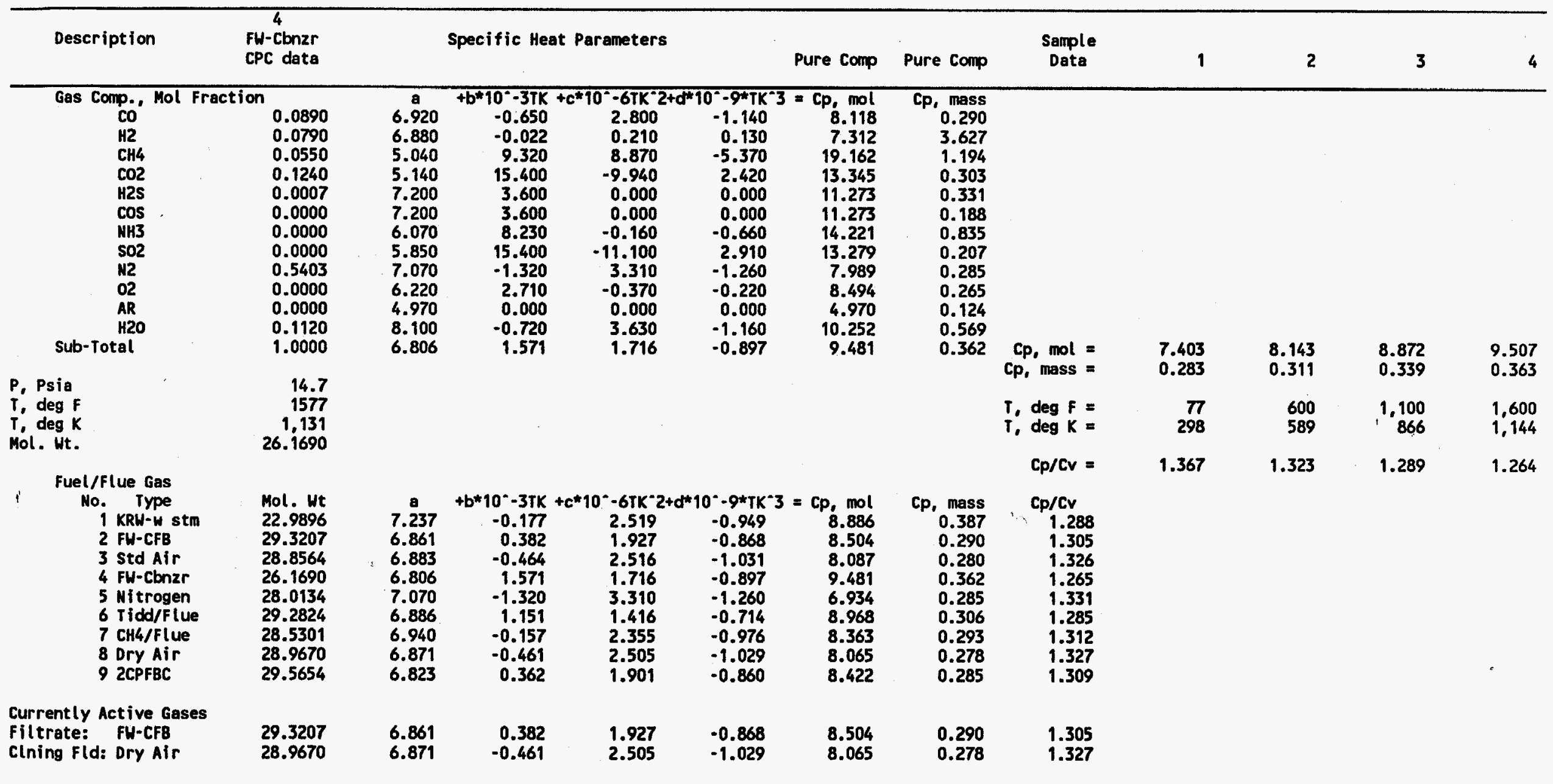


S: Fil-Gas2, Cln-Gast

Filter Eff. $L(m), 95 \%$ norm.

Nominal $0 . D$.

Nominal I.D.

Mean Filt. Area $(\mathrm{m} 2)$

Porosity

P. Dia. Dp (microm)

Gas Type:

Press., (psia)

Temp., (F)

Temp. (K)

**** Mol. Wt.

Density, Rho $(1 \mathrm{bm} / \mathrm{ft} 3)$

*** Visc. Mu (lbm/ft.sec)

*** Sp Ht, Cp (Btu/(b/F) Dust Loading (ppmw)

Forward Face Velocity $u(f t / m i n)$ $u$ (ft/min)

Mass flow Rate $u(\mathrm{~cm} / \mathrm{sec})$ Reynolds No. Re

Friction Coef., Ergun fp

Filtration Cycle Time $t$ (min)

Cake Bulk Density, (lb/ft3)

Cake Cleaning Eff. = LC/ (LC+LrC)

Permeability Coef.. B (m2)

Mass permeability, $\mathrm{Km}$ (lbm/ft)

Cake/mediun Thickness, $L(f t)$

Areal Density W (lb/ft2)

Pressure Drop, del $P$ (psia/ft)

Cake del $P$ only (psia)

Pressure, $P$ (Psia)

Sp. Res. K2, (in.H)/(fpm)/(lb/ft2)
Fresh cake FORWARD FILTRATIOH PERIOD

\section{Total}

\begin{tabular}{rrr}
\hline 1.4250 & 1.4250 & 1.4250 \\
& & 0.0600 \\
0.0600 & 0.0600 & 0.0300 \\
0.2686 & 0.2686 & 0.1938 \\
2.8913 & 2.8913 & 2.0856 \\
0.8300 & 0.8200 & 0.4000 \\
2.1000 & 2.1000 & 80.0000 \\
$2.1000 E-06$ & $2.1000 E-06$ & $8.0000 E-05$ \\
2 & \multicolumn{3}{c}{2} & \\
2 & \multicolumn{1}{c}{2} & \\
190.0000 & 188.7218 & 188.6913 \\
1600.0000 & 1600.0000 & 1600.0000 \\
1144.2611 & 1144.2611 & 1144.2611 \\
29.3207 & 29.3207 & 29.3207 \\
0.2521 & 0.2504 & 0.2503 \\
$3.1214 E-05$ & $3.1214 E-05$ & $3.1214 E-05$ \\
0.2906 & 0.2906 & 0.2906 \\
1.000 & \multicolumn{3}{c}{} \\
$2.5206 E-04$ & & \\
10.0000 & 10.0677 & 13.9591 \\
5.0800 & 5.1144 & 7.0912 \\
7.2877 & 7.2877 & 7.2877 \\
0.0093 & 0.0093 & 0.4897 \\
2751.7185 & 2913.4814 & 185.5324 \\
\hline
\end{tabular}

90.0000

$187.2000 \quad 193.4400$

0.9800

$5.8168 \mathrm{E}-13 \quad 5.0032 E-13 \quad 7.5852 E-12$

2.6772E-10 $1.1283 E-08 \quad 5.0568 E-10 \quad 1.7237 E-10$

$1.9913 E-10 \quad 1.8740 E-10$

7.1284E-03 $1.4548 E-04$

$2.1727 \quad 0.0443$

0.0492

$0.2269 \quad 0.0051$

15.0000

$\begin{array}{rrrr}179.3080 & 209.8726 & 19.3648 & \\ 1.2782 & 0.0305 & 0.9530 & 2.2617 \\ 188.7218 & 188.6913 & 187.7383 & 1.3087\end{array}$

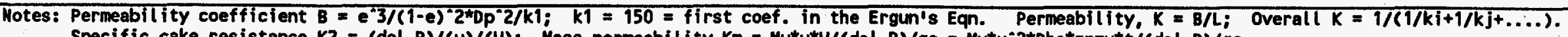

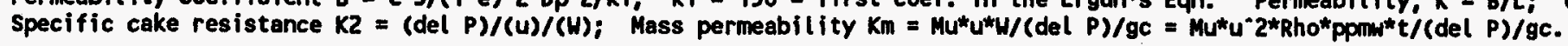


TABLE 3 FLOW THROUGH POROUS MEDIA - PRESSURE DROPS (2) (Reverse Cleaning Period)

07/26/94 05:24 PM

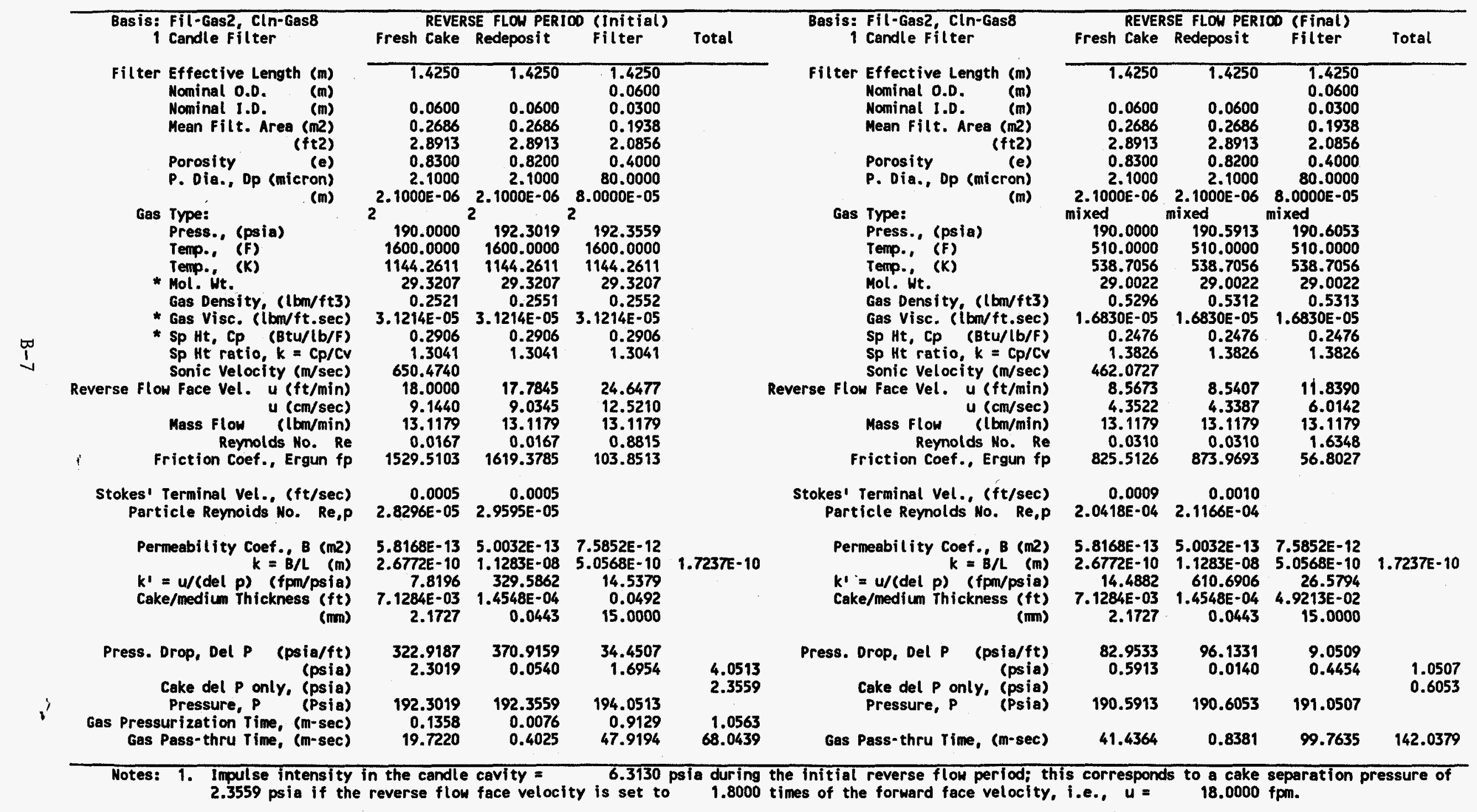


TABLE 4 FLOW FROM CANDLE TO EJECTOR MIXING ZOME - PRESSURE DROPS

(Reverse Cleaning Period)

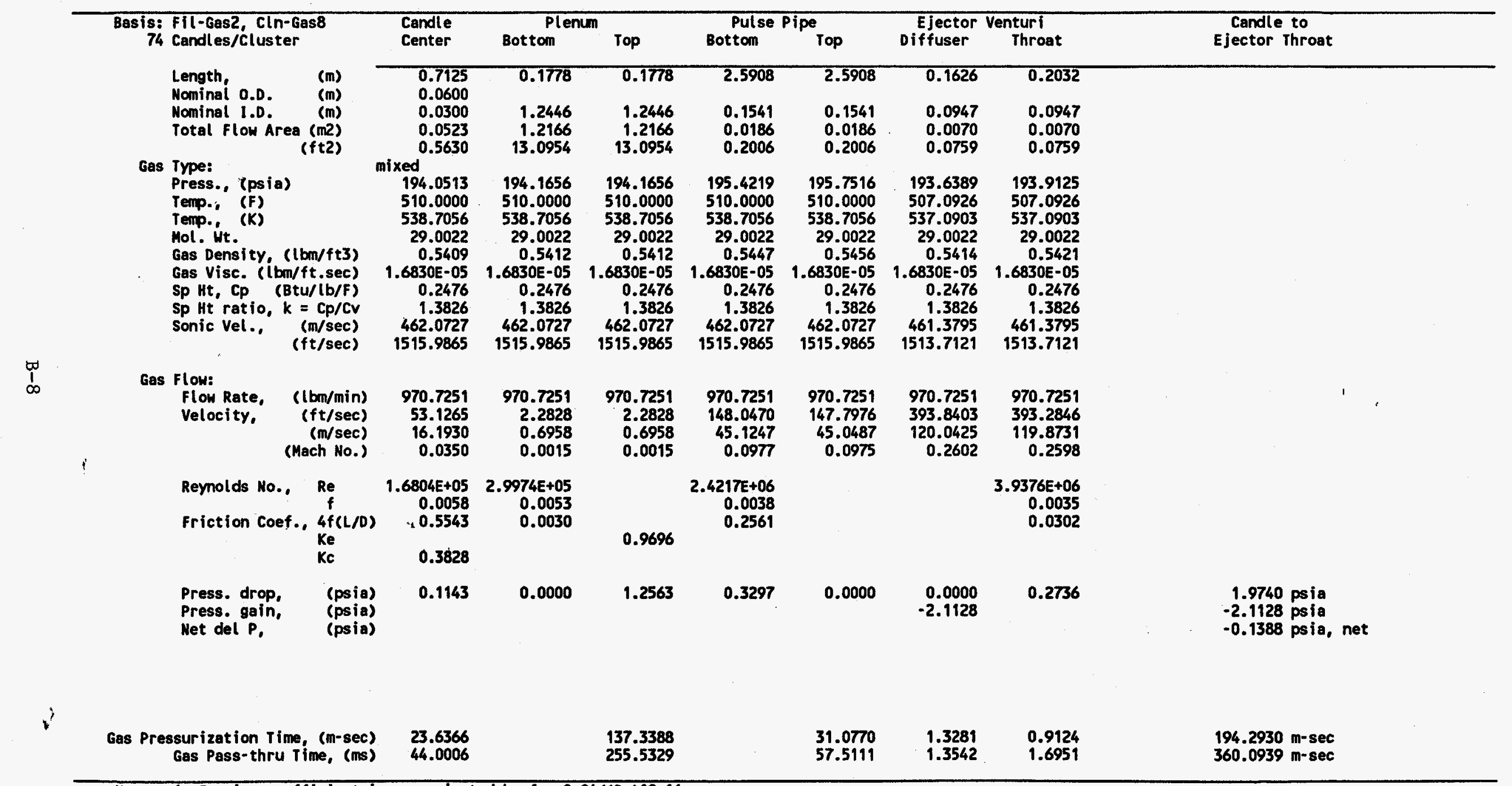

Notes: 1. Fanning coefficient is approximated by $f=0.04 /(\mathrm{Re})^{\wedge} 0.16$

2. Flow is assumed isothermal from candle to pulse pipe; flow in the diffuser is assuned isentropic. 
74 Candles/Cluster
Cil-Gas2, Cln-Gas

\begin{tabular}{rrrr}
$\begin{array}{c}\text { Mixed Pulse } \\
\text { Gas }\end{array}$ & \multicolumn{1}{c}{$\begin{array}{c}\text { Nozzle } \\
\text { Gas }\end{array}$} & \multicolumn{1}{c}{$\begin{array}{c}\text { Entrained } \\
\text { Gas }\end{array}$} & side Area \\
\hline 0.0947 & 0.0483 & 0.1541 & \\
0.0070 & 0.0409 & 0.0483 & \\
0.0759 & 0.0013 & 0.0168 & 0.0116 \\
100.0000 & 18.6309 & 0.1809 & 0.1247 \\
& & 238.4422 & 164.3893
\end{tabular}

mixed

ixer Mominal 0.0 Nominal I.D. Cross flow Area (m2) Rel flow Area, $(\boldsymbol{x})$

Gas Type:

P. (Psia)

T. (F)

** Mol. Ht.

Gas Density, (lbm/ft3)

* Gas Visc. (lbm/ft.sec)

* Sp Ht, Cp (Btu/lb/F)

Sp Ht ratio, $k=C p / C v$

Sonic Vel., (m/sec)

$P, c r i t=((k+1) / 2) \cdot(k /(k-1))$

$P$, nozzle gas $/ P$, entrained gas

Mass Balance: Specify op.

Flow Rate, (lbm/min)
Velocity, (ft/sec)

$(\mathrm{m} / \mathrm{sec})$

$$
\text { (Mach No.) }
$$
(lb-mol/min)

$$
193.9
$$

8

18.6309

2

$\begin{array}{lll}507.0926 & 281.2251 & 1600.0000\end{array}$

$\begin{array}{lll}537.0903 & 411.6084 & 1144.2611\end{array}$

$\begin{array}{rrr}0.5421 & 0.9662 & 0.2483\end{array}$

1.6830E-05 1.5237E-05 3.1214E-05

$\begin{array}{lll}0.2476 & 0.2428 & 0.2906\end{array}$

$\begin{array}{lll}1.3826 & 1.3937 & 1.3041\end{array}$

$\begin{array}{lll}461.3795 & 405.7721 & 650.4740\end{array}$

$\begin{array}{lll}1513.7121 & 1331.2733 & 2134.1009\end{array}$

1.8891

1.4171

conditions; Press Alt-R to update table.

$970.7251 \quad 872.8758 \quad 97.8493$

$\begin{array}{lll}393.2846 & 1065.0187 & 36.3065\end{array}$

$\begin{array}{lll}119.8731 & 324.6177 & 11.0662\end{array}$

$\begin{array}{rrr}0.2598 & 0.8000 & 0.0170 \\ 33.4707 & 30.1335 & 3.3372\end{array}$ mole fraction

Momentum Balance: Estimated Pn =

$\begin{array}{crr}\text { Estimated } P n= & 265.1813 \text { Psia } \\ \text { (PA), lbf } & 2118.9123 & 539.8638\end{array}$

(PA), libf $\quad 218.9123$

(MU/gC), lbf $\quad 197.6041$

$4 \mathrm{f}(\mathrm{L} / \mathrm{D}), \mathrm{Ke}$, or $\mathrm{Kc}$

Frictions, lbf $\begin{array}{rr}0.0000 \\ \text { Reynolds }\end{array}$

0.0000

$\begin{array}{rr}30.1335 & 3.3372 \\ 0.9003 & 0.0997\end{array}$

$\begin{array}{rrr}539.8638 & 4875.6383 & 3422.3401 \\ 481.1744 & 1.8388 & 0.0000\end{array}$

481.1744

0.6621

0.4000

0.0000
0.0000

159.2911

0.3678

0.0000

Energy Balance: $\quad$ Est 0.003

$\begin{array}{lllll}M C p T & 1.2188 E+05 & 5.9607 E+04 & 4.5502 E+04 \\ M U^{\prime} 2 /(2 g C) & 2.9967 E+03 & 1.9761 E+04 & 2.5743 E+00\end{array}$

Total H (Btu) $\quad 1.2487 E+05 \quad 7.9367 E+04 \quad 4.5505 E+04$

- Mass flow: Relative to Dirty Gas

Relative to Nozzle Gas
1.6186

0.1814

side Area

(102

Gas Type:

P. (Psia)

T. (F)

* Mol. He.

Gas Density, (lbm/ft3)

** Gas Visc. (lbon/ft.sec)

** Sp Ht, Cp (Btu/lb/F)

Sp Ht ratio, $k=\mathrm{Cp} / \mathrm{Cv}$

Sonic Vel.. $(m / \mathrm{sec})$

$(\mathrm{ft} / \mathrm{sec})$

Crit.Mass flow, (lbm/min)

Nozzl

Lance

Gas

Side Area

Mass Balance: If lance dimension is altered, press Alt-S to update table Flow Rate, (lbm/min) $872.8758 \quad 872.8758$

$\begin{array}{lll}\text { Velocity, (ft/sec) } & 1065.0187 & 788.6050\end{array}$

(m/sec) $\quad 324.6177 \quad 240.3668$

Ave. Vel. (ft/sec) 926.8118

Momemtum Balance: Estimated PI $=377.9298$ Psia

$\begin{array}{lrrr}\text { (PA), lbf } & 539.8638 & 769.4005 & 0.0000 \\ \text { (HU/gC), lbf } & 481.1744 & 356.2910 & 0.0000 \\ \text { 4f(L/D), Ke, or Ke } & 0.5744 & 0.0000 & 0.0000 \\ \text { Frictions, lbf } & 104.6530 & 0.0000 & 0.0000\end{array}$

Reynolds No., Re $9.0606 \mathrm{E}+06$

Energy Balance: $\quad$ Est imated $\mathrm{Tl}=322.1868 \mathrm{deg} F$$$
\text { CpT }
$$

$\begin{array}{cc}\text { Est imated } \mathrm{Tl}= & 322.1868 \\ 5.9607 \mathrm{E}+04 & 6.8533 \mathrm{E}+04 \\ 1.9761 \mathrm{E}+04 & 1.0834 \mathrm{E}+04\end{array}$

$\begin{array}{lll}M U^{\circ} 2 /(2 g c) & 1.9761 E+04 & 1.0834 E+04 \\ \text { Total H (Btu) } & 7.9367 E+04 & 7.9367 E+04\end{array}$

Gas Pressurization Time, (m-sec)

Gas Pass-Thru time, (ms)
5.3765

7.9254 Notes: 1. Clean gas press. drop from candle center to mixing zone $=0.6093$ psia. The impulse intensity required in the mixing $20 n e=$
2. Mixed pulse gas viscosity and specific heat are molar-averaged values of nozzle and entrained gases. Ejector venturi area ratio $=$ 


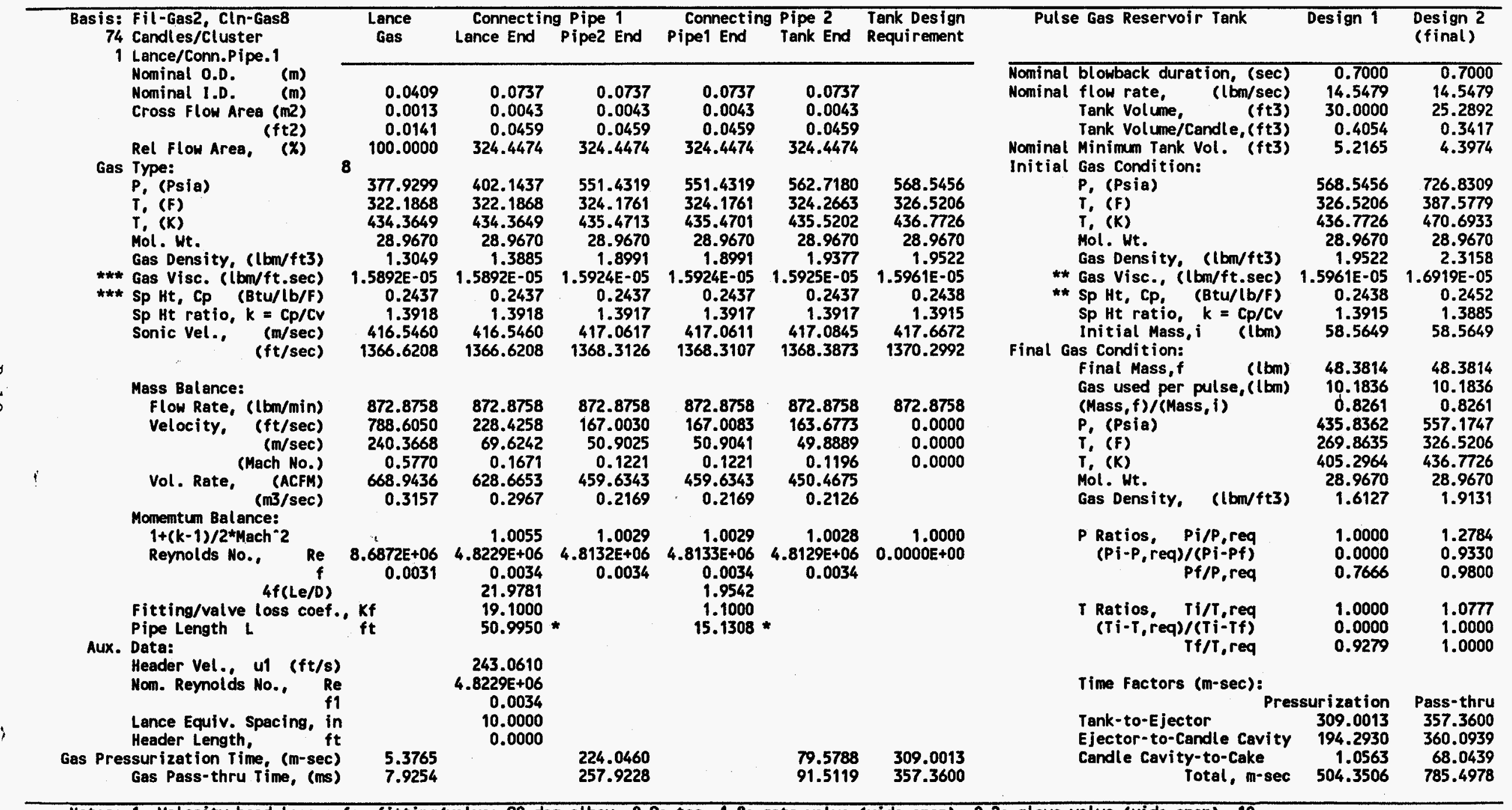

Notes: 1. Velocity head losses for fitting/valve: 90 deg elbow, $0.9 ;$ tee, 1.8; gate valve (wide open), $0.2 ;$ glove valve (wide open), 10.

2. Flow in connecting pipes is fanno (adiabatic \& frictional); last section of pipe2 to reservoir tank is assumed frictionless. 
Bas is: Fil-Gas2, Cln-GasB

74 Candles/Cluster

4 Clusters served/Reservoir

PULSE GAS COMPRESSION WORK/POWER:

No. of stage

Adia. efficiency

$P$ initial (psia)

$T$, initial (F) 120.0000

$T$, initial (F) $\quad 120.0000$

P, final (psia) $\quad \mathbf{7 2 6 . 8 3 0 9}$

$r$ final (F) $\quad 651.9113$

(R) 1111.5813

Compr. work, (Btu/lb) $\quad 260.8096$

(Kwh/lb) $\quad 0.076$

1

$$
\text { (Kwh/pulse) } \quad 0.7782
$$

Compressor Power/reservoir:

No of pulse/hr

No. of pulse/hr
Pulse gas flow, Ibm/hr

KW/Reservoir

2.6667

27.1561

$\begin{array}{ll} & 2.0752 \\ \text { Hp/Reservoir } \quad 2.7829\end{array}$

Total No. of Reservoirs $\quad 4.0000$

Pulse gas flow, lbm/hr 108.6245

$\begin{array}{ll}\text { Total KW } & 8.3007\end{array}$

lotal Hp $\quad 11.1314$ 


\section{CASE 3}

\section{Plant Configuration: PFBC}

Pulse Gas: Hot Pulse

Mode of Cleaning: On-Line 


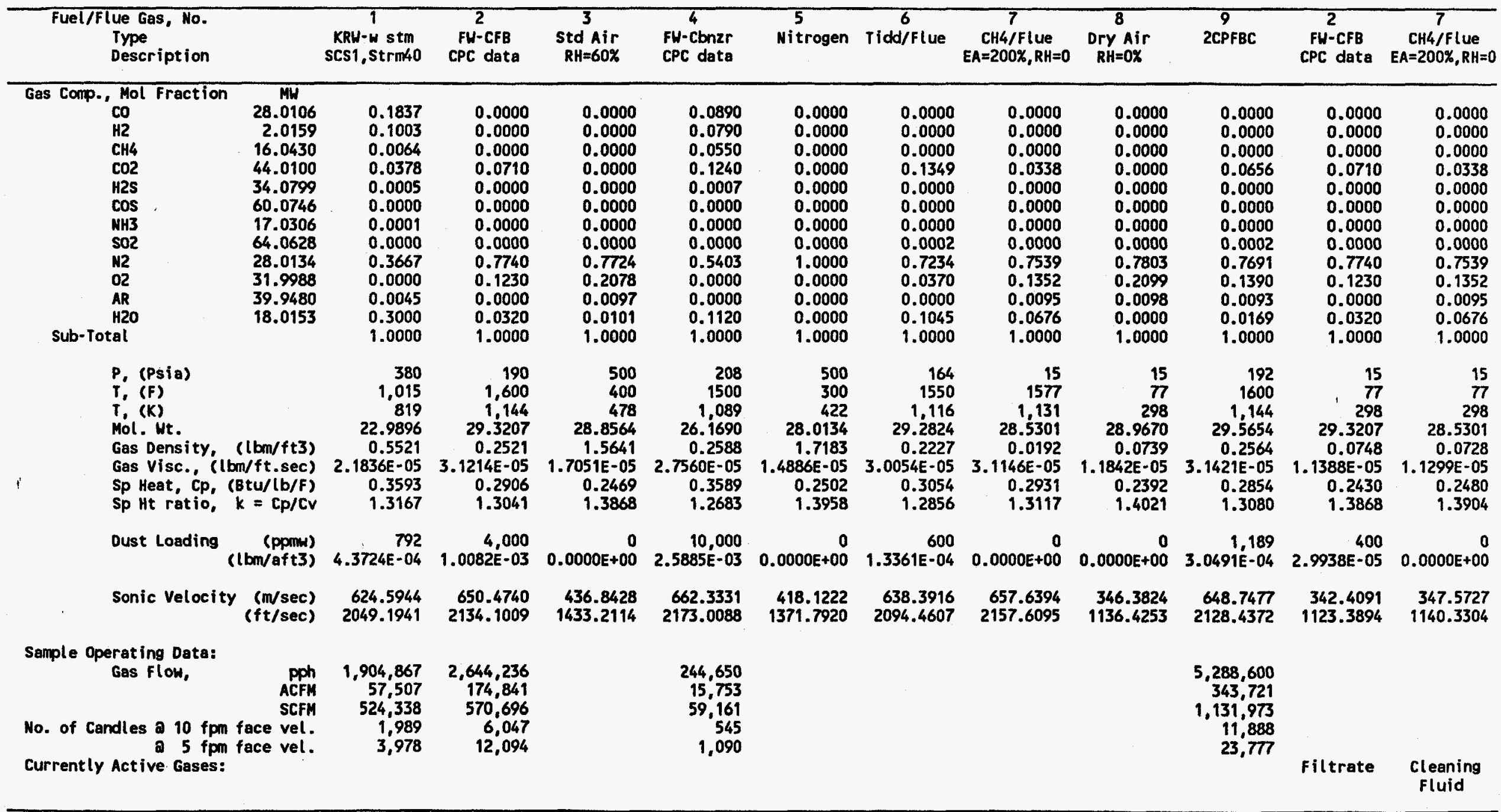

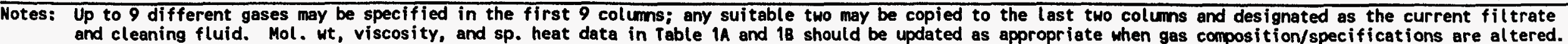


HTC/F-CASE3. WK

TABLE 1A Viscosity Correlations

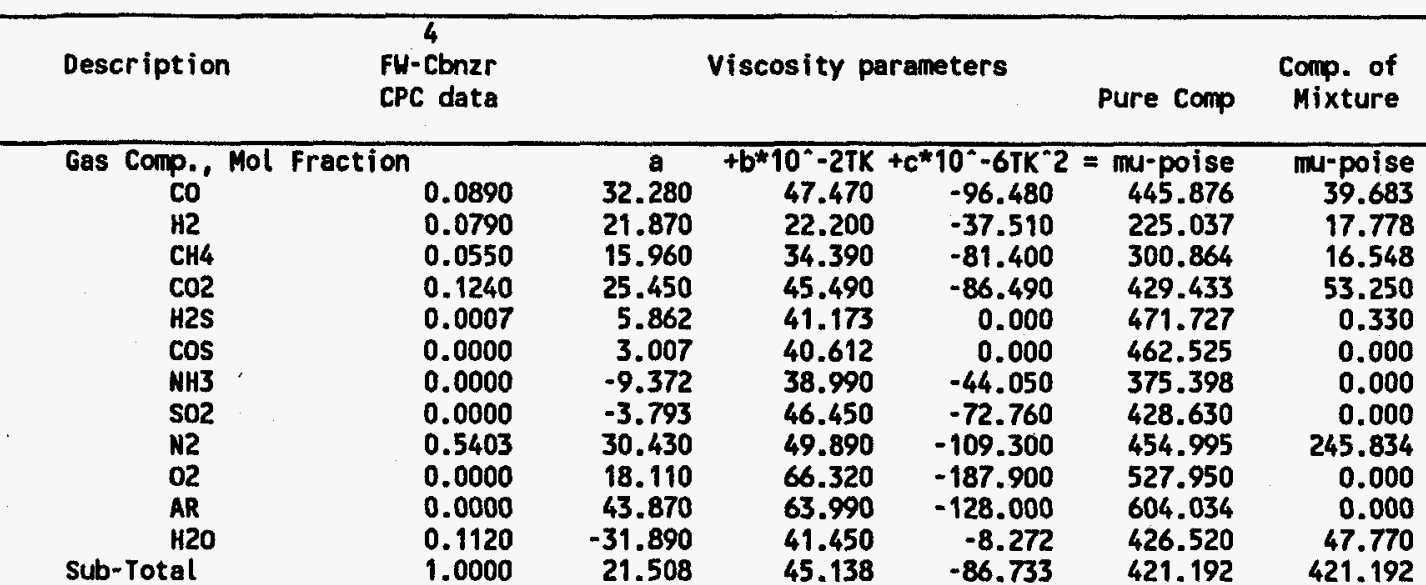

ए. Psia

1
$\sigma$ ,, $\operatorname{deg} F$

15

1577

$\begin{array}{rr}\text { Mol. Wt. } & 1,131 \\ & 26.1690\end{array}$

Fuel/Flue Gas
Ho. Type
1 KRW-W stm
2 FW-CFB
3 Std Air
4 FW-Cbnzr
5 Nitrogen
6 Tidd/Flue
7 CH4/Flue
8 Dry Air
9 2CPFBC

Mol.

Mol. Wt.

22.9896

29.3207

28.8564
26.1690

26.1690
28.0134

28.0134
29.2824

29.2824
28.5301

28.9670

29.5654

$a$
10.979
26.567
27.371
21.508
30.430
22.782
24.510
27.975
27.458

$+b * 10^{-}-2 T K+c * 10^{-}-6 T K^{*} 2=$ mu-poise $(b / f(t . s e c)$

$43.929 \quad-68.418 \quad 420.431 \quad 2.8253 \mathrm{E}-05$

$\begin{array}{llll}51.329 & -114.117 & 461.251 & 3.0996 E-05\end{array}$

$\begin{array}{llll}53.356 & -124.794 & 471.313 & 3.1672 E-05\end{array}$

$\begin{array}{llll}45.138 & -86.733 & 421.192 & 2.8304 E-05\end{array}$

$49.890 \quad-109.300 \quad 454.995 \quad 3.0576 E-05$

$\begin{array}{llll}49.022 & -98.565 & 451.264 & 3.0325 \mathrm{E}-05 \\ 51.526 & -112.503 & 463.481 & 3.1146 \mathrm{E}-05\end{array}$

$\begin{array}{llll}51.526 & -112.503 & 463.481 & 3.1146 E-05 \\ 53.477 & -125.983 & 471.770 & 3.1703 E-05\end{array}$

Currently Active Gases

Filtrate: FW-CFB

29.3207
28.5301

$51.873-117.194$

464.357 3.1205E-05

clning Fld: $\mathrm{CH}_{4} / \mathrm{Flu}$ lue

26.567
24.510

$\begin{array}{ll}51.329 & -114.117 \\ 51.526 & -112.503\end{array}$

$461.251 \quad 3.0996 E-05$

463.481 3.1146E-05 $i^{3}$

Notes: Micro-poise $=$ Mu-poise $=0.000001 *$ poise; 1 poise $(P)=100$ centi-poise $(\mathrm{cP})=0.0672 \mathrm{lbm} /(\mathrm{ft}-\mathrm{sec})=242 \mathrm{lbm} /(\mathrm{ft}-\mathrm{h})$.

When a new gas is designated as the current filtrate or cleaning fluid, be sure to update the corresponding viscosity data in the bottom two rows. 


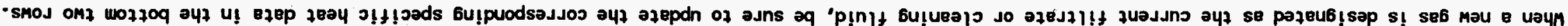

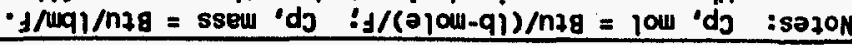

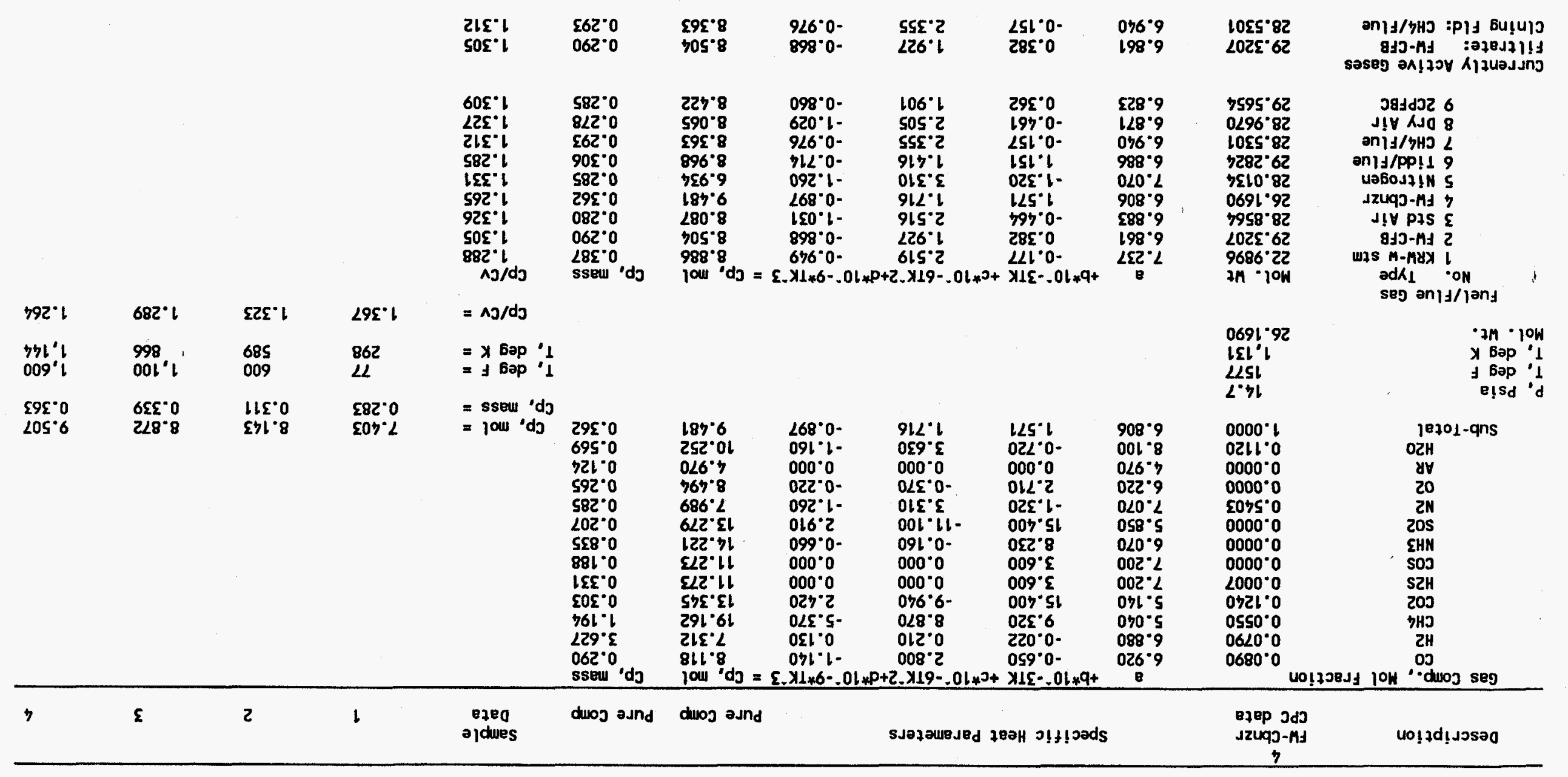

Wd $52: 50 \quad 76 / 92 / 20$

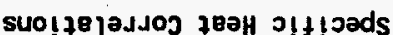

8l $378 \mathrm{l}$

8! a6ed

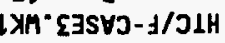


Basis: fil-Gas2, Cln-Gas7

1 Candle Filter

Filter Eff. $L(m), 95 \%$ norm. Nominal 0.0 . (m) Nominal I.D. $(\mathrm{m})$ Mean Filt. Area $\left(\mathrm{m}^{2}\right)$ Porosity (e) P. Dia., Dp (micron)

Gas Type:

Press., (psia)

Temp., (F)

Temp. (K)

tht Mol. Wt.

Density, Rho (lbm/ft3)

*t* Visc. Mu (lbm/ft.sec)

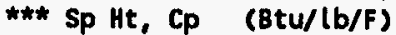

oust Loading (ppmw) Forward Face Velocity $u$ (ft/min)

$u(\mathrm{~cm} / \mathrm{sec})$

Mass flow Rate in (lbm/min)

Friction Coef. Ergun Re

Filtration Cycle Time $t$ (min) Cake Bulk Density, (lb/ft3)

Cake Cleaning Eff. = LC/(LC+Lrc)

Permeability Coef., B (m2) $k=B / L \quad(m)$

Mass permeability, $\mathrm{Km}(\mathrm{lbm} / \mathrm{ft})$

Cake/medium Thickness, L ( $f t$ )

Areal Density H (lb/ft2)

Pressure Drop, del $P$ (psia/ft) Cake del $P$ only, (psia) Pressure, $P$ (Psia) FORWARD FILTRATION PERIOD

Fresh Cake Redeposit Filter Total

$\begin{array}{r}1.4250 \\ 0.0600 \\ 0.2686 \\ 2.8913 \\ 0.8300 \\ 2.1000 \\ \hline\end{array}$

2

$190.0000^{2} 189.1479^{2}$

$\begin{array}{lll}190.0000 & 189.1479 & 188.6503\end{array}$

$\begin{array}{rrr}29.3207 & 29.3207 & 29.3207\end{array}$

1,000

$2.5206 \mathrm{E}-04$

2751.7185

$\begin{array}{lll}5.8168 E-13 & 5.0032 E-13 & 7.5852 E-12 \\ 4.0157 E-10 & 6.9081 E-10 & 5.0568 E-10\end{array}$

$1.9913 \mathrm{E}-10$

4.7523E-03
$1600.0000 \quad 1600.0000 \quad 1600.0000$

$1144.2611 \quad 1144.2611 \quad 1144.2611$

$\begin{array}{rrr}0.2521 & 0.2509 & 0.2503\end{array}$

$0.2906 \quad 3.1214 E 0060.1214 E-05$

$\begin{array}{lll}10.0000 & 10.0451 & 13.9621\end{array}$

5.0800

7.2877

0.0093

60.0000

187.2000

0.6667

1.4485

$1.8740 \mathrm{E}-10$

2.3761E-03

0.1512

0.7242

179.3080

0.8521

209.3999

209.3999
0.4976

189.1479

188.6503

16.5791

Total

7.0928
7.2877

7.2877
0.4897

185.5324

15.6027

\subsection{E-10 1.6905E-10}

0.0492

15.0000

\subsection{1}

$0.9532 \quad 2.3029$

187.6971
Sp. Res. K2, (in.H) $/(\mathrm{fpm}) /(\mathrm{lb} / \mathrm{ftz})$

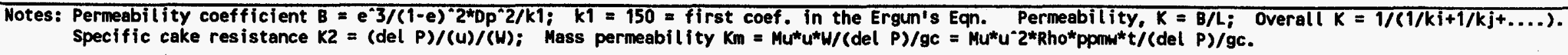




\begin{tabular}{|c|c|c|c|c|c|c|c|c|c|}
\hline $\begin{aligned} \text { Basis: Fil-Gas2, Cln-Gas7 } \\
1 \text { Candle Filter }\end{aligned}$ & $\begin{array}{l}\text { REVER } \\
\text { Fresh Cake }\end{array}$ & $\begin{array}{l}\text { RSE FLOW PERIO } \\
\text { Redeposit }\end{array}$ & $\begin{array}{c}\text { OD (Initial) } \\
\text { Filter }\end{array}$ & Total & $\begin{aligned} \text { Basis: Fil-Gas2, Cln-Gas7 } \\
1 \text { Candle Filter }\end{aligned}$ & $\begin{array}{l}\text { REVER } \\
\text { Fresh Cake }\end{array}$ & $\begin{array}{l}\text { RSE FLOW PERI } \\
\text { Redeposit }\end{array}$ & $\begin{array}{l}100 \text { (Final) } \\
\text { Filter }\end{array}$ & Total \\
\hline 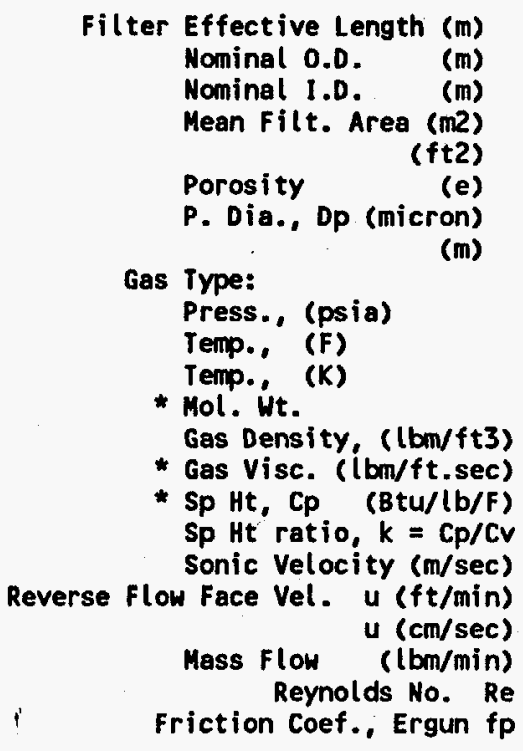 & $\begin{array}{r}1.4250 \\
0.0600 \\
0.2686 \\
2.8913 \\
0.8300 \\
2.1000 \\
2.1000 \mathrm{E}-06 \\
2 \\
190.0000 \\
1600.0000 \\
1144.2611 \\
29.3207 \\
0.2521 \\
3.1214 \mathrm{E}-05 \\
0.2906 \\
1.3049 \\
650.4740 \\
18.0000 \\
9.1440 \\
13.1179 \\
0.0167 \\
1529.5103\end{array}$ & $\begin{array}{r}1.4250 \\
0.0600 \\
0.2686 \\
2.8913 \\
0.8200 \\
2.1000 \\
2.1000 E-06 \\
2 \\
2 \\
191.5346 \\
1600.0000 \\
1144.2611 \\
29.3207 \\
0.2541 \\
3.1214 E-05 \\
0.2906 \\
1.3041 \\
17.8558 \\
9.0707 \\
13.1179 \\
0.0167 \\
1619.3785\end{array}$ & $\begin{array}{r}1.4250 \\
0.0600 \\
0.0300 \\
0.1938 \\
2.0856 \\
0.4000 \\
80.0000 \\
8.0000 E-05 \\
2 \\
192.4195 \\
1600.0000 \\
1144.2611 \\
29.3207 \\
0.2553 \\
3.1214 E-05 \\
0.2906 \\
1.3041 \\
24.6395 \\
12.5169 \\
13.1179 \\
0.8815 \\
103.8513\end{array}$ & & 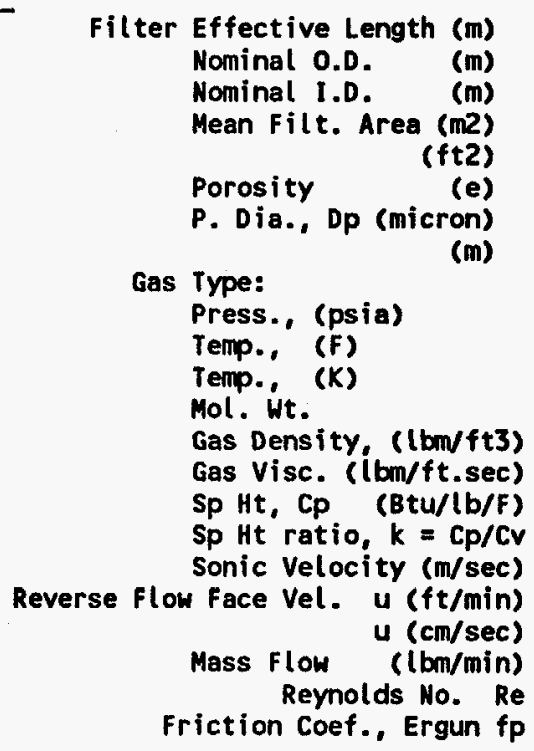 & $\begin{array}{r}1.4250 \\
0.0600 \\
0.2686 \\
2.8913 \\
0.8300 \\
2.1000 \\
2.1000 \mathrm{E}-06 \\
\text { mixed } \\
190.0000 \\
1500.0000 \\
1088.7056 \\
28.7367 \\
0.2596 \\
2.9212 E-05 \\
0.2868 \\
1.3177 \\
644.2368 \\
17.4741 \\
8.8769 \\
13.1179 \\
0.0178 \\
1431.5263\end{array}$ & $\begin{array}{r}1.4250 \\
0.0600 \\
0.2686 \\
2.8913 \\
0.8200 \\
2.1000 \\
2.1000 \mathrm{E}-06 \\
\text { mixed } \\
191.3943 \\
1500.0000 \\
1088.7056 \\
28.7367 \\
0.2616 \\
2.9212 E-05 \\
0.2868 \\
1.3177 \\
17.3468 \\
8.8122 \\
13.1179 \\
0.0178 \\
1515.6308\end{array}$ & $\begin{array}{r}1.4250 \\
0.0600 \\
0.0300 \\
0.1938 \\
2.0856 \\
0.4000 \\
80.0000 \\
8.0000 \mathrm{E}-05 \\
\text { mixed } \\
192.1989 \\
1500.0000 \\
1088.7056 \\
28.7367 \\
0.2627 \\
2.9212 \mathrm{E}-05 \\
0.2868 \\
1.3177 \\
23.9471 \\
12.1651 \\
13.1179 \\
0.9419 \\
97.3030\end{array}$ & \\
\hline $\begin{array}{l}\text { Stokes' Terminal Vel.. (ft/sec) } \\
\text { Particle Reynolds Ho. Re,p }\end{array}$ & $\begin{array}{r}0.0005 \\
2.8296 E-05\end{array}$ & $\begin{array}{r}0.0005 \\
2.9477 \mathrm{E}-05\end{array}$ & & & $\begin{array}{l}\text { Stokes' Terminal Vel., (ft/sec) } \\
\text { Particle Reynolds No. Re,p }\end{array}$ & $\begin{array}{r}0.0005 \\
3.3278 E-05\end{array}$ & $\begin{array}{r}0.0006 \\
3.4641 E-05\end{array}$ & & \\
\hline $\begin{array}{r}\text { Permeability Coef., B (m2) } \\
k=B / L(m) \\
k^{\prime}=u /(\text { del } p)(f p m / p s i a) \\
\text { Cake/medium Thickness (ft) } \\
\text { (mm) }\end{array}$ & $\begin{array}{r}5.8168 \mathrm{E}-13 \\
4.0157 \mathrm{E}-10 \\
11.7294 \\
4.7523 \mathrm{E}-03 \\
1.4485\end{array}$ & $\begin{array}{r}5.0032 E-13 \\
6.9081 E-10 \\
20.1787 \\
2.3761 E-03 \\
0.7242\end{array}$ & $\begin{array}{r}7.5852 E-12 \\
5.0568 E-10 \\
14.5379 \\
0.0492 \\
15.0000\end{array}$ & $1.6905 E-10$ & $\begin{array}{r}\text { Permeability Coef., B (m2) } \\
k=B / L(m) \\
k^{\prime}=u /(\text { del p) (fpm/psia) } \\
\text { Cake/medium Thickness (ft) } \\
(\mathrm{mm})\end{array}$ & $\begin{array}{r}5.8168 E-13 \\
4.0157 E-10 \\
12.5323 \\
4.7523 E-03 \\
1.4485\end{array}$ & $\begin{array}{r}5.0032 E-13 \\
6.9081 E-10 \\
21.5600 \\
2.3761 E-03 \\
0.7242\end{array}$ & $\begin{array}{r}7.5852 E-12 \\
5.0568 E-10 \\
15.5163 \\
4.9213 E-02 \\
15.0000\end{array}$ & $1.6905 E-10$ \\
\hline 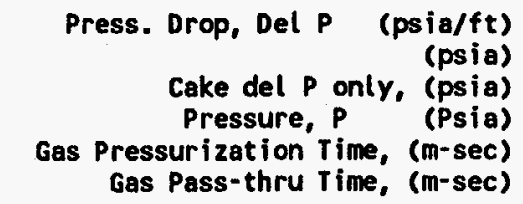 & $\begin{array}{r}322.9187 \\
1.5346 \\
\\
191.5346 \\
0.0934 \\
13.1480\end{array}$ & $\begin{array}{r}372.4018 \\
0.8849 \\
192.4195 \\
0.0986 \\
6.5473\end{array}$ & $\begin{array}{r}34.4393 \\
1.6948 \\
\\
194.1143 \\
0.9390 \\
47.9353\end{array}$ & $\begin{array}{l}4.1143 \\
2.4195\end{array}$ & $\begin{array}{r}\text { Press. Drop, Del P (psia/ft) } \\
\text { (psia) } \\
\text { Cake del P only, (psia) } \\
\text { Pressure, P } \\
\text { (Psia) } \\
\text { Gas Pass-thru Time, (m-sec) }\end{array}$ & $\begin{array}{r}293.4019 \\
1.3943 \\
191.3943 \\
13.5437\end{array}$ & $\begin{array}{r}338.6084 \\
0.8046 \\
192.1989\end{array}$ & $\begin{array}{r}193.7423 \\
49.3213\end{array}$ & $\begin{array}{l}3.7423 \\
2.1989\end{array}$ \\
\hline
\end{tabular}


TABLE 4 FLOW FROM CANDLE TO EJECTOR MIXING ZOME - PRESSURE DROPS (Reverse Cleaning Period)

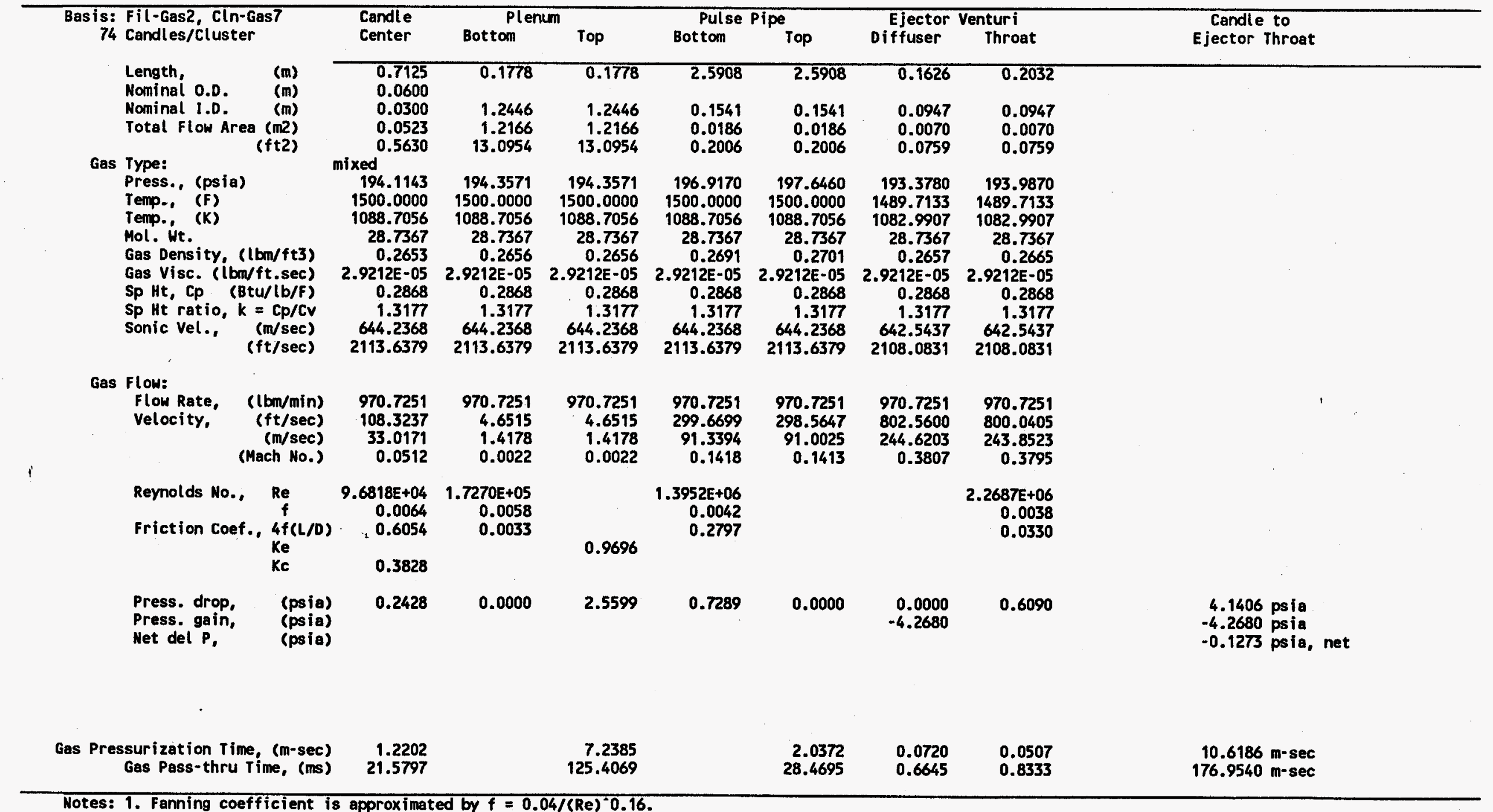

Notes: 1. Fanning coefficient is approximated by $f=0.04 /(\operatorname{Re})^{-0} 0.16$.

2. Flow is assumed isothermal from candle to pulse pipe; flow in the diffuser is assumed isentropic. 


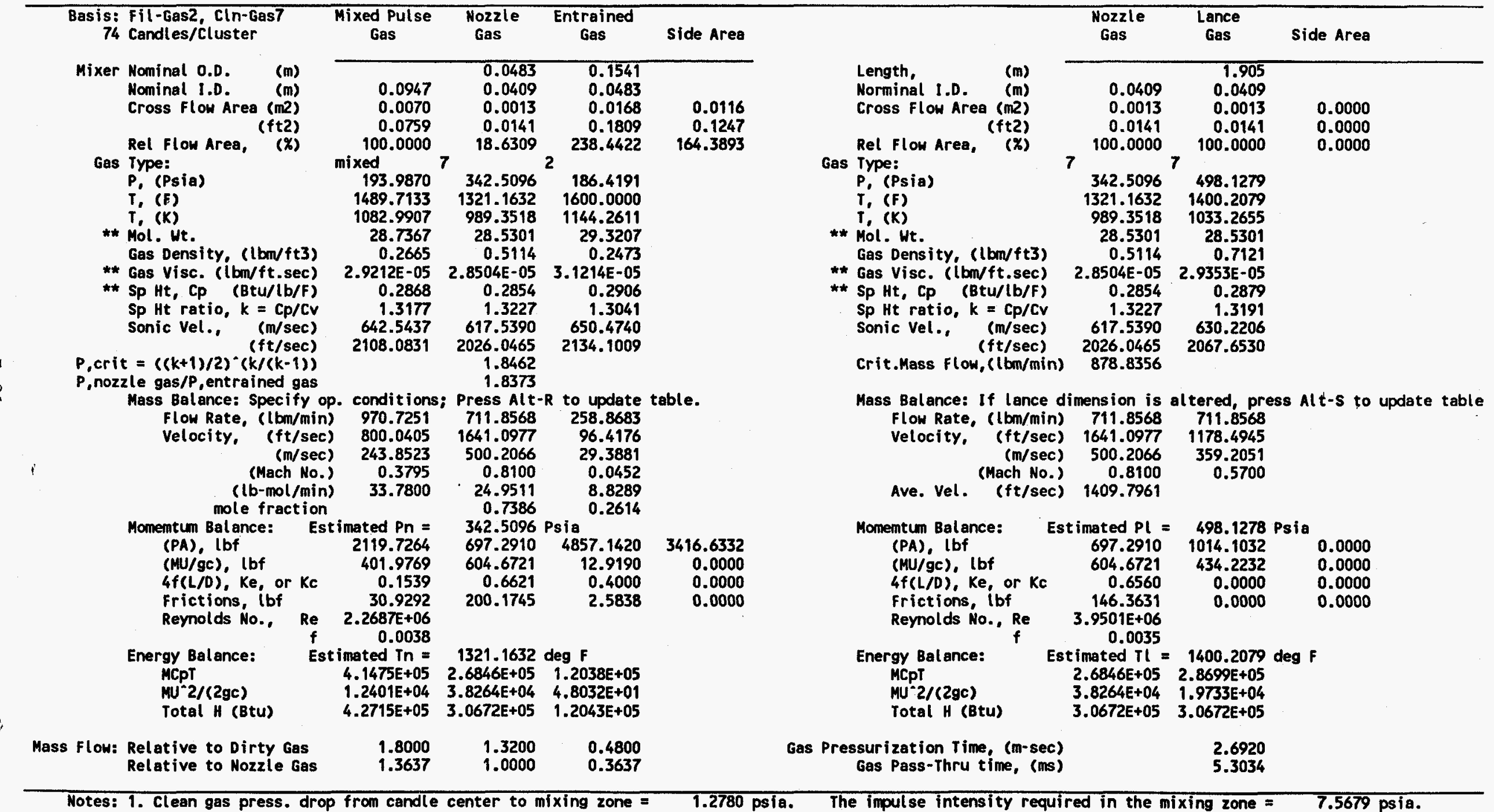




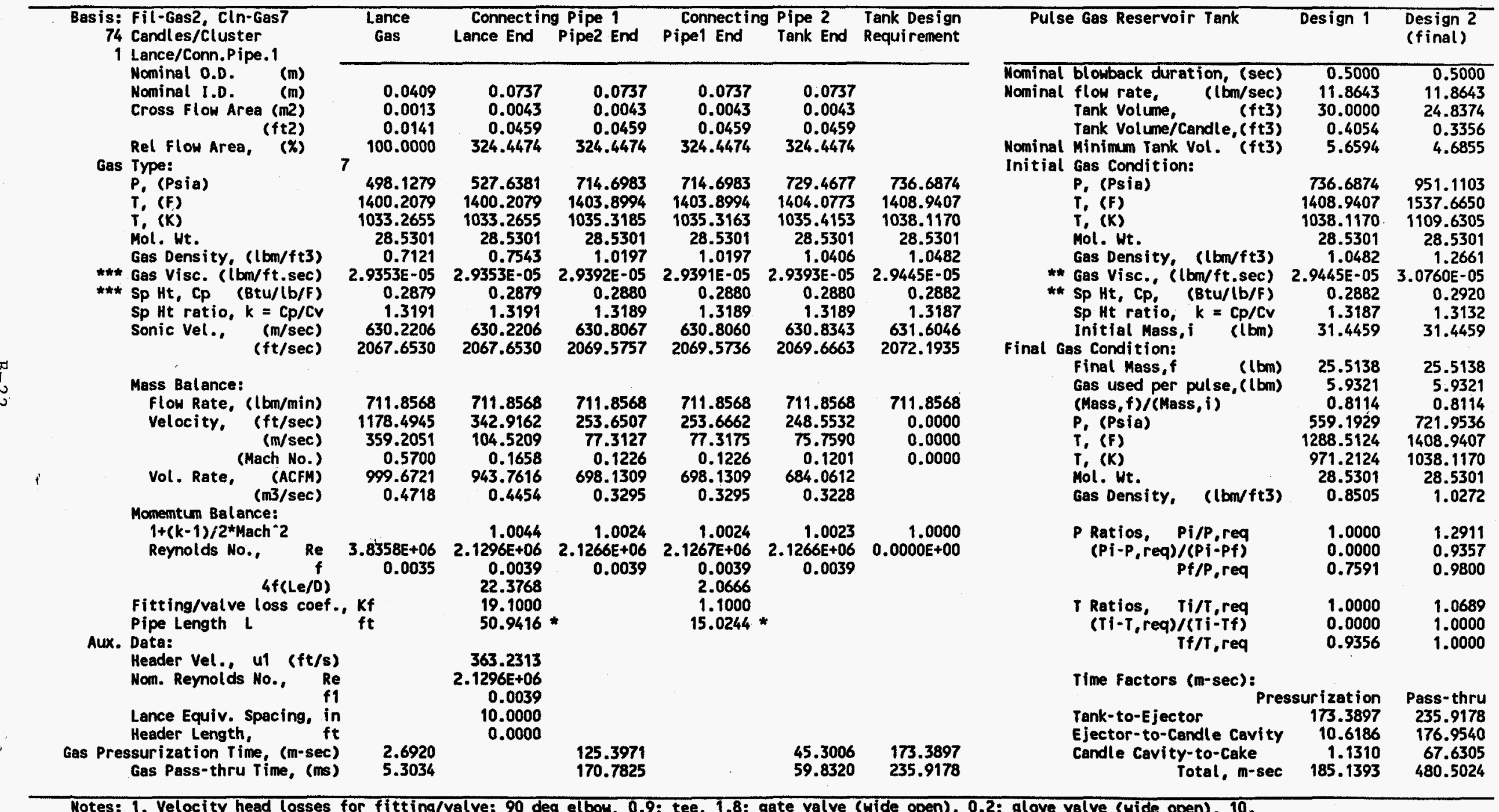
Hotes: 1. Velocity head losses for fitting/valve: 90 deg elbow, $0.9 ;$ tee, 1.8 ; gate valve (wide open), $0.2 ;$ glove valve (wide open), 10.
2. Flow in connecting pipes is Fanno (adiabatic \& frictional); last section of pipe2 to reservoir tank is assumed frictionless. 
Basis: Fil-Gas2, Cln-Gas7

74 Candles/Cluster

4 Clusters served/Reservoir

PULSE GAS COMPRESSION WORK/PONER:

No. of stage

Adia. efficiency $0.9000^{2}$

$P$, initial (psia) $\quad 14.7000$

$T$, initial (F) 120.0000

$\begin{array}{ll}\text { (R) } & \mathbf{5 7 9 . 6 7 0 0}\end{array}$

P. final (psia) 951.1103

$T$, final (F) $\quad 599.3247$

(R) 1058.9947

Compr. work, (Btu/lb) $\quad 279.9359$

(Kwh/pulse)

Compressor Power/reservoir

No. of pulse/hr
Pulse gas flow, lbm/hr 23.72000

$\begin{array}{lr}\text { Kw/Reservoir } & 23.7286 \\ & 1.9462\end{array}$

Hp/Reservoir $\quad 2.6099$

Total No. of Reservoirs

Pulse gas flow, $1 \mathrm{bm} / \mathrm{hr}$

4.0000

Total $\mathrm{KW}$

94.9142

Total Hp

7.7849
10.4397

0.4397 


\section{CASE 4}

Plant Configuration: PFBC

Pulse Gas: Hot Pulse

Mode of Cleaning: Off-Line

$B-25$ 


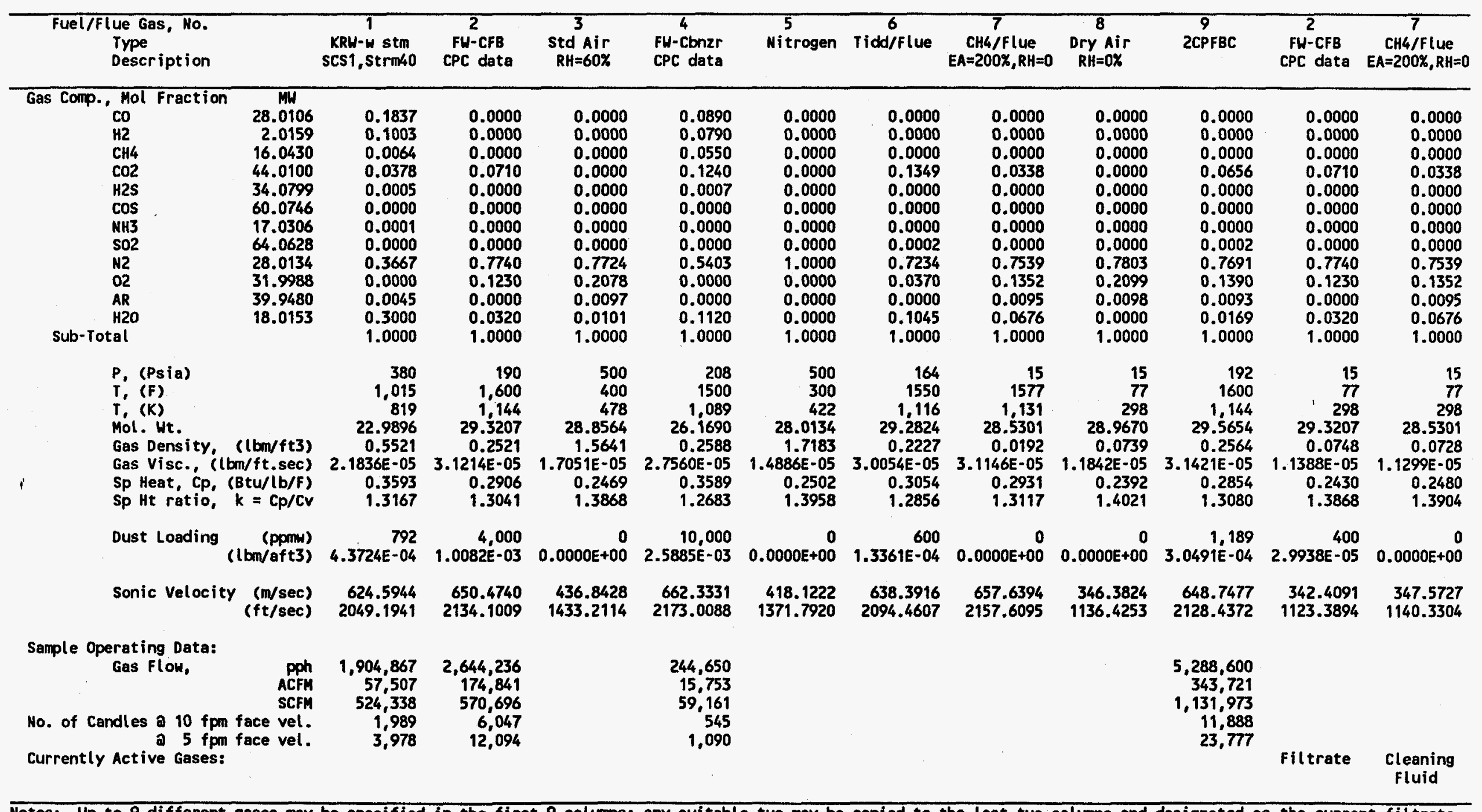




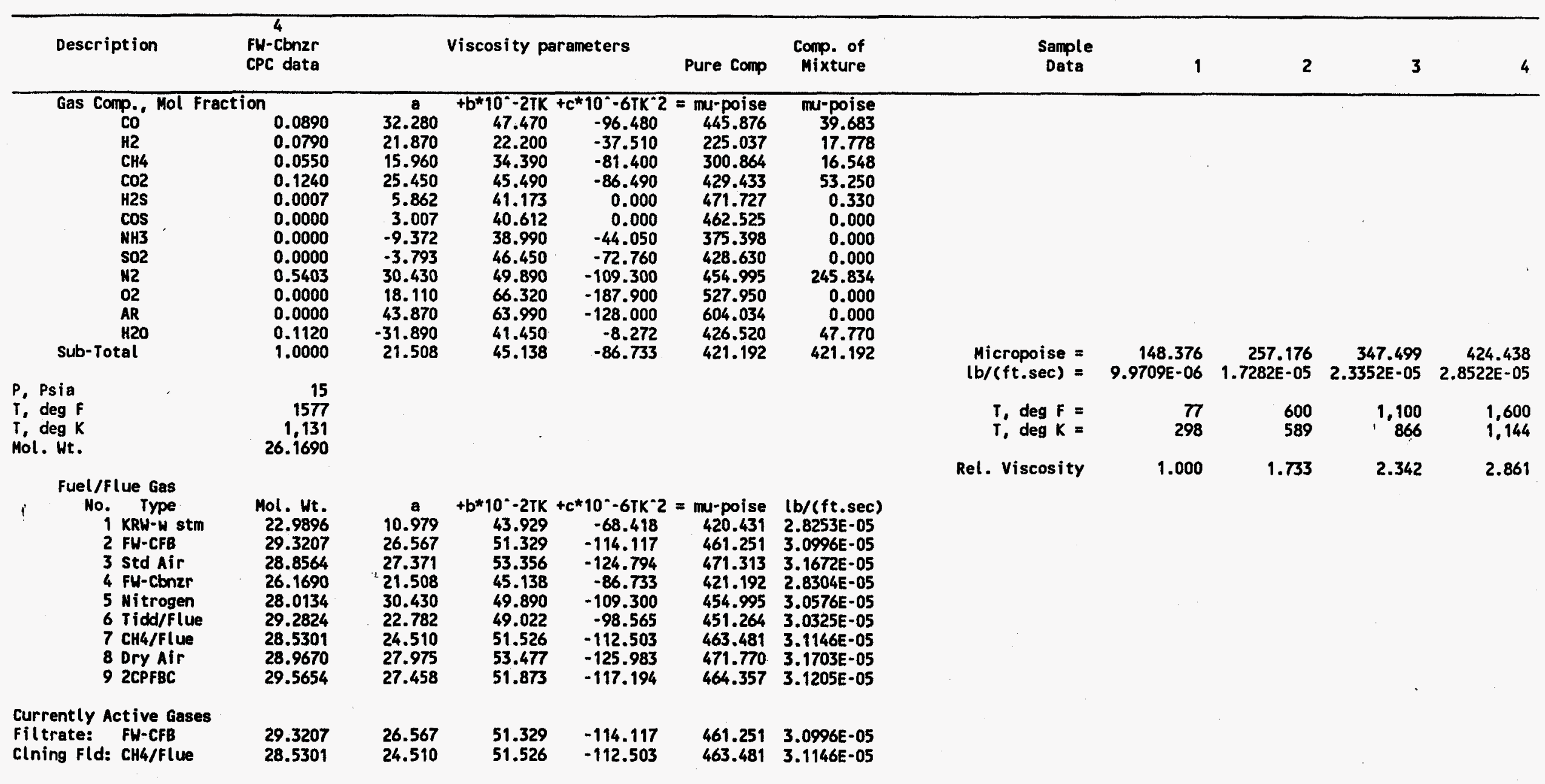

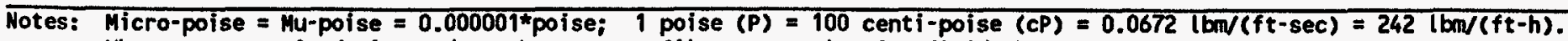
When a new gas is designated as the current filtrate or cleaning fluid, be sure to update the corresponding viscosity data in the bottom two rows. 


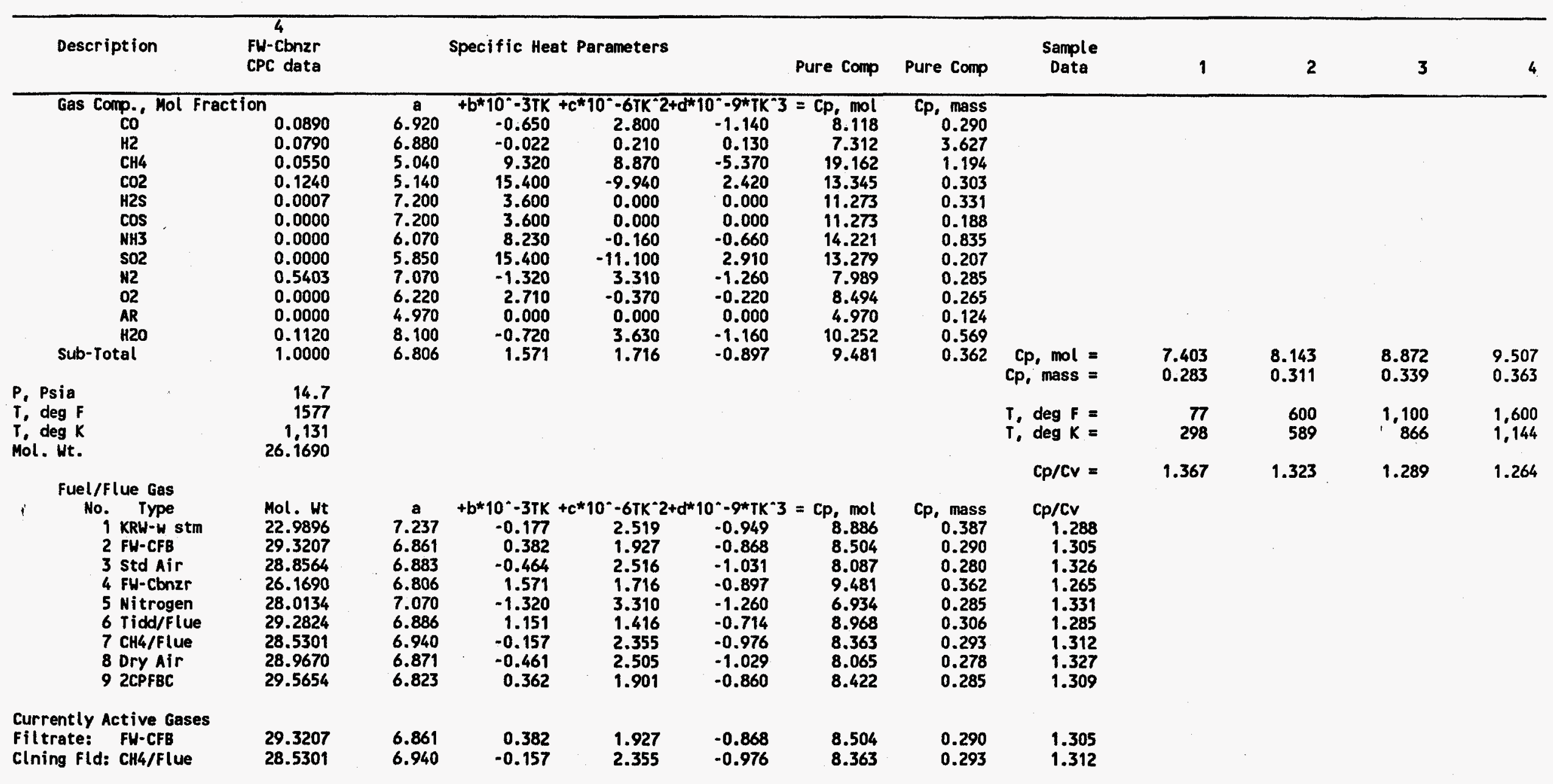

Notes: $C p, \operatorname{mol}=B t u /(b-m o l e) / F ; \quad C p$, mass $=B t u /(b m / F$. 
Filter Eff. L (m), $95 \%$ norm. Nominal 0.0 . (m) Nominal I.D. (m) Mean Filt. Area $(\mathrm{m} 2)$ Porosity (e) P. Dia., Dp (micron) FORUARD FILTRATI

filter

Total

$$
\text { (in) }
$$

Type:

\begin{tabular}{rrr}
\hline 1.4250 & 1.4250 & 1.4250 \\
0.0600 & 0.0600 & 0.0600 \\
0.2686 & 0.2686 & 0.0300 \\
2.8913 & 2.8913 & 0.1938 \\
0.8300 & 0.8200 & 0.0856 \\
2.1000 & 2.1000 & 80.00000 \\
$2.1000 E-06$ & $2.1000 E-06$ & $8.0000 E-05$ \\
2 & \multicolumn{2}{c}{$2^{2.000}$}
\end{tabular}

Temp. ( $F$ )

*** Mol. Út.

Density, Rho (lbm/ft3)

*** Visc. Mu (lbm/ft.sec)

*** Sp Ht Cp (Btu/lb/F) Dust Loading (ppmw) Forward face Velocity $u(\mathrm{ft} / \mathrm{min})$ $u(\mathrm{~cm} / \mathrm{sec})$

2 $2^{2}$

$190.0000 \quad 188.7218$

$1600.0000 \quad 1600.0000 \quad 168.6913$

$\begin{array}{lll}1144.2611 & 1144.2611 & 1144.2611\end{array}$

$\begin{array}{lrr}29.3207 & 29.3207 & 29.3207\end{array}$

$\begin{array}{rrr}0.2521 & 0.2504 & 0.2503\end{array}$

3.1214E-05 $3.1214 E-05 \quad 3.1214 E-05$

0.2906
1,000

$0.2906 \quad 0.2906$

2.5206E-04

$\begin{array}{lll}10.0000 & 10.0677 & 13.9591\end{array}$

$\begin{array}{lll}\mathbf{5 . 0 8 0 0} & \mathbf{5 . 1 1 4 4} & \mathbf{7 . 0 9 1 2}\end{array}$

$\begin{array}{lll}7.2877 & 7.2877 & 7.2877\end{array}$

Mass flow Rate m (Lbm/min)

Friction Coef.., Ergun fp

0.0093

0.4897

2751.7185

2913.4814

185.5324

Filtration Cycle Time $t$ (min) Cake Bulk Density, (lb/ft3) Cake Cleaning Eff. = LC/ (LC+LrC)

Permeability Coef., $B(m 2)$
$k=B / L(m)$

90.0000

187.2000

0.9800

193.4400

$5.8168 E-13 \quad 5.0032 E-13 \quad 7.5852 E-12$

2.6772E-10 $\quad 1.1283 E-08 \quad 5.0568 E-10 \quad 1.7237 E-10$

(lom/ft)

Cake/medium Thickness, L (ft)

Areal Density $W$ (lb/ftz)

$1.9913 E-10 \quad 1.8740 E-10$

$1284 E-03 \quad 1.4548 E-04$

$2.1727 \quad 0.0443$

\subsection{2}

$0.2269 \quad 0.0051$

Pressure Drop, del P (psia/ft)

Cake del $P$ only (psia)

Pressure, $P$ (Psia)

179.3080

$209.8726 \quad 19.3648$

15.0000

$\begin{array}{lll}188.7218 & 188.6913 & 187.7383\end{array}$

2.2617

Sp. Res. K2, (in.W)/(fpm)/(lb/ft2)

$15.6027 \quad 16.5791$

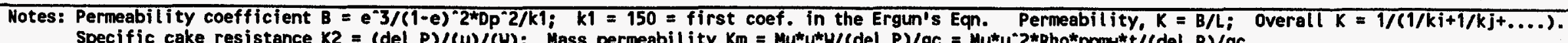

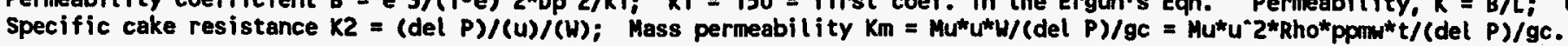


Fil-Gas2, Cln-Gas7

Filter Effective Length (m) Nominal O.D. (m) Nominal 1.0 . Mean filt. Area $\left(\mathrm{m}^{2}\right)$ Porosity (ft2) P. Dia., Op (micron)

Gas Type:

Press., (psia)
Temp. (F)

Temp., (K)

* Mol. Wt.

Gas Density, (lbm/ft3)

* Gas Visc. (ibm/ft.sec)

* Sp Ht, Cp (Btu/b/f) Sp Ht, Cp (Btu/b/F)
Sp Ht ratio, $k=C p / C v$ Sp Ht ratio, $k=\mathrm{Cp} / \mathrm{Cr}$
Sonic Velocity $(\mathrm{m} / \mathrm{sec})$ Reverse Flow Face Vel. u (ft/min) u (cm/sec)

Mass flow (lbm/min) Reynolds No. Re

Friction Coef., Ergun fp

Stokes' Terminal Vel., (ft/sec)

Particle Reynolds No. Re,p

Permeability Coef... $B(\mathrm{~m} 2)$ $k^{\prime}=u /($ del p) $(f \mathrm{pm} / p s i a)$ Cake/medium Thickness ( $\mathrm{ft}$ ) (min)

Press. Drop, Del P (psia/ft) Cake del $P$ only, (psia) Pressure, $P$ (Psia) Gas Pressurization Time, (m-sec) Gas Pass-thru Time, (m-sec)

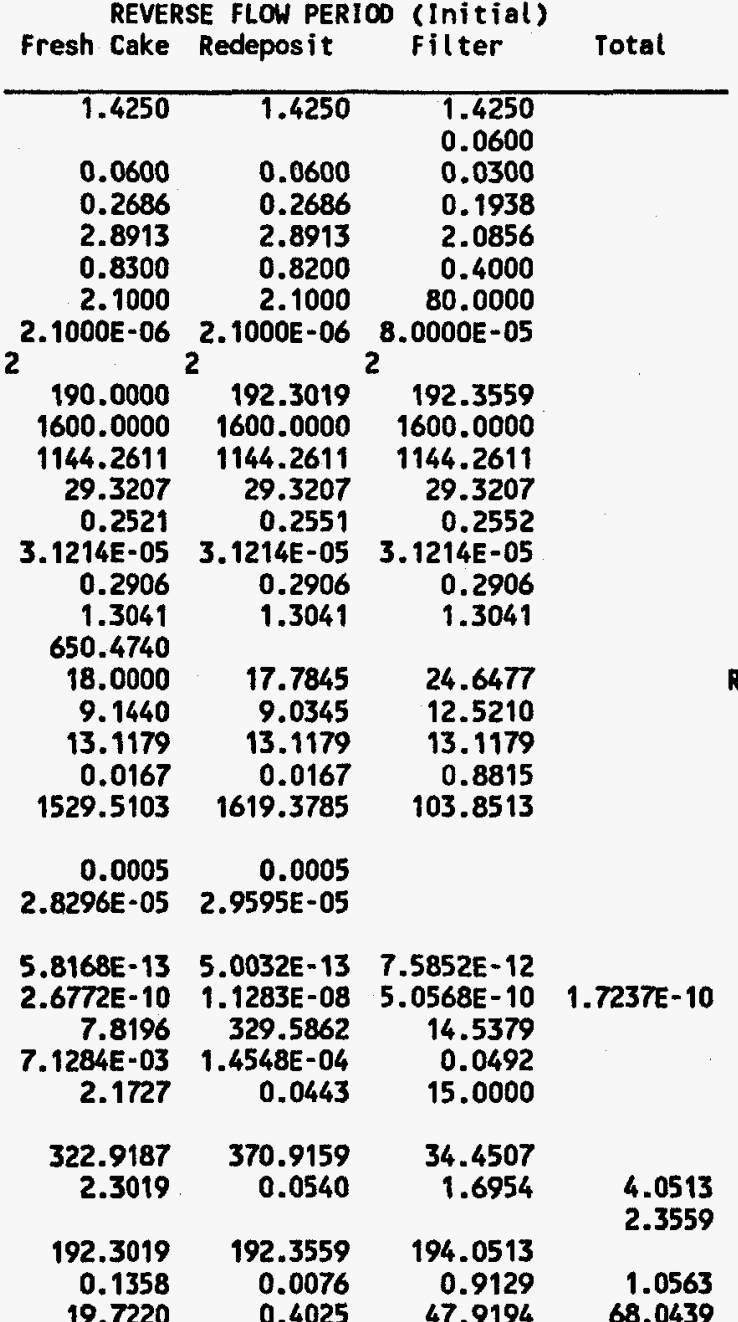

Basis: Fil-Gas2, Cln-G

1 Candle Filter

Filter Effective Length $(m)$ Nominal $0 . D$. (m) Nominal 1.D. Mean filt. Area (m2) Porosity (ft2) P. Dia., Dp (micron)

Gas Type:

Press., (psia)

Temp.. (F)

Temp. (K)

Gas Density (lbm/ft3)

Gas Visc. (ibm/ft.sec) Sp Ht, Cp (Btu/lb/F) Sp Ht, Cp (Btu/(b/F) Sp Ht ratio, $k=\mathrm{Cp} / \mathrm{Cv}$
Sonic Velocity $(\mathrm{m} / \mathrm{sec})$ Reverse Flow Face Vel. u (ft/min) $u(\mathrm{ft} / \mathrm{min})$
$u(\mathrm{~cm} / \mathrm{sec})$ Rewnolds (lbm/min) Friction Coef., Ergun fp

Stokes' Terminal Vel., (ft/sec) Particle Reynolds No. Re,p

Permeability Coef. , B (m2) $k=B / L \quad(m)$ $k^{\prime}=u /(\operatorname{del} p)$
Cake/medium Thickness (ft) (mm)

Press. Drop, Del P (psia/ft) (psia)
Cake del P only, (psia)
Pressure, $P$

Pressure, $P$ (Psia)

Gas Pass-thru Time, (m-sec)

\begin{tabular}{|c|c|c|c|}
\hline $\begin{array}{l}\text { REVERS } \\
\text { Fresh Cake }\end{array}$ & $\begin{array}{l}\text { RSE FLOW PER } \\
\text { Redeposit }\end{array}$ & $\begin{array}{c}100 \text { (Final) } \\
\text { Filter }\end{array}$ & Total \\
\hline $\begin{array}{r}1.4250 \\
0.0600 \\
0.2686 \\
2.8913 \\
0.8300 \\
2.1000 \\
2.1000 E-06 \\
\text { mixed } \\
190.0000 \\
1500.0000 \\
1088.7056 \\
28.7377 \\
0.2597 \\
2.9214 E-05 \\
0.2868 \\
1.3177 \\
644.2211 \\
17.4735 \\
8.8765 \\
13.1179 \\
0.0178 \\
1431.6412\end{array}$ & $\begin{array}{r}0.0600 \\
0.2686 \\
2.8913 \\
0.8200 \\
2.1000 \\
2.1000 \mathrm{E}-06 \\
\text { mixed } \\
192.0916 \\
1500.0000 \\
1088.7056 \\
28.7377 \\
0.2625 \\
2.9214 \mathrm{E}-05 \\
0.2868 \\
1.3177 \\
\\
17.2833 \\
8.7799 \\
13.1179 \\
0.0178 \\
1515.7524\end{array}$ & $\begin{array}{r}1.4250 \\
0.0600 \\
0.0300 \\
0.1938 \\
2.0856 \\
0.4000 \\
80.0000 \\
8.0000 \mathrm{E}-05 \\
\text { mixed } \\
192.1407 \\
1500.0000 \\
1088.7056 \\
28.7377 \\
0.2626 \\
2.9214 \mathrm{E}-05 \\
0.2868 \\
1.3177 \\
\\
23.9536 \\
12.1684 \\
13.1179 \\
0.9418 \\
97.3107\end{array}$ & \\
\hline $\begin{array}{r}0.0005 \\
3.3274 E-05\end{array}$ & $\begin{array}{r}0.0006 \\
3.4763 E-05\end{array}$ & & \\
\hline $\begin{array}{r}5.8168 E-13 \\
2.6772 E-10 \\
8.3542 \\
7.1284 E-03 \\
2.1727\end{array}$ & $\begin{array}{r}5.0032 E-13 \\
1.1283 E-08 \\
352.1188 \\
1.4548 E-04 \\
0.0443\end{array}$ & $\begin{array}{r}7.5852 E-12 \\
5.0568 E-10 \\
15.5151 \\
4.9213 E-02 \\
15.0000\end{array}$ & $1.7237 E-10$ \\
\hline $\begin{array}{r}293.4154 \\
2.0916 \\
192.0916\end{array}$ & $\begin{array}{r}337.3949 \\
0.0491\end{array}$ & $\begin{array}{r}31.3719 \\
1.5439\end{array}$ & $\begin{array}{l}3.6846 \\
2.1407\end{array}$ \\
\hline 20.3162 & 0.4141 & 49.3080 & 70.0383 \\
\hline
\end{tabular}

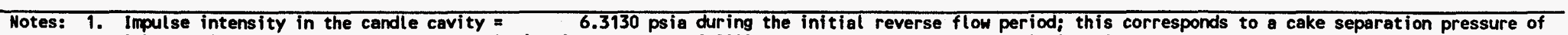
2.3559 psia if the reverse flow face velocity is set to 1.8000 times of the forward face velocity, i.e., $u=418.0000$ fpm. 
TABLE 4 FLOW FROM CANDLE TO EJECTOR MIXING ZOME - PRESSURE DROPS

Page 4

(Reverse Cleaning Period)

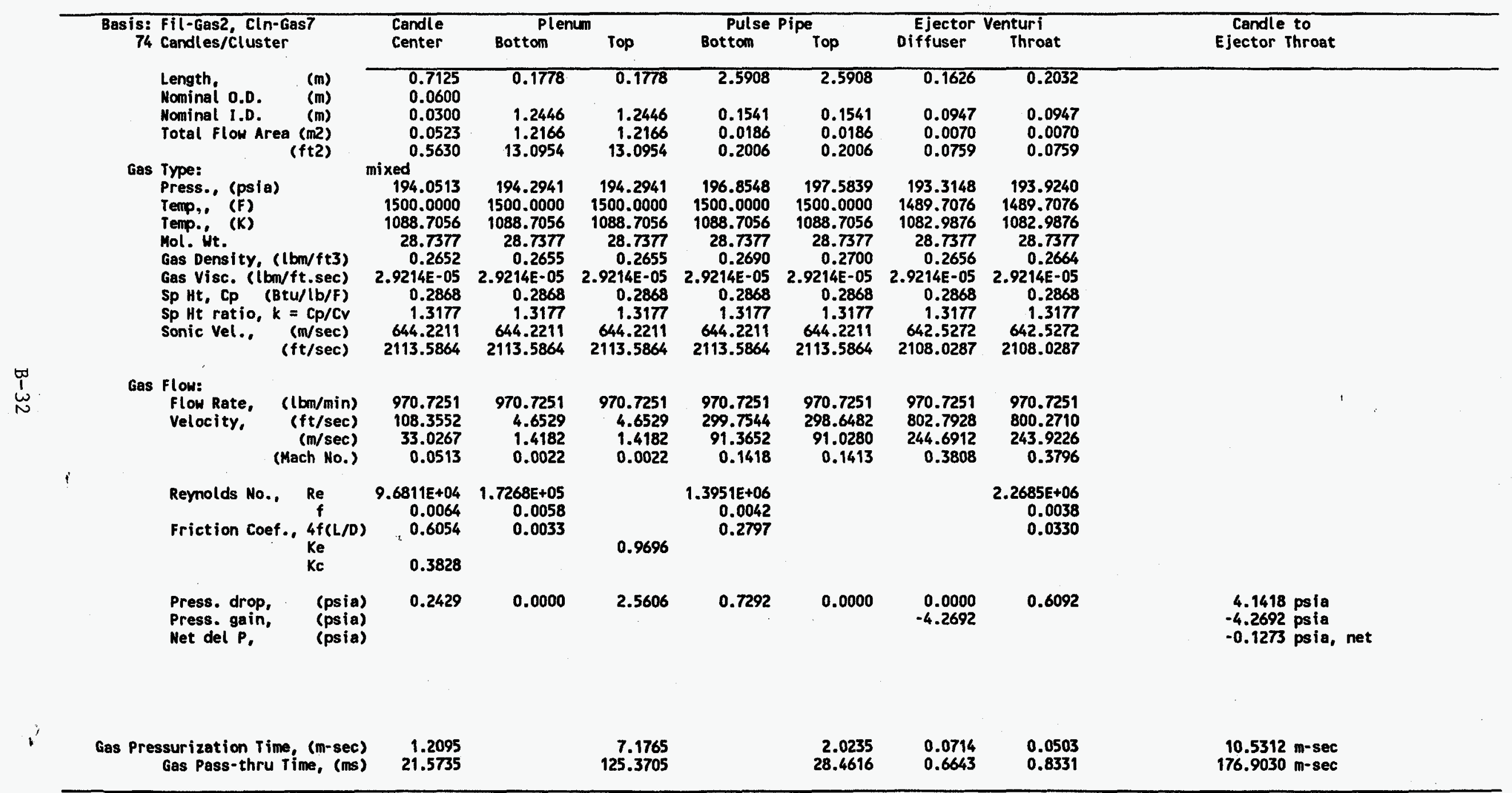

Notes: 1. Fanning coefficient is approximated by $f=0.04 /(\mathrm{Re})^{\top} 0.16$

2. Flow is assumed isothermal from candle to pulse pipe; flow in the diffuser is assumed isentropic. 


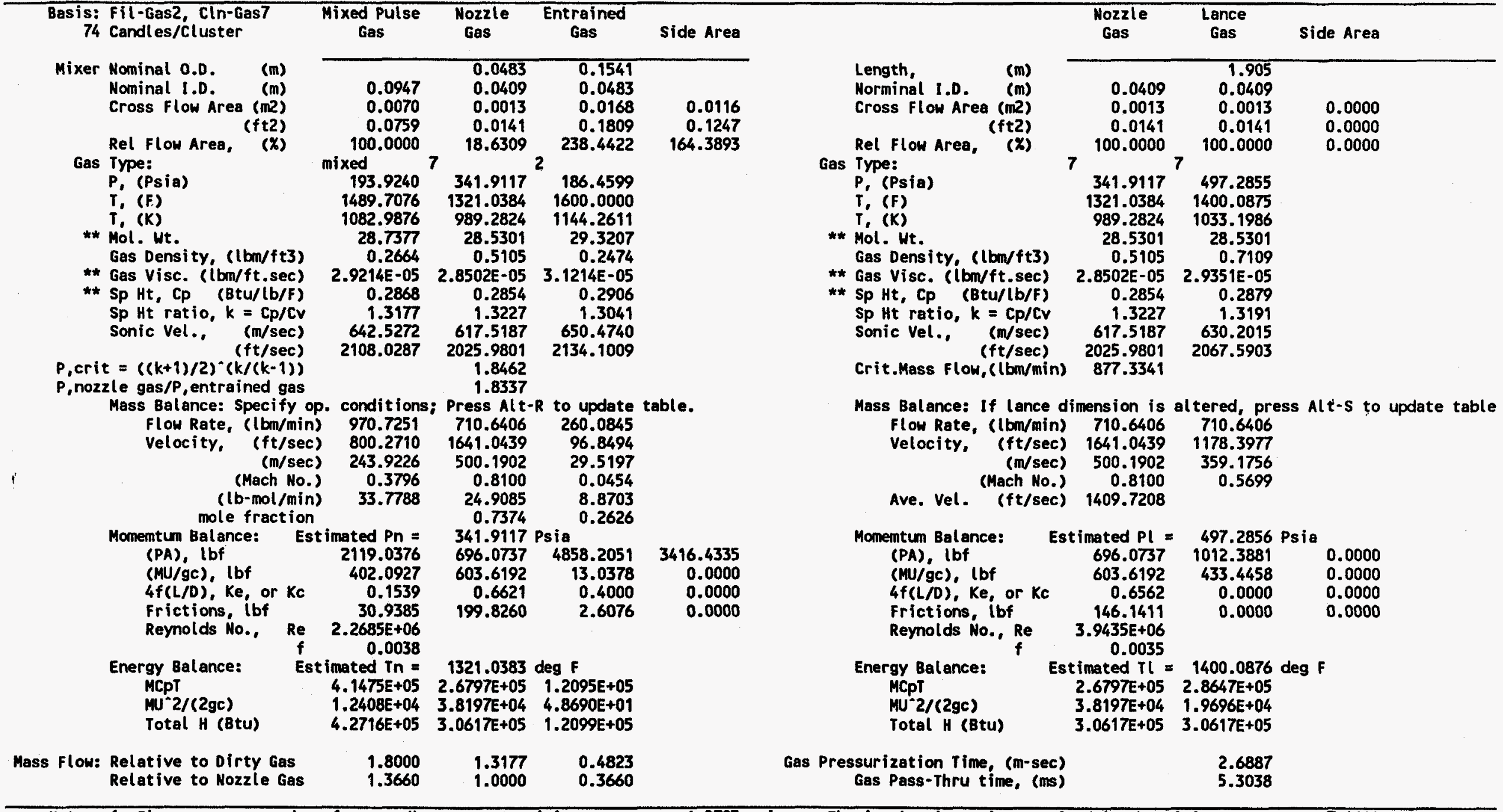

Notes: 1. Clean gas press. drop from candle center to mixing zone $=1.2783$ psia. 2. Mixed pulse gas viscosity and specific heat are molar-averaged values of nozzle and entrained gases. $E$ jector venturi area ratio 
TABLE 6 FLON FROM NOZZLE/LANCE-TO-RESERVOIR TANK Page 6 (Reverse Cleaning Period)

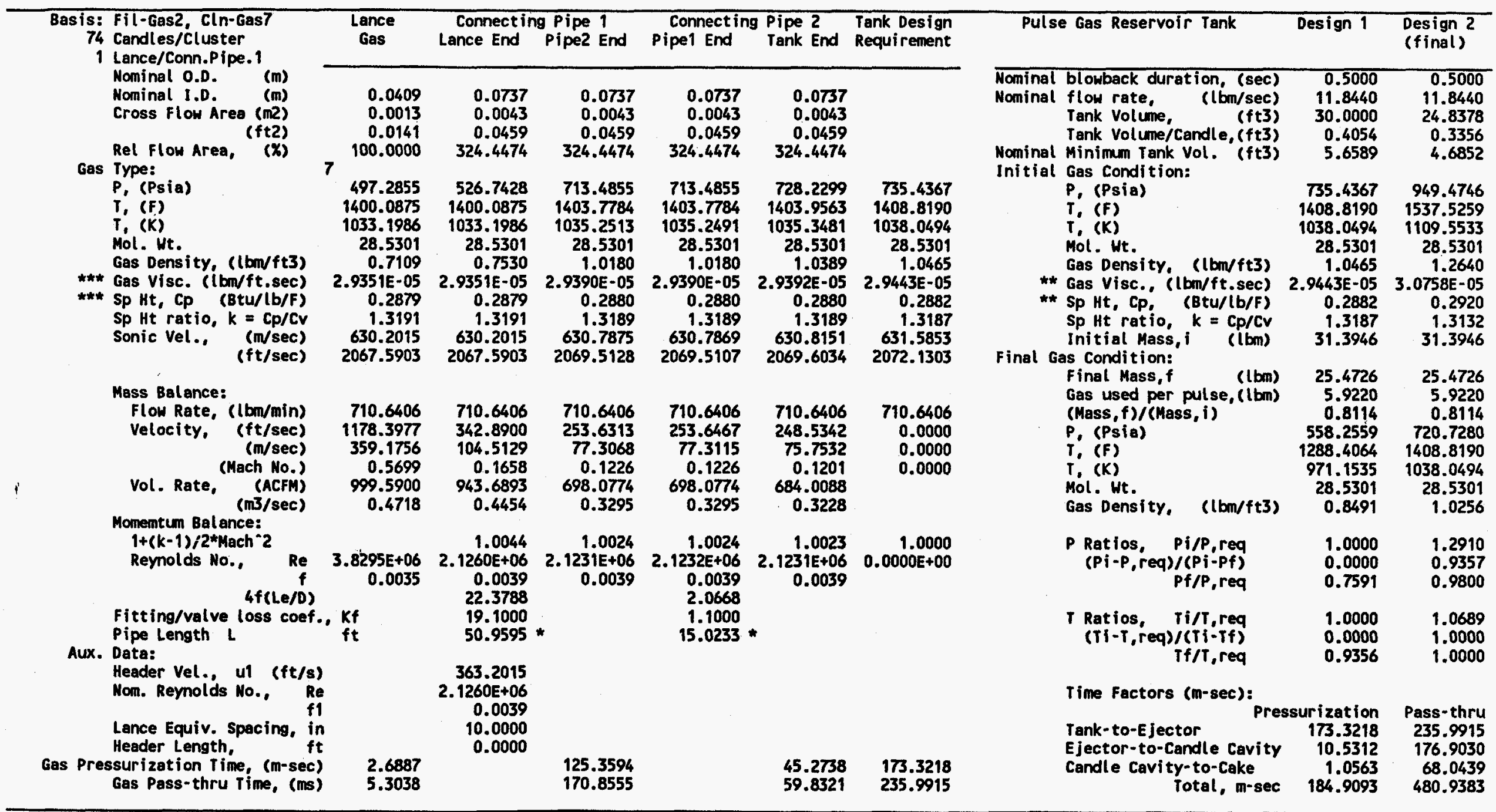

Notes: 1. Velocity head losses for fitting/valve: 90 deg elbow, 0.9; tee, 1.8; gate valve (wide open), $0.2 ;$ glove valve (wide open), 10.

2. Flow in connecting pipes is fanno (adiabatic \& frictional); last section of Pipez to reservoir tank is assumed frictionless. 
Basis: Fil-Gas2, Cln-Gas7

74 Candles/Cluster

4 Clusters served/Reservoir

PULSE GAS COMPRESSION WORK/POWER:

No. of stage

Adia. efficiency

(psia) $\quad 14.7000$

, initial (F) 120.0000

(R) $\quad 579.6700$

$P$, final (psia) 949.4746

$T$, final (F) $\quad 599.1144$

$\begin{array}{cr}\text { (R) } & 1058.7844 \\ \text { Compr. work, (Btu/lb) } & 279.8093\end{array}$

(Kwh/lb) $\quad 0.082$

(Kwh/pulse) $\quad 0.4855$

$\stackrel{\varpi 0}{\omega}$

Compressor Power/reservoir

No. of pulse/hr

Pulse 2.6667

Total No. of Reservoirs $\quad 4.0000$

Pulse gas flow, $\mathrm{l} \mathrm{bm} / \mathrm{hr} \quad 63.1681$

Total KW $\quad 5.1787$

Total HP 6.9448

Notes: 1. Compressor work/power calculations based on simple multi-stage adiabatic compression with inter-coolers; data for preliminary estimations only. 


\section{CASE 5}

Plant Configuration: Carbonizer

Pulse Gas: Cold Pulse

Mode of Cleaning: On-Line

B-37 


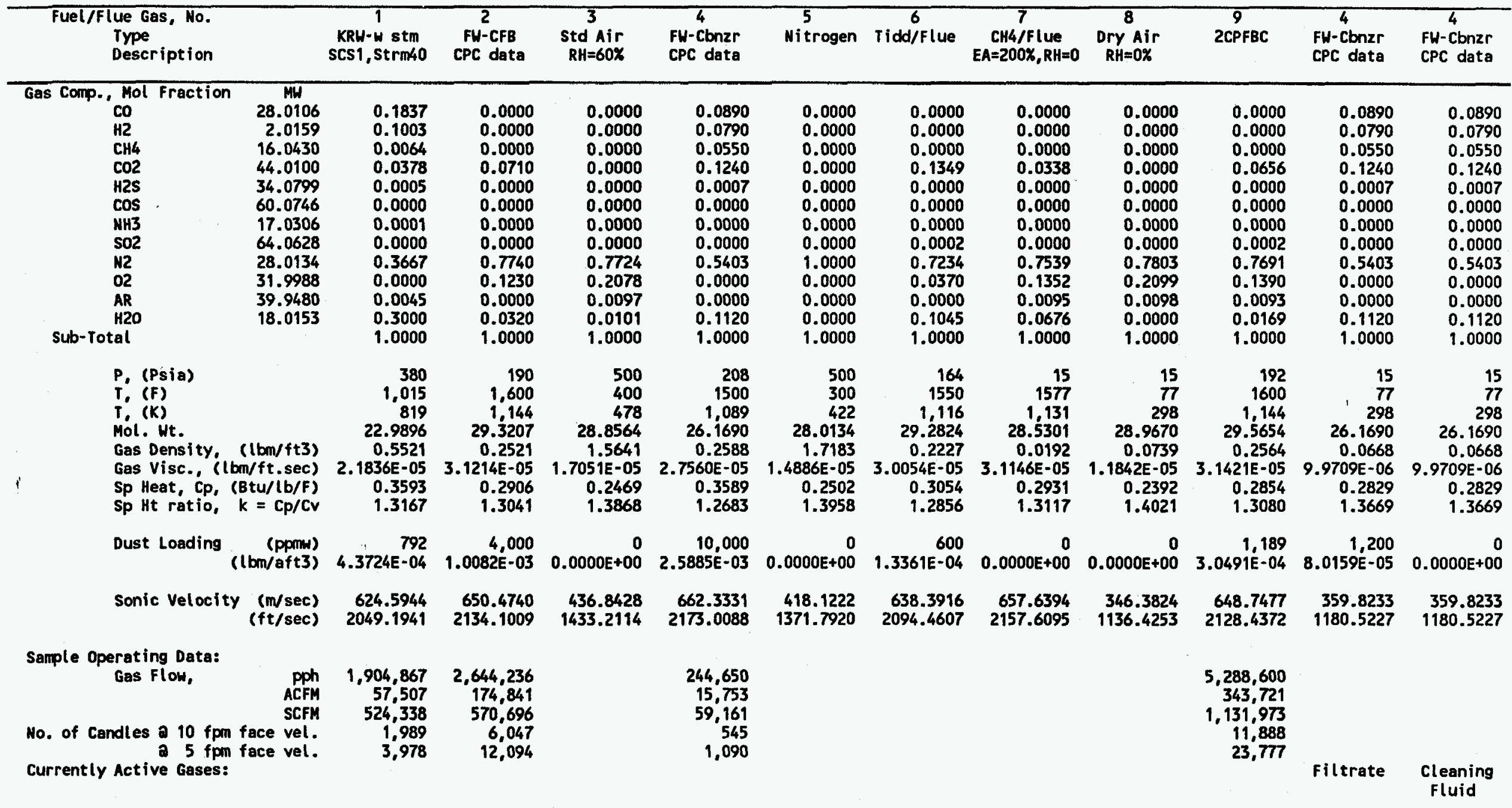


HTC/F-CASE5. WK1

TABLE iA Viscosity Correlations

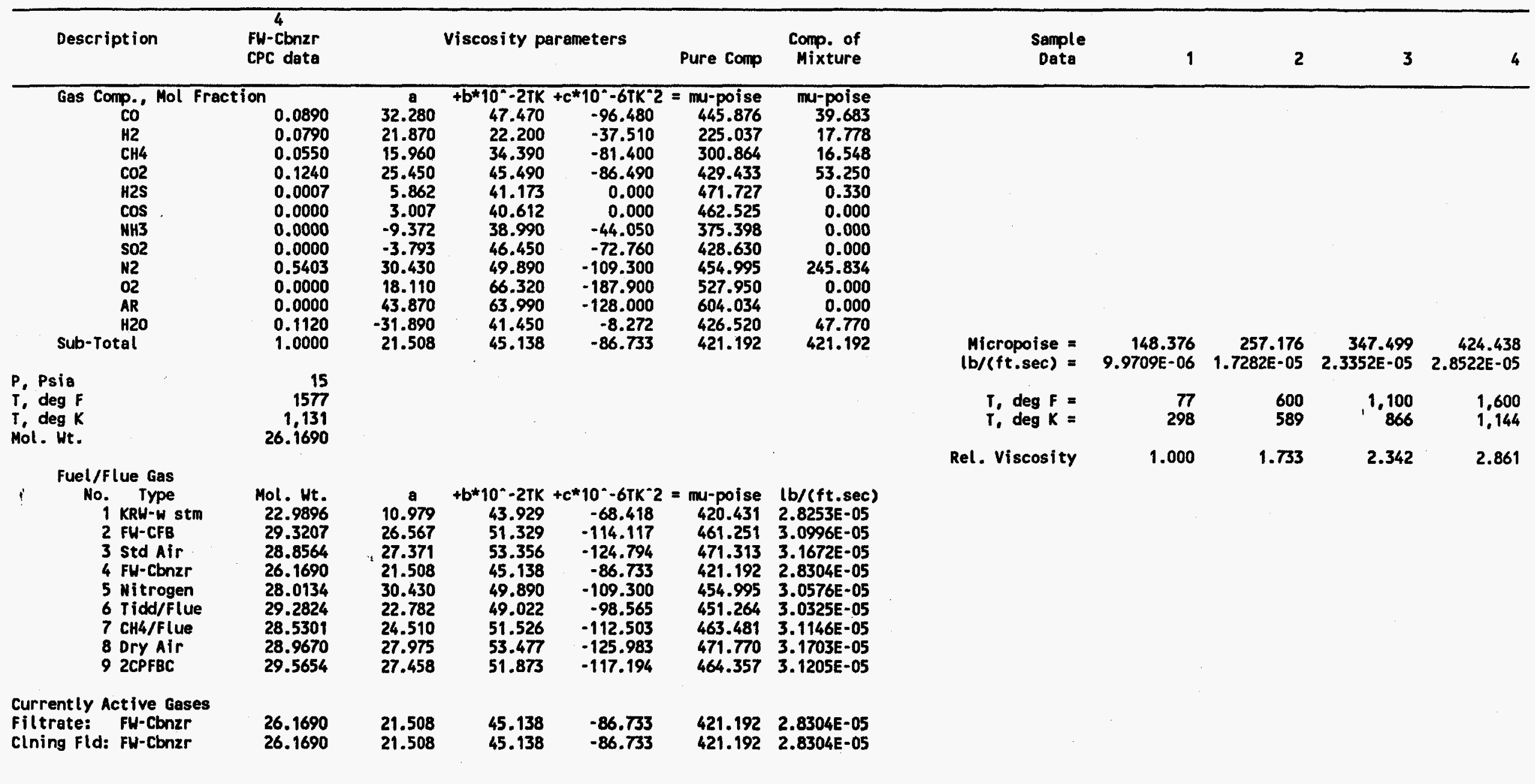

Motes: Micro-poise $=$ Mu-poise $=0.000001^{*}$ poise; 1 poise $(p)=100$ centi-poise (cp) $=0.0672(b \mathrm{bm} /(\mathrm{ft}-\mathrm{sec})=242 \mathrm{lbm} /(\mathrm{ft}-\mathrm{h})$.

When a new gas is designated as the current filtrate or cleaning fluid, be sure to update the corresponding viscosity data in the bottom two rows. 


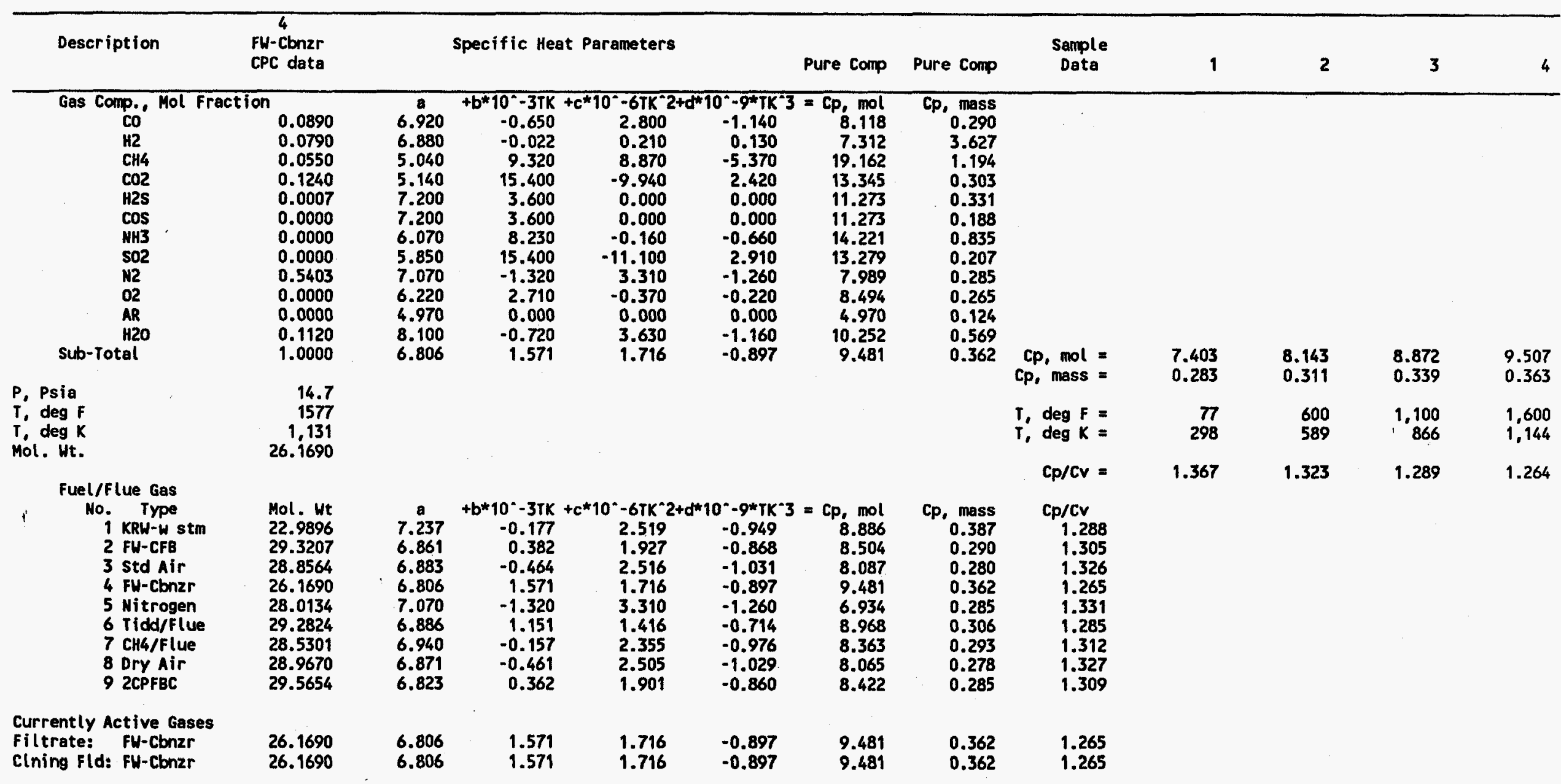

Notes: $C_{p}, \mathrm{~mol}=\mathrm{Btu} /(\mathrm{lb}-\mathrm{mole}) / \mathrm{F} ; \mathrm{Cp}$, mass $=\mathrm{Btu} / \mathrm{lbm} / \mathrm{F}$.

When a new gas is designated as the current filtrate or cleaning fluid, be sure to update the corresponding specific heat date in the bottom two rows. 


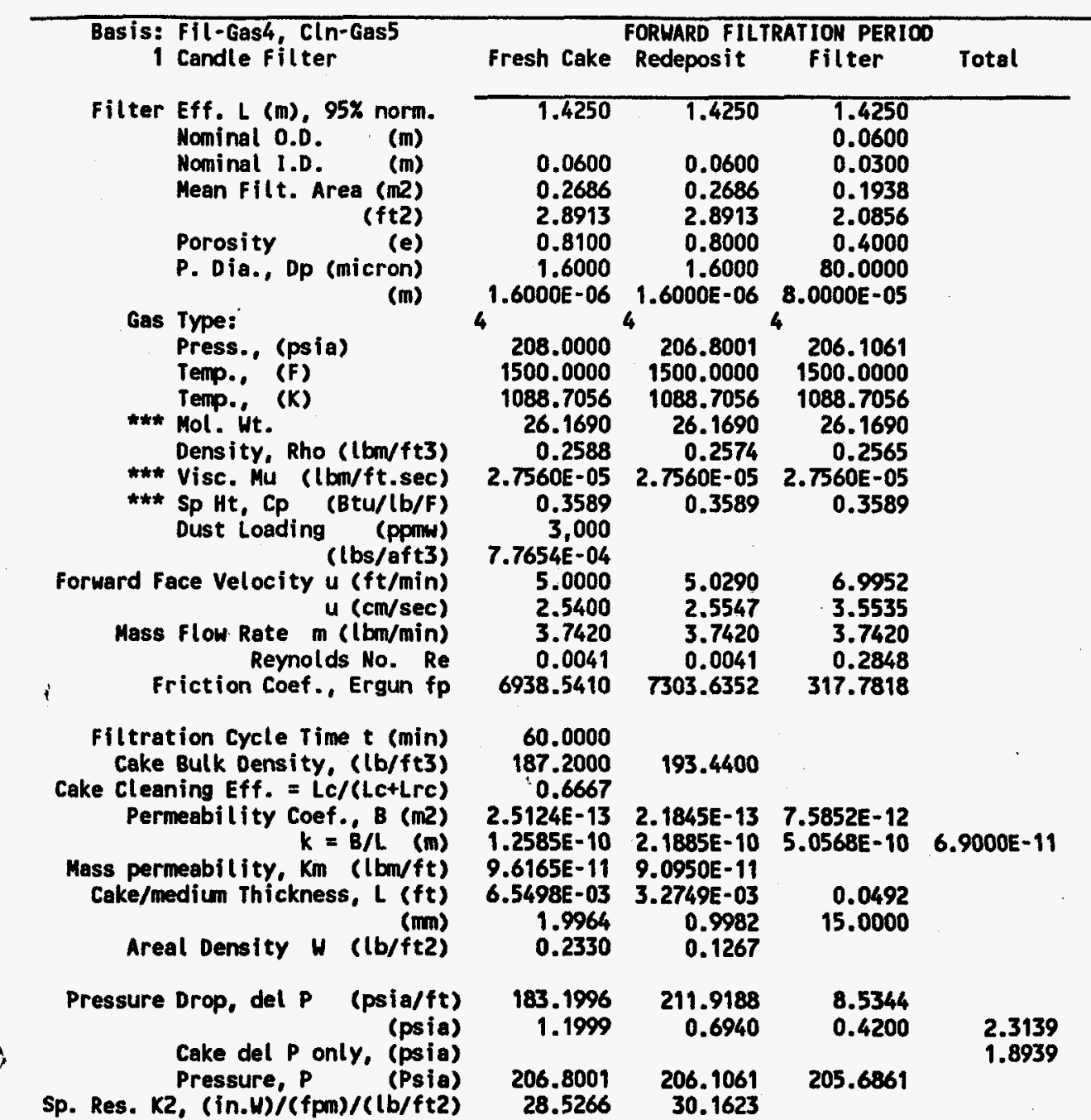

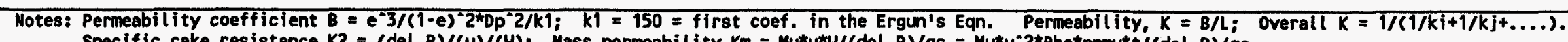

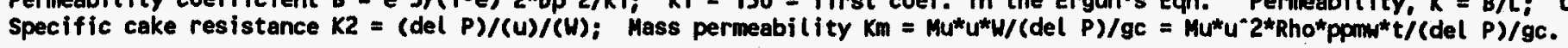




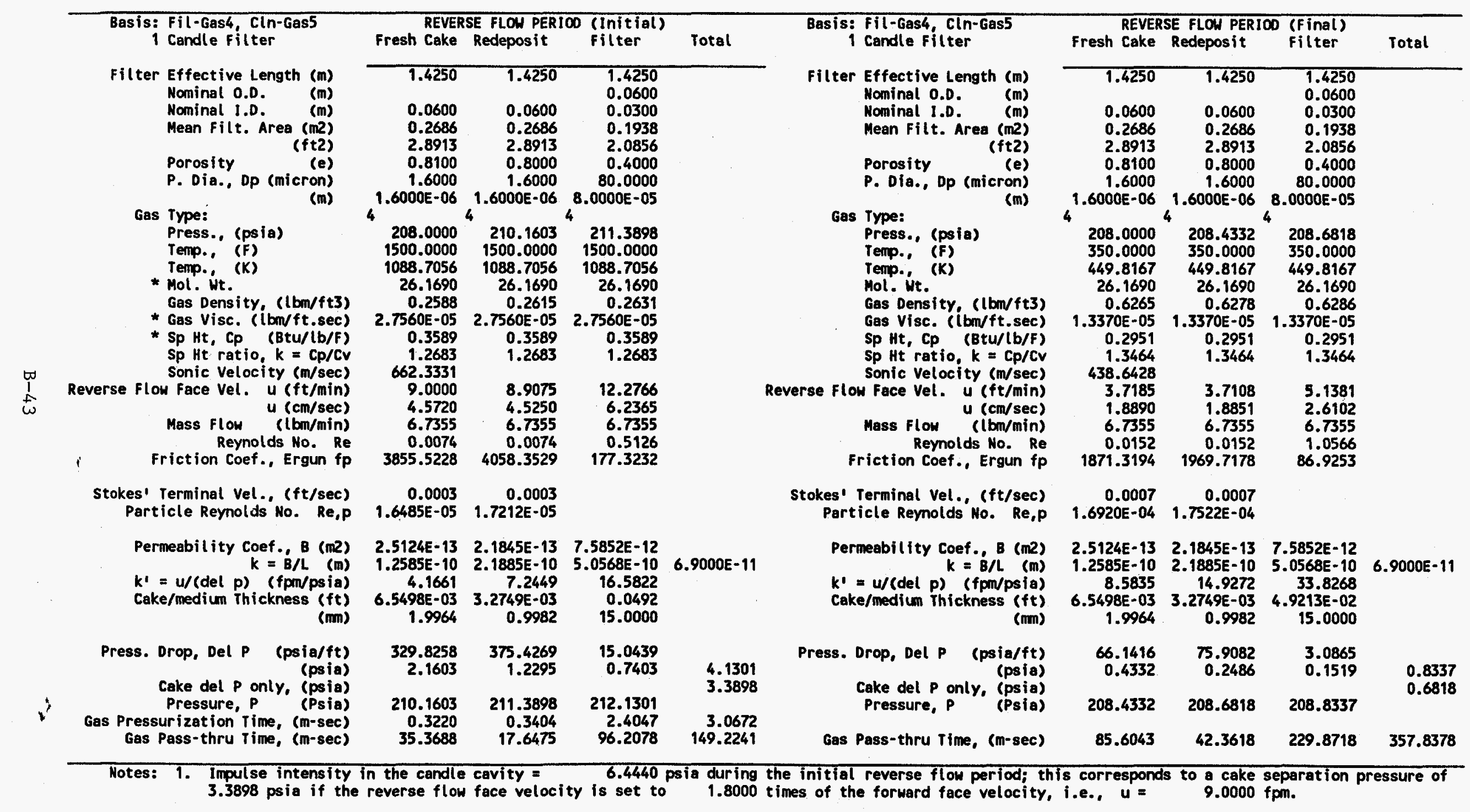


TABLE 4 FLOW FRON CAMDLE TO EJECTOR MIXING ZOME - PRESSURE DROPS (Reverse Cleaning Period)

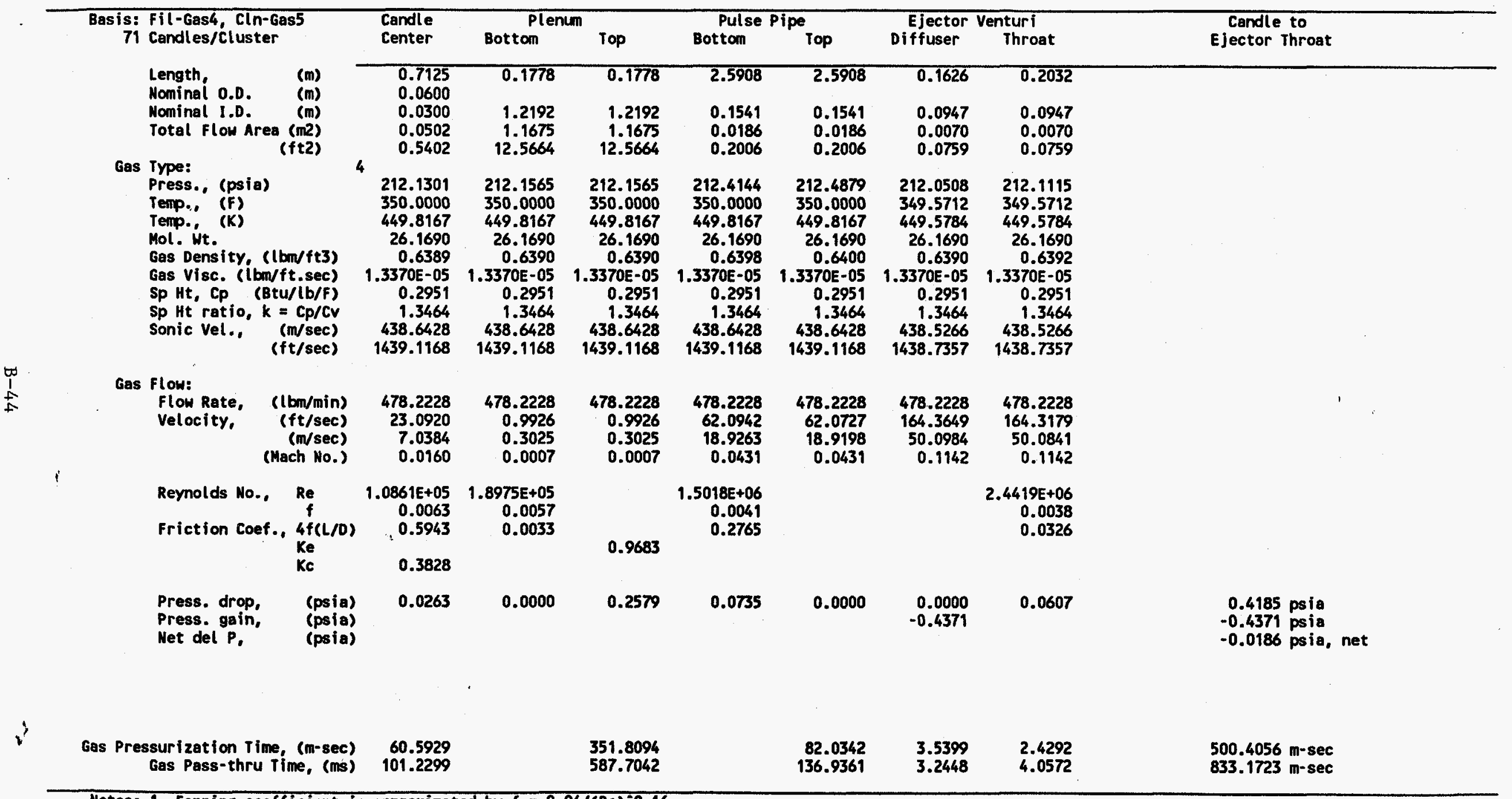

Motes: 1. Fanning coefficient is approximated by $f=0.04 /(\mathrm{Re})^{-0.16}$.

2. Flow is assumed isothermal from candle to pulse pipe; flow in the diffuser is assumed isentropic. 


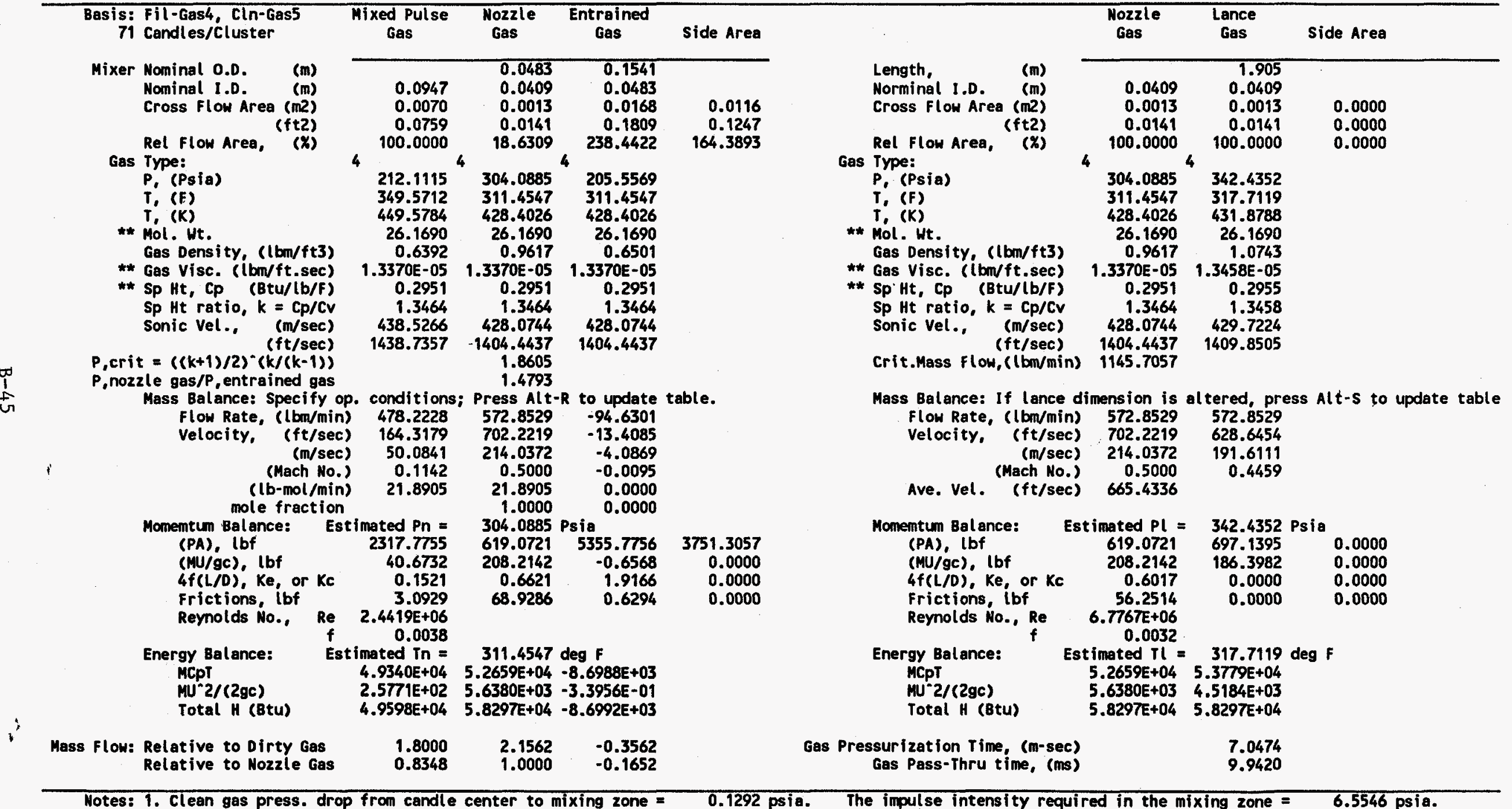

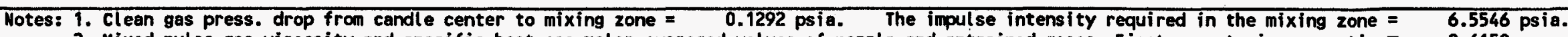
2. Mixed pulse gas viscosity and specific heat are molar-averaged values of nozzle and entrained gases. Ejector venturi area ratio $a$ 0.6150 
TABLE 6 FLOW FROM NOZZLE/LANCE-TO-RESERVOIR TANK

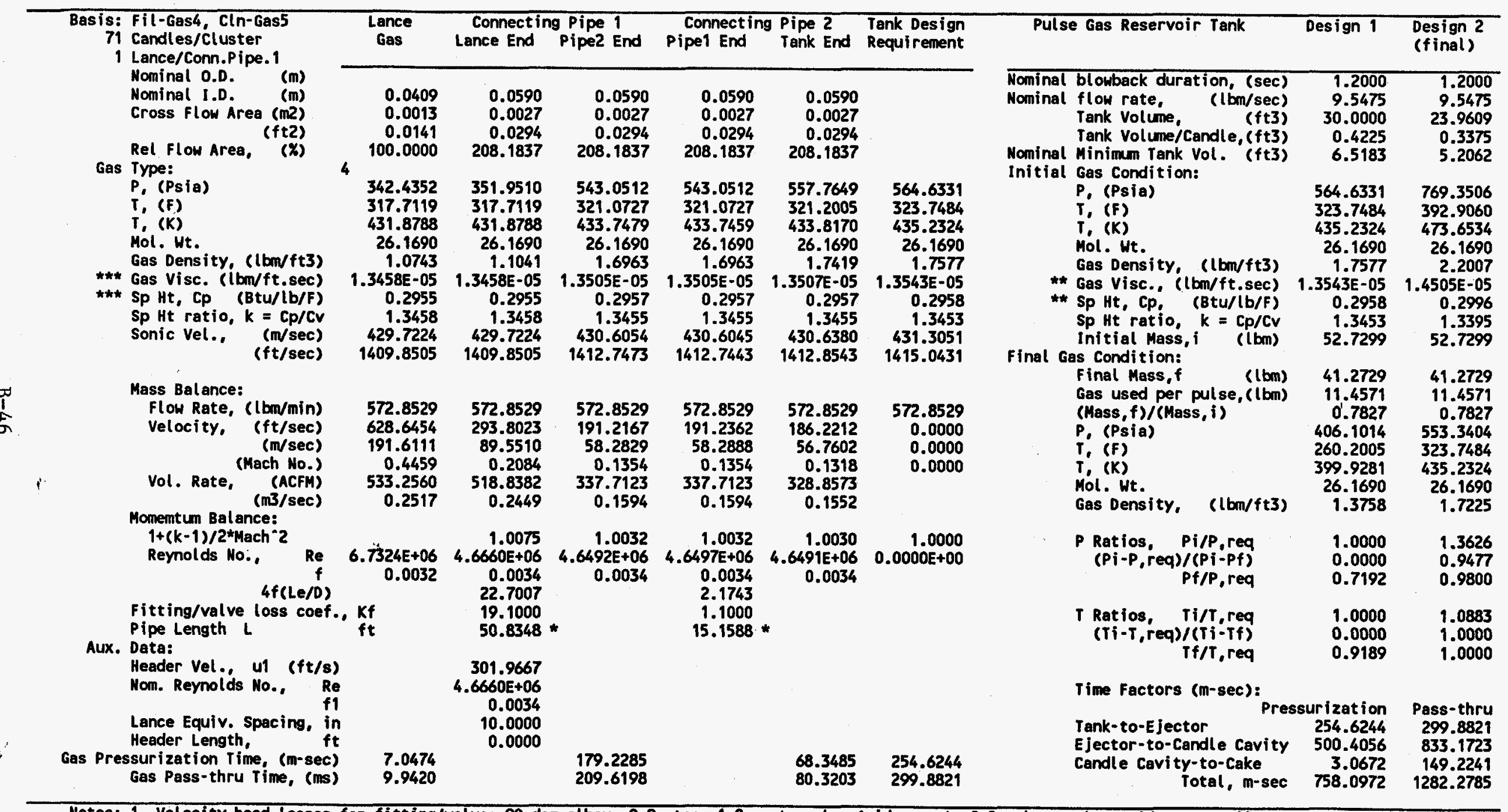

Hotes: 1. Velocity head losses for fitting/valve: 90 deg elbow, $0.9 ;$ tee, 1.8; gate valve (wide open), 0.2 ; glove valve (wide open), 10. 2. Flow in connecting pipes is Fanno (adiabatic \& frictional); last section of Pipez to reservoir tank is assumed frictionless. 
Basis: Fil-Gas4, Cln-Gas5

71 Candles/Cluster

4 Clusters served/Reservoir

PULSE GAS COMPRESSION WORK/POWER:

No. of stage

Adia. efficiency $\quad 0.9000$

$P$, initial (psia) $\quad 200.0000$

$T$, initial (F) $\quad 330.0000$

(R) $\quad 789.6700$

P. final (psia) $\quad 769.3506$

$T$, final (F) $\quad 581.0818$

(R) $\quad 1040.7518$

Compr. Nork, (Btu/lb) 150.4442

(Kwh/(b) 0.044

(Kwh/pulse) $\quad 0.5050$

0
1
\pm
\pm

Compressor Power/reservoir:

No. of pulse/hr 4.0000

Pulse gas flow, l bm/hr 45.8282

Kw/Reservoir $\quad 2.0201$

Hp/Reservoir $\quad 2.7090$

Total No. of Reservoirs $\quad 4.0000$

Pulse gas flow, I bm/hr 183.3129

Total KW $\quad 8.0804$

Total Hp $\quad 10.8360$

Notes: 1. Compressor work/power calculations based on simple multi-stage adiabatic compression with inter-coolers; data for preliminary estimations only. 


\section{CASE 6}

\section{Plant Configuration: Carbonizer}

Pulse Gas: Cold Pulse

Mode of Cleaning: Off-Line 


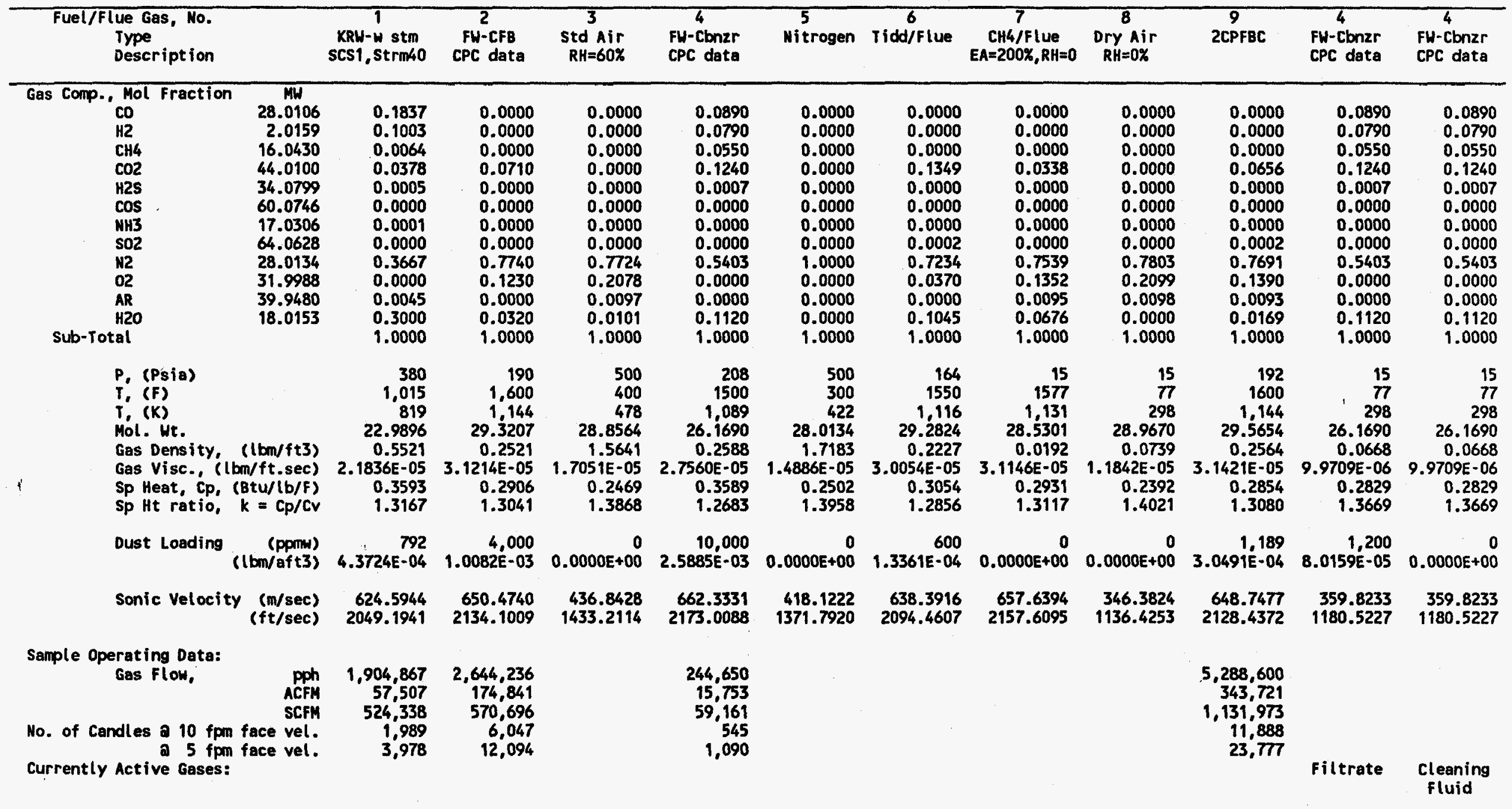

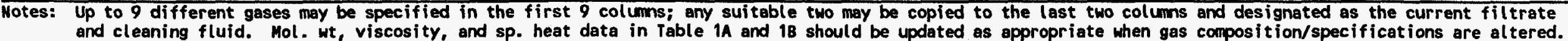




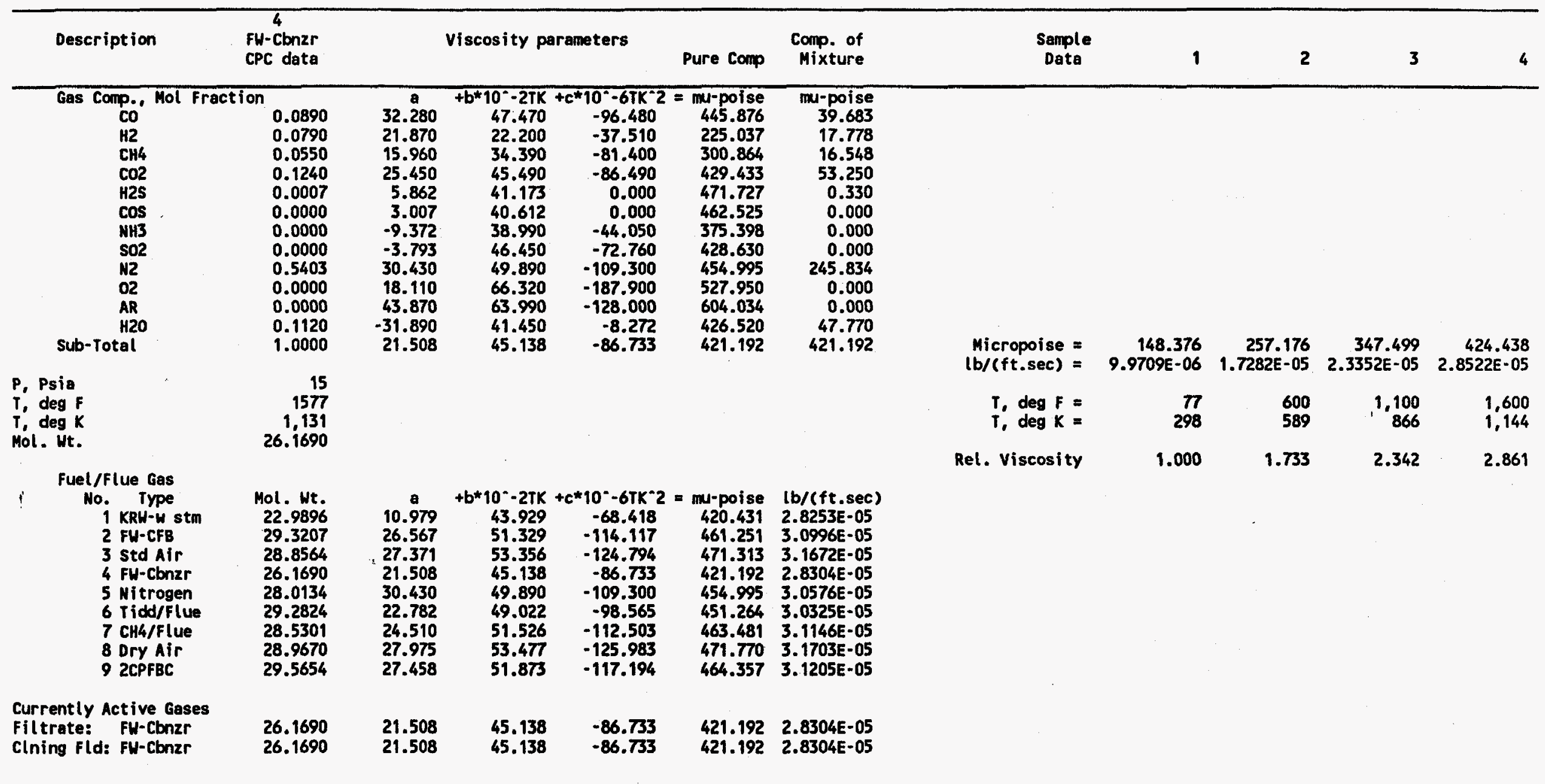

Notes: Micro-poise $=$ Mu-poise $=0.000001 *$ poise; 1 poise $(P)=100$ centi-poise $(c p)=0.0672$ (bn/ft-sec) $=242$ (bn/ $(\mathrm{ft}-\mathrm{h})$.

When a new gas is designated as the current filtrate or cleaning fluid, be sure to update the corresponding viscosity data in the bottom two rows. 


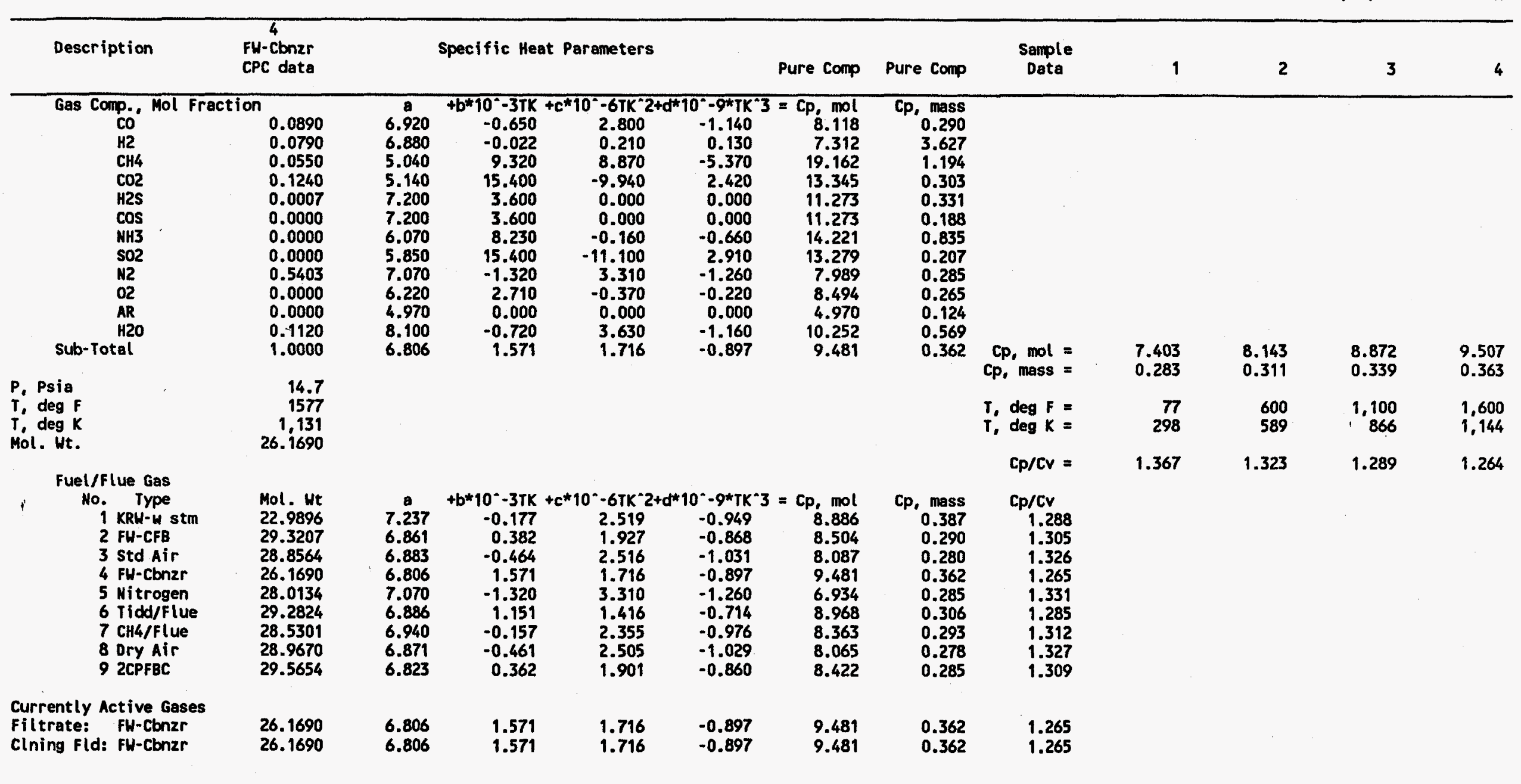




\section{Basis: Fil-Gas4, Cln-Gas5}

1 Candle Filter

Filter Eff. $L(m), 95 \%$ norm.

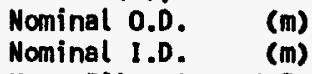

Mean Filt. Area $(\mathrm{m} 2)$

Porosity

(ft2)

P. Dia., Dp (micron)

Gas Type:

Press., (psia)
Temp.. (F)

Temp. (K)

Density, Rho (lbm/ft3)

*** Visc. Mu (lbm/ft.sec)

*** Sp Ht, Cp (Btu/lb/F)

Dust Loading (pprm)

$\underset{1}{1}$

Forward Face Velocity u (ft/min) u $(\mathrm{cm} / \mathrm{sec})$

Mass flow Rate in (Ibm/min) Reynolds No. Re

i

Friction Coef.. Ergun fp

Filtration cycle Time $t$ (min)

Cake Bulk Density, (lb/ft3)

Cake Cleaning Eff. $=L C /(L C+L r C)$

Permeability coef., B (m2)

Mass permeability, $\mathrm{Km}$ (lbm/ft)

Cake/medium Thickness, L ( $f t)$

Areal Density (m)

Pressure Drop, del P (psia/ft)

Cake del $P$ only, (psia)

Pressure, $P$ (Psia)

Sp. Res. K2, (in.W)/(fpm)/(lb/ft2)
Fresh Cake Redeposit Filter Total

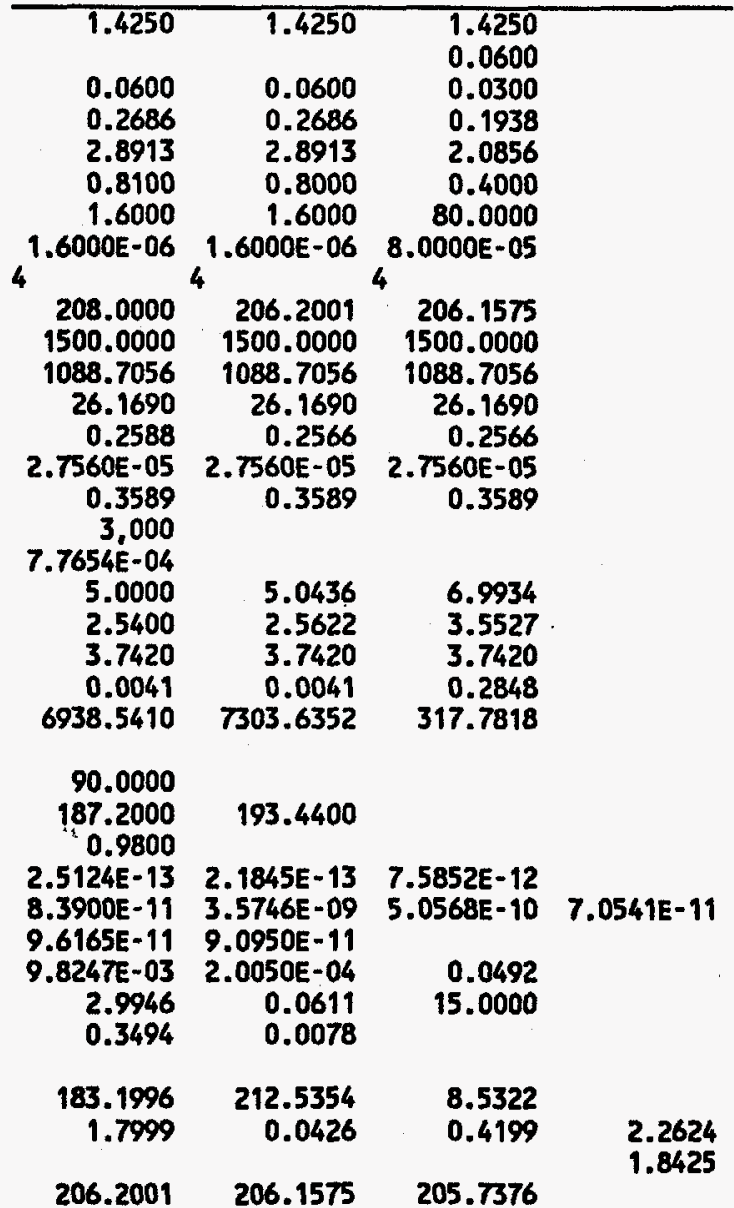

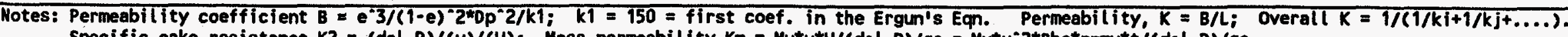

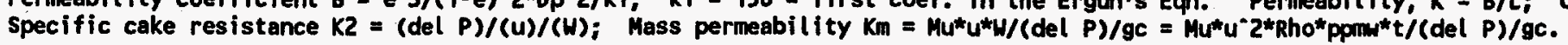


TABLE 3 FLOU THROUGH POROUS MEDIA - PRESSURE DROPS (2) Page 3 (Reverse Cleaning Period)

07/26/94 05:31 PM

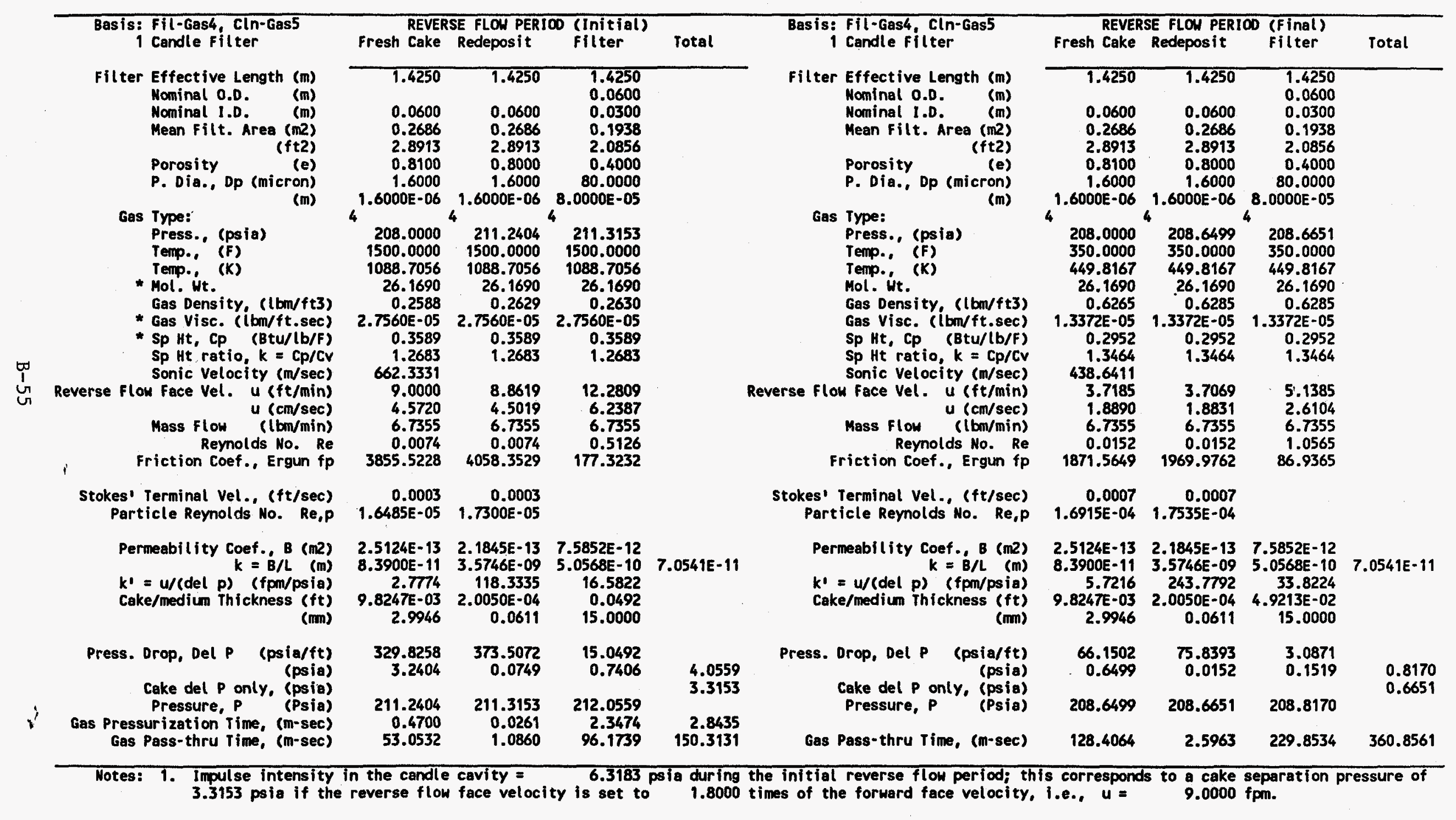


TABLE 4 FLON FROM CANDLE TO EJECTOR MIXING ZOME - PRESSURE DROPS (Reverse Cleaning Period)

Plenum Pulse Pipe

Top

Ejector Venturi
Diffuser Throet

Candle to

is: Fil-Gas4, Cln-Gas5
71 Candles/Cluster

Candle
Center

Bottom

Bottom

Top

Throat

Ejector Throat

Length,

Nominal 0.0 .

(m)

0.1778

0.1778

2.5908

2.5908

0.1626

0.2032

Nominal I.D.

(m)

Gas Type:

(ft2)

Press.. (psia)

Temp.: (F)

Temp:- (K)

Mol. Ht.

Gas Density, (lbm/ft3)

Gas Visc. (ibm/ft.sec)

Sp Ht, Cp (Btu/lb/F)

$\mathrm{Sp} H \mathrm{Ht}$ ratio, $k=\mathrm{Cp} / \mathrm{Cv}$

0.0600

0.0300

1.2192

0.1541

0.1541

12.5664

0.0186

0.1541
0.0186

0.0947

0.0947

4

$0.5402 \quad 12.5664$

0.2006

0.2006

0.0070

0.0947
0.0070

$212.0559 \quad 212.0823$

$212.0823 \quad 212.3403$

$350.0000 \quad 350.0000$

212.0823
350.0000

350.0000

212.4138

$449.8167 \quad 449.8167$

449.8167

350.0000
449.8167

350.0000

0.0759

0.0759

$26.1690 \quad 26.1690$

$26.1690 \quad 26.1690$

$\begin{array}{r}26.1690 \\ \hline\end{array}$

449.8167

211.9765

349.5709
449.5783

212.0373

$0.6387 \quad 0.6388$

49.8167
26.1690

349.5709

$46.1690 \quad 26.1690$
0.6388

$\begin{array}{lllllll}0.2052 & 1.3372 E-05 & 1.3372 E-05 & 1.3372 E-05 & 1.3372 E-05 & 1.3372 E-05 & 1.3372 E-05\end{array}$

$\begin{array}{lllllll}0.2952 & 0.2952 & 0.2952 & 0.2952 & 0.2952 & 0.2952 & 0.2952 \\ 1.3464 & 1.3464 & 1.3464 & 1.3464 & 1.3464 & 1.3464 & 1.3464\end{array}$

Sonic Vel., (m/sec)

$438.6411 \quad 438.6411$

.3464

1.3464

$1439.1111 \quad 1439.111$

438.6411

438.6411

438.6411

438.5248

438.5248

$1438.7297 \quad 14297$

Gas Flow:

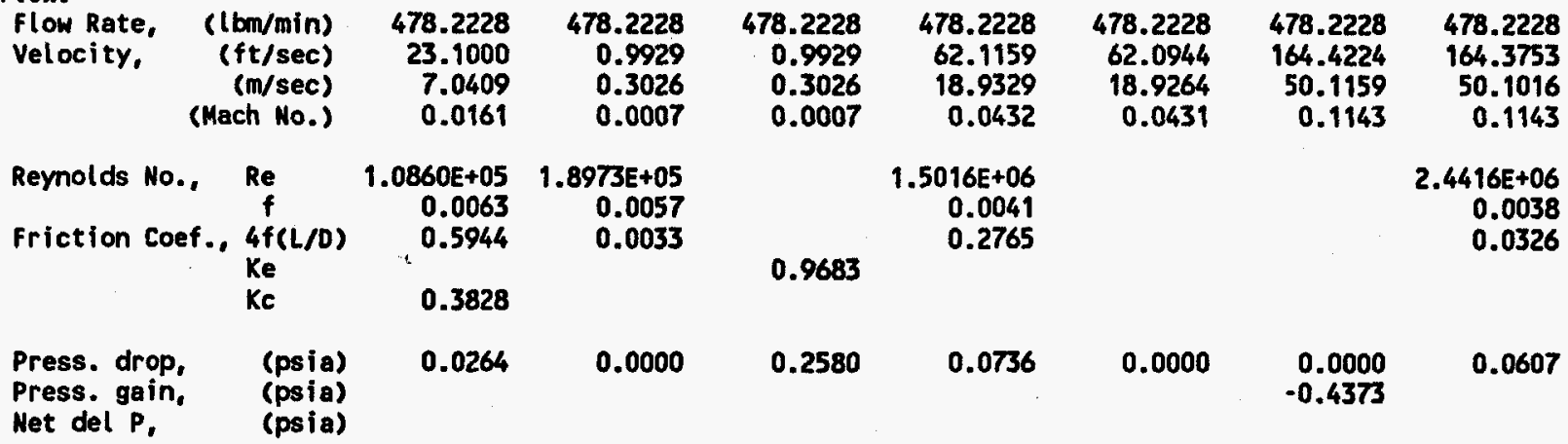

0.4187 psia

-0.0186 psia, net

3

Gas Pressurization Time, $(m-s e c)$

60.5473

351.5450
587.4987

81.9728

3.5372
3.2437

2.4274
4.0558

$500.0297 \mathrm{~m}-\mathrm{sec}$

$832.8811 \mathrm{~m}-\mathrm{sec}$

Motes: 1. Fanning coefficient is approximated by $f=0.04 /(\mathrm{Re})^{\wedge} 0.16$

2. Flow is assumed isothermal from candle to pulse pipe; flow in the diffuser is assumed isentropic. 
71 Candles/Cluster
Cól

Mixed Pu
Gas

Mixer Nominal 0.0 . (m) Nominal I.D. (m)

Cross flow Area (m2) Rel Flow Area, ( $\quad(x)$

Gas Type:

P. (Psia)

T, (F)

** Mol. Wt.

Gas Density, (lbm/ft3)

** Gas Visc. (l bm/ft.sec)

* Sp Ht, Cp (Btu/lb/f) $\mathrm{sp} \mathrm{Ht}$ ratio, $k=\mathrm{Cp} / \mathrm{C}$ Sonic Vel., (m/sec)

$P, c r i t=((k+1) / 2) \cdot(k /(k-1))$

$P$, nozzle gas/ $P$, entrained gas

Mass Balance: Specify op

Flow Rate, (Ibm/min)

Velocity, (ft/sec) (m/sec)

(Mach No.)
(lb-mol/min)
mole fraction

(Mach No.)
$($ (lb-mol/min)
mole fraction Momemtum Balance

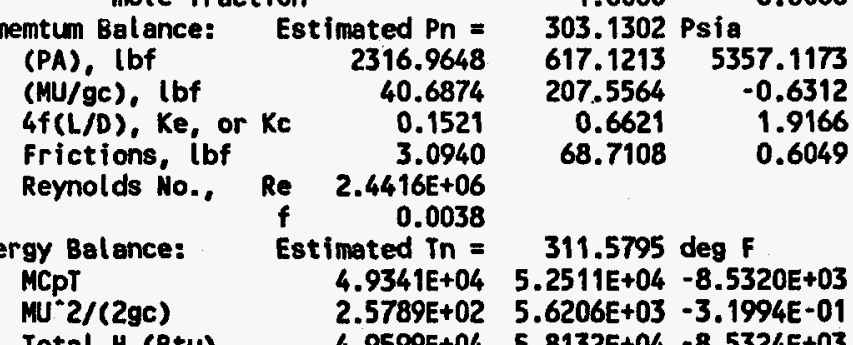

MU"2/(2gc) $\quad 2.5789 E+02 \quad 5.6206 E+03-3.1994 E-01$

$\begin{array}{rrrr} & & & \\ 0.0947 & 0.0483 & 0.1541 & \\ 0.0070 & 0.0409 & 0.0483 & \\ 0.0759 & 0.0013 & 0.0168 & 0.0116 \\ 100.0000 & 0.0141 & 0.1809 & 0.1247 \\ & 18.6309 & 238.4422 & 164.3893\end{array}$

4 $212.0373^{4} 303.1302^{4} 205.6084$ $\begin{array}{lll}349.5709 & 311.5794 & 311.5794\end{array}$ $\begin{array}{lll}449.5783 & 428.4719 & 428.4719\end{array}$ $\begin{array}{rrr}26.1690 & 26.1690 & 26.1690\end{array}$

1.3372E-05 1.3372E-05 1.3372E-05

$\begin{array}{lrr}0.2952 & 0.2952 & 0.2952\end{array}$

$\begin{array}{lll}1.3464 & 1.3464 & 1.3464\end{array}$

$\begin{array}{lrr}438.5248 & 428.1074 & 428.1074\end{array}$

$1438.7297 \quad 1404.5517 \quad 1404.5517$

1.8605

1.4743

conditions; Press Alt-R to update table.

$\begin{array}{lll}478.2228 & 570.9992 & -92.7764\end{array}$

$\begin{array}{lll}164.3753 & 702.2759 & -13.1447\end{array}$

$50.1016 \quad 214.0537 \quad-4.0065$

$\begin{array}{lll}0.1143 & 0.5000 & -0.0094\end{array}$

$\begin{array}{rr}21.8197 & 0.0000\end{array}$

$1.0000 \quad 0.0000$

303.1302 Psia

.1173

3751.1018

0.0000

0.0000
0.0000

0.0000

$4.9599 E+04 \quad 5.8132 E+04-8.5324 E+03$
0.1247
64.3893

side Area

Length,

Norminal 1.D. (m)

Cross flow Area (m2)

Rel flow Area, ( $(x)$

Gas Type:

P, (Psia)

T. (F)

T. (K)

** Mol. Wt.

Gas Density, (lbm/ft3)

** Gas Visc. (libn/ft.sec)

* Sp Ht, Cp (Btu/lb/F)

sp Ht ratio, $k=\mathrm{Cp} / \mathrm{CV}$

sonic vel.. (m/sec)

(ft/sec)

Crit.Mass Flow, (lbm/min)

Nozzle Lance
Gas

Gas

Side Area

Mass Balance: If lance dimension is altered, press Alt-S to update table Flow Rate, (lbm/min) $\mathbf{5 7 0 . 9 9 9 2 \quad 5 7 0 . 9 9 9 2}$

Velocity, (ft/sec) $702.2759 \quad 628.6625$

(m/sec) $214.0537 \quad 191.6163$

$\begin{array}{rrr}\text { (Mach No.) } & 0.5000 & 0.4459\end{array}$

Momemtum Balance: Estimated PI $=341.3739$ Psia

$$
\begin{array}{lrrr}
\text { (PA), lbf } & 617.1213 & 694.9790 & 0.0000 \\
\text { (MU/gC), Ibf } & 207.5564 & 185.8001 & 0.0000 \\
\text { 4f(L/D), Ke, or Kc } & 0.6020 & 0.0000 & 0.0000 \\
\text { Frictions, lbf } & 56.1013 & 0.0000 & 0.0000
\end{array}
$$

f $6.7539+06$

Energy Balance: $\quad$ Estimated $\mathrm{Tl}=317.8398 \mathrm{deg} \mathrm{F}$

$$
\begin{array}{lll}
\text { MCpT } & 5.2511 E+04 & 5.3628 E+04 \\
M U^{-2} 2(2 g C) & 5.6206 E+03 & 4.5041 E+03
\end{array}
$$

$5.6206 E+03 \quad 4.5041 E+03$

Total H (Btu) $\quad 5.8132 E+04 \quad 5.8132 E+04$

Gas Pressurization rime, (m-sec) $\quad \mathbf{7 . 0 3 8 6}$

Gas Pass-Thru time, (ms) $\quad 9.9417$

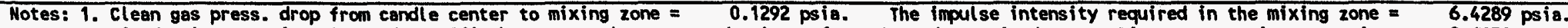

2. Mixed pulse gas viscosity and specific heat are molar-averaged values of nozzle and entrained gases. Ejector venturi area ratio = 0.6150 


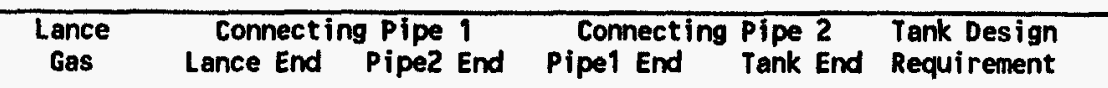

71 Candles/Cluster

1 Lance/Conn Pipe 1

Lance End Pipez End Pipe1 End Tank End Requirement

Noninal 0.0 .

(m)

Nominal I.D. (m)

(ft2)

Gas Type

Area, $(x)$

P. (Psia)

$T$, (F)

$T,(K)$

Mol. Wt.

Gas Density, (lbm/ft3)

*** Gas Visc. (lbm/ft.sec)

Sp Ht, Cp (Btu/lb/F)

Sp Ht ratio, $k=\mathrm{Cp} / \mathrm{CV}$

Sonic Vel., (m/sec)

(ft/sec)

\subsection{9}

0.0013

0.0141

4

100.0000

341.3740

317.8398

431.9499

26.1690

1.0707

$1.3460 \mathrm{E}-05$
0.2955

0.2955
1.3458

429.7560

1409.9607

Mass Balance:

Flow Rate, (lbm/min)

Velocity, (ft/sec)

(m/sec)

(Mach No.)
(ACFM)

Momemtum Balance:

$1+(k-1) ; 2 *$ Wach $* 2$

Reynolds No.. (Asec)

\subsection{2}

628.6625

191.6163

0.4459
533.2706

533.2706

0.2517

0.0590
0.0027
0.0294

0.0590

0590

0.0590
0.0027

0.0590

$\begin{array}{rrr}0.0027 & 0.0027 & 0.0027 \\ 0.0294 & 0.0294 & 0.0294\end{array}$

$\begin{array}{llll}208.1837 & 208.1837 \quad 208.1837 & 208.1837\end{array}$

$\begin{array}{lll}350.8593 & 541.3665 & 541.3665 \\ 317.8398 & 321.2008 & 321.2008\end{array}$

317.8398
431.9499

431.9499
26.1690

1.1005

$1.3460 \mathrm{E}-05$

321.2008
433.8191

556.0346

556.0346
321.3286

321.3286
433.8882

$26.1690 \quad 433.8171$
1.6907

$\begin{array}{rr}26.1690 & 26.1690 \\ 1.6907 & 1.6907\end{array}$

26.1690

1.7363

0.2955

.3507E-05

$1.3509 E-05$

$\begin{array}{rrrr}0.2957 & 0.2957 & 0.2957 & 0.2958\end{array}$

$409.9607 \quad 1412.8575 \quad 1412.8544$

430.6715

431.3387
1415.1532

$570.9992 \quad 570.9992 \quad 570.9992$

$293.8112 \quad 191.2225$

89.5537

58.2846

191.2420
58.2906

0.964

$\begin{array}{rr}0.2084 & 0.1353 \\ 0.8539 & 337.7224\end{array}$

$\begin{array}{rr}0.2449 & 0.1594\end{array}$

58.2906
0.1354

570.9992

186.2268

56.7619

570.9992

0.0000

0.0000

37.7224

0.1318

0.0000

$\begin{array}{r}0.1552 \\ \hline\end{array}$

$1.0075 \quad 1.0032$

1.0032

$1.0030 \quad 1.0000$

$\begin{array}{rrr}4.6341 E+06 & 4.6334 E+06 & 0.0000 E+00\end{array}$

0.0034

0.0034

Fitting/valve loss (Le/D)

Pipe Length L

0.0032

$\mathrm{kf}$
$\mathrm{ft}$

Aux. Data:

Header Vel., u1 (ft/s)

Nom. Reynolds No., Re

Lance Equiv. Spacing, in

Header Length,

Gas Pressurization Time, $(m-s e c)$

Gas Pass-thru rime, (ms)
22.7031

19.1000
50.8417

1.1000

15.1538 *

301.9750

$4.6503 E+06$

0.0034

10.0000

0.0000

7.0386
9.9417

$\begin{array}{lll}179.1057 & 68.2820 & 254.4263 \\ 209.6420 & 80.2918 & 299.8756\end{array}$

Notes:

2. Flow in connecting pipes is Fanno (adiabatic \& frictional); last section of pipe2 to reservoir tank is assumed frictionless.
2.

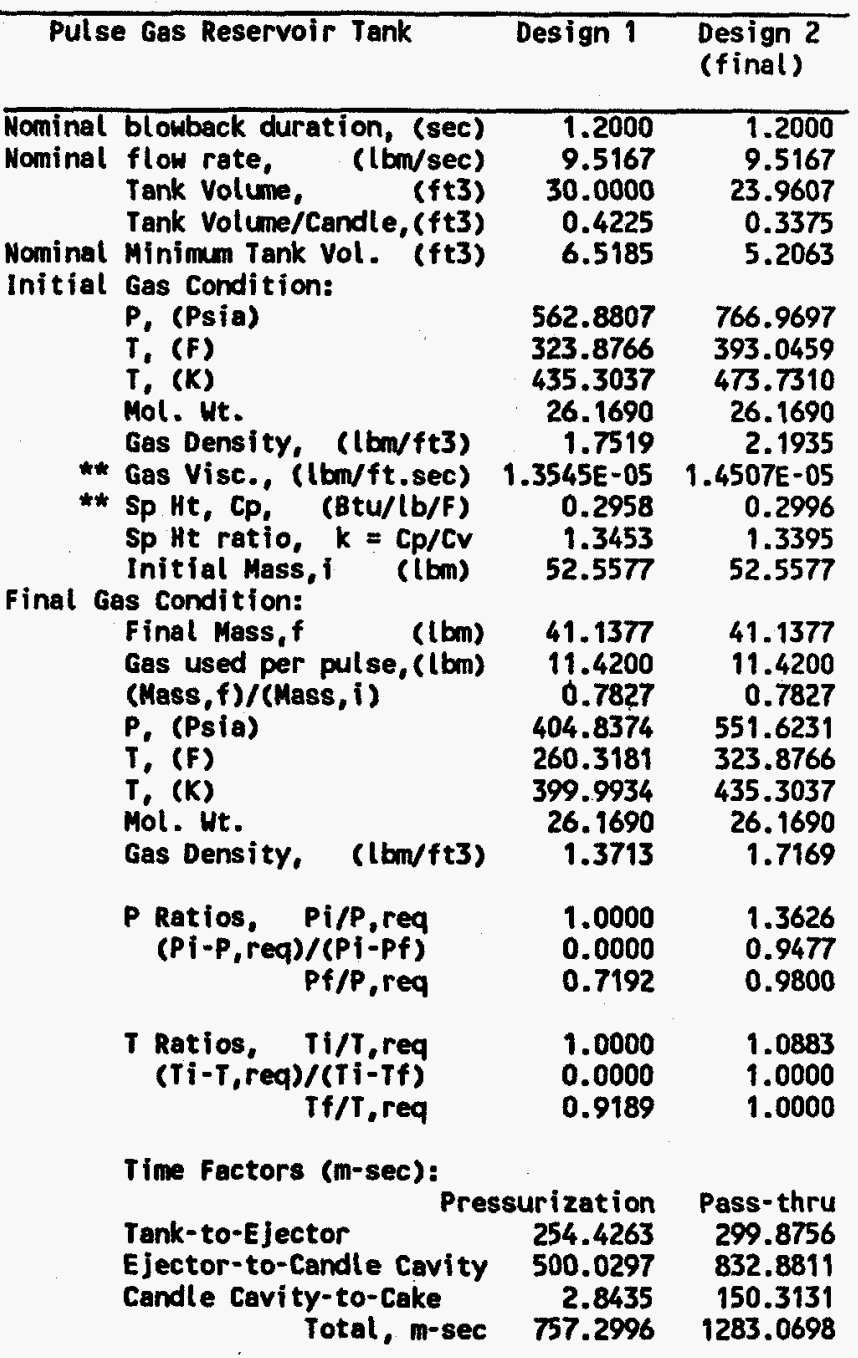


Basis: Fil-Gas4, Cln-Gas5

71 Candles/Cluster

4 Clusters served/Reservoir

PULSE GAS COMPRESSION WORK/POUER:

No. of stage

Adia. efficiency

$P$, initial (psia)

$0.9000^{2}$

$T$, initial (F)

(200.0000

P, final (psia) $\quad 766.9697$

$T$, final (F) $\quad 580.6686$

(R) $\quad 1040.3386$

Compr. work, (Btu/lb) $\quad 150.2004$

(Kwh/lb) $\quad 0.0440$

(Kwh/pulse) $\quad 0.5026$

Compressor Power/reservoir:

No. of pulse/hr

2.6667

pulse gas flow, l bm/hr $\quad 30.4533$

Kw/Reservoir $\quad 1.3402$

$\begin{array}{ll}\text { Hp/Reservoir } & 1.7972\end{array}$

Total No. of Reservoirs $\quad 4.0000$

Pulse gas flow, l bm/hr 121.8132

Total KH $\quad \mathbf{5 . 3 6 0 8}$

Total Hp $\quad 7.1889$

Hotes: 1. Compressor work/power calculations based on simple multi-stage adiabatic compression with inter-coolers; data for preliminary estimations only. 


\section{CASE 7}

\section{Plant Configuration: KRW-Based IGCC}

Pulse Gas: Cold Pulse

Mode of Cleaning: On-Line 


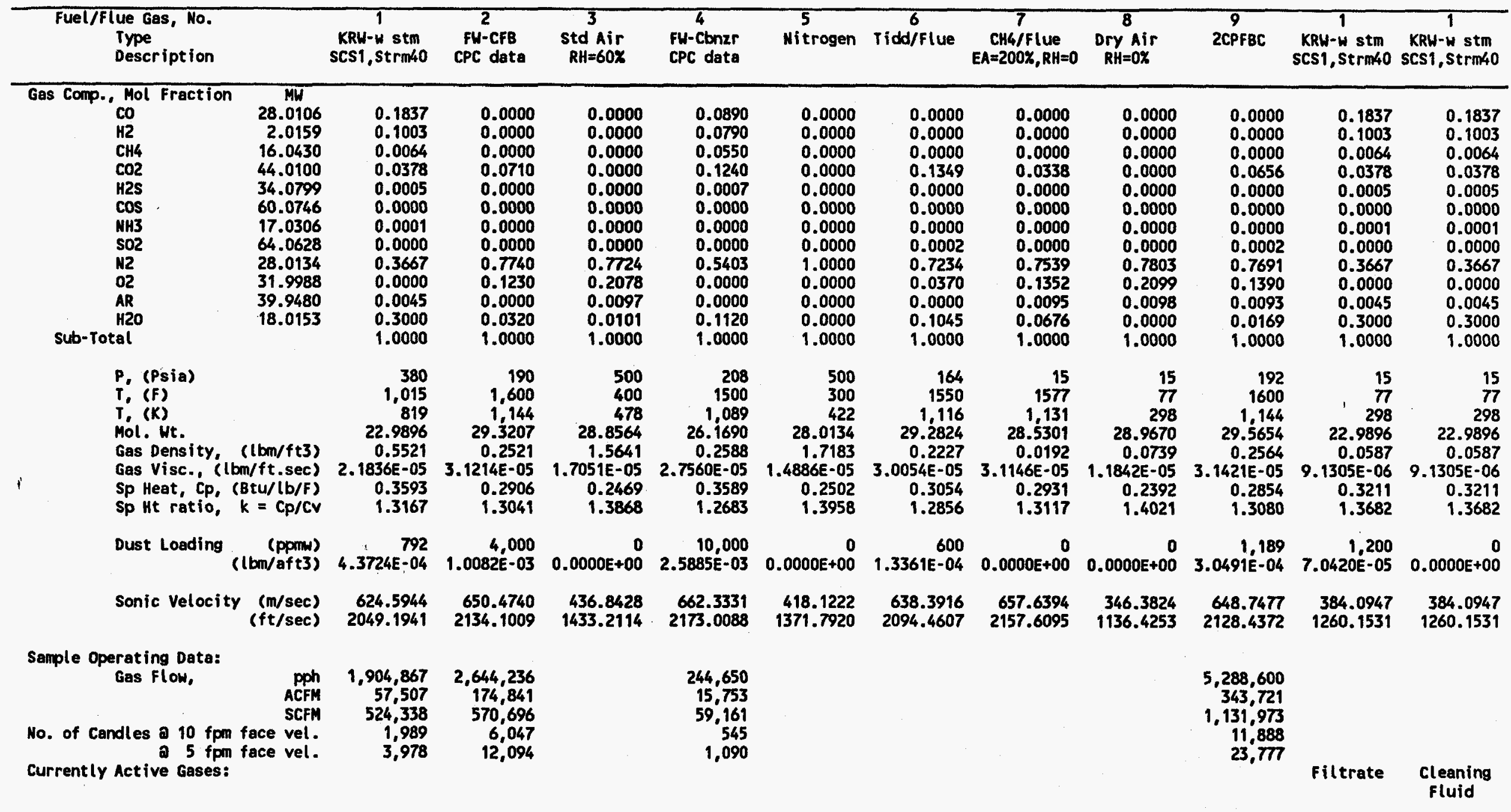

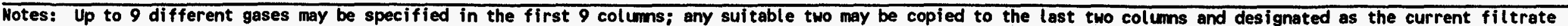

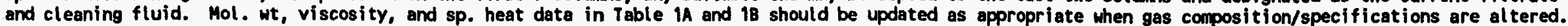




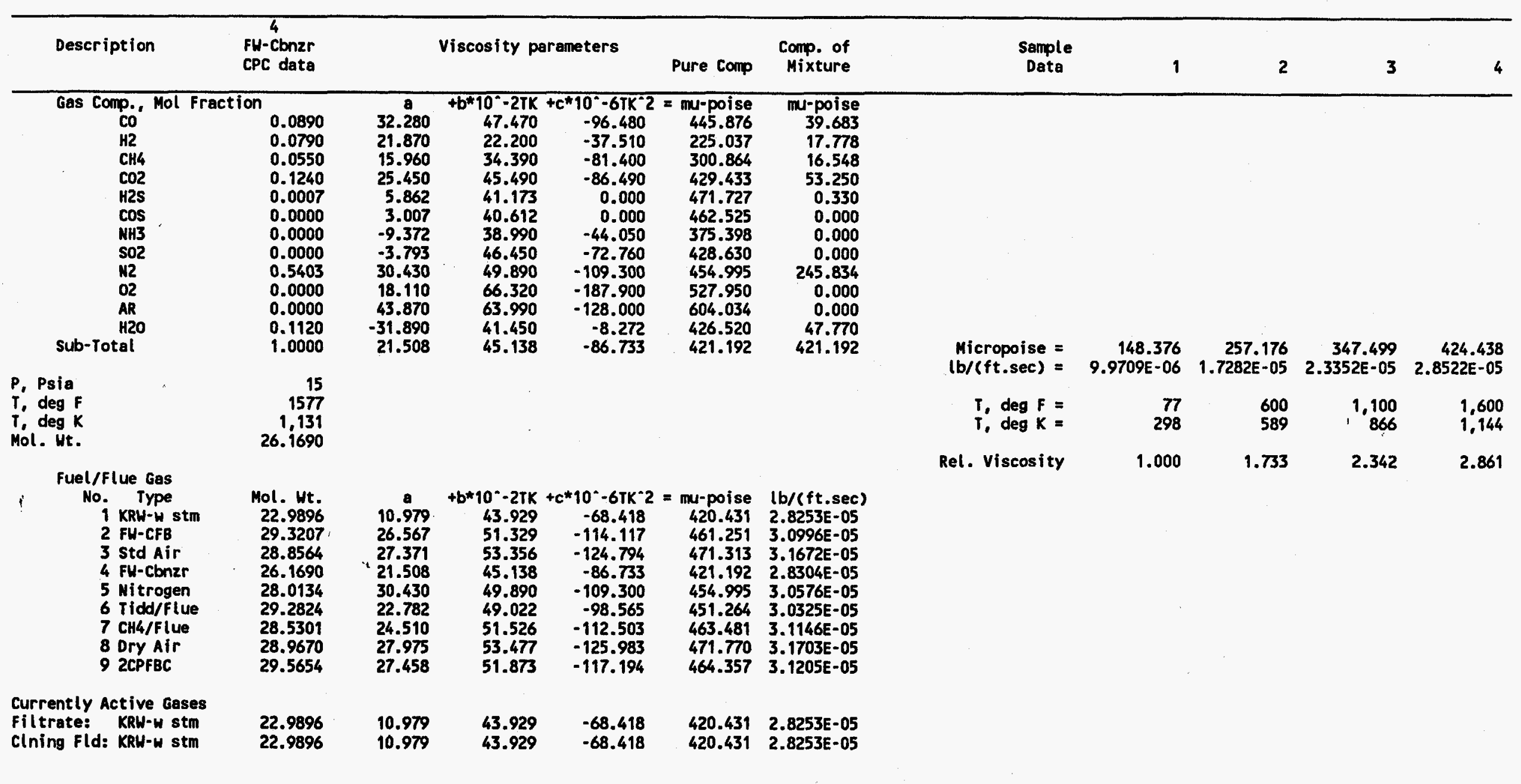

Motes: Micro-poise $=$ Mu-poise $=0.000001^{\star}$ poise; 1 poise $(P)=100$ centi-poise $(\mathrm{cP})=0.0672$ (bm/(ft-sec) $=242 \mathrm{lbm} /(\mathrm{ft}-\mathrm{h})$

When a new gas is designated as the current filtrate or cleaning fluid, be sure to update the corresponding viscosity data in the bottom two rows. 


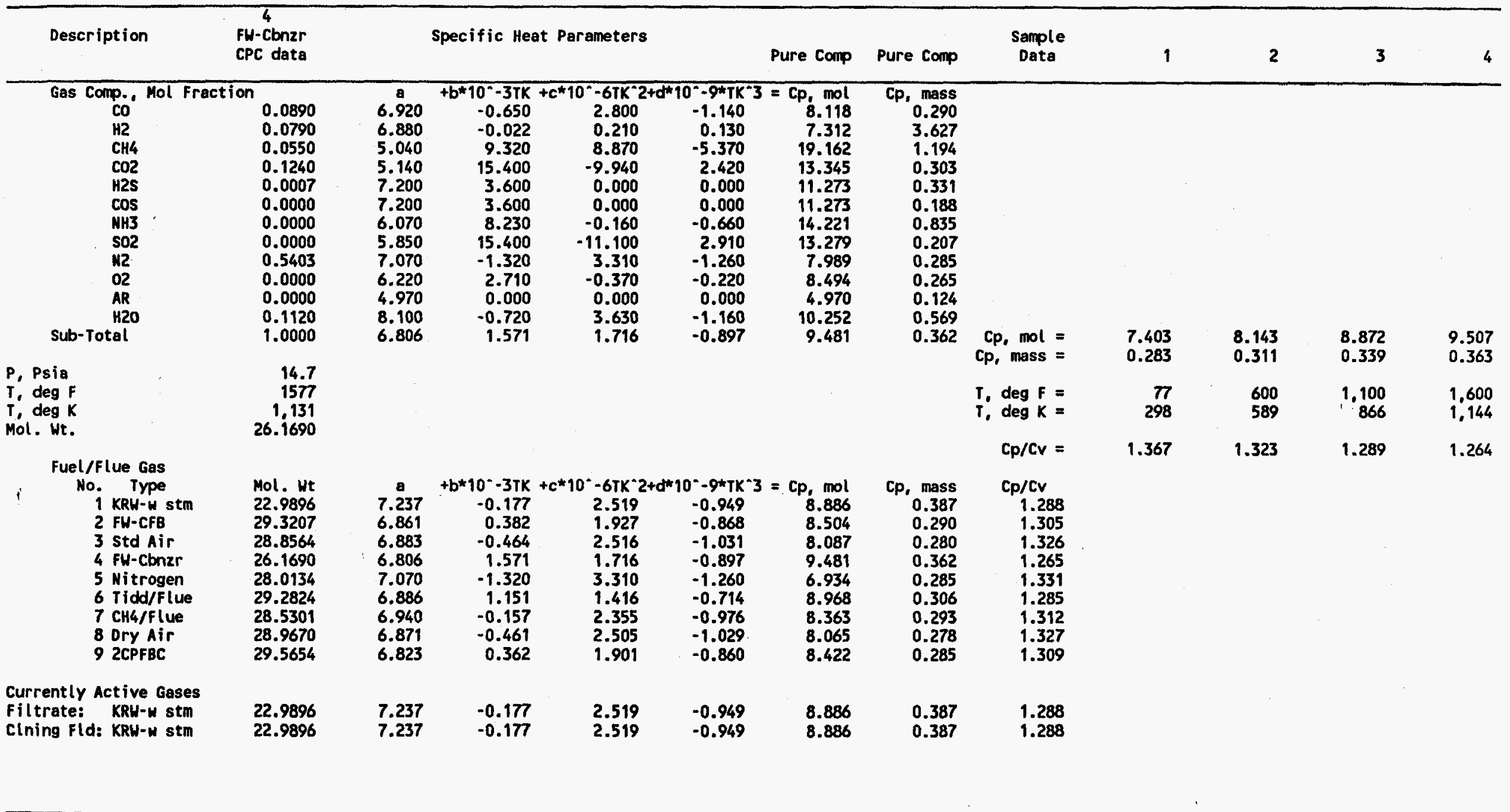

Notes: $C p, \mathrm{~mol}=\mathrm{Btu} /(\mathrm{tb}-\mathrm{mole}) / \mathrm{F}_{;} \mathrm{Cp}$, mass $\mathrm{D} \mathrm{Btu} / \mathrm{lbm} / \mathrm{F}$. 
: Fil-Gas1, Cln-Gas Fresh Cake FORHARD FILTRATION PERIOD

\section{Total}

Filter Eff. $L(m), 95 \%$ norm. $\begin{array}{lll}\text { Nominal } & 0.0 . & (\mathrm{m}) \\ \text { Nominal } & \text { I.D. } & (\mathrm{m})\end{array}$ Mean Filt. Area $(m 2)$

Porosity (ft2)

P. Dia., Dp (micron)

Gas Type:

Press., (psia)

Temp., (F)

Temp.

Density, Rho ( $\mathrm{bm} / \mathrm{ft} 3)$

tht Visc. Mu (lbm/ft.sec)

tw* Sp Ht, CP (Btu/lb/f) Dust Loading (ppmw) Forward Face Velocity $u$ ( $(\mathrm{ft} / \mathrm{min})$ $u(\mathrm{~cm} / \mathrm{sec})$

Mass Flow Rate in (lbm/min) Reynolds No. Re

Friction Coef., Ergun fp

Filtration Cycle Time $t$ (min)

Cake Bulk Density, (lb/ft3) Cake cleaning Eff. = Lc/(LC+LrC)

Permeability Coef., $B(m 2)$

Mass permeability, $\mathrm{Km}(\mathrm{lbm} / \mathrm{ft})$

Cake/medium Thickness, L (ft)

Areal Density W (lb/ft2)

Pressure Drop, del P (psia/ft)

Cake del $P$ only, (psia)

Pressure, $P$ (Psia)

\begin{tabular}{rrr}
\hline 1.4250 & 1.4250 & 1.4250 \\
& & 0.0600 \\
0.0600 & 0.0600 & 0.0300 \\
0.2686 & 0.2686 & 0.1938 \\
2.8913 & 2.8913 & 2.0856 \\
0.8000 & 0.7900 & 0.4000 \\
1.2000 & 1.2000 & 80.0000 \\
$1.2000 E-06$ & $1.2000 E-06$ & $8.0000 E-05$
\end{tabular}

1

1 1

$\begin{array}{lll}380.0000 & 378.6868 & 377.9325\end{array}$

$1015.0000 \quad 1015.0000 \quad 1015.0000$

$819.2611 \quad 819.2611 \quad 819.2611$

$22.9896 \quad 22.9896 \quad 22.9896$

$\begin{array}{lll}0.5521 & 0.5502 & 0.5491\end{array}$

2.1836E-05 2.1836E-05 2.1836E-05

$\begin{array}{lll}0.3593 & 0.3593 & 0.3593\end{array}$

8.2811E-04

5.0000

2.5400

7.9809

0.0083

5.0173

2.5488

7.9809

0.0083

6.9694

3.5405

7.9809

0.7666

$\begin{array}{lll}3618.5282 & 3799.3672 & 119.1529\end{array}$

40.0000

187.2000
0.6667

193.4400

$1.2288 E-13 \quad 1.0733 E-13 \quad 7.5852 E-12$

$9.1135 E-11 \quad 1.5920 E-10 \quad 5.0568 E-10 \quad 5.1998 E-11$

$4.9497 E-11 \quad 4.6908 E-11$

4.4237E-03 2.2118E-03

$\begin{array}{ll}1.3483 & 0.6742\end{array}$

0.0492

$0.1656 \quad 0.0898$

15.0000

$\begin{array}{rrrr}296.8529 & 341.0374 & 6.7998 & \\ 1.3132 & 0.7543 & 0.3346 & 2.4021 \\ 378.6868 & 377.9325 & 377.5979 & 2.0675 \\ 43.9127 & 46.3359 & & \end{array}$

Sp. Res. K2, (in.H)/(fpm)/(lb/ft2)

$\begin{array}{ll}43.9127 & 46.3359\end{array}$

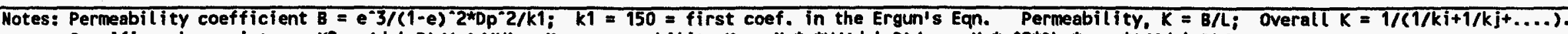

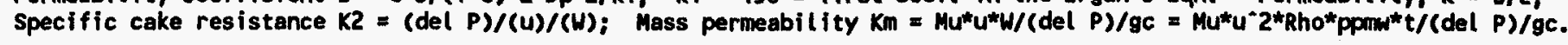




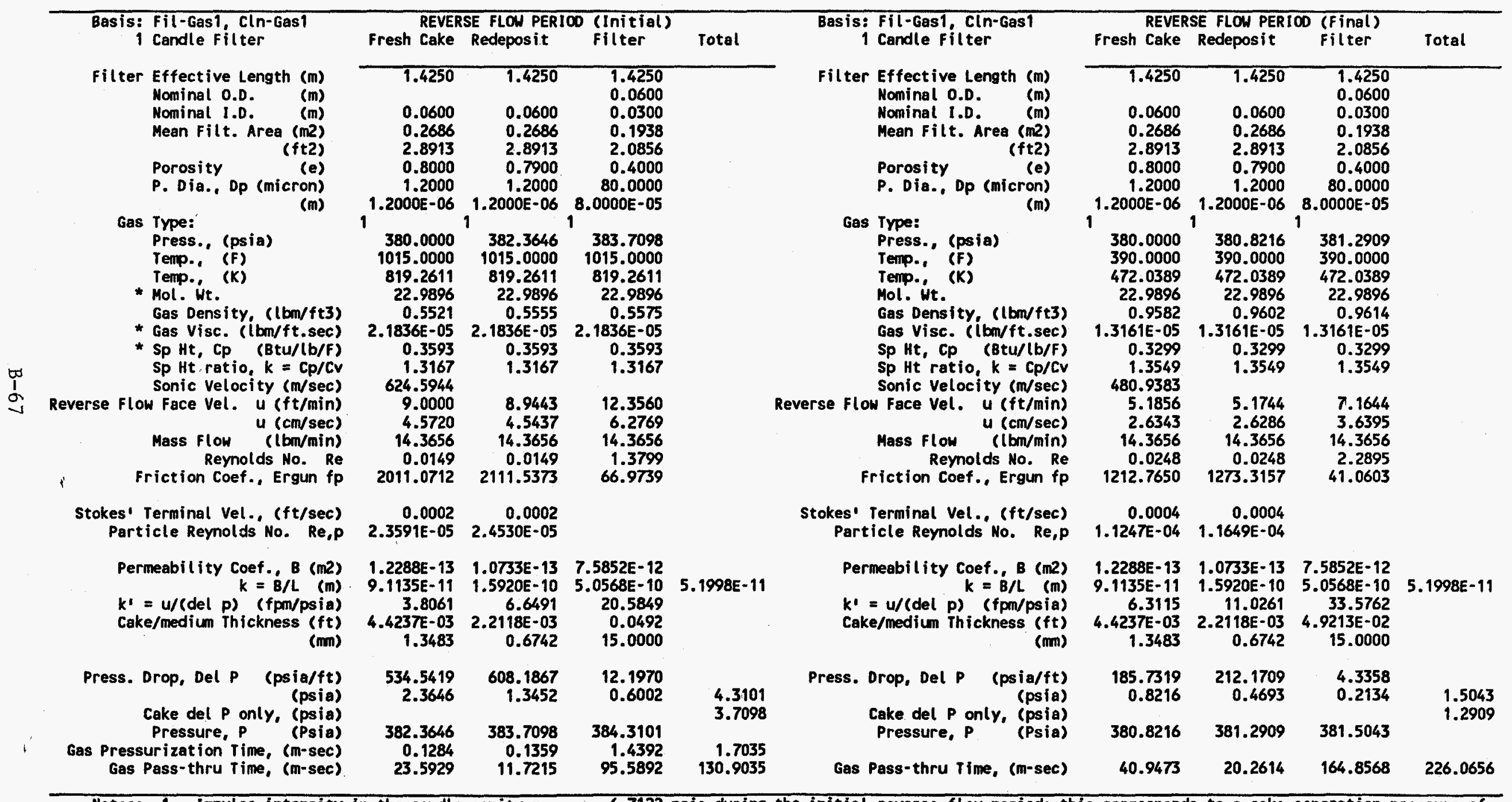

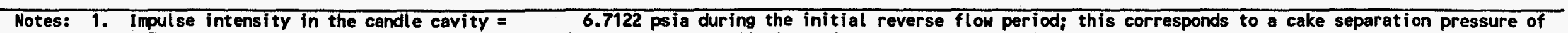
3.7098 psia if the reverse flow face velocity is set to 1.8000 times of the forward face velocity, i.e., u $=9.0000 \mathrm{fpm}$. 
TABLE 4 FLON FRON CANDLE TO EJECTOR MIXING ZOME - PRESSURE DROPS (Reverse Cleaning Period)

Page 4

Candle Plenum Pulse Pipe Ejector Venturi

Candle to

62 Candles/Cluster

Candle

Bottom Top

Bottom

2.5908

iffuser

Throat

Ejector Throat

Length,

Hominal 0.0

(m)

0.7125

0.1778

0.1778

2.5908

0.1626

0.2032
Nominal I.D. (m) $\quad 0.0300$

Total flow Area $(\mathrm{m} 2)$
$(\mathrm{ft} 2)$

Gas Trpe:

0.0438
0.4717

1.1684
1.0722

0.1541

0.1541
0.0186

0.0947

0.0947

1

11.5410

0.2006

0.2006

0.0759

0.0070

11.5410

20730

384.3101

$384.3849 \quad 384.3849$

Temp., (F)

Temp. Hol.

Gas Density, (lbm/ft3)

Gas Visc. (ibm/ft.sec)

Sp Ht, Cp (Btu/lb/F)

Sp Ht ratio, $k=\mathrm{Cp} / \mathrm{Cr}$

Sonic Vel.. (m/sec)

472.0389

22.9896

390.0000

390.0000

384.9730

385.1248

384.1255

0.0759

3161E-05

22.9896

472.0389

390.0000

390.0000

384.2509

22.9896

(390.0000

389.4219

389.4219

$0.9692 \quad 0.9707$

471.7177

471.7177

$\begin{array}{llllll}1.3161 E-05 & 1.3161 E-05 & 1.3161 E-05 & 1.3161 E-05 & 1.3161 E-05 & 1.3161 E-05\end{array}$

$\begin{array}{lllllll}0.3299 & 0.3299 & 0.3299 & 0.3299 & 0.3299 & 0.3299 & 0.3299\end{array}$

$\begin{array}{lllllll}1.3549 & 13549 & 1.3549 & 1.3549 & 1.3549 & 1.3549 & 1.3549\end{array}$

$480.9383 \quad 480.9383 \quad 480.9383 \quad 480.9383 \quad 480.9383 \quad 480.7746 \quad 480.7746$

$\begin{array}{lrrrrrr}1577.8815 & 1577.8815 & 1577.8815 & 1577.8815 & 1577.8815 & 1577.3446 & 1577.3446\end{array}$

Gas Flow:

$(\mathrm{ft} / \mathrm{sec})$

\begin{tabular}{lrrrrrrrr} 
& & & & \\
Flow Rate, & (lbm/min) & 890.6689 & 890.6689 & 890.6689 & 890.6689 & 890.6689 & 890.6689 & 890.6689 \\
Velocity, & (ft/sec) & 32.4737 & 1.3271 & 1.3271 & 76.2235 & 76.1934 & 201.8340 & 201.7681 \\
\hline & (m/sec) & 9.8980 & 0.4045 & 0.4045 & 23.2329 & 23.2238 & 61.5190 & 61.4989
\end{tabular}

$\begin{array}{llllllll}(\mathrm{m} / \mathrm{sec}) & 9.8980 & 0.4045 & 0.4045 & 23.2329 & 23.2238 & 61.5190 & 61.4989\end{array}$

(Mach $\mathrm{No}, \mathrm{s}$

0.0206

0.0008

0.0008

0.0483

0.0483

0.1280

0.1279

Reynolds No.. Re $2.3534 E+05 \quad 3.7464 E+05$

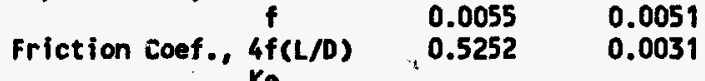

$\mathrm{Ke}$

0.3837

Press. drop, (psia) 0.0748

0.0000

$2.8415 E+06$

0.0037

4.6203E+06

0.0034

0.9655

0.2496

0.0295

Press. drop, (psia)
Press. gain, (psia) Net del P. (psia)

0.5881

0.1518

0.0000

0.0000

0.1254

0.9402 psia

-0.9994 psia

-0.0592 psia, net 


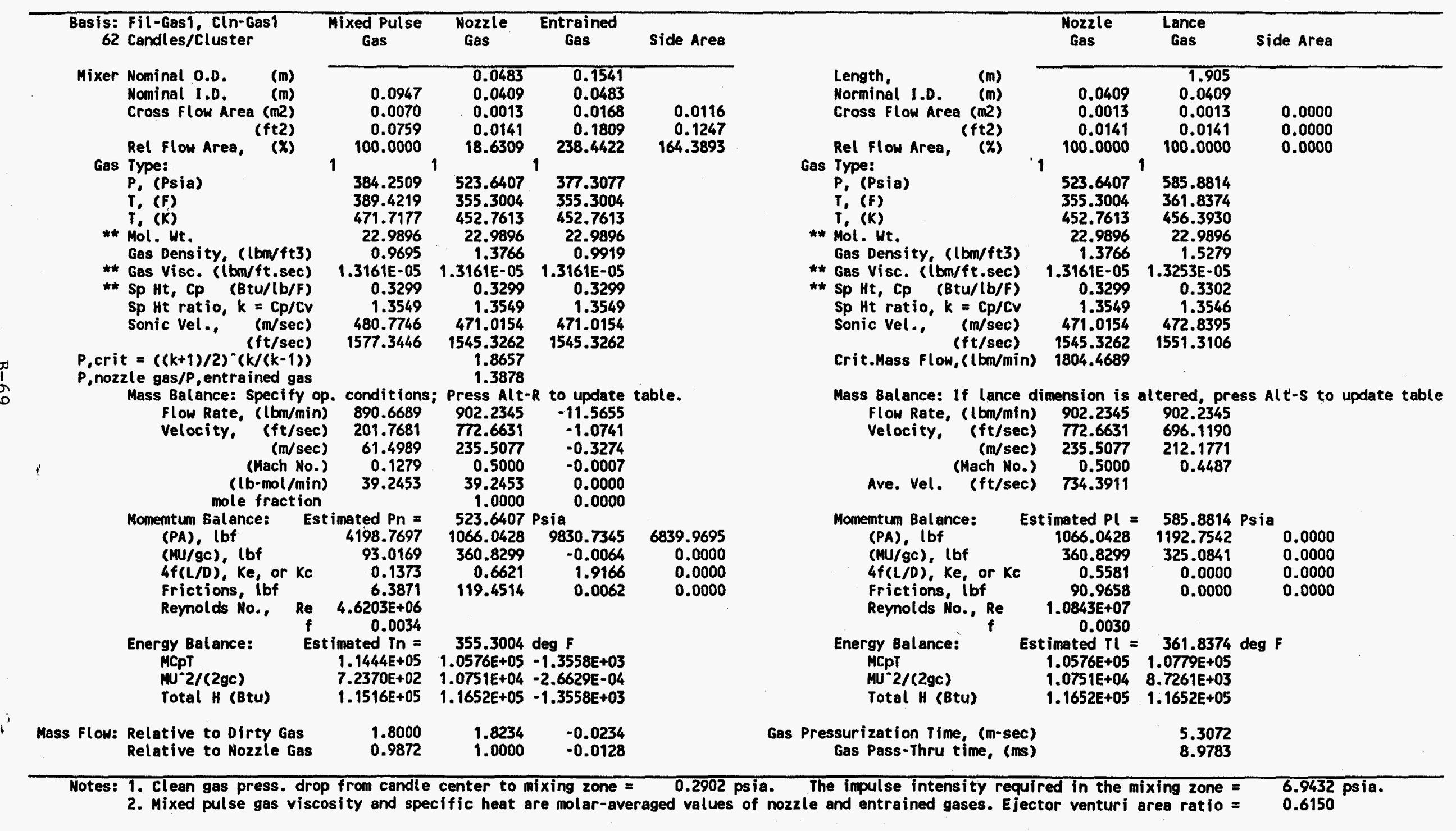


TABLE 6 FLOW FRON NOZZLE/LANCE-TO-RESERVOIR TANK (Reverse Cleaning Period)

$07 / 26 / 94$

$05: 32 \mathrm{PM}$

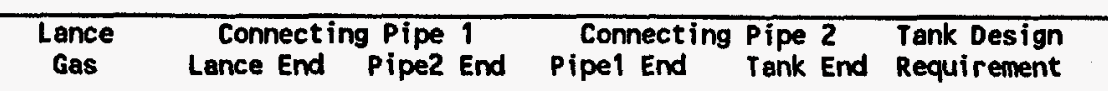

Lance/Conn Pipe 1

Nominal 0.0 .

Nominal I.D.

( $f+2)$

Gas Type:

Type:

T. (K)

Mol. He.

Gas Density, (lbm/ft3)

*** Gas Visc. (lbm/ft.sec)

*** Sp Ht, Cp (Btu/lb/F)

sp $\mathrm{Ht}$ ratio, $k=\mathrm{Cp} / \mathrm{CV}$

Sonic Vel.. (m/sec)

(ft/sec)

Mass Balance:

Flow Rate, (lbm/min)

Velocity, ( $\mathrm{ft} / \mathrm{sec})$

(m/sec)

Vol. Rate, (Mach Ho.)

$(\mathrm{m} 3 / \mathrm{sec})$

Momemtum Balance:

$1+(k-1) / 2 *$ Mach“2
Reynolds No.. Re
4f(Le/D)

Fitting/valve loss coef., Kf

Aux. Data:

Header Vel., ut $(\mathrm{ft} / \mathrm{s})$

Nom. Reynolds No., Re

Lance Equiv. Spacing, in
Header Length,

Gas Pressurization Time, (m-sec)
Gas Pass-thru Time, (ms)

0.0409
0.0013
0.0141
100.0000
1
585.8814
361.8374
456.3930
22.9896
1.5279
$1.3253 E-05$
0.3302
1.3546
472.8395
1551.3106

0.0590

0.0590
0.0027

0.0027
0.0294

0.0294
208.1837

602.4772

361.8374

456.3930
22.9896

22.9896
1.5712

$1.3253 \mathrm{E}-05$

0.3302

1.3546
472.8395

472.8395
1551.3106

1551.3106

902.2345

696.1190

212.1771

0.4487
590.4913

0.2787

902.2345

325.1666

99.1108
0.2096

574.2256

74.2256
0.2710

0.2710

1.0078

0.0030

$4628 E+06$
0.0032

0.0032
22.4021

19.1000

0.0590

0.0590

0.0027
0.0294

10.0590

0.0590

0.0027

208. 1837

0.0294
208.1837

0.0590
0.0027

0.0294

208.1837

931.1195

$365.5293 \quad 365.5293$

458.4463

22.9896

2.4174

365.5293

22.9896

2.4174

0.3303

$1.3305 E-05$

1.3544

1.3544

473.8671
1554.6822

473.8660

902.2345

211.3288

64.4130

902.2345

211.3433

64.4174

0.1359

373.2202

0.1761

0.2202
0.1761

1.0033

1.0033

$4331 \mathrm{E}+06$

$7.4337 E+06$

0.0032
2.1159

1.1000

15.4519 *

334.3773

$7.4628 E+06$

0.0032

10.0000

$\mathbf{0 . 0 0 0 0}$

5.3072

\begin{tabular}{l}
$\mathbf{5} .9783$ \\
\hline
\end{tabular} ank End Requirement

$\begin{array}{lll}142.1688 & 57.4794 & 204.9555 \\ 187.3554 & 74.0728 & 270.4065\end{array}$

956.0549

956.0549
365.6674

365.6674
458.5208

458.5208
22.9896

2.4818

$.3307 E-05$

0.3303

1.3544

473.9044

1554.8045

968.0066

368.3862

460.0312

22.9896

2.5045
$.3345 E-05$

0.3304

1.3542

474.6586
1557.2789

902.2345

205.8650

62.7477

902.2345

0.0000
0.0000

0.0000
0.0000

363.5469

0.1716

$1.0031 \quad 1.0000$

$\begin{array}{rr}7.4326 E+06 & 0.0000 E+00\end{array}$

0.0032

74.0728

Notes: 1. Velocity head losses for fitt ing

Pulse Gas Reservoír Tank

Design 1

Design 2

(final)

\begin{tabular}{llrr}
\hline Mominal blowback duration, (sec) & 1.0000 & 1.0000 \\
Mominal flow rate, (l bm/sec) & 15.0372 & 15.0372 \\
Tank Volume, $\quad(\mathrm{ft3})$ & 60.0000 & 55.0979 \\
Tank Volume/Candle,(ft3) & 0.9677 & 0.8887 \\
Mominal Minimm Tank Vol. (ft3) & 6.0040 & 5.5135
\end{tabular}

Nominat Minimem Tank Vol. (ft3) Gas Condition:

$$
P \text {, (Psia) }
$$

$T$, (F)

$T$ (K)

Mol. Wt.

Gas Density, (lbm/ft3)

* Gas Visc., (lbm/ft.sec)

Sp Ht, Cp, (Btu/lb/F)

sp Ht ratio, $k=\mathrm{Cp} / \mathrm{Cv}$

Final Initial Mass

Final Mass, $f$

Gas used per pulse, (lbm)

(Mass, $f$ )/(Mass, i)

P. (Psia)

T. (F)

T. (K)

Mol. Wt.

Gas Density, (lbm/ft3)

968.0066

368.3862

368.3862
460.0312

22.9896

2.5045

$1.3345 \mathrm{E}-05$

0.3304

1.3542

150.2718

135.2345

135.2345
15.0372

0.8999

839.2043

338.0290

443.1661

22.9896

$P$ Ratios, $P i / P, r e q$

(Pi-P, req)/(Pi-Pf)
Pf/P, req

1.0000

0.0000

0.0000
0.8669

T Ratios, Ti/T, req

$(T i-T, r e q) /(T i-T f)$

$T f / T$, req

1.0000

0.0000

0.9633

1094.2460

399.8988

477.5382

22.9896

$3786 E-05$

0.3316

150.2718

135.2345

15.0372

0.8999

948.6464

460.0312

22.9896

1.1304

0.8670

0.9800

Time Factors (m-sec):

rank-to-Ejector

Pressurization Pass-thru

$\begin{array}{lll}204.9555 & 270.4065 \\ \text { Ejector-to-Candle Cavity } & 273.7244 & 629.0490\end{array}$

Candle Cavity-to-Cake $\quad 1.7035 \quad 130.9035$

Total, $\mathrm{m}$-sec $\quad 480.3833 \quad 1030.3590$

2. Flou

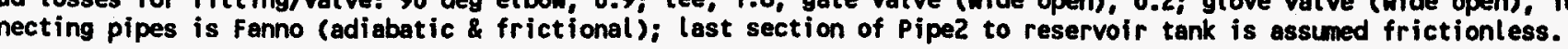


Basis: Fil-Gas1, Cln-Gas1

62 Candles/Cluster

4 Clusters served/Reservoir

PULSE GAS COMPRESSION WORK/PONER:

No. of stage

Adia. efficiency $\quad 0.9000$

$P$, initial (psia) $\quad 295.0000$

$\begin{array}{lll}P \text {, initial (F) } & 295.0000 \\ & \text { (R) } & 330.0000 \\ & & 789.6700\end{array}$

P. final (psia) $\quad 1094.2460$

T. final (F) $\quad 581.1957$

$\begin{array}{lr}\text { (R) } & 1040.8657 \\ \text { Compr. work, (Btu/lb) } & 166.5941\end{array}$

(Kuh/lb) $\quad 0.5941$

(Kwh/pulse) $\quad 0.7340$

W. Compressor Power/reservoir:

Compressor Power/reservoir: $\quad 6.0000$
No. of pulse/hr

$\begin{array}{lr}\text { Pulse gas flow, lbm/hr } \quad 90.2234 \\ \text { Kw/Reservoir } & 4.4040\end{array}$

$\begin{array}{ll}\text { Kw/Reservoir } & 4.4040 \\ \text { Hp/Reservoir } & 5.9058\end{array}$

1. Total No. of Reservoirs $\quad 4.0000$

Pulse gas flow, Ibm/hr 360.8938

$\begin{array}{ll}\text { Total KW } & 17.6158\end{array}$

iotal Hp 23.6232 


\section{CASE 8}

Plant Configuration: KRW-Based IGCC

Pulse Gas: Cold Pulse

Mode of Cleaning: Off-Line

B-73 


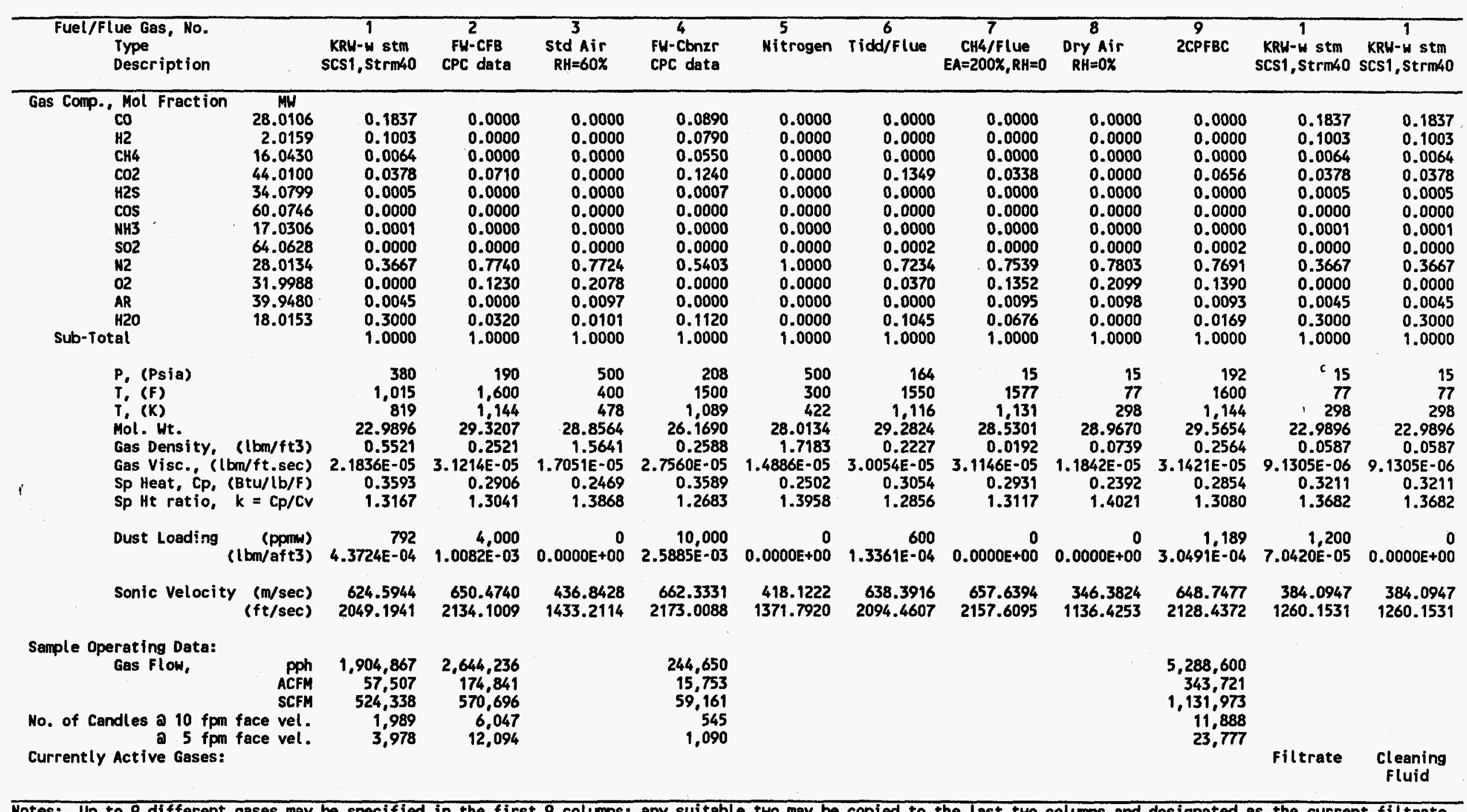

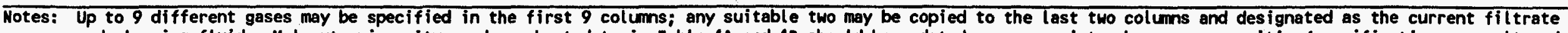

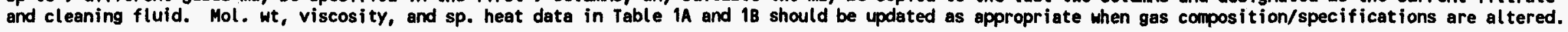




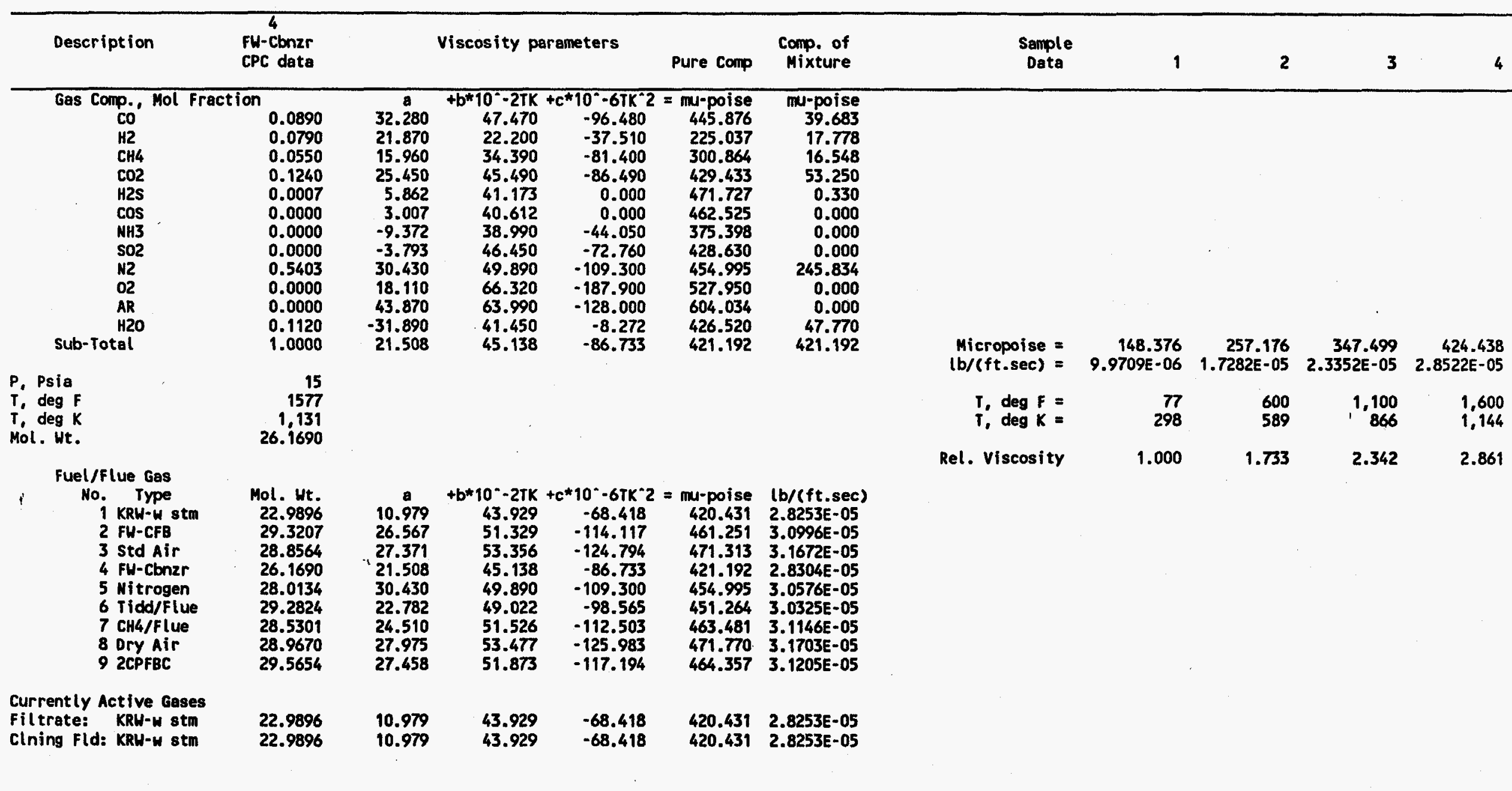




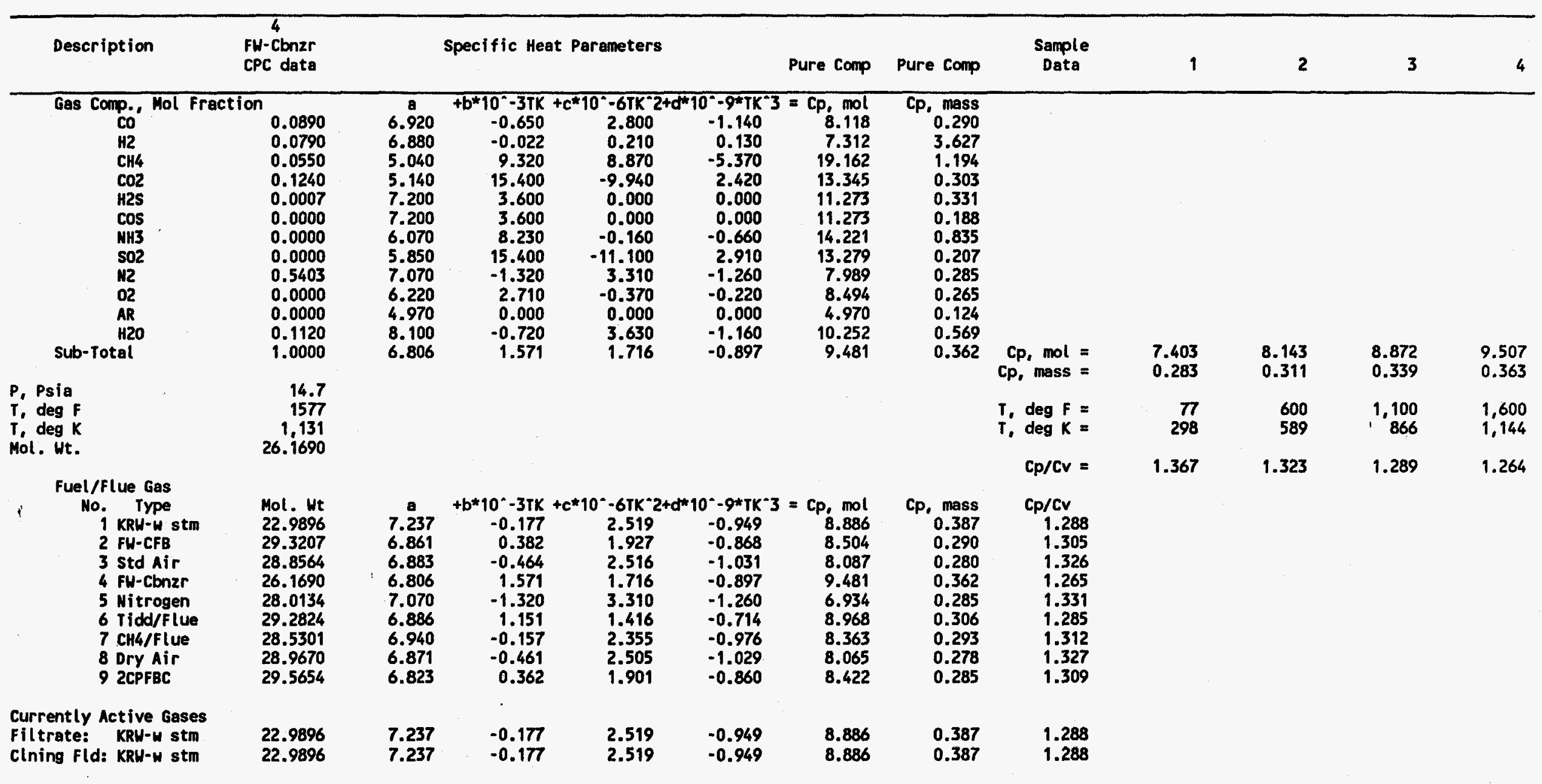

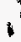

Notes: Cp, mol $=$ Btu/(lb-mole $) / F ; \quad$ Cp, mass $=$ Btu/lbm/F. 
Filter Eff. L (m), 95\% norm. Nominal $0 . \dot{0}$. Nominal 1.0 . Mean Filt. Area $\left(\mathrm{m}^{2}\right)$ Porosity (ft2) P. Dia., op (micron)

Gas Type:

$$
\begin{aligned}
& \text { Press., (psia) } \\
& \text { Temp., (F) }
\end{aligned}
$$

Forward Face Velocity $u(\mathrm{ft} / \mathrm{min})$ $u(\mathrm{ft} / \mathrm{min})$

Mass Flow Rate $\mathrm{u}$ (lbm/min) Reynolds No. Re

Friction Coef.., Ergun fp

filtration Cycle Time $t$ (min) Cake Bulk Density, (lb/ft3) Cake Cleaning Eff. $=$ Lc $/(L c+L r C)$

Permeability Coef.. B (m2)
$k=B / L(m)$ Mass permeabil ity, $\mathrm{Km}$ (lbm/ft) Cake/medium Thickness, L ( $\mathrm{ft}$ )

Areal Density $W(\mathrm{lb} / \mathrm{ft} 2)$

Fresh cake RORWARD FILTRATION PERIOD

\begin{tabular}{lrrr} 
& & & \\
\cline { 2 - 4 } (m) & 1.4250 & 1.4250 & 1.4250 \\
(m) & & & 0.0600 \\
2) & 0.0600 & 0.0600 & 0.0300 \\
(e) & 0.2686 & 0.2686 & 0.1938 \\
(e) & 2.8913 & 2.8913 & 2.0856 \\
(m) & 0.8000 & 0.7900 & 0.4000 \\
& 1.2000 & 1.2000 & 80.0000 \\
& $1.2000 E-06$ & $1.2000 E-06$ & $8.0000 E-05$
\end{tabular}

1

$1,1.2000 E-06$,

$380.0000 \quad 378.0302 \quad 377.9840$

$\begin{array}{lll}1015.0000 & 1015.0000 & 1015.0000\end{array}$

$819.2611 \quad 819.2611 \quad 819.2611$

$\begin{array}{lll}22.9896 & 22.9896 & 22.9896\end{array}$

$\begin{array}{rrr}0.5521 & 0.5492 & 0.5491 \\ 2.1836 E-05 & 2.1836 E-05 & 2.1836 E-05\end{array}$

$\begin{array}{rrr}1836 E-05 & 2.1836 E-05 & 2.1836 E-05\end{array}$

$$
\begin{array}{r}
0.3593 \\
1,500
\end{array}
$$

0.3593

0.3593

$8.2811,504$

$\begin{array}{r}5.0000 \quad 5.0261 \quad 6.9684 \\ \hline\end{array}$

$\begin{array}{lll}2.5400 & 2.5532 & 3.5400\end{array}$

$\begin{array}{lll}7.9809 & 7.9809 & 7.9809\end{array}$

$\begin{array}{rrr}3618.5282 & 3799.3672 & 119.1529\end{array}$

$\begin{array}{rrrr}60.0000 & & & \\ 187.2000 & 193.4400 & & \\ 0.9800 & & & \\ 1.2288 E-13 & 1.0733 E-13 & 7.5852 E-12 & \\ 6.0757 E-11 & 2.6003 E-09 & 5.0568 E-10 & 5.3131 E-11\end{array}$

6.0757E-11 2.6003E-09 5.0568E-10

4.9497E-11 4.6908E-11

$\begin{array}{lll}6.6355 E-03 & 1.3542 E-04 & 0.0492\end{array}$

$\begin{array}{lll}2.0225 & 0.0413 & 15.0000\end{array}$

$\begin{array}{llllll}\text { Pressure Drop, del P } & \text { (psia/ft) } & 296.8529 & 341.6297 & 6.7989\end{array}$

$\begin{array}{lllll}\text { Cake del P only, (psia) } & 1.9698 & 0.0463 & 0.3346 & 2.3506 \\ & & & & 2.0160\end{array}$

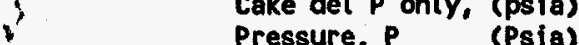

Sp. Res. K2, (in.H)/(fpm)/(lb/ft2)

$\begin{array}{llll}378.0302 & 377.9840 & 377.6494 & 2.0160\end{array}$

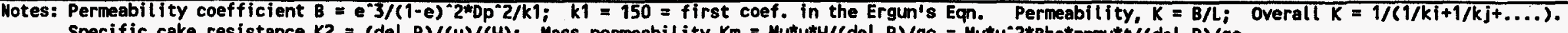

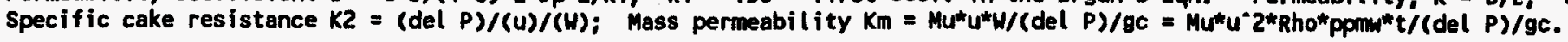


TABLE 3 FLOW THROUGH POROUS MEDIA - PRESSURE DROPS (2) Page 3 (Reverse Cleaning Period)

Basis: Fil-Gasi, Cln-Gas 1
1 Candle Filter
Filter Effective Length $(\mathrm{m})$
Nominal O.D. $\quad(\mathrm{m})$
Nominal I.D. $\quad(\mathrm{m})$
Mean Filt. Area $(\mathrm{m} 2)$
(ft2)
Porosity r (e)
P. Dia., Dp (micron)

Gas Type:

Press., (psia)
Temp., (F)

Temp.. (F)

* Mol. Wt.

Gas Density, (lbm/ft3)

* Gas Visc. (lbor/ft.sec)

* Sp Ht, Cp (Btu/lb/F) sp Ht ratio, $k=\mathrm{Cp} / \mathrm{Cy}$ Sonic Velocity (m/sec)

Reverse Flow Face Vel. u (ft/min) $u(\mathrm{ft} / \mathrm{min})$
$u(\mathrm{~cm} / \mathrm{sec})$

Mass Flow (lbm/min) Reynolds No. Re

Friction Coef., Ergun fp

Stokes' Terminal Vel., (ft/sec)

Particle Reyno!ds No. Re,p

Permeability Coef.. $B(m 2)$
$k=8 / L(m)$

$k^{\prime}=u /(\operatorname{del} p) \quad(f p m / p s i a)$

Cake/mediun Thickness (ft)

(min)

Press. Drop, Del P (psia/ft)

Cake del P only, (psia)

Pressure, $P$ (Psia)
(Psia)

) Gas Pressurization Time, (m-sec)

Gas Pass-thru Time, (m-sec)

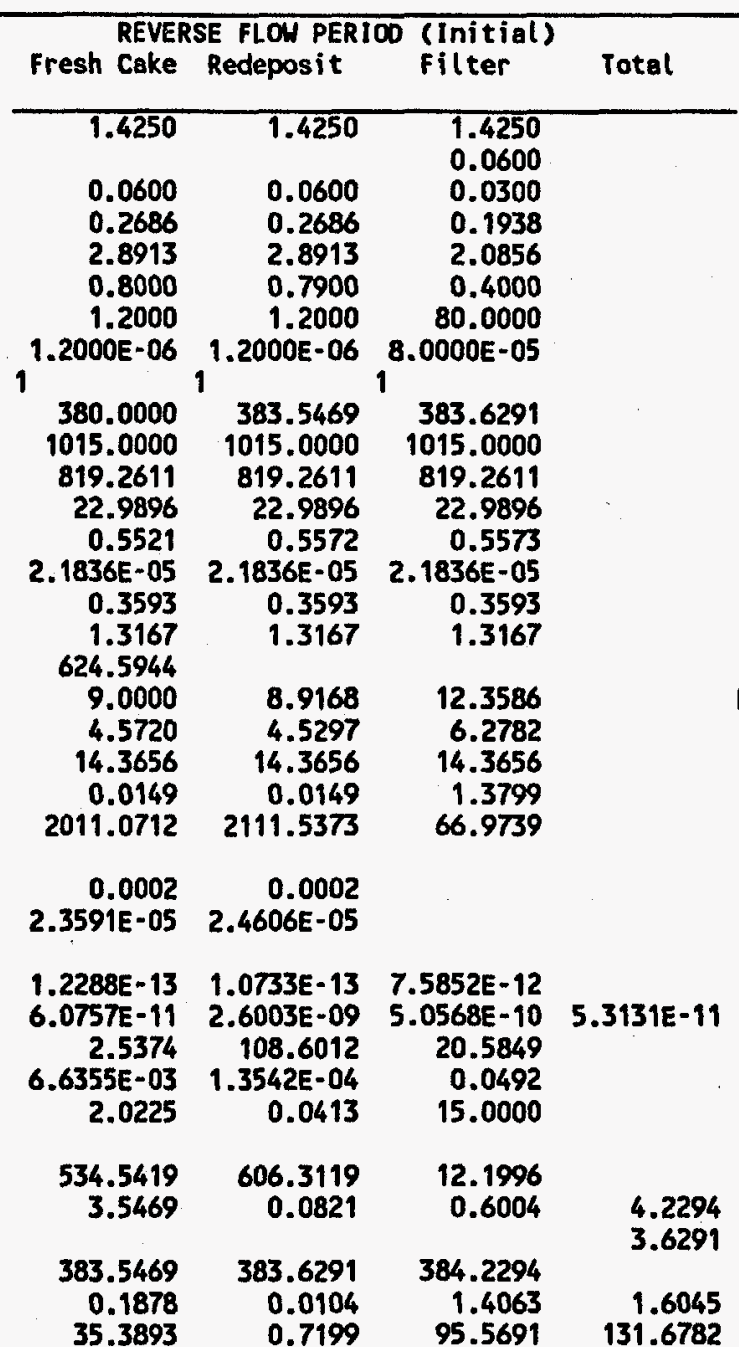

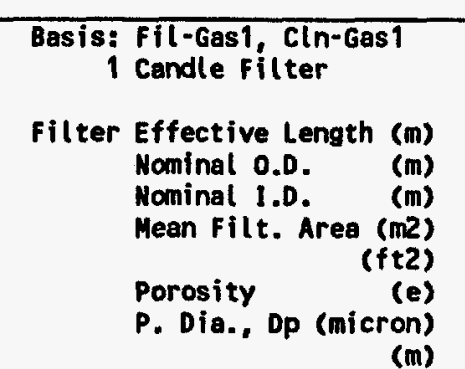

Gas Type:

Press., (psia)

Temp., (F)

Temp. Wol. (K)

Gas Density, (lbm/ $f t 3)$

Gas Visc. (lbm/ft.sec)

$\mathrm{Sp} H \mathrm{H}, \mathrm{Cp}$ (Btu/(b/F)

sp $\mathrm{Ht}$ ratio, $k=\mathrm{Cp} / \mathrm{Cv}$

Sonic Velocity $(\mathrm{m} / \mathrm{sec})$

Reverse flow Face vel. $u$ (ft/min) $u(\mathrm{~cm} / \mathrm{sec})$

Mass flow (l bm/min) Reynolds No. Re

Friction Coef.. Ergun fp

Stokes' Terminal Vel.. (ft/sec)

Particle Reynolds No. Re,p

$\begin{aligned} & \text { Permeability Coef., } B(m 2) \\ & K=B / L(m)\end{aligned}$ $k=B / L \quad(m)$

$k^{\prime}=u /(\operatorname{del} p)$ (fpm/psia)
Cake/medium Thickness (ft)

(mm)

Press. Drop, Del P (psia/ft) Cake del $P$ only, (psia) Pressure, $P$ (Psia)
Psia)
REVERSE FLOW PERIOD (Final
Fresh Cake Redeposit filter

Total

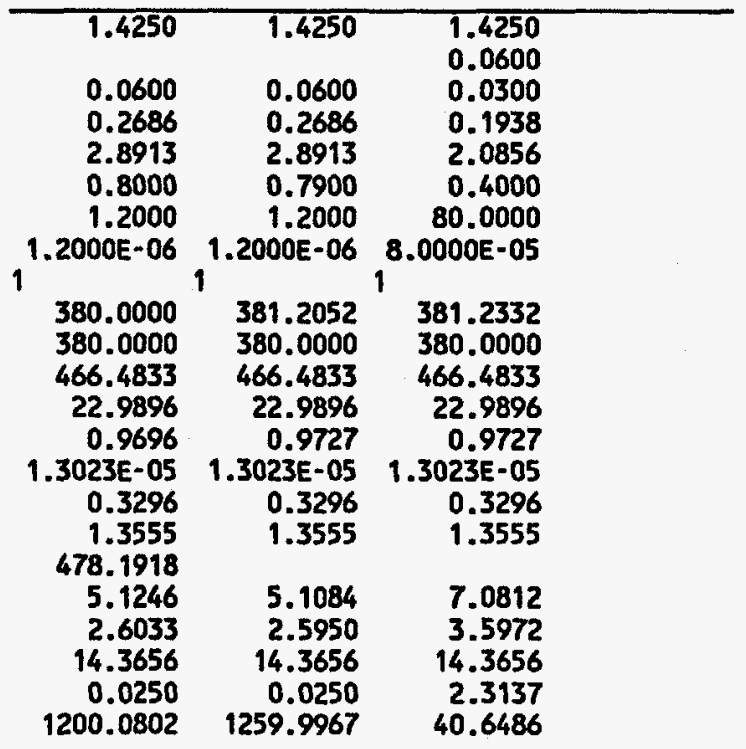

\section{$0.0004 \quad 0.0004$}

1.1622E-04 1.2050E-04

$1.2288 \mathrm{E}-13 \quad 1.0733 \mathrm{E}-13 \quad 7.5852 \mathrm{E}-12$

6.0757E-11 2.6003E-09 $5.0568 E-10 \quad 5.3131 E-11$

$\begin{array}{rrr}4.2521 & 181.9968 & 33.9163 \\ 6.6355 E-03 & 3542 E-04 & 4.9213 E-02\end{array}$

$\begin{array}{rrr}2.0225 & 0.0413 & 15.0000\end{array}$

181.6261207 .2718

$\begin{array}{rrr}1.2052 & 0.0281 & 0.2088\end{array}$

$381.2052 \quad 381.2332 \quad 381.4420$

1.4420

$381.4420-1.2332$

Gas Pass-thru Time, (m-sec)

62.1524

1.2565

166.7950

230.2039 
TABLE 4 FLOW FROM CAMDLE TO EJECTOR MIXING ZOME - PRESSURE DROPS

(Reverse Cleaning Period)

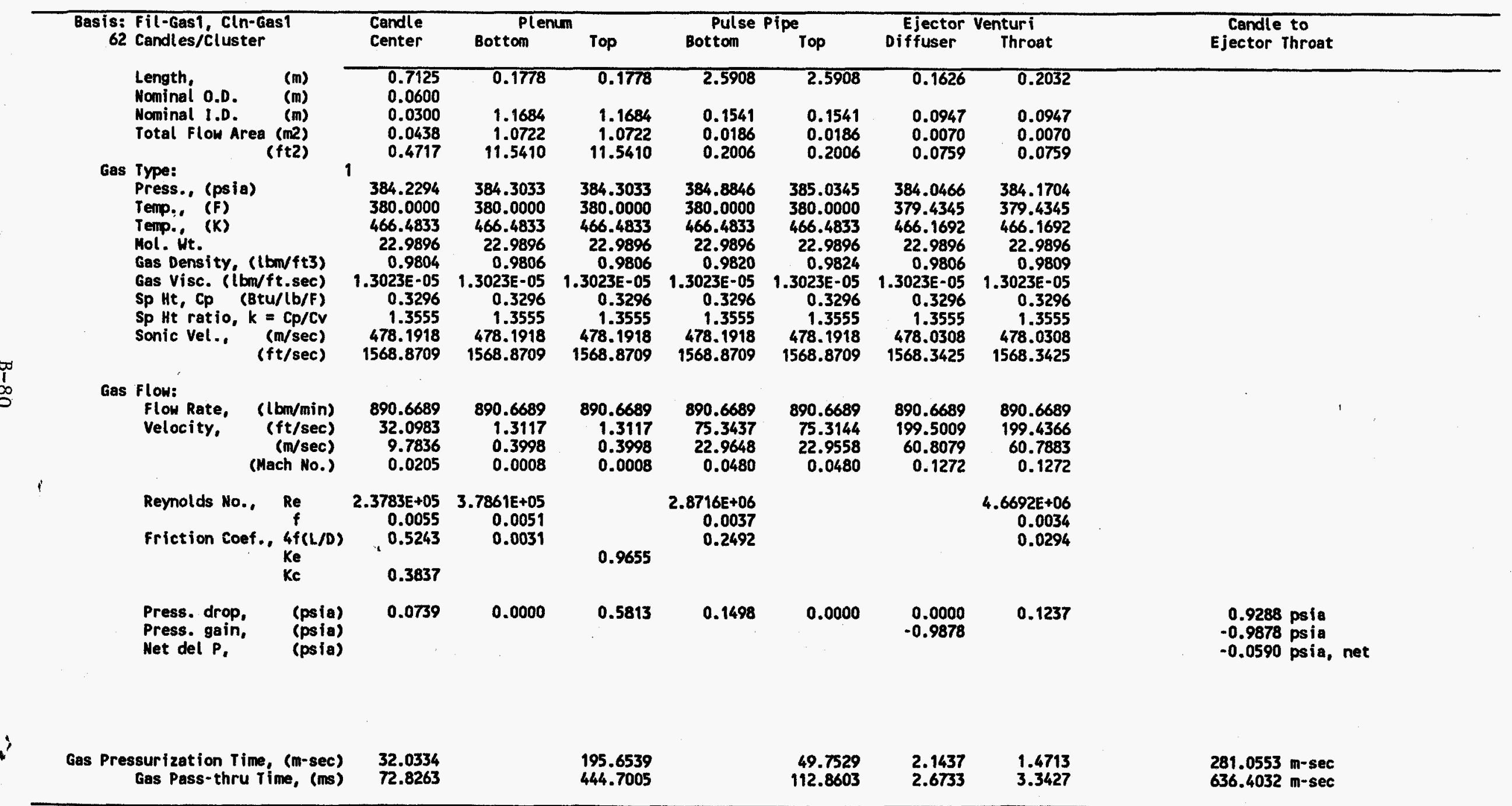

Notes: 1. Fanning coefficient is approximated by $f=0.04 /(\mathrm{Re}) * 0.16$

2. Flow is assumed isothermal from candle to pulse pipe; flow in the diffuser is assumed isentropic. 


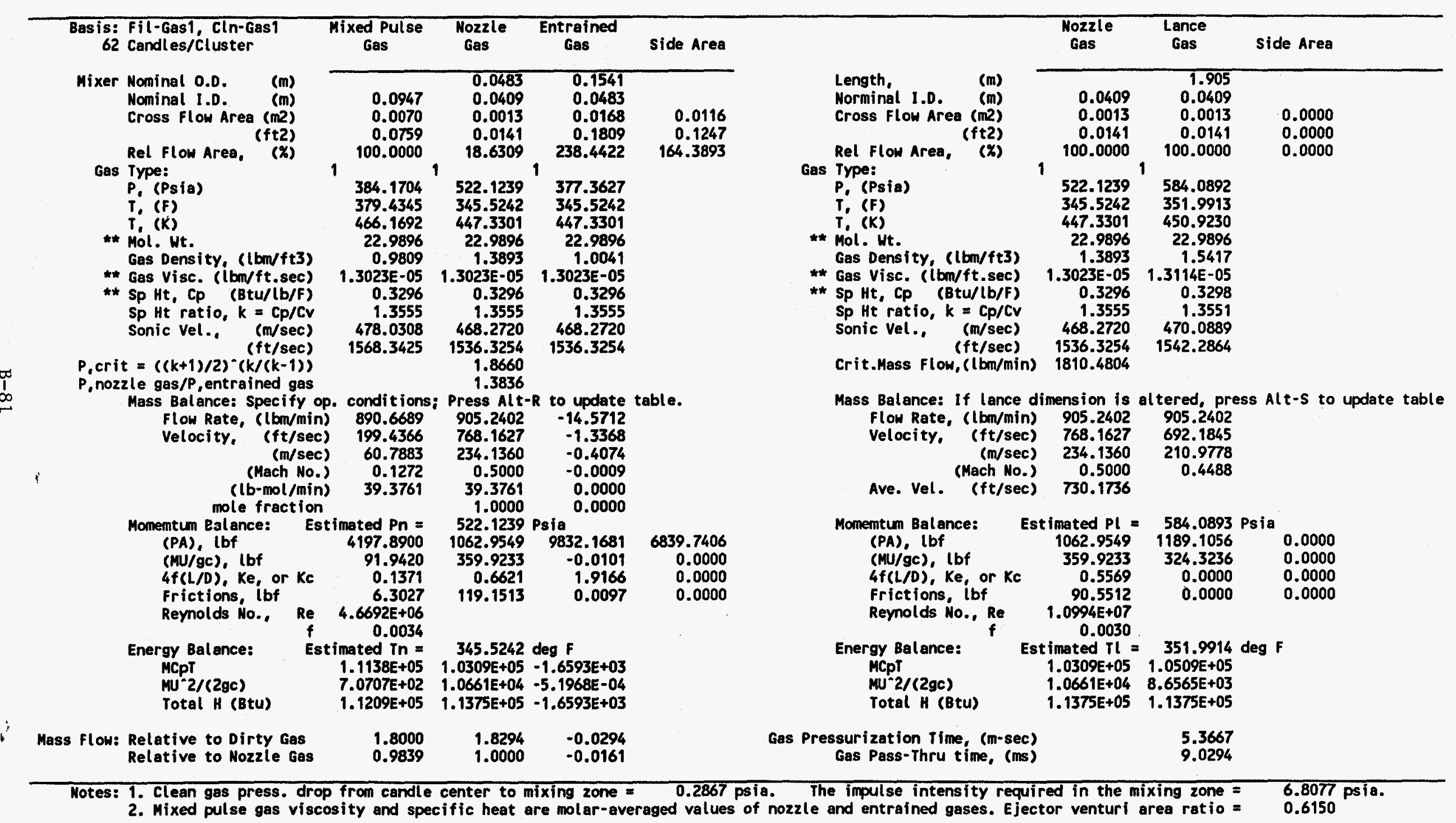




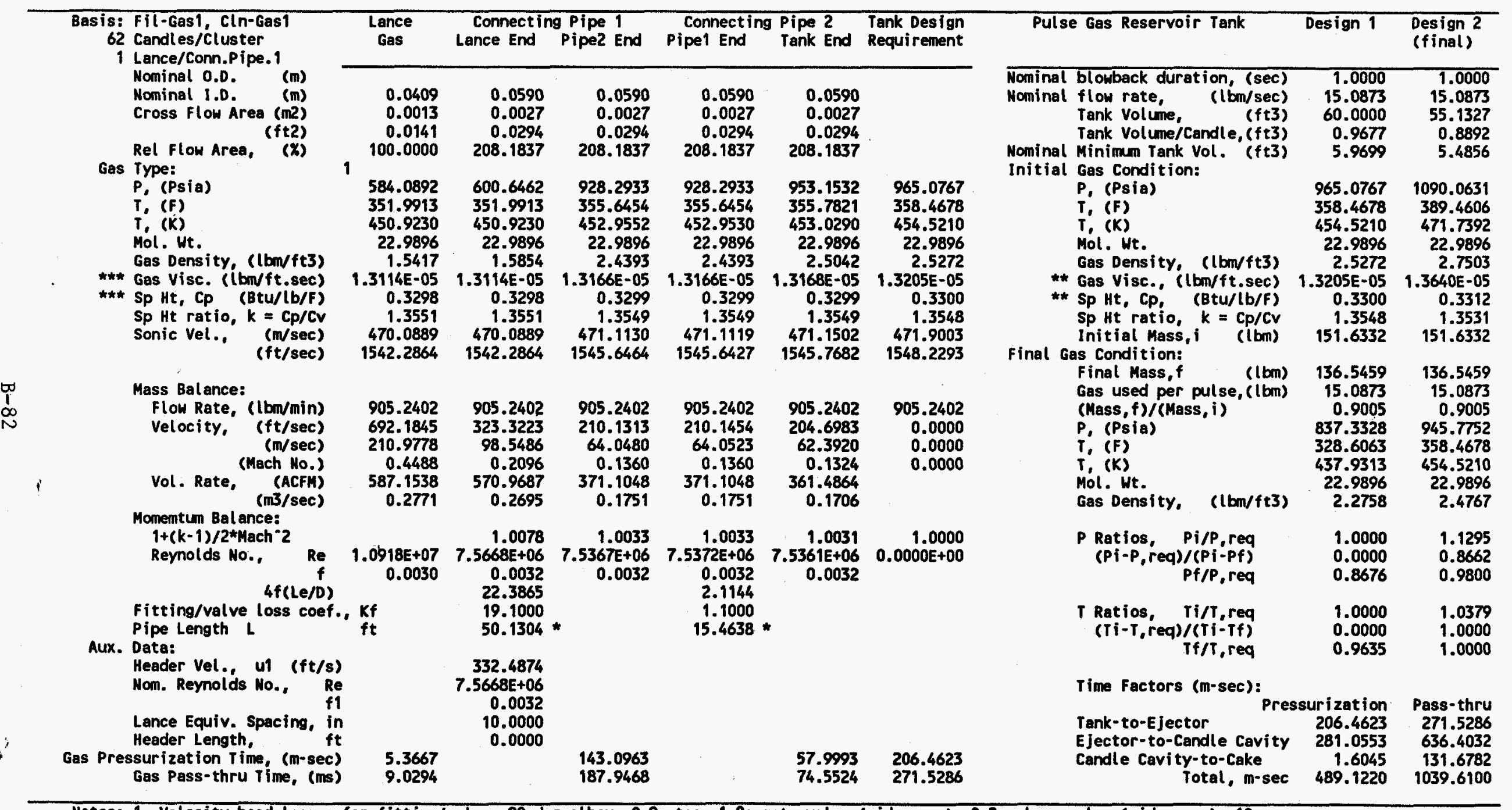

Motes: 1. Velocity head losses for fitting/valve: 90 deg elbow, $0.9 ;$ tee, 1.8 ; gate valve (wide open), 0.2 ; glove valve (wide open), 10. 2. Flow in connecting pipes is fanno (adiabatic \& frictional); last section of Pipez to reservoir tank is assumed frictionless. 
Basis: Fil-Gas1, Cln-Gas

62 Candles/Cluster

4 Clusters served/Reservoir

PULSE GAS COMPRESSION WORK/POWER:
No. of stage
Adia. efficiency $\quad 0.9000^{2}$
$P$, initial (psia) $\quad 295.0000$
$T$, initial (F) $\quad 330.0000$
(R) $\quad 789.6700$
$P$, final (psia) $\quad 1090.0631$
T, final (F) $\quad 580.8885$
$\begin{array}{llr}T \text {, final } & \text { (F) } & 580.8885 \\ & (R) & 1040.5585\end{array}$
$\begin{array}{lr}\text { Compr. work, (Btu/(b) } & 166.1914 \\ \text { (Kth/(b) } & 0.0487\end{array}$
$\begin{array}{ll}\text { (Kwh/lb) } & 0.0487 \\ \text { (Kwh/pulse) } & 0.7347\end{array}$

Compressor Power/reservoir:

$\begin{array}{lr}\text { No. of pulse/hr } & 4.0000 \\ \text { Pulse gas flow, I } \mathrm{bm} / \mathrm{hr} & 60.3493\end{array}$

Ku/Reservoir $\quad 2.9386$

Hp/Reservoir $\quad 3.9408$

Total No. of Reservoirs $\quad 4.0000$

Pulse gas flow, $\mathrm{lbm} / \mathrm{hr} \quad 241.3974$

Total KW $\quad 11.7545$

Total Hp $\quad 15.7631$ 


\section{APPENDIX C}

This appendix contains complete cost details including the Total Plant Cost Summary Sheets and the Capital Investment and Revenue Requirement Summary Sheets. 
Cllent: DOE/METC

Report Date:

04-Oct-94

Proloct: HGCU BLOWBACK STUDY

TOTAL PLANT COST SUMMARY

Case: Case 1 - CPFBC with Conventional Blowback

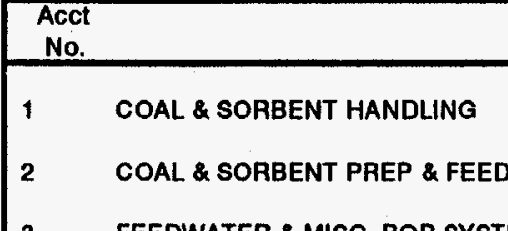

3 FEEDWATER \& MISC. BOP SYSTEMS

4 CARBONIZER, PFBC \& PFB HTX

5 HOT GAS CLEANUP \& PIPING

5.1 Carbonlzer Filter Vessel

5.2 CPFBC Filter Vessel

5.3 Hot Gas Piplng

5.4 Blowback Gas \& Alr Systems

5.9 HGCU Foundations

6 COMBUSTION TURBINE/ACCESSORIE

\begin{tabular}{|c|c|c|}
\hline $\begin{array}{c}\text { Equipment } \\
\text { Cost }\end{array}$ & $\begin{array}{c}\text { Materlal } \\
\text { Cost }\end{array}$ & \multicolumn{2}{|c|}{ Lab } \\
& & Dlrect \\
\hline
\end{tabular}

Cost Year $1994: \$ \times 1000$

6.2 Combustion Turbine Accessories

7 HRSG, DUCTING \& STACK

7.1 Heat Recovery Steam Generator

7.2 HRSG Accessorles

B STEAM TURBINE GENERATOR

8.1 Steam TG Accessorles

8.2 Turbine Plant Auxillarles

9 COOLING WATER SYSTEM

to ASH/SPENT SORBENT HANDLING SYS

11 ACCESSORY ELECTRIC PLANT

12 INSTRUMENTATION \& CONTROL

13 IMPROVEMENTS TO SITE

BUILDINGS \& STRUCTURES 


\section{TITLE/DEFINITION}

Case:

Plant Size:

Fuel(type):

Design/Construction:

TPC(Plant Cost) Year:

Capacity Factor:

CAPITAL INVESTMENT

Process Capital \& Facilities

Engineering(incl.C.M.,H.O.\& Fee)

Process Contingency

Project Contingency

TOTAL PLANT COST(TPC)

TOTAL CASH EXPENDED

AFDC

TOTAL PLANT INVESTMENT(TPI)

Royalty Allowance

Preproduction Costs

Inventory Capital

Initial Catalyst \& Chemicals(w/equip.)

Land Cost

TOTAL CAPITAL REQUIREMENT(TCR)

OPERATING \& MAINTENANCE COSTS(First Year)

Operating Labor

Maintenance Labor

Maintenance Material

Administrative \& Support Labor

TOTAL OPERATION \& MAINTENANCE(1st yr.)

FIXED $O$ \& $M$ (1st yr.)

VARIABLE $O \& M$ (1st yr.)

CONSUMABLE OPERATING COSTS(less Fuel)

Water \& Chemicals

Auxilliary Power

Other Consumables

Waste Disposal

TOTAL CONSUMABLES(1st yr.,-fuel)

BY-PRODUCT CREDITS(First Year)

FUEL COST(First Year)

LEVELIZED OPERATION \& MAINTENANCE COSTS

Fixed $O \& M$

Variable $O \& M$

Consumables

By-product Credit

Fuel

LEVELIZED CARRYING CHARGES(Capital)

LEVELIZED BUSBAR COST OF POWER

30 Year at a Capacity Factor of:

Case 1 - CPFBC with Conventional Blowback

Pittsburgh \#8 453.0 (MW, net)

1 (years)

-1994 (Dec.)

$65(\%)$
HeatRate:

Cost:

BookLife:

TPI Year:

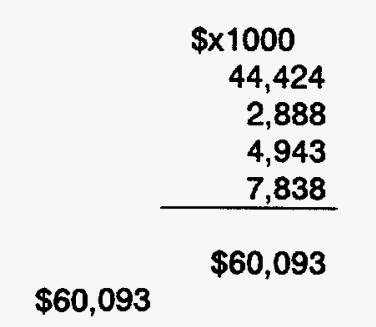

$\$ 60,093$

1,548

187

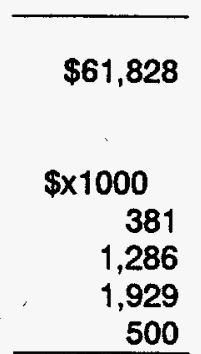

$\$ 4,097$

$\$ \times 1000$

35

$\$ 35$
7,822 (Btu/kWh)

1.60 (\$/MMBtu)

30 (years)

1995 (Jan.)

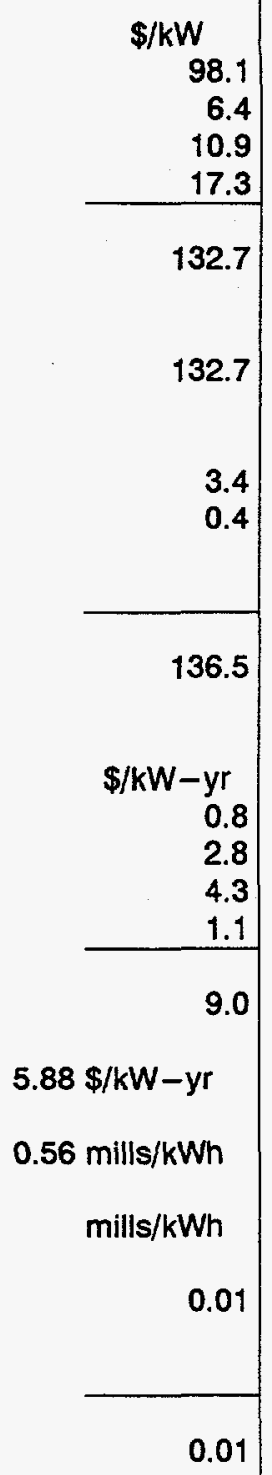

$9.1 \$ / k W-y r=$

$23.1 \$ / \mathrm{kW}-\mathrm{yr}=$
1.6 mills $/ \mathrm{kWh}$

0.9 mills $/ \mathrm{kWh}$

0.0 mills $/ \mathrm{kWh}$

mills/kWh

mills/kWh

4.1 mills $/ k W h$

6.5 mills/kWh 


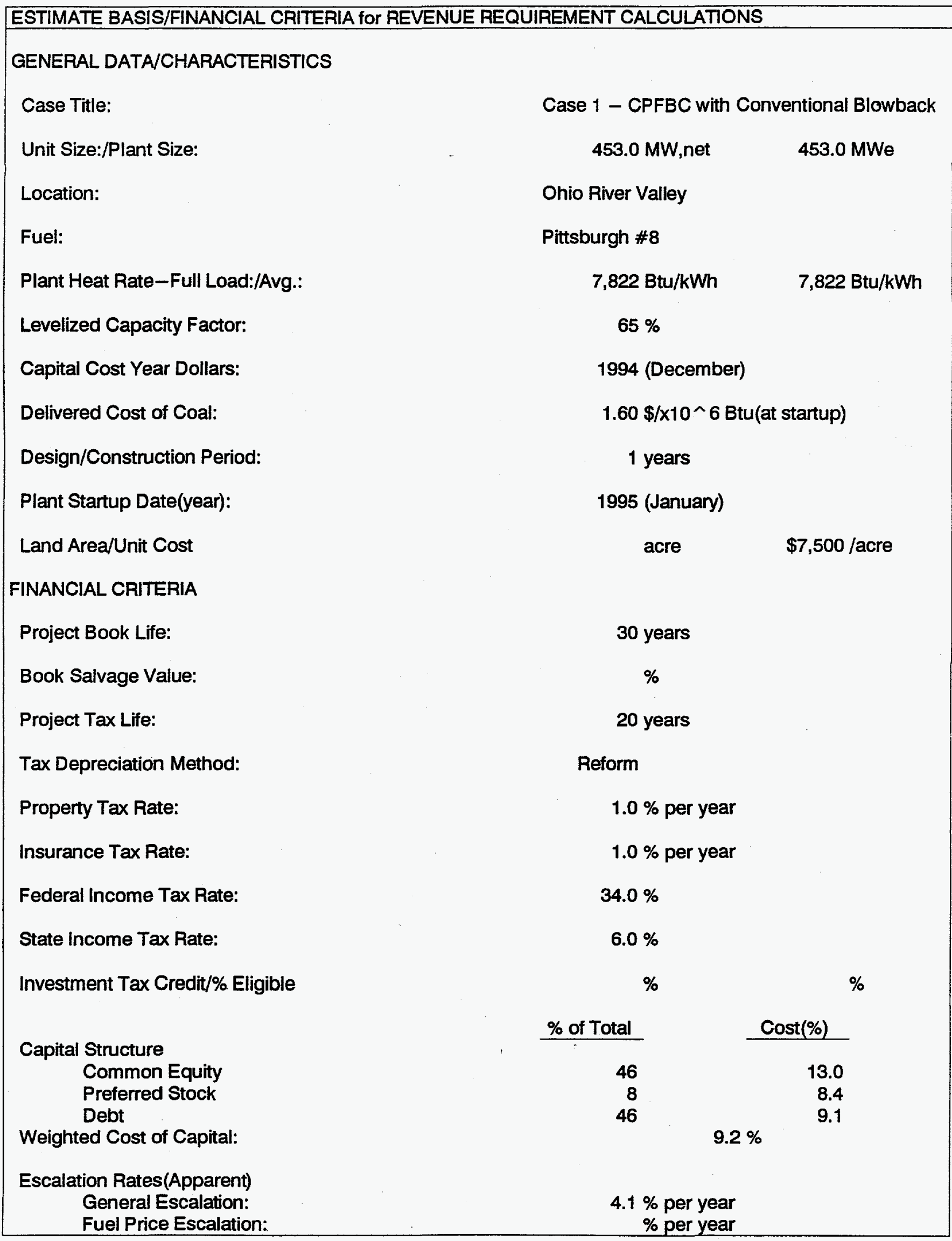


i

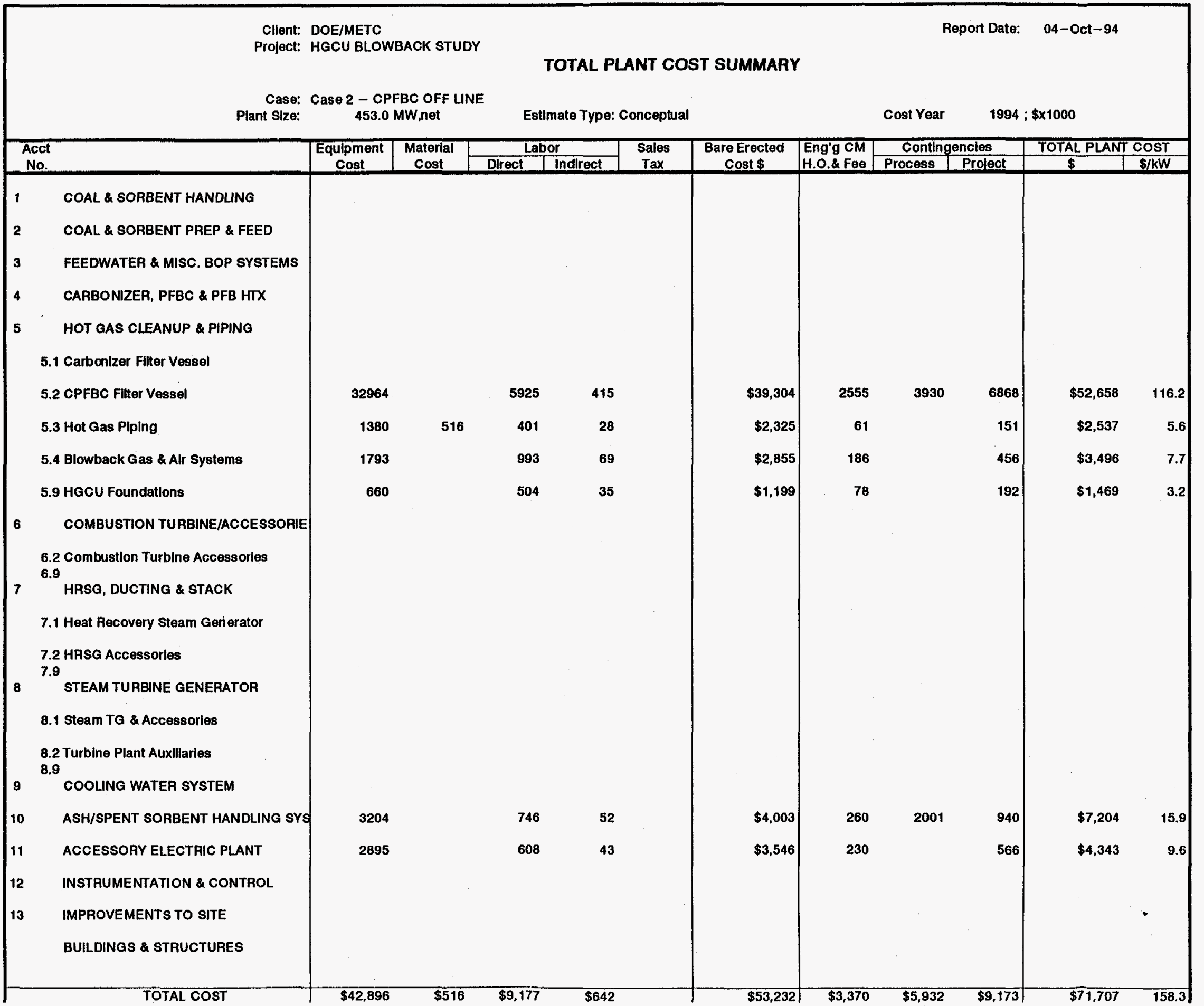


TITLE/DEFINITION

Case:

Plant Size:

Fuel(type):

Design/Construction:

TPC(Plant Cost) Year:

Capacity Factor:

CAPITAL INVESTMENT

Process Capital \& Facilities

Engineering(incl.C.M.,H.O.\& Fee)

Process Contingency

Project Contingency

TOTAL PLANT COST(TPC)

TOTAL CASH EXPENDED

AFDC

TOTAL PLANT INVESTMENT(TPI)

Royalty Allowance

Preproduction Costs

Inventory Capital

Initial Catalyst \& Chemicals(w/equip.)

Land Cost

TOTAL CAPITAL REQUIREMENT(TCR)

OPERATING \& MAINTENANCE COSTS(First Year)

Operating Labor

Maintenance Labor

Maintenance Material

Administrative \& Support Labor

TOTAL OPERATION \& MAINTENANCE(1st yr.)

FIXED $O$ \& $M(1$ st yr.)

VARIABLE O \& M (1st yr.)

CONSUMABLE OPERATING COSTS(less Fuel)

Water \& Chemicals

Auxilliary Power

Other Consumables

Waste Disposal

TOTAL CONSUMABLES(1st yr.,-fuel)

BY-PRODUCT CREDITS(First Year)

FUEL COST(First Year)

LEVELIZED OPERATION \& MAINTENANCE COSTS

Fixed $O$ \& $M$

Variable $O$ \& M

Consumables

By-product Credit

Fuel

LEVELIZED CARRYING CHARGES(Capital)

LEVELIZED BUSBAR COST OF POWER

30 Year at a Capacity Factor of:
Case 2 - CPFBC OFF LINE

453.0 (MW, net) HeatRate:

Pittsburgh \#8 1 (years) 1994 (Dec.)

$65(\%)$

\section{Cost:}

BookLife:

TPI Year:

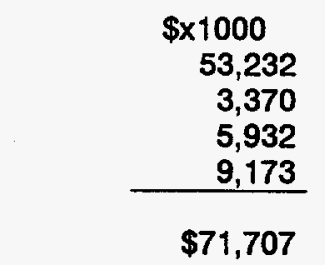

$\$ 71,707$

$\$ 71,707$

1,837

221

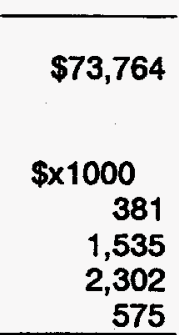

$\$ 4,792$

$6.88 \$ / \mathrm{kW}-\mathrm{yr}$

0.65 mills $/ k W h$

$\$ \times 1000$

mills/kWh

24

0.01

$\$ 24$

$10.6 \$ / \mathrm{kW}-\mathrm{yr}=$

1.9 mills $/ \mathrm{kWh}$

1.0 mills $/ \mathrm{kWh}$

0.0 mills $/ \mathrm{kWh}$

mills/kWh

mills/kWh

$27.5 \$ / k W-y r=$

$4.8 \mathrm{mills} / \mathrm{kWh}$

7.7 mills/kWh 


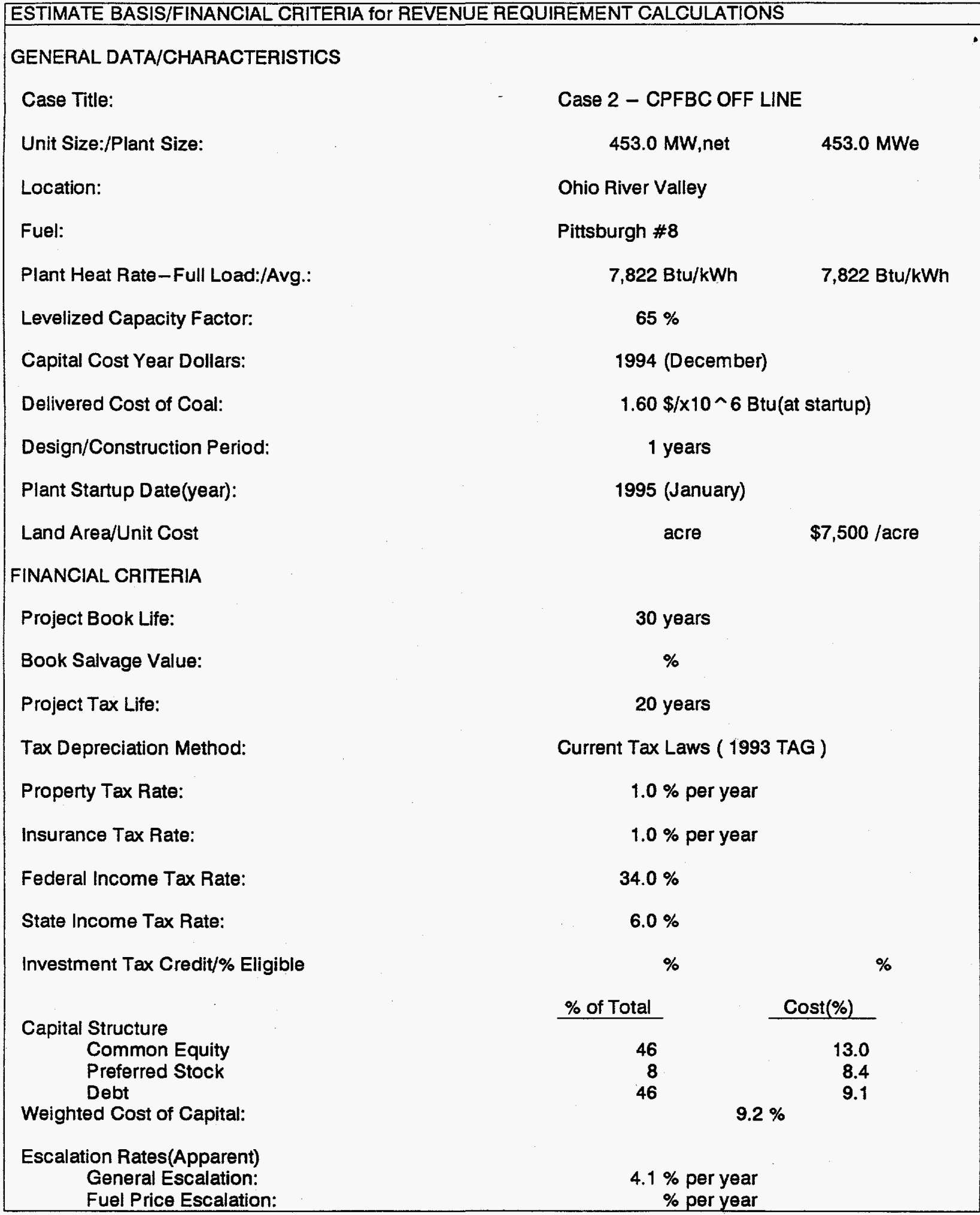


i

Cllent: DOE/METC

Prolect: HGCU BLOWBACK STUDY

Report Date:

$04-$ Oct-94

TOTAL PLANT COST SUMMARY

Case: Case 3 - CPFBC RP

Plant Slze: $\quad 453.0 \mathrm{MW}$, net

Estimate Type: Conceptual

Cost Year $\quad 1994: \$ \times 1000$

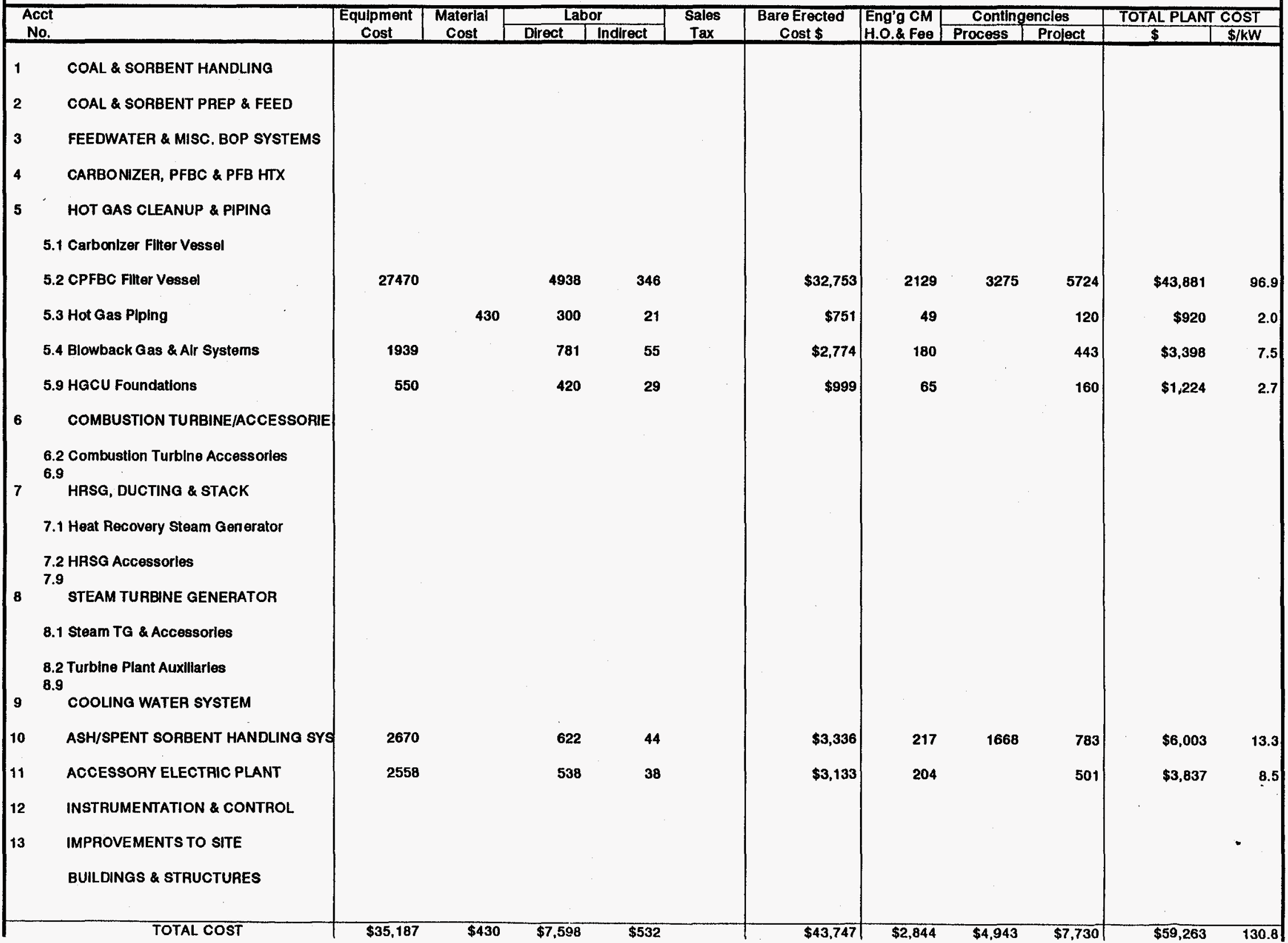




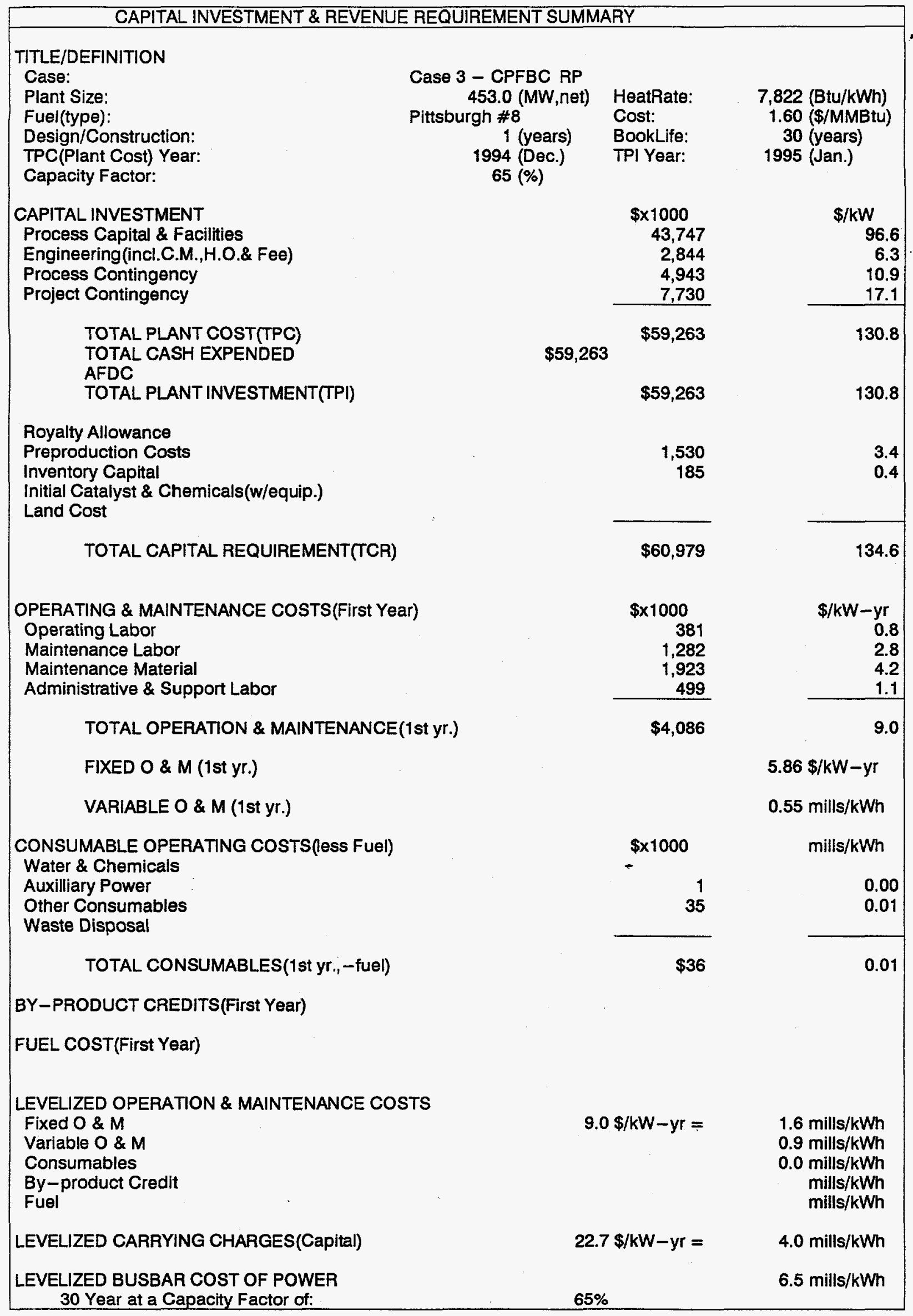




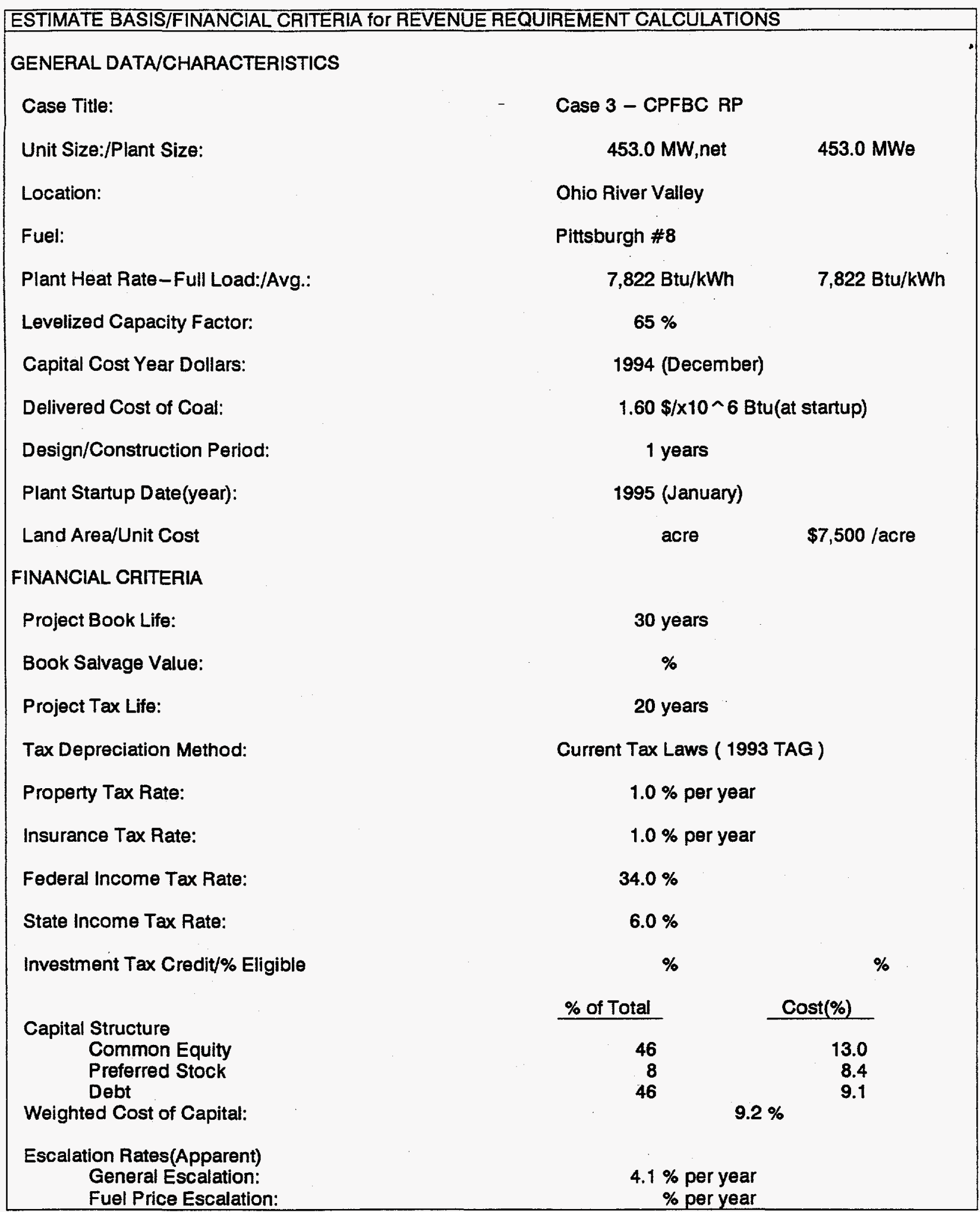




\section{TOTAL PLANT COST SUMMARY}

Case: Case 4 - CPFBC RP-OFF LINE Plant Size:

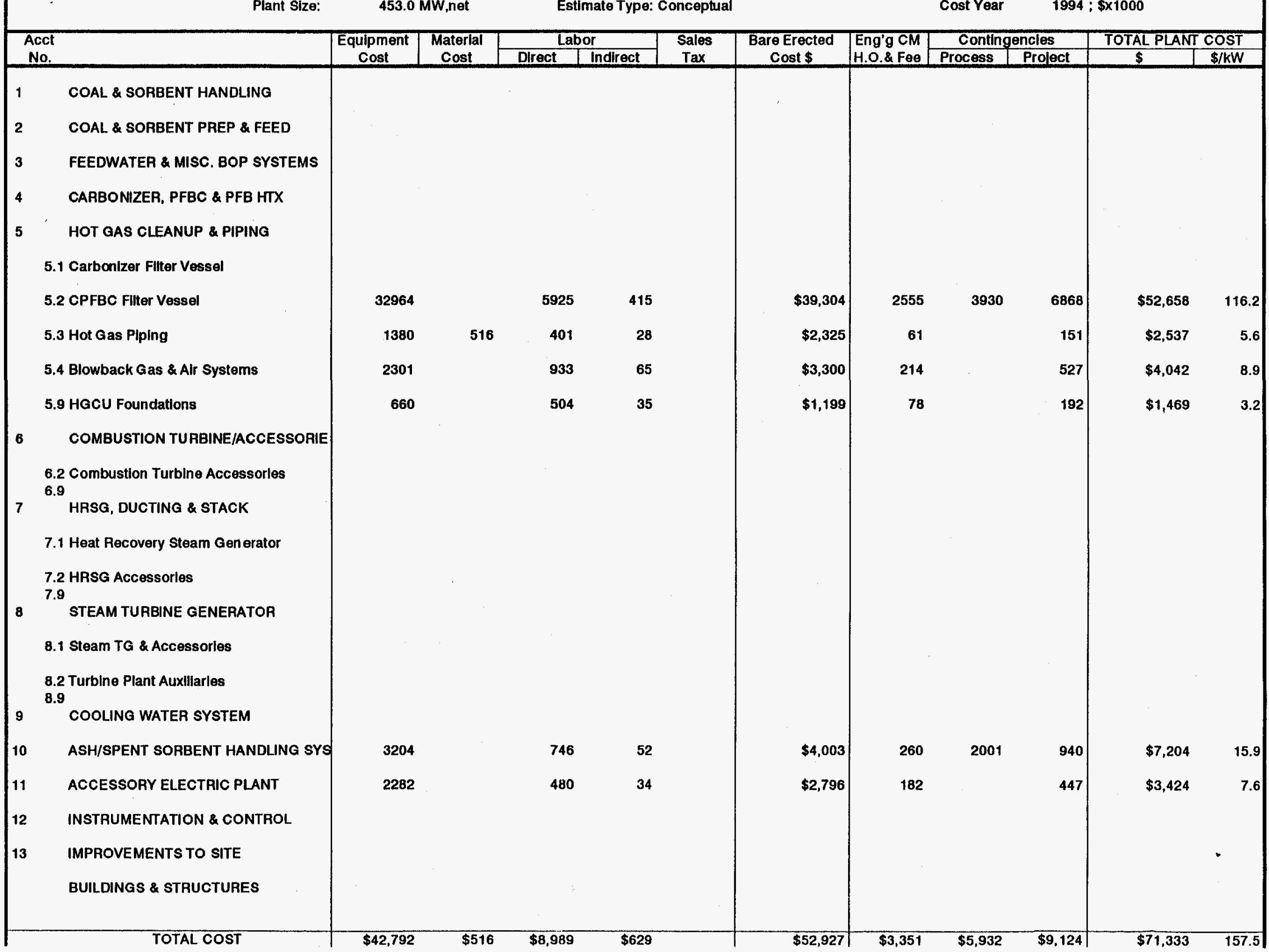


TITLE/DEFINITION

Case:

Plant Size:

Fuel(type):

Design/Construction:

TPC(Plant Cost) Year:

Capacity Factor:

CAPITAL INVESTMENT

Process Capital \& Facilities

Engineering(incl.C.M.,H.O.\& Fe日)

Process Contingency

Project Contingency

TOTAL PLANT COST(TPC)

TOTAL CASH EXPENDED

AFDC

TOTAL PLANT INVESTMENT(TPI)

Royalty Allowance

Preproduction Costs

Inventory Capital

Initial Catalyst \& Chemicals(w/equip.)

Land Cost

TOTAL CAPITAL REQUIREMENT(TCR)

OPERATING \& MAINTENANCE COSTS(First Year)

Operating Labor

Maintenance Labor

Maintenance Material

Administrative \& Support Labor

TOTAL OPERATION \& MAINTENANCE(1st yr.)

FIXED $O \& M(1$ st yr.)

VARIABLE $O \& M$ (1st yr.)

CONSUMABLE OPERATING COSTS(less Fuel)

Water \& Chemicals

Auxilliary Power

Other Consumables

Waste Disposal

TOTAL CONSUMABLES(1st yr.,-fuel)

BY-PRODUCT CREDITS(First Year)

FUEL COST(First Year)

LEVELIZED OPERATION \& MAINTENANCE COSTS

Fixed $O$ \& $M$

Variable $O$ \& $M$

Consumabies

By-product Credit

Fuel

LEVELIZED CARRYING CHARGES(Capital)
$7,822(\mathrm{Btu} / \mathrm{kWh})$ 1.60 (\$/MMBtu) 30 (years) 1995 (Jan.) 1994 (Dec.) TPI Year: $65(\%)$

$\$ \times 1000$

52,927

3,351

5,932

9,124

$\$ 71,333$

$\$ 71,333$

$\$ 71,333$

1,829

220

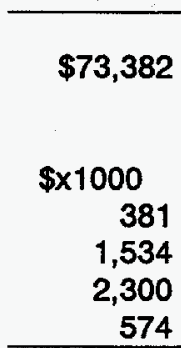

$\$ 4,790$

$\$ \times 1000$

$\$ / \mathrm{kW}$

116.8

7.4

13.1

20.1

157.5

157.5

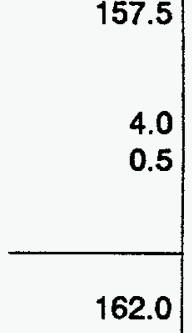

$\$ / k W-y r$

0.8

3.4

5.1

1.3

10.6

$6.87 \$ / k W-y r$

0.65 mills/kWh

mills/kWh

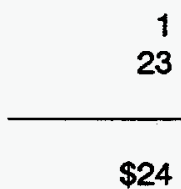

$\$ 24$
$27.4 \$ / k W-y r=$

$10.6 \$ / \mathrm{kW}-\mathrm{yr}=$

$65 \%$
$1.9 \mathrm{mills} / \mathrm{kWh}$ 1.0 mills $/ k W h$

0.0 mills $/ \mathrm{kWh}$ mills/kWh mills/kWh

4.8 mills $/ k W h$

7.7 mills/kWh 


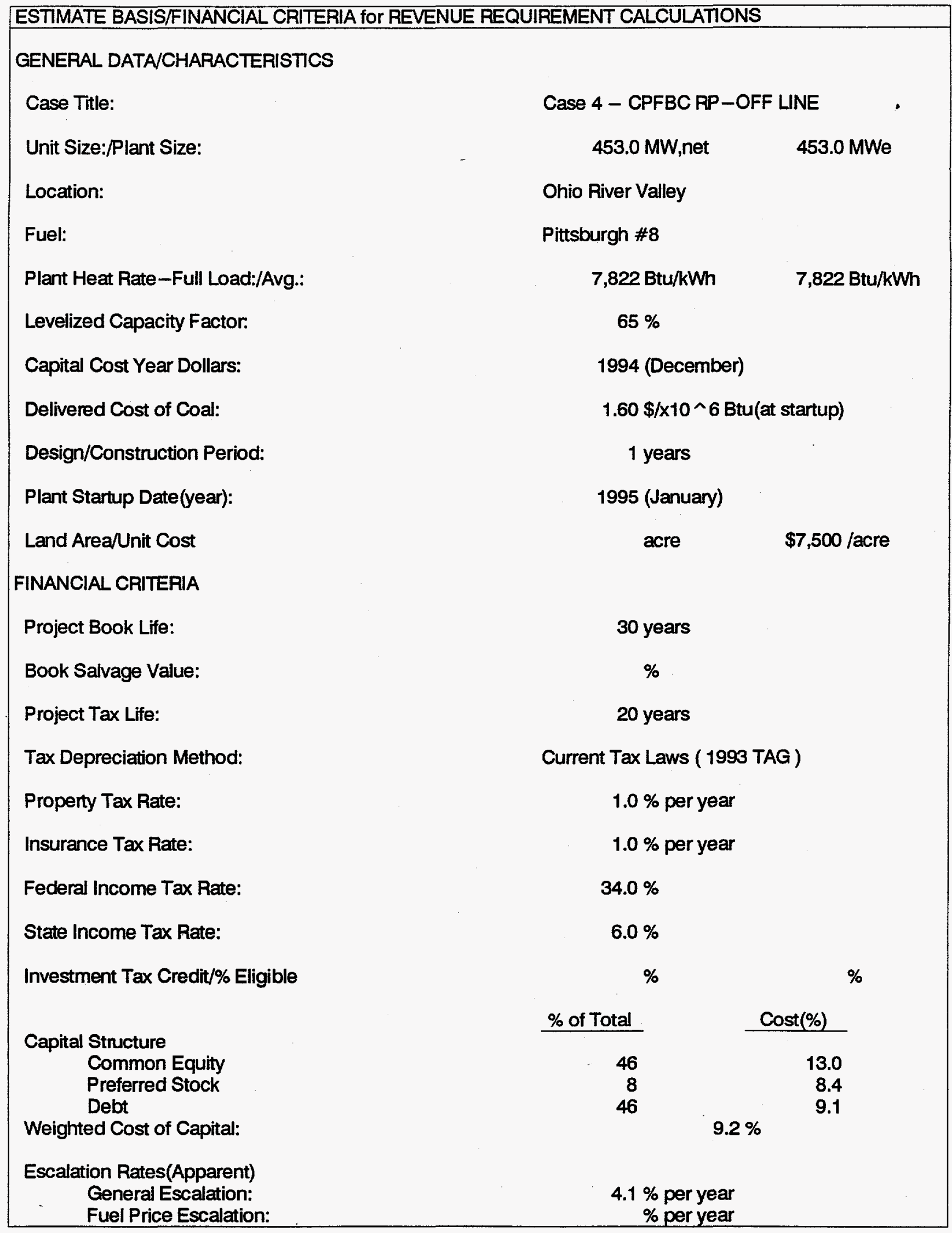




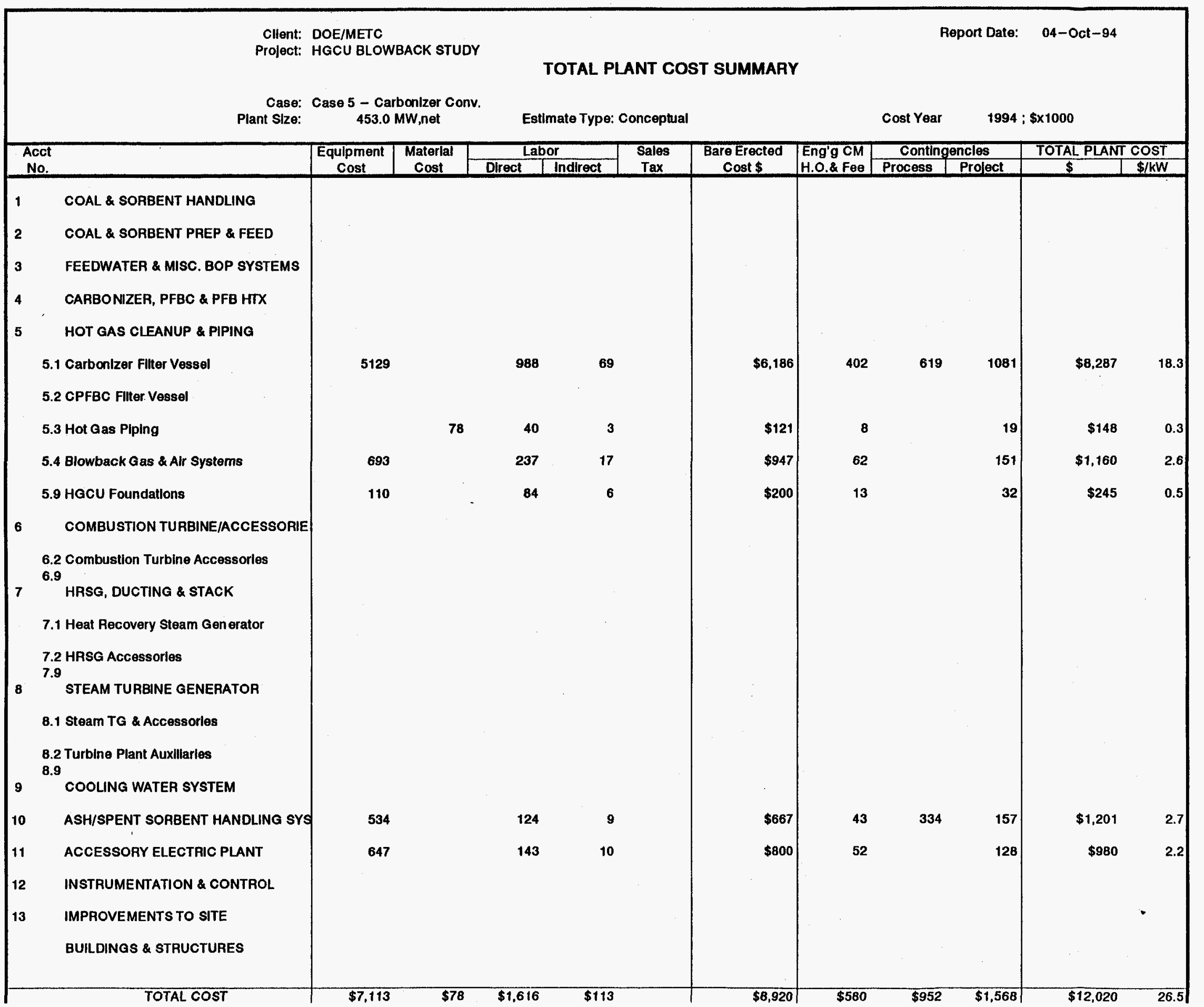




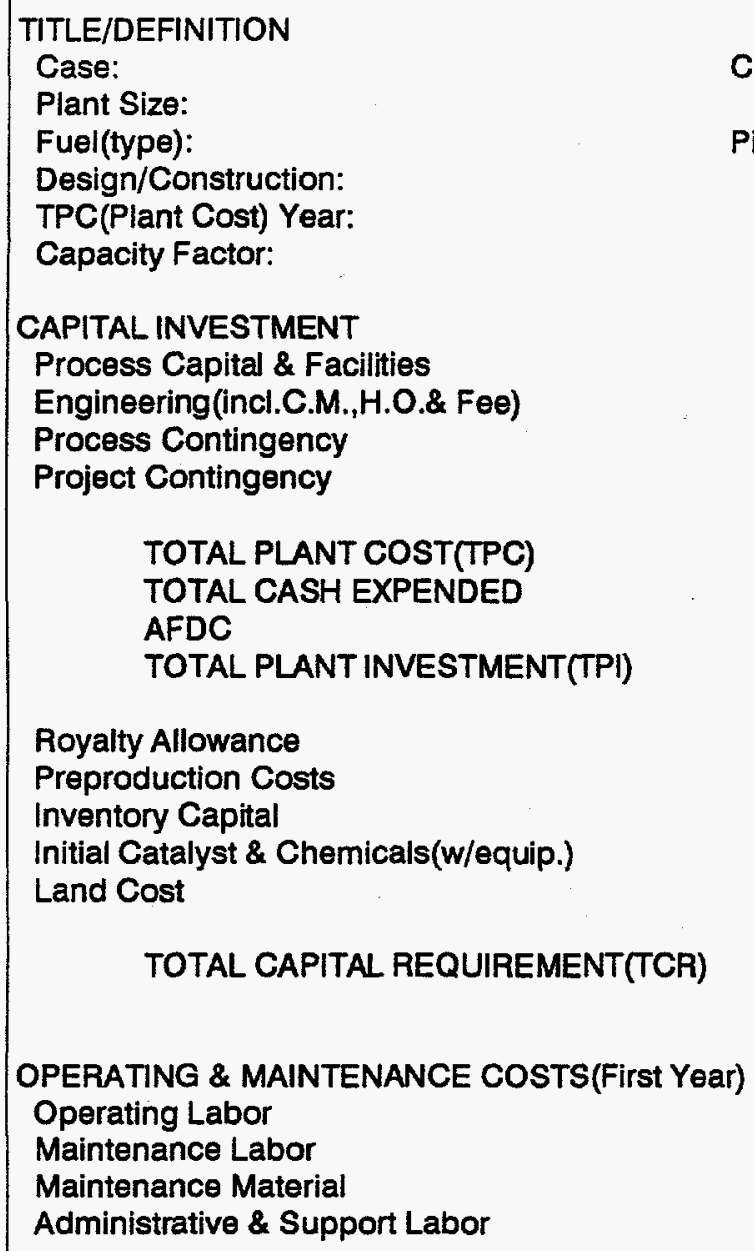

$7,822(B t u / k W h)$ $1.60(\$ / \mathrm{MMBtu})$ 30 (years) 1995 (Jan.) 1994 (Dec.) TPI Year: $65(\%)$

- Carbonizer Conv. Pittsburgh \#8 HeatRate: Cost:

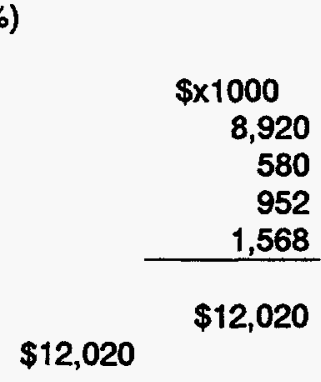

$\$ 12,020$ 340

0.16 mills $/ k W h$

$0.8 \mathrm{mills} / \mathrm{kWh}$ $0.2 \mathrm{mills} / \mathrm{kWh}$ 0.0 mills $/ k W h$ mills/kWh mills/kWh

1.5 mills/kWh
0.5 mills $/ k W h$ 


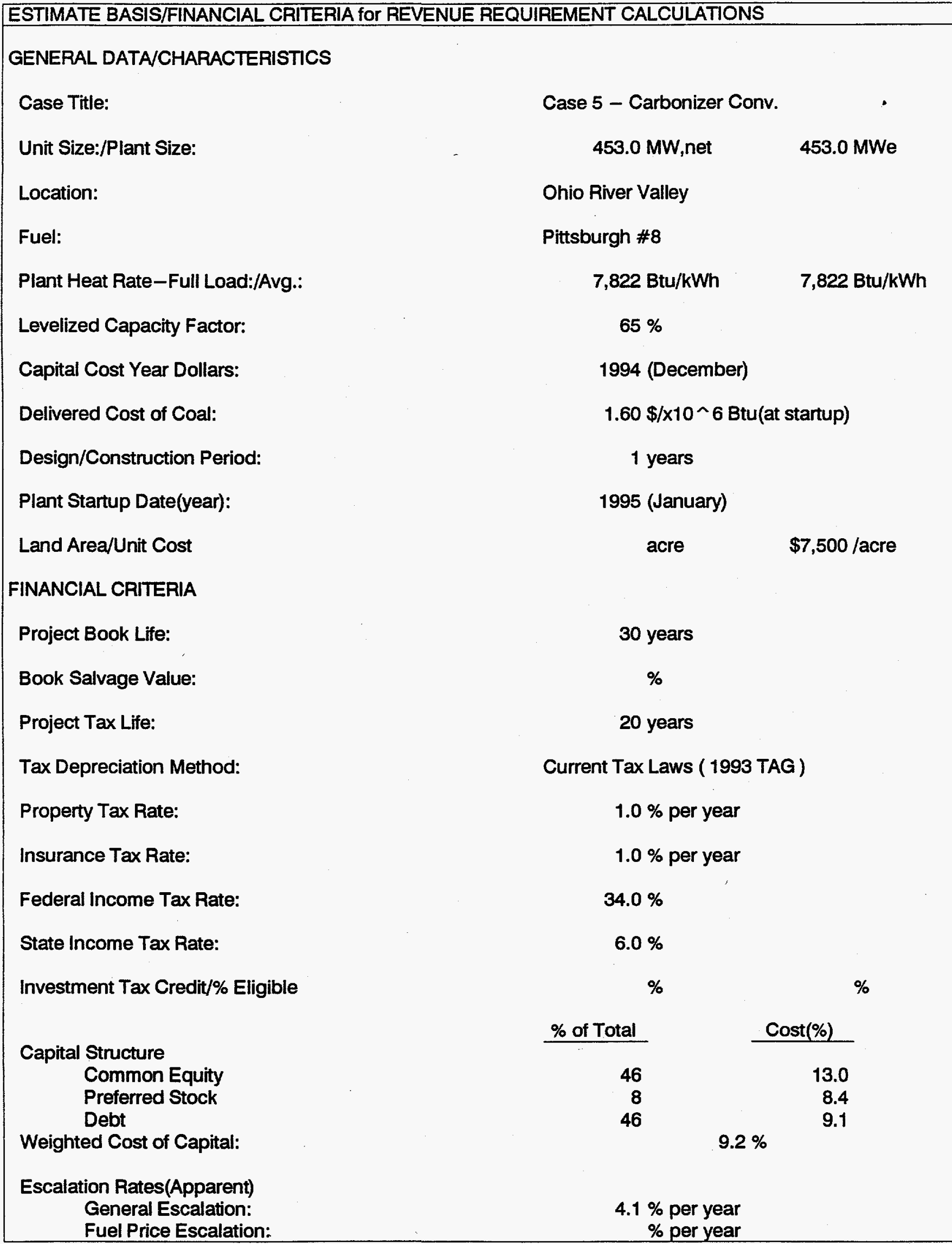




\section{TOTAL PLANT COST SUMMAAY}

Case: Case 6 - Carbonizer Off - Line

Plant Slze: $\quad 453.0 \mathrm{MW}$,

Estimate Type: Conceptual

Cost Year $1994 ; \$ \times 1000$

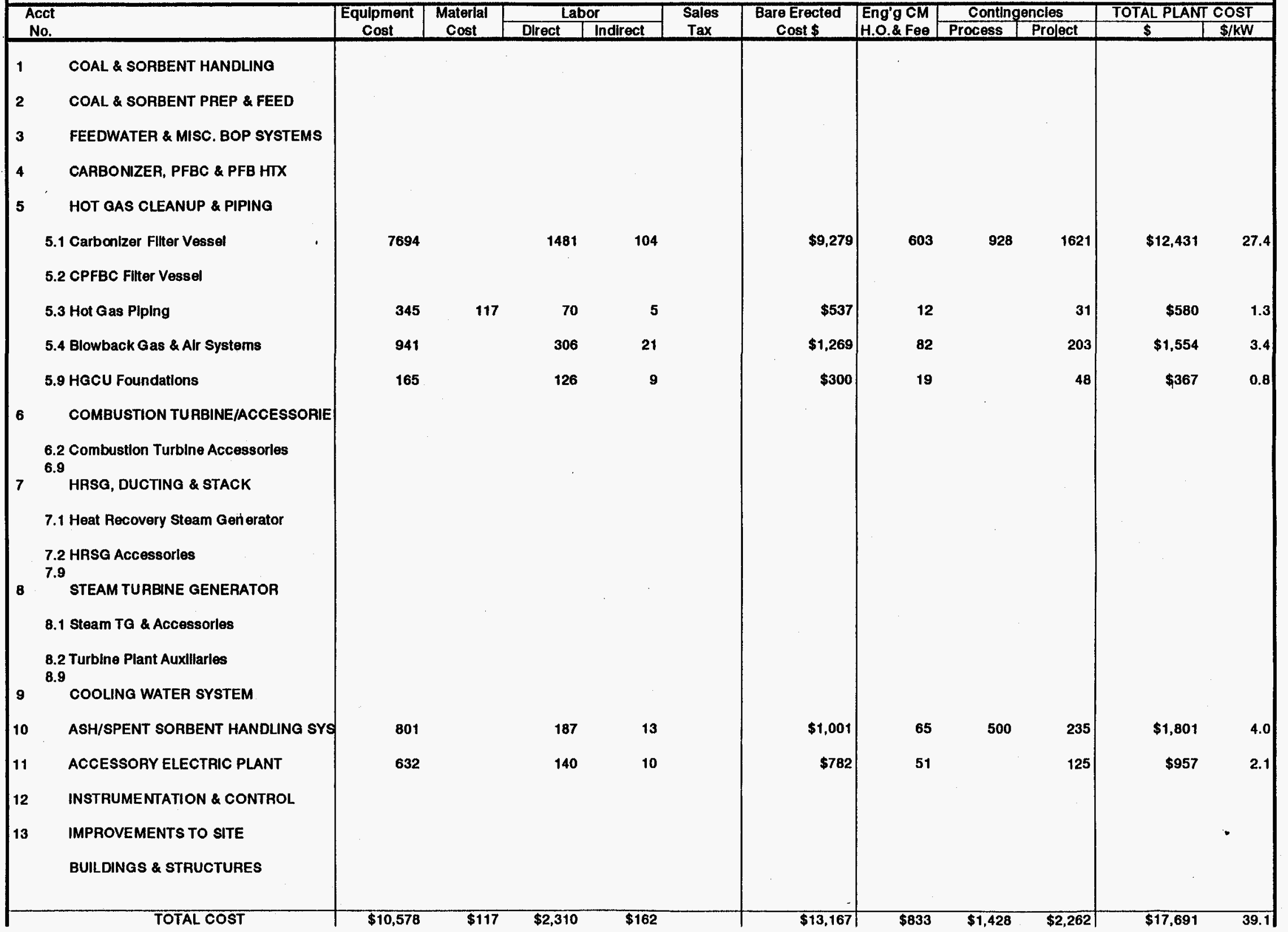


TITLE/DEFINITION

Case:

Plant Size:

Fuel(type):

Design/Construction:

TPC(Plant Cost) Year:

Capacity Factor:

CAPITAL INVESTMENT

Process Capital \& Facilities

Engineering(incl.C.M.,H.O.\& Fee)

Process Contingency

Project Contingency

TOTAL PLANT COST(TPC)

TOTAL CASH EXPENDED

AFDC

TOTAL PLANT INVESTMENT(TPI)

Royalty Allowance

Preproduction Costs

Inventory Capital

Initial Catalyst \& Chemicals(w/equip.)

Land Cost

TOTAL CAPITAL REQUIREMENT(TCR)

OPERATING \& MAINTENANCE COSTS(First Year)

Operating Labor

Maintenance Labor

Maintenance Material

Administrative \& Support Labor

TOTAL OPERATION \& MAINTENANCE(1st yr.)

FIXED $O$ \& $M$ (1st yr.)

VARIABLE O \& M (1st yr.)

CONSUMABLE OPERATING COSTS(less FUel)

Water \& Chemicals

Auxilliary Power

Other Consumables

Waste Disposal

TOTAL CONSUMABLES(1st yr.,-fuel)

BY-PRODUCT CREDITS(First Year)

FUEL COST(First Year)

LEVELIZED OPERATION \& MAINTENANCE COSTS

Fixed $O \& M$

Variable $O$ \& $M$

Consumables

By-product Credit

Fuel

LEVELIZED CARRYING CHARGES(Capital)

LEVELIZED BUSBAR COST OF POWER

30 Year at a Capacity Factor of:

\author{
Case 6 - Carbonizer Off-Line \\ 453.0 (MW,net) HeatRate: \\ Pittsburgh \#8 \\ Cost: \\ 1 (years) BookLife: \\ 1994 (Dec.) TPI Year: \\ $65(\%)$ \\ $\$ \times 1000$ \\ 13,167 \\ 833 \\ 1,428 \\ 2,262 \\ $\$ 17,691$ \\ $\$ 17,691$
}

$\$ 17,691$

481

54

1.1

0.1

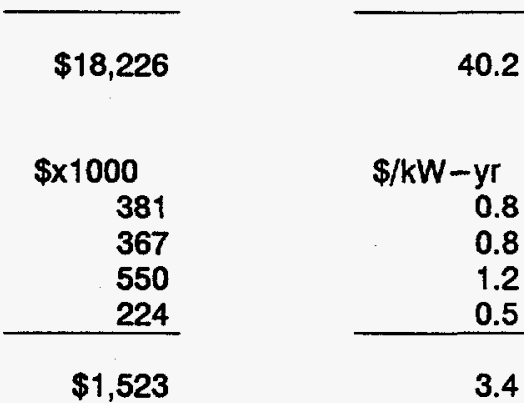

$2.19 \$ / k W-y r$

$0.21 \mathrm{mills} / \mathrm{kWh}$

$\$ \times 1000$

mills/kWh

3

0.00

$\$ 3$

0.00

$3.4 \$ / k W-y r=$

0.6 mills $/ k W h$

0.3 mills $/ \mathrm{kWh}$

0.0 mills $/ k W h$

mills/kWh

mills/kWh

$6.8 \$ / k W-y r=\quad 1.2$ mills $/ \mathrm{kWh}$

2.1 mills/kWh 


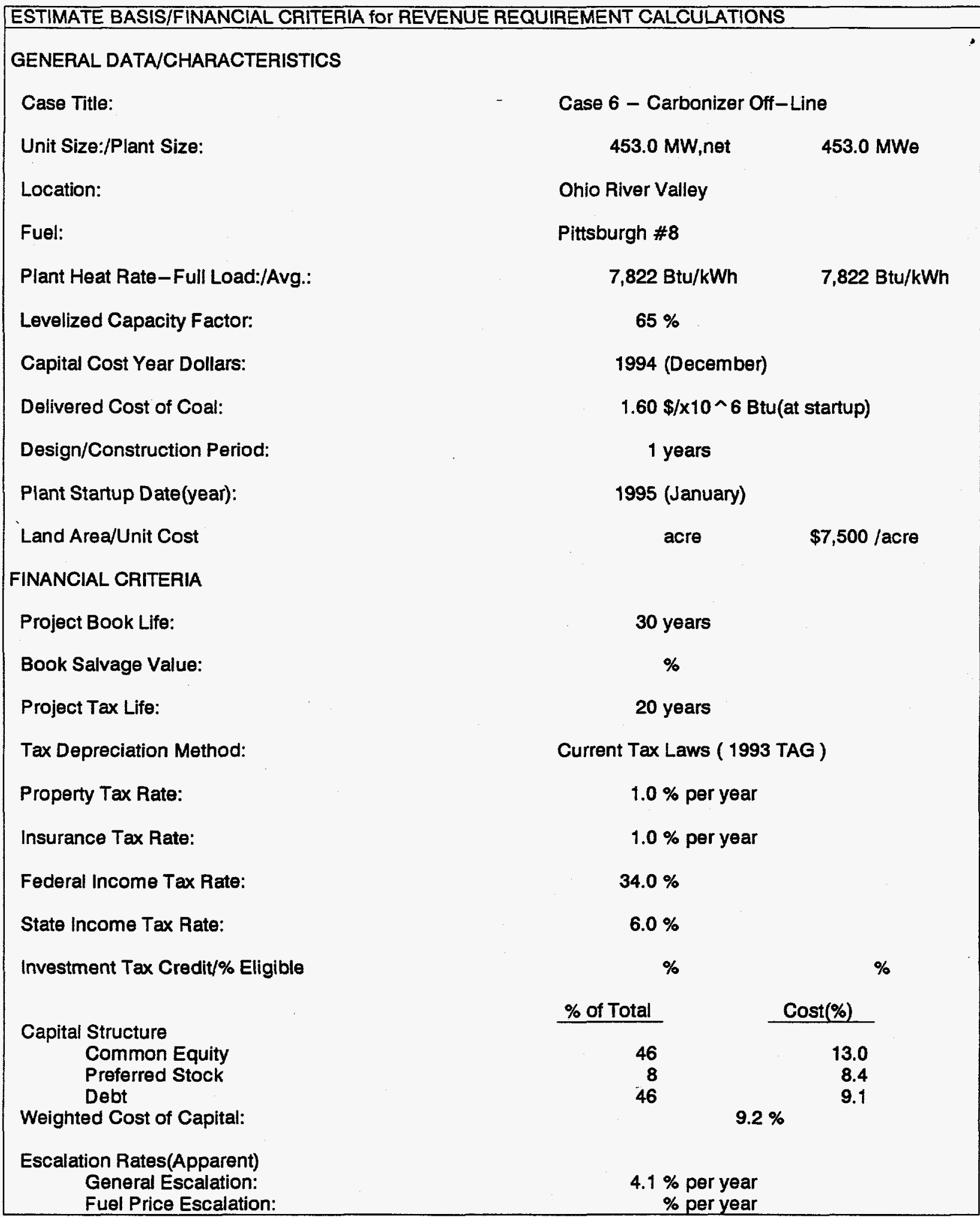




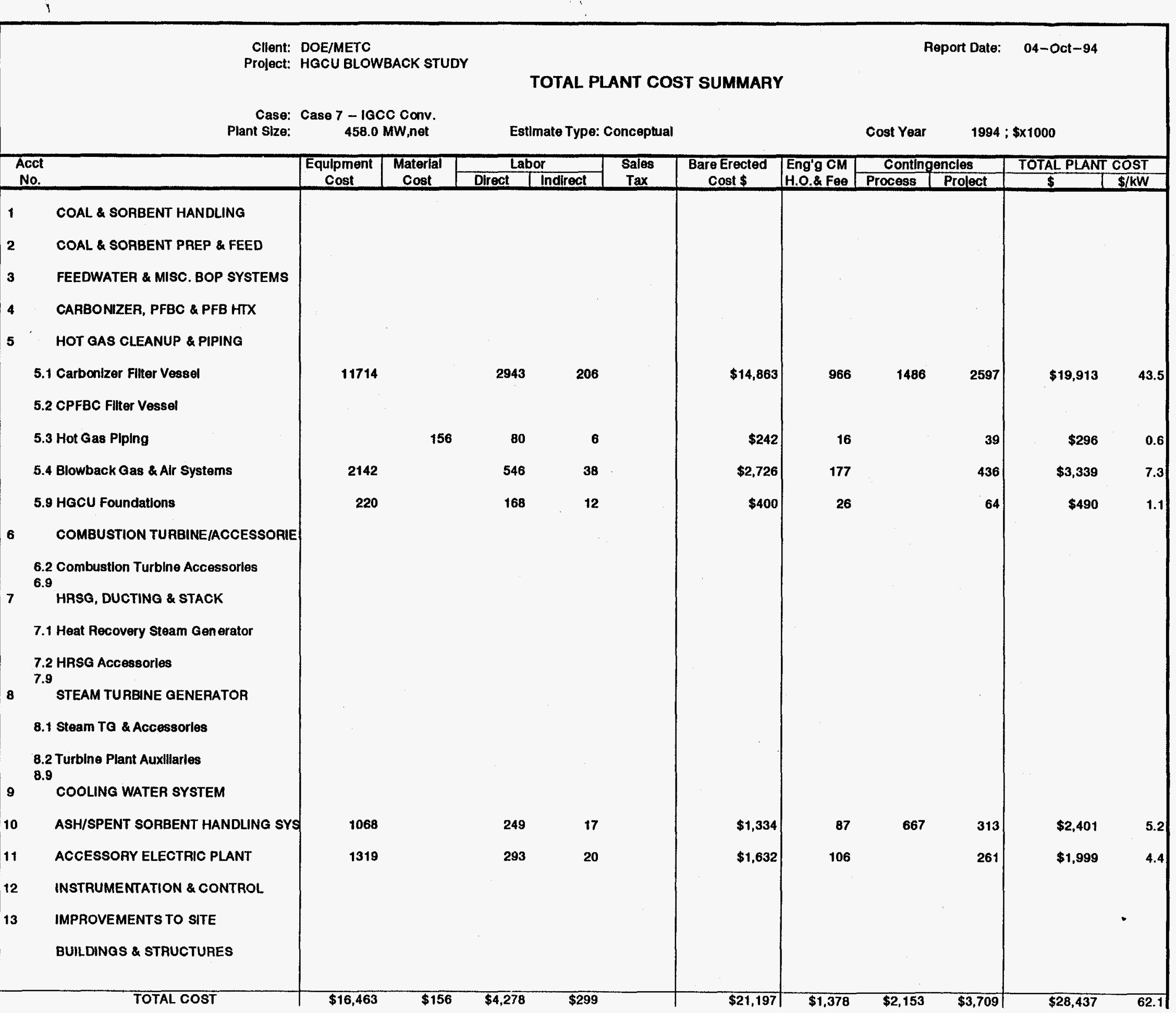




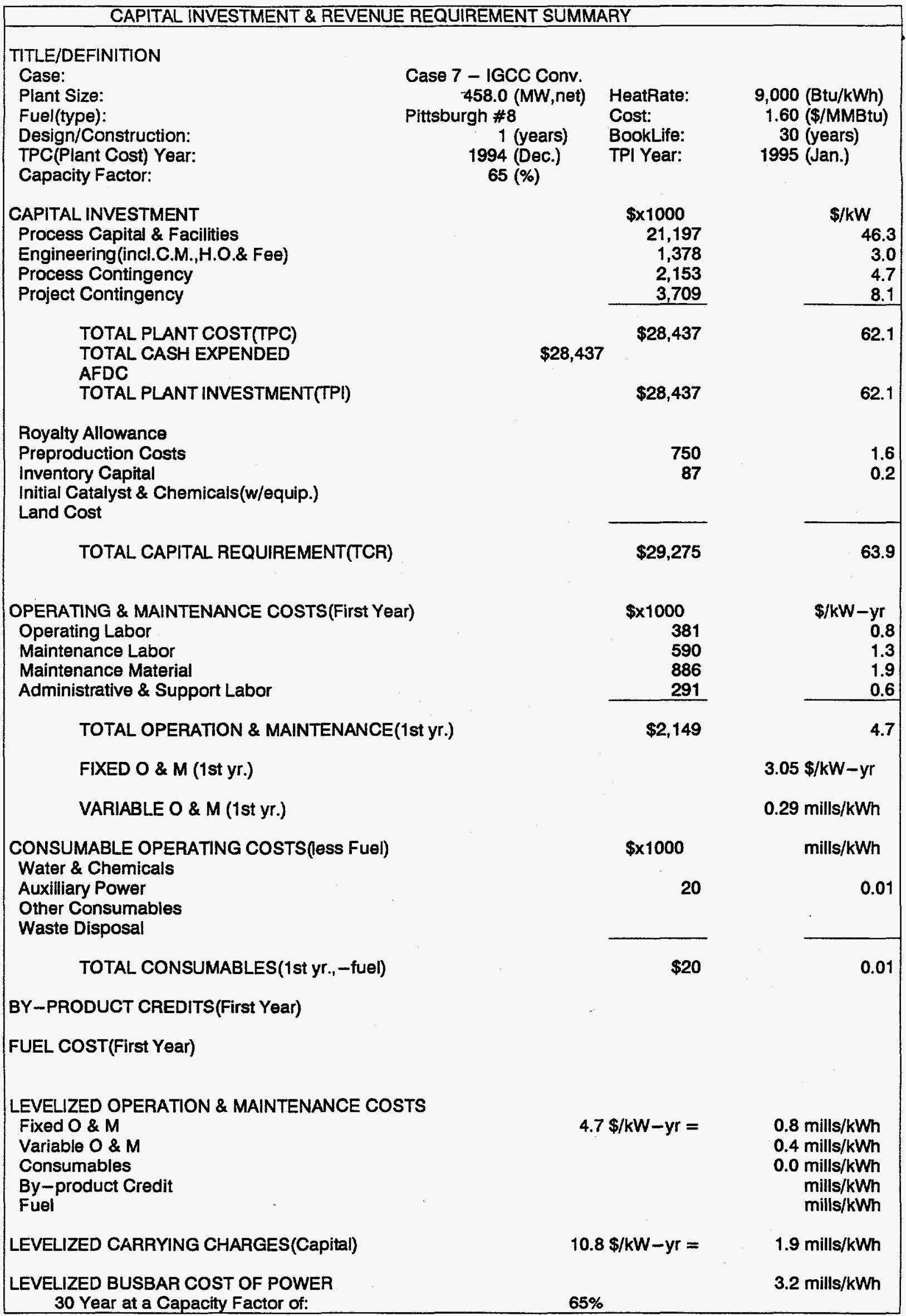




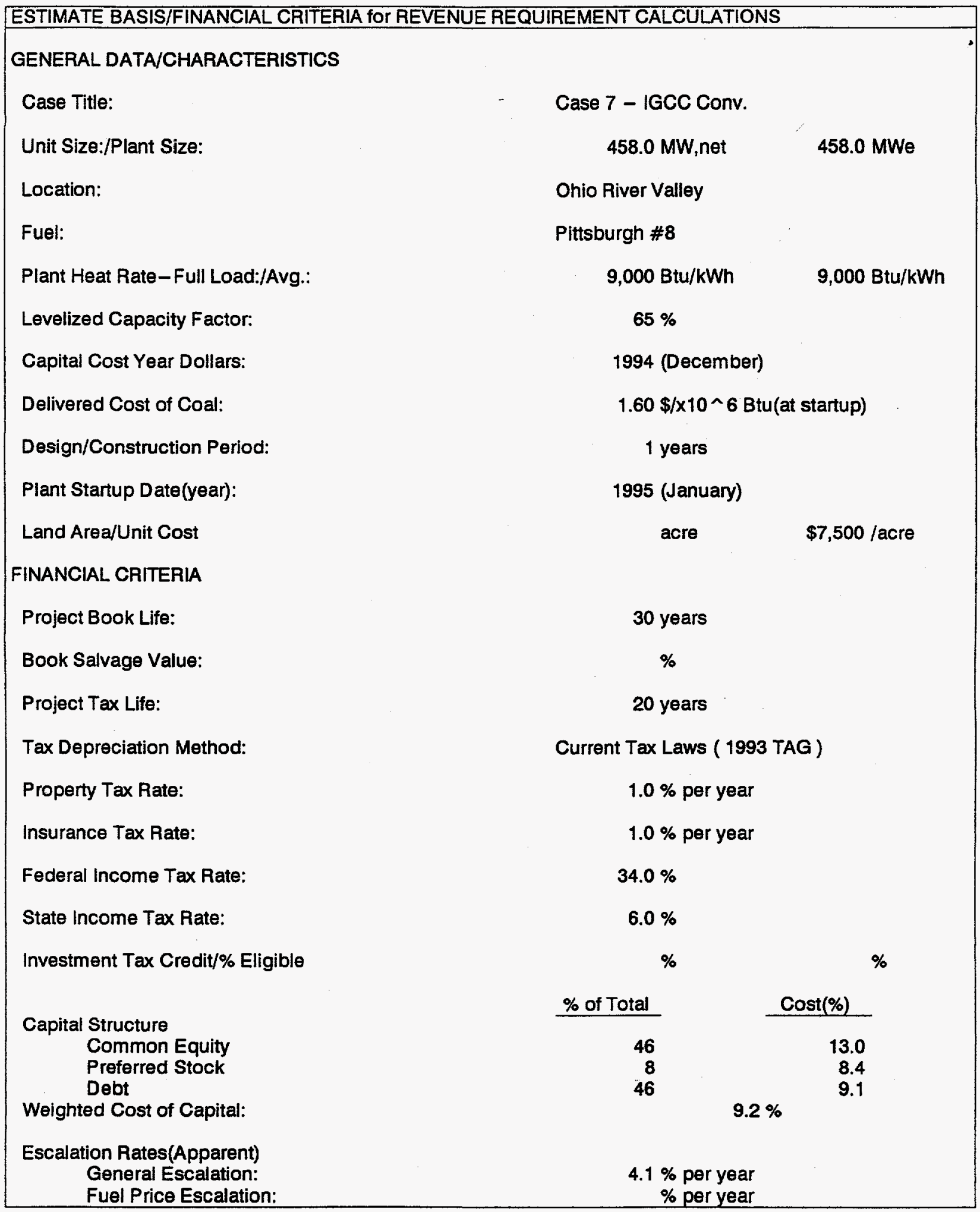


TOTAL PLANT COST SUMMARY

Case: Case 8 - IGCC Off-Line Plant SIze: $\quad 458.0$ MW, net

Estimate Type: Conceptua

Cost Year $1994 ; \$ \times 1000$

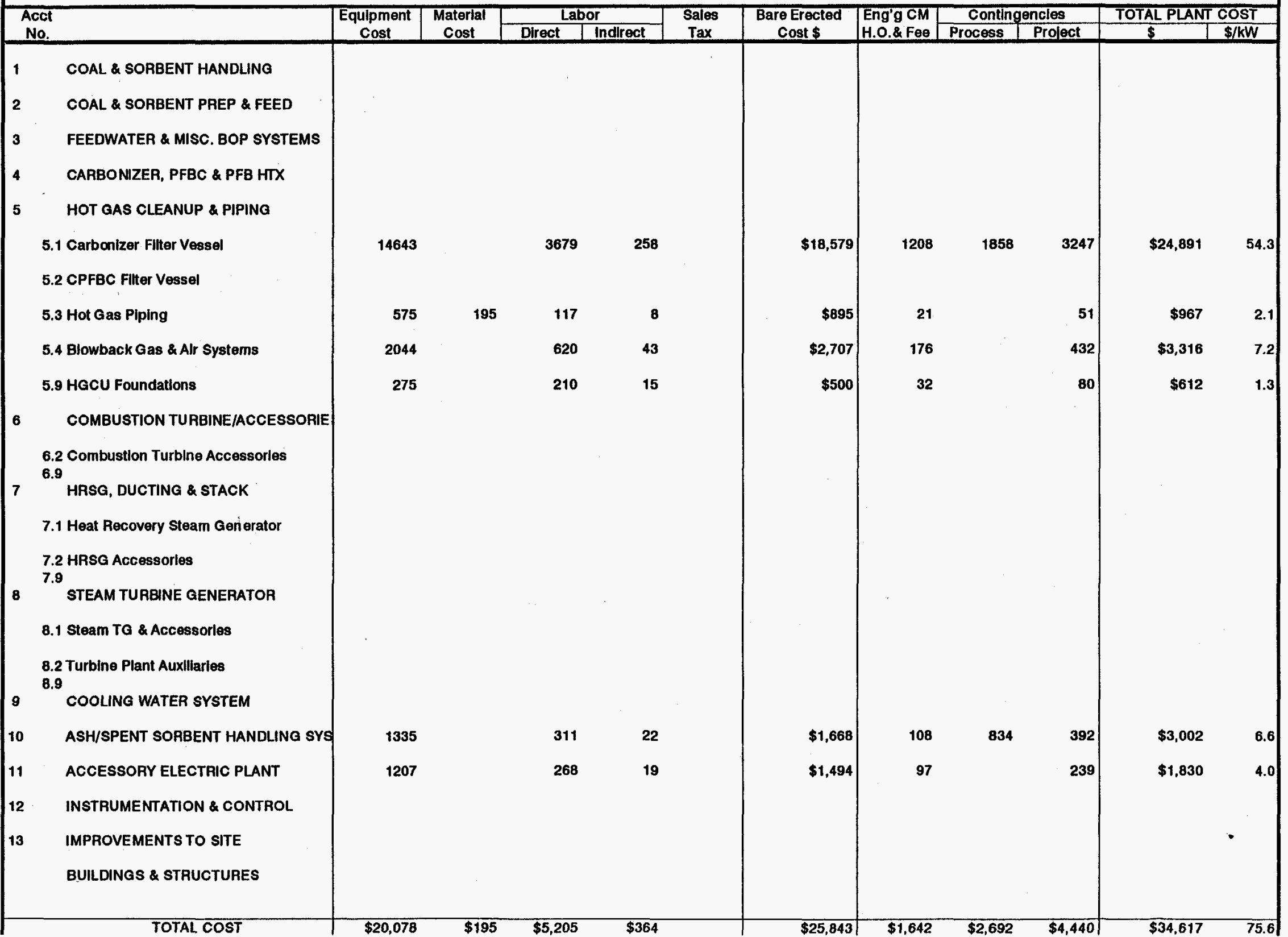




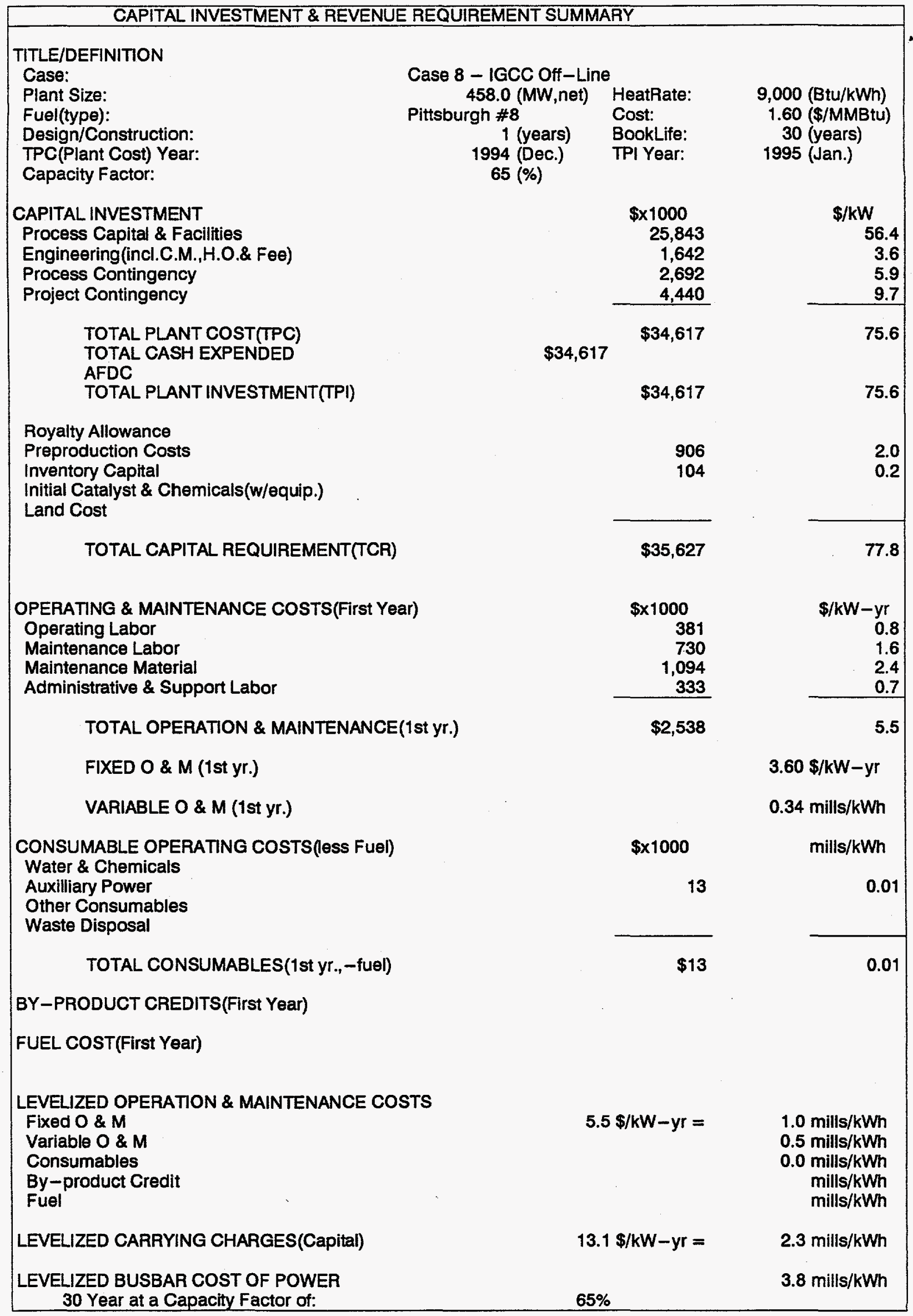




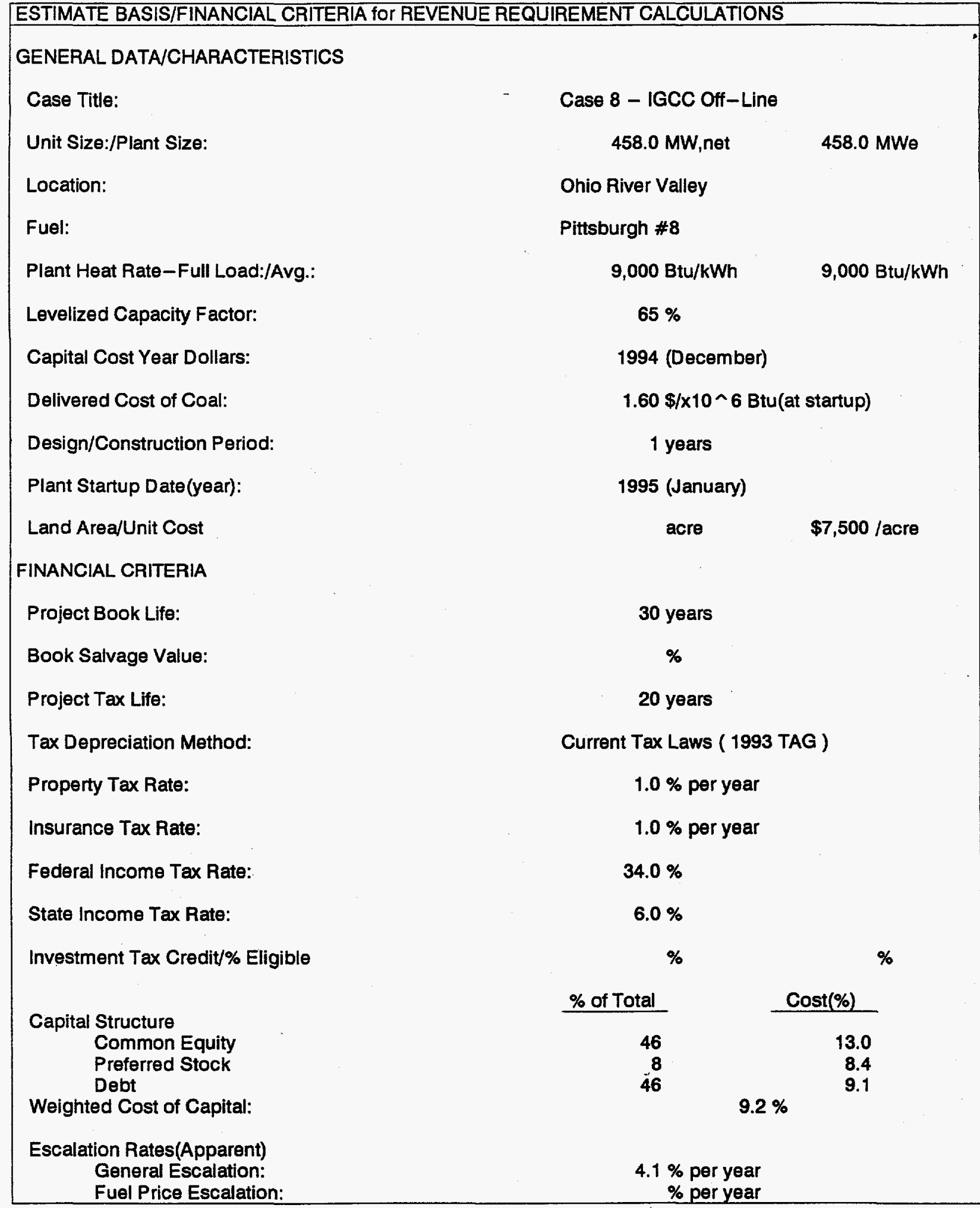

